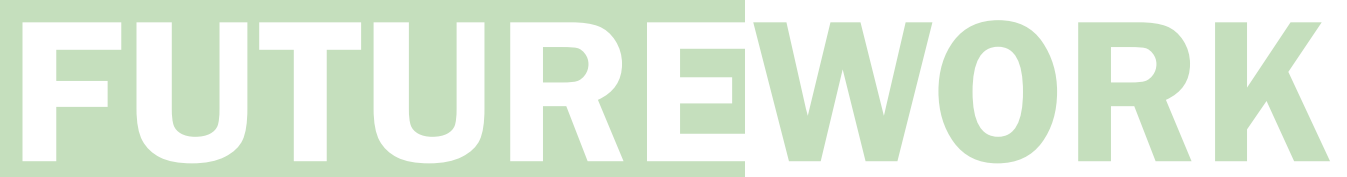

EXPLORING THE FUTURE OF WORK SPACES

IN THE CONTEXT OF WELLINGTON

A. MCLENNAN 2020 



\title{
Exploring the Future of Work Spaces in the Context of Wellington
}

\author{
Adam Mclennan
}

A 120-point thesis submitted to the Victoria University of Wellington in partial fulfilment of the requirements for the degree of Master of Architecture (Professional)

Victoria University of Wellington

School of Architecture \& Design 


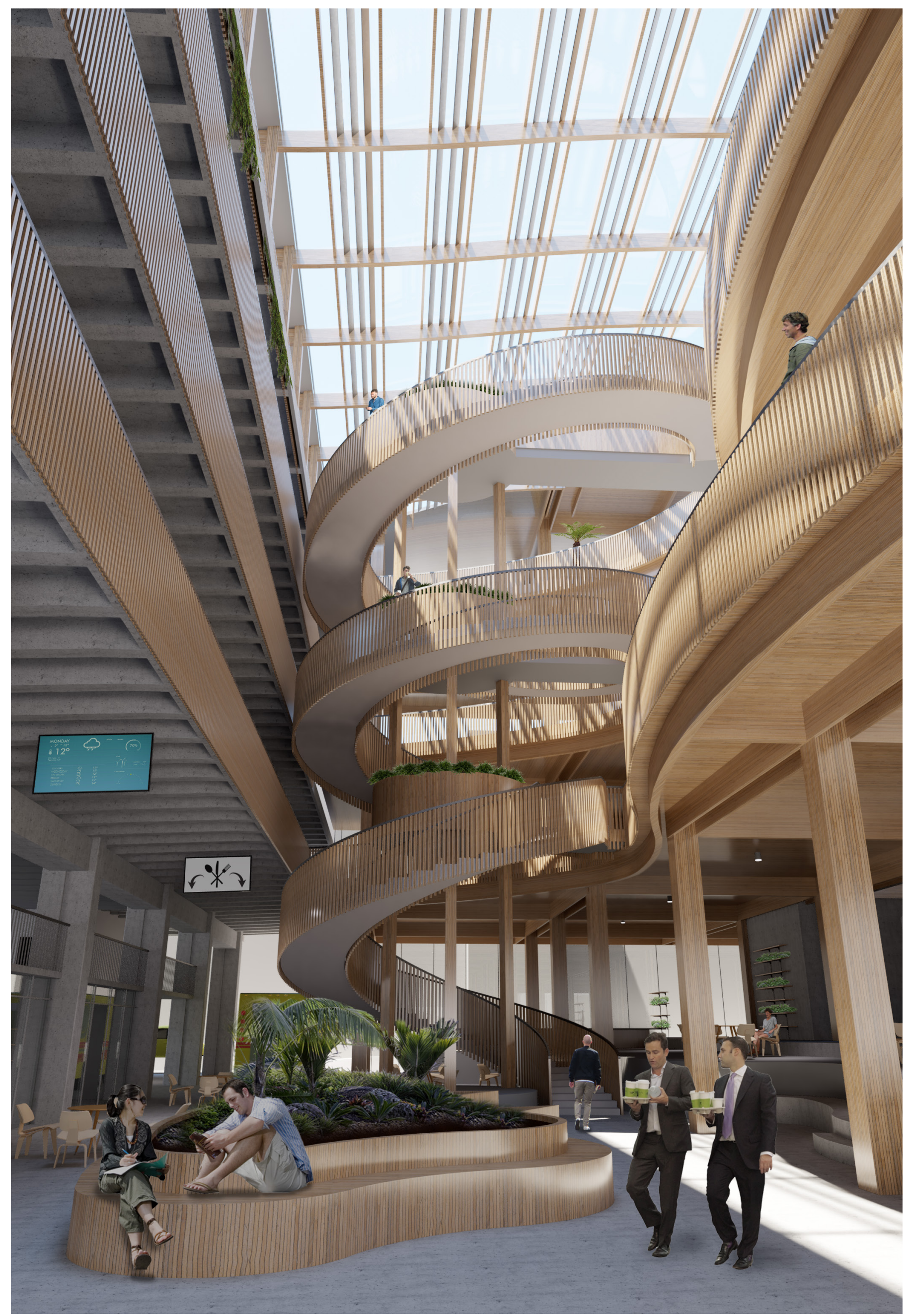




\section{ABSTRACT}

This research analyses the forces that have led to the design of contemporary offices, examining how these forces are likely to change; with the goal of exploring what the future of workspaces might be. Digital technologies such as artificial intelligence are changing the world of work at a rapid rate, threatening to greatly increase effects of automation. Social changes in the way people work are also taking place, seen in the recent explosion in coworking. This gives rise to the question of what the implications of this are on the design of workspaces. This research uses the local context of Wellington as a vehicle to explore what the future of workspaces could be for the city, as well as wider New Zealand. A process of design led research is utilised, as the topic of work in general is vast, encompassing many different areas. This research also reviews how other designers and architects are responding to current workplace design issues, utilising these different approaches in the iterative design phase. The implications of this research relate directly to the city of Wellington, giving an idea of what the future of the office could be. The broad nature of the initial investigation also allows some conclusions to be applied internationally, as work in general is greatly examined.

Figure 1: (Left) Central stair of developed design. 


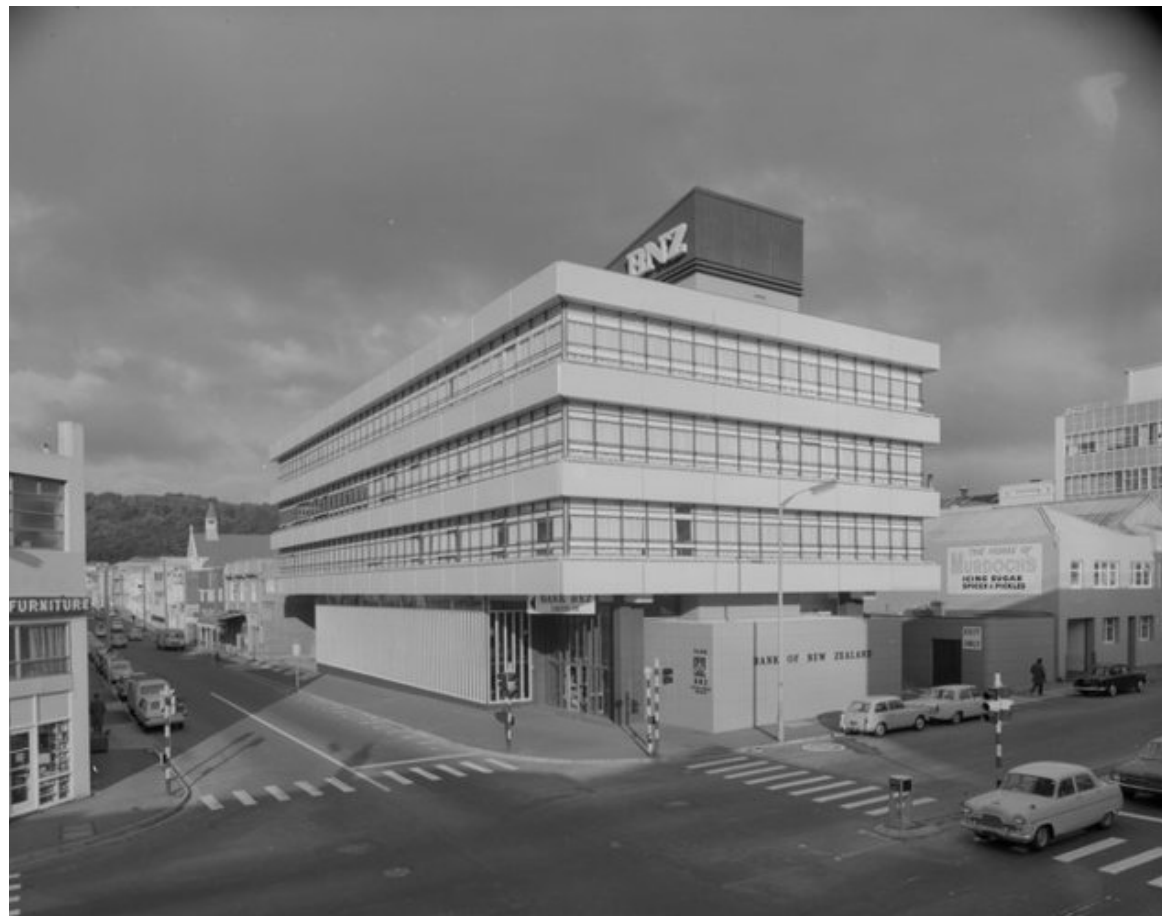

Figure 2: The former 'Future of Work', the BNZ Computer Centre, 1968. (Ref: DW-3249-F Alexander Turnbull Library) 


\section{ACKNOWLEDGMENTS}

\section{A big thanks to all those who helped me along the way,}

Firstly l'd like to thank Mum, Dad, Lucy and Rodney, for your continuing support and inspiration.

Thanks to my supervisor, Guy Marriage, for your guidance and humour, both are much appreciated.

Thanks must also go to my friends and flat mates, Ellis, Michael, Josh and Thomas, keep on keep onning.

Also a thank you Sam, not sure why. 


\section{CONTENTS}

$\begin{array}{ll}1.0 \text { INTRODUCTION } & 1\end{array}$

2.0 HISTORY OF WORK SPACES

3.0 HOW IS WORK CHANGING?

4.0 PROJECT REVIEW

5.0 CONTEXT ANALYSIS

61

6.0 PRELIMINARY DESIGN

7.0 DEVELOPED DESIGN

8.0 CONCLUSION

151

9.0 CitATIONS

157

10.0 ADDENDUM

165 

INTRODUCTION 


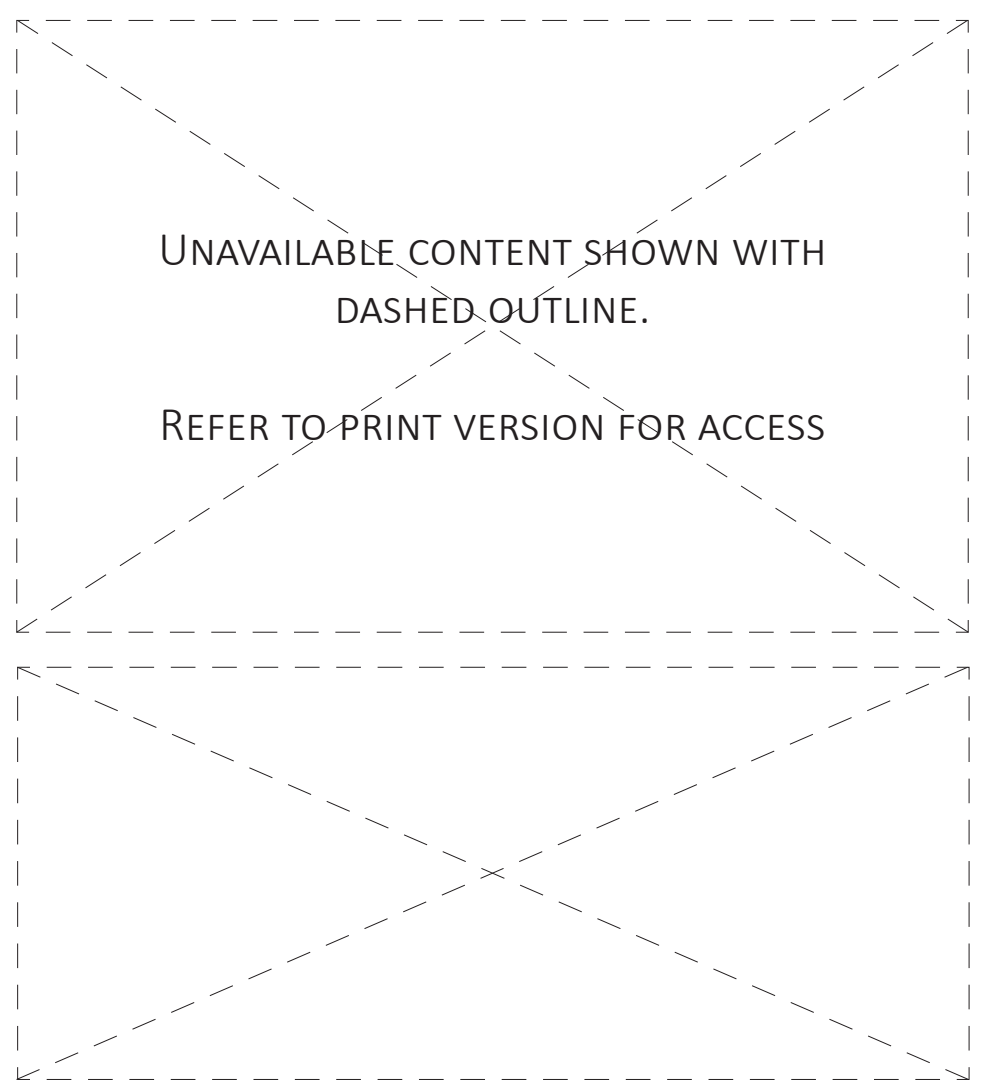

Figure 3 \& 4: Google's Proposed Mountainview Campus. (Archdaily, 2015)

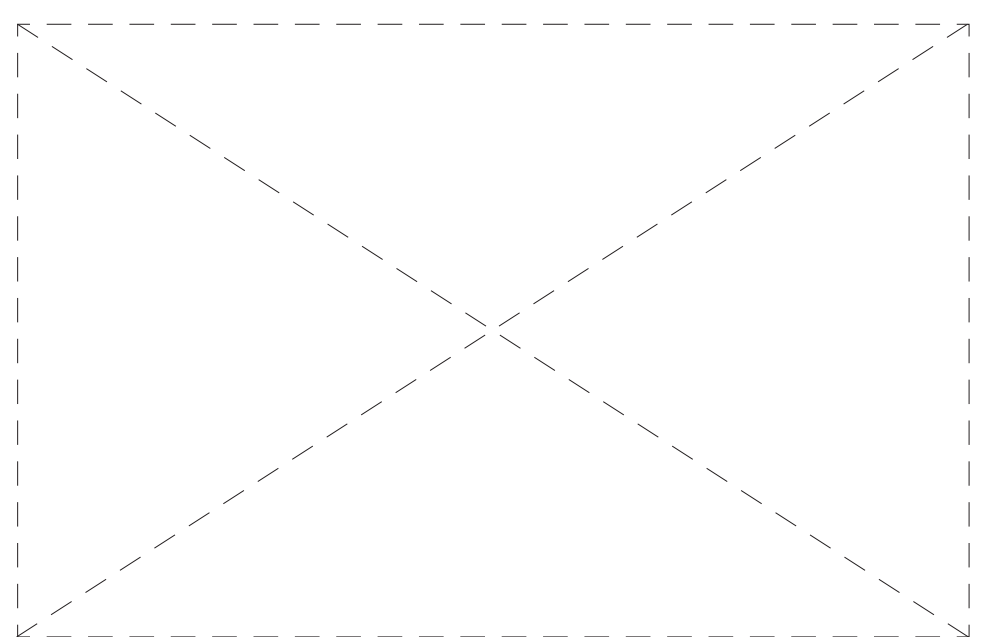

Figure 5: Amazon's Spheres, a greenhouse-like workspace in Seattle. (NBBJ, 2019) 
1.0

INTRODUCTION

The work people do and the way they do it has always been in a constant state of change. Recently, the rate of this change has begun to increase rapidly. The development of digital technologies such as artificial intelligence have begun to blur the line between what a human can do and what a machine can do. Coupled with other technological advancements, it means that that the threat of automation not only impacts low-skilled workers, but almost all occupations. In 2016, the New Zealand Government set up the Future of Work commission to try and anticipate and prepare the country for these coming changes to employment (NZ Future of Work Commission, 2016). Social changes are also impacting work, with co-working exploding globally, signalling a shift in the kind of workspaces people desire. Workplace expert Jeremy Myerson summarises this, stating that "on the fast-moving and fluid subject of the future of the workplace, everyone can agree on one thing: we are on the cusp of a totally new epoch." (Gillen, 2019). With workspaces scheduled to continually and drastically change, how can they be designed with this future in mind? This research examines the direction workspace design is heading, with the goal of developing a holistic design that represents what he future of work could look like.

"We do not need a definitive answer to appreciate that

the nature and experience of work is changing rapidly.

Our best response is to prepare ourselves to be in a position to both respond to and shape the future"

NZ Future of Work Commission Report 2016, pg 7 


\section{1}

\section{RESEARCH QUESTION}

Given these predicted changes coming to work, this thesis examines how workspaces are likely to change, using the local context of the city of Wellington as a vehicle for exploring what this future of work will look like for New Zealand. This research can be summarised by the following question:

\section{How will the future of work spaces evolve in the context of Wellington?}

\section{2}

\section{AIMS AND OBJECTIVES}

This research analyses how contemporary workspace design has developed, examining the forces that has shaped the office of today. This analysis will serve as the foundation for the investigation into how work is changing, with the goal of identifying how workspaces are likely to change in the future. The following research aim is broken into three distinct objectives, with these being used a means of structuring the research. The research aim and objectives are as follows:

Research Aim: To evaluate the changing nature of work in urban settings, and explore its architectural implications.

\section{OBJECTIVES:}

1. Analyse the forces that have influenced the design of workspaces today

2. Examine how these forces are changing and their potential implications on the future of workspaces

3. Explore these potential implications in a specific context, resulting in a speculative example of what the future of work spaces could be 


\section{3}

\section{RESEARCH Methodology}

As the topic of work and workspaces has a vast number of contributing factors, an iterative, design-led approach was chosen. The different factors impacting the future of work will be researched, with global and local precedents being examined to see how architects are approaching contemporary workplace issues. This will all help to inform the design procees, along with an analysis into the local context of Wellington. Resulting designs will be critically reflected on, informing the next set of design experiments. This process will continue until a final design is developed.

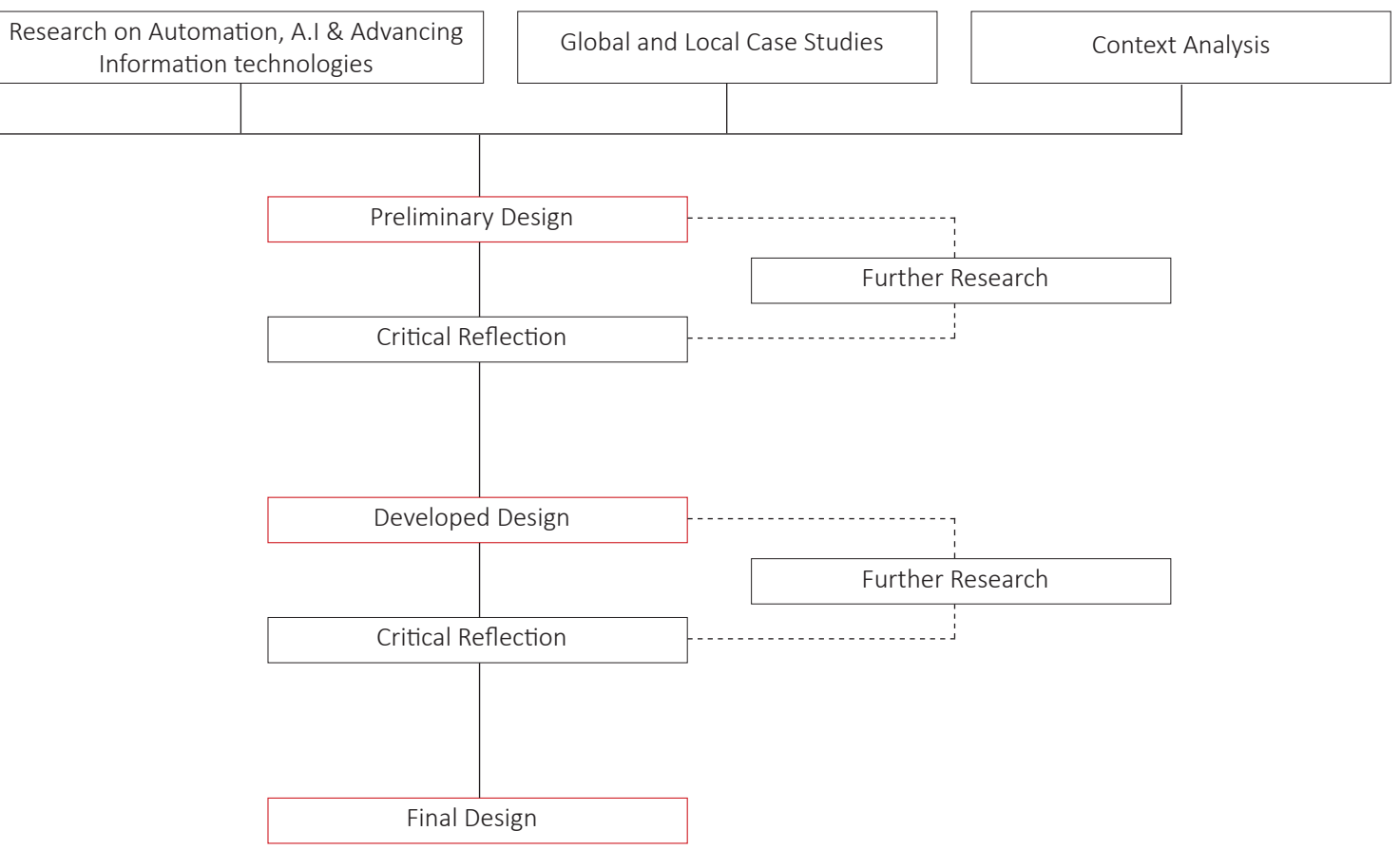




\section{4}

\section{SCOPE OF RESEARCH}

This research has a focus on the context of central Wellington but conclusions could be applied to other New Zealand cities. The broad nature of the initial research means that some conclusions could be applied internationally. For the purposes of this research the term 'office' and 'workspace' are used somewhat interchangeably, referring to the environment that surrounds a sedentary worker or workers. The term 'workplace' refers to an entire building or the broader work environment. Although there are many kinds of work, this research relates to the kinds of work conventionally done in an office or a purpose built workspace.

\section{5}

\section{THESIS STRUCTURE}

\section{Chapter One: Introduction}

The first chapter introduces the subject and the aims and objectives of the research.

\section{Chapter Two: History of Work Spaces}

The second chapter analyses how the workspaces of today have come to be, through looking at the history of the office. The objective of this chapter is to uncover the forces that have influenced the design of contemporary work spaces, relating to the first objective of this research.

\section{Chapter Three: How is Work Changing?}

The forces observed throughout chapter two will be then examined in this chapter, with the goal of analysing how these identified forces are likely to change in the future. This will be used to develop a set of key drivers that represent the main design issues facing future workplace designers. This relates to the second objective of this research.

\section{Chapter Four: Project Review}

This chapter focusses on key global and local design precedents, with the intention of looking at the various approaches and strategies architects and designers are using in these changing times. 


\section{Chapter Five: Context Analysis}

Chapter five analyses a specific site and its surrounding context, as these factors have a large effect on the design of a workplace. The future of work in the city of Wellington is also a focus, as this future could differ greatly from other cities, resulting in a different workspace being required.

\section{Chapter Six: Preliminary Design}

This chapter takes the lessons learned from the previous chapters, and applies them to the specific context of Wellington. Various design experiments explore how to best express the identified key drivers, as well as seeing how best to capitalise on site conditions.

\section{Chapter Seven: Developed Design}

This chapter builds upon what was learnt in the preliminary design phase, culminating in a speculative design that represents what the future of work could be for the city of Wellington.

\section{Chapter Eight: Conclusion}

This chapter reflects on how the resulting design aligns with the aims and objectives originally set out. It also discusses the final conclusions and the significance of this researchs findings. 

HISTORY OF WORK SPACES

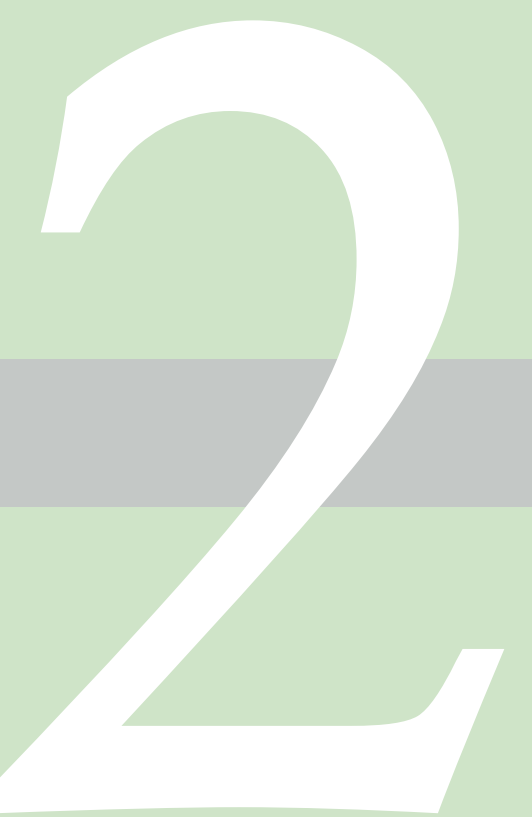




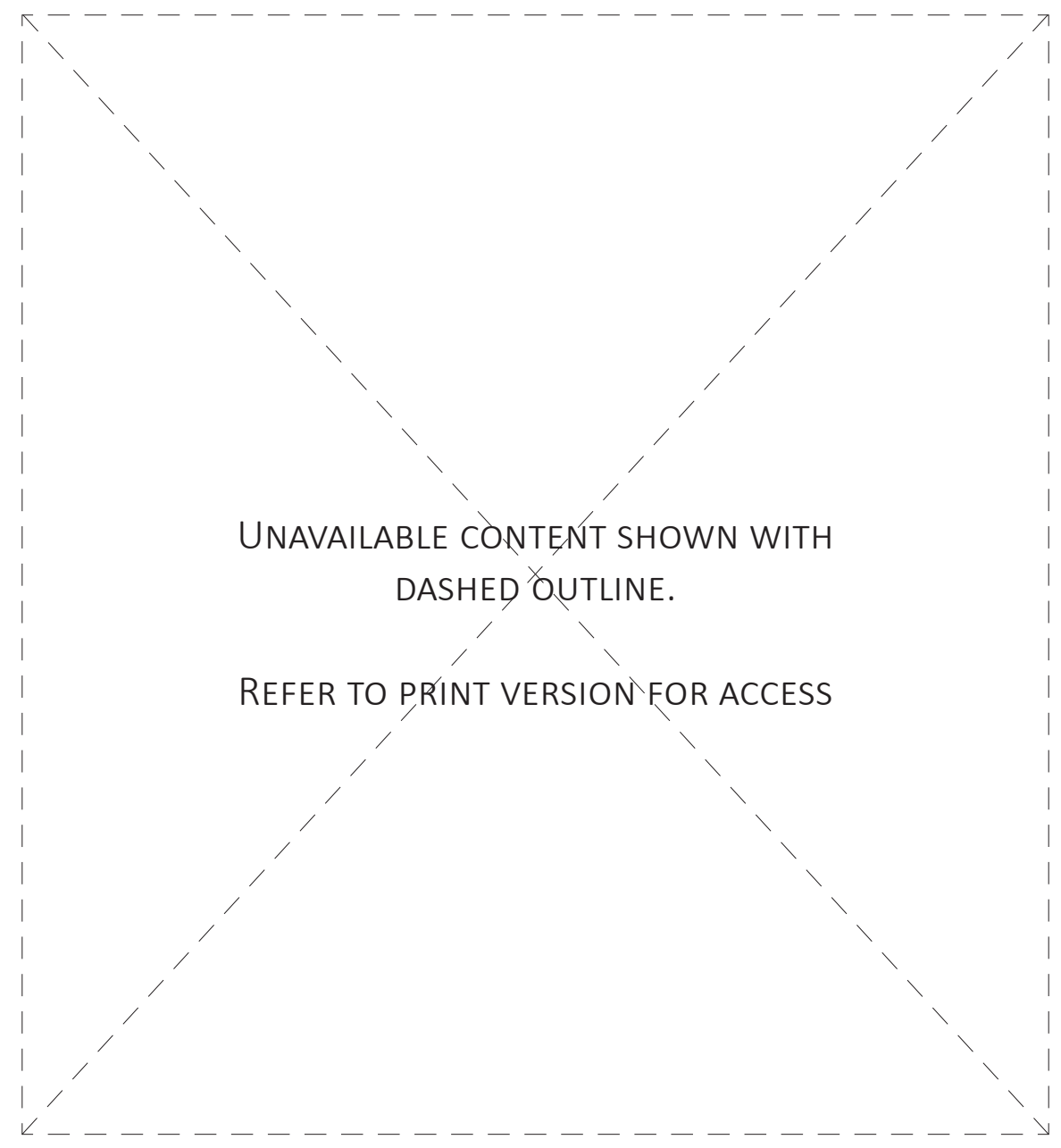

Figure 6: Saint Matthew, folio 15 recto of the Coronation Gospels (Gospel Book of Charlemagne), from Aachen, Germany, c. 800-810. (Khan Academy, 2019) 
2.0

INTRODUCTION

This chapter analyses how workspaces have come to be, taking a broad look at the history of the office. The objective of this chapter is to uncover the primary historic forces that have contributed to the design of today's workspaces. This is not a complete history of the development of the office, however this research highlights key theories, developments and buildings that have influenced contemporary workspace design. Although the term 'work' and 'workspaces' could relate to a variety of tasks and the spaces that house them, this research focusses specifically on the office and the completion of sedentary tasks within it. This chapter relates to the first objective of this research:

1. Analyse the forces that have influenced the design of workspaces today.

"Before you prescribe new solutions, you need to describe and understand the present situation. What are the forces that shape our offices?...Without a full understanding it is hard to say anything realistic about how the office of the future will or should look"

Juriaan van Meel, Office design and National Context. (2000, p. 10) 


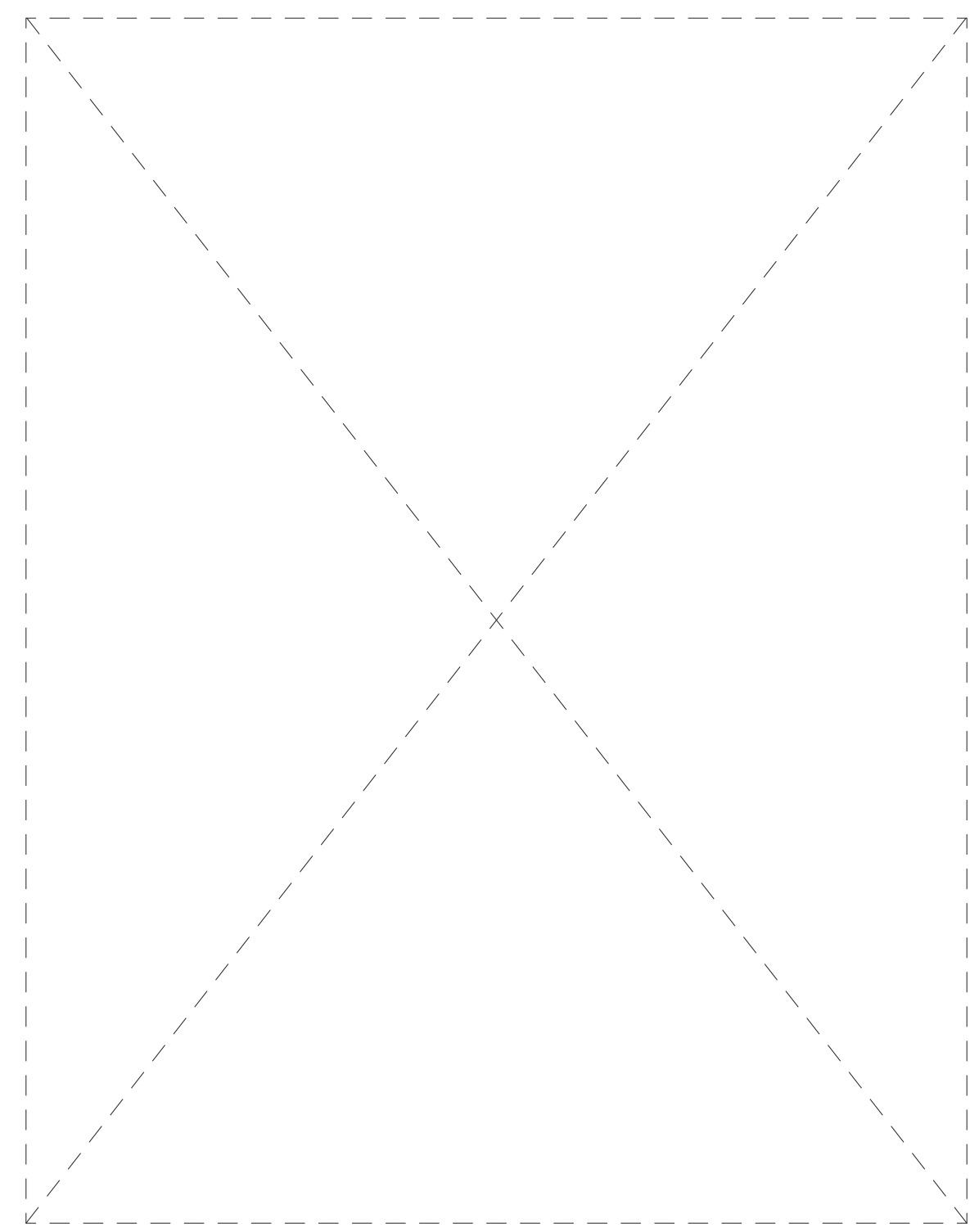

Figure 7: St Jerome in His Study, Antonello da Messina, c. 1475. (Wikipedia, 2019) 


\section{1}

\section{THE FIRST OfFICES (-1700)}

Work has always played a key role in human life. Initially, work was survival; with tight knit communities hunting and gathering wherever possible. But as civilisations advanced, the kinds of tasks needing completing required a different kind of space. With the development of written language, along with mediums of recording it such as papyrus, a place was needed to collect and organise this kind of information (Gillen, 2019). The earliest known offices are those of scribes in ancient Egypt, where they would often occupy a private room that allowed for the scrolls to be worked on and stored. This use of an early office by scribes continued into classical antiquity, with the Greeks and later the Romans utilizing them to manage the large amount of administration work created by empire. Roman palaces and markets also incorporated private offices for scribes. (Haines-Eitzen, 2012).

After the fall of Rome, medieval monks were the next notable group to use office conditions for the writing of manuscripts. The copying of religious texts in the middle ages saw a rise in the need for these spaces. It is from this period where we see the earliest depictions of offices. In the coronation gospels found in the tomb of Charlemagne, a 9th century depiction of Saint Matthew can be seen working away at his desk (Figure 6). This humble workspace, consisting of just a lectern and chair, shows the office in its most basic form. Skipping forward to the 15th century, we see another saint being depicted in a workspace. St Jerome at his Study by Antonello da Messina (Figure 7) is one of the first depictions of a fully designed office. Although multiple versions of this painting exist, this one shows the most detailed rendering of the purpose-built workspace. With thought being put into both the functional and spatial aspects of the office, it is much more elaborate than those seen before, and comparable to many offices of today. The influence of this painting can still be seen in modern times, with prominent Wellington architect Bill Toomath building an exact replica of the study into his own house in 2002 (NZOS, 2007).

Religious orders were not the only ones utilising private workspaces. Administration work for centralised governments was carried out in record rooms, known as chanceries (Corèdon \& Williams, 2004). Appearing first in the middle Ages, this was a private office where government letters and contracts were written.

Looking through the history of the early office, it can be seen that it was the domain of a select few, with only religious orders, governments and people of power having a use for them. 


\section{2}

\section{The emergence of 'White Collar Factories' (1700-1920)}

Desk-based requirements began to change in the 1700s, where the growth of industry saw an increase in administration work for governments and companies. The paperwork required to run these complex organisations led to the development of the first purpose-built workplaces (Gillen, 2019). The London Headquarters for the East India Company was one of these. Built in 1729, it located 200 clerks together in an open room with large rows of seats. The large groupings of workers and the "command and conquer" style of management employed set the precedent for offices to come (Gillen, 2019).

The industrial revolution of the 18th and 19th century saw a vast increase in the amount of administration work available. This increased the scale of office work dramatically, seeing a larger and larger portion of the population being employed in this sector. Factories of the time were the only comparable business model, so many workspaces were operated as such; being dubbed 'white-collar factories' (van Meel, 2000). Spaces typically consisted of large floor plans filled with rows of identical workstations. This kind of work environment and management style was widely adopted in Europe and the US during the latter half of the 19th century (van Meel, 2000). The invention of the typewriter in 1868 saw it become widely used in offices by the mid-1880s, improving the efficiency of each worker. This would remain the workhorse of the typical office for decades to come, being the main vehicle in which information was recorded.

In the early 20th century, the work of American engineer Fredrick Taylor became widely popular, quickly making an impact on how offices were managed and designed. In his book, The Principles of Scientific Management, Taylor emphasised efficiency over all else, applying many of the improvements seen in the industrial sector to office work (Taylor, 1911). His ideas were translated into office design through concepts such as orienting all desks in one direction, towards the supervisor, and the bunching of clerical staff together in an open plan as to not "obstruct the flow of work" (Donald \& Powell, 1931). Managers were also separated from the other workers, being given their own cellular offices with windows viewing out over the employees (van Meel, 2000). A famous example of the implementation of these ideas was the Larkin Building by Frank Lloyd Wright (figure 8). Built in 1904, it consisted of a central atrium space that was bordered by manager's offices. The clerical staff occupied this atrium space and no partition walls separated the workstations. Hierarchy and control were embedded in its design. Alongside its technological innovations such as a primitive form of air-conditioning, it set the scene for the modern office building. 


\section{3}

\section{HIGH RISES \& GLASS BOXES (1920-1950)}

The rigid ideas of hierarchy and supervision that Taylorism introduced quickly became engrained in 20th century office building design, most intensely in America. When this was paired with the rising price of land in cities such as Chicago and New York, it resulted in the development of the iconic high rises we know today. Examples such as the Empire State Building in the 1930s became visible statements of prestige and power. This representation of power continued in the workspaces themselves, with managers typically occupying the outer perimeter of these towers, and staff occupying the inner bullpen (Duffy, 1997).

Following the Second World War, economic expansion and technological advancements saw the beginning of a new era of office buildings. New materials such as glass became much more available, and with the growing interest in modernism, the 'glass boxes' of the international style were born (van Meel, 2000). The new ideas of the time were exemplified in the design of Lever House by Skidmore Owings and Merrill, which completed in 1952 (Figure 9). Although aesthetically very different, the principles of Taylorism still lay at the core of its workspaces (Gillen, 2019). The introduction of air-conditioning in the 30s and fluorescent lighting in the 40s also allowed these buildings to be much deeper in plan than before (van Meel, 2000). However, this did not change much for the employees, with hierarchy and supervision still keeping spatial arrangements much the same.
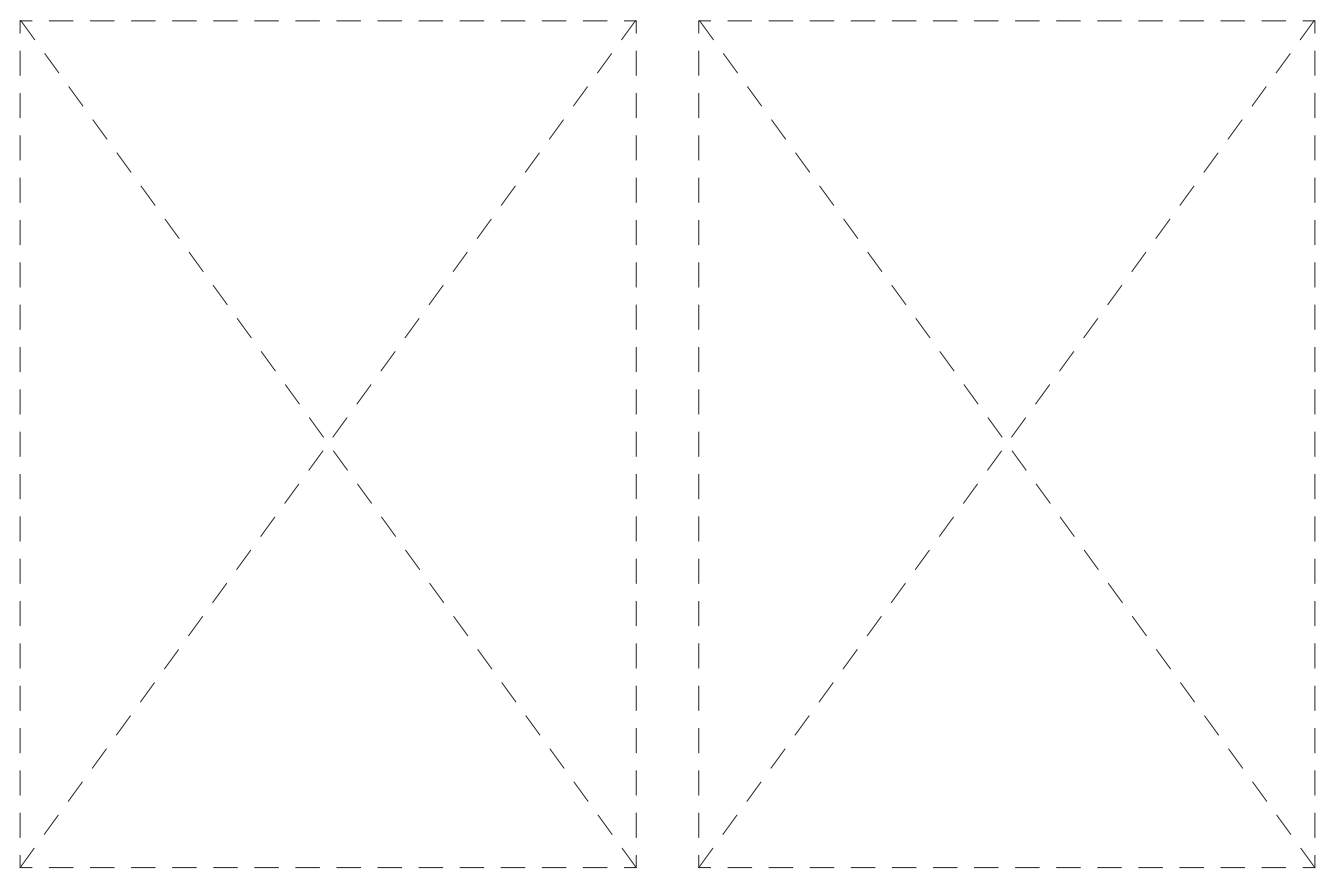

Figure 8 \& 9: Larkin Building, 1904 (Left), and Lever House, 1952 (Right). (Fliart, n.d) \& (Pictify, 2019) respectively. 


\section{4}

The Liberalisation Of THE OfFiCE (1960-1980)

It wasn't until the 1960s that the ideas of Fredrick Taylor finally began to fall out of favour. Social change brought about a rethinking of the status quo. This notion was epitomized in the work of behavioural theorist Douglas Mcgregor, specifically in his book, The Human Side of Enterprise (van Meel, 2000). Released in 1960, it posited the theory of $X$ and $Y$, which related to what motivates employees and therefore how they ought to be managed. Theory $X$ took the position that workers were innately lazy and required supervision, which aligned with the Taylorist management style of control. Theory $Y$ took the opposite position, theorising that people are self-motivated and will work on their own accord (McGregor, 1960). The position theory $Y$ took quickly gained notoriety, and the historically dominant ideas of hierarchy and supervision came directly into question. Ideas familiar to us today such as interaction and human-centred design began to take hold in European countries, resulting in numerous new interpretations of what a workspace ought to be.

One of these outcomes of this was Burolandschaft, or the office landscape. Developed by German brothers Wolfgang and Eberhard Schnelle, this approach gained momentum in the 60s and saw the breaking up of ordered desks and the incorporation of organic arrangements of space (Gillen, 2019). Described as "a somewhat disorderly variation of the open plan" (Staal, 1988), Burolandschaft championing egalitarianism through encouraging all staff to occupy the same space. The office landscape focussed on putting human centred design at the heart of the office floor, however Dutch architect Herman Hertzberger took this a step further, applying it to the whole building (Gillen, 2019). The Centraal Beheer Insurance Building (1972) had teamwork and collaboration at its centre, being made up of 56 blocks of team spaces arranged in four large quadrants (Figure 10). Social spaces were generous and the workspaces encouraged interaction between co-workers. The design of this building and its workspaces embodied many of the qualities we strive for today, being very much ahead of its time. New ideas broke the mould of Taylorism that had been dominant for decades. People were no longer thought of as cogs in a machine. It would be the infusion of new technologies that would change the office next.
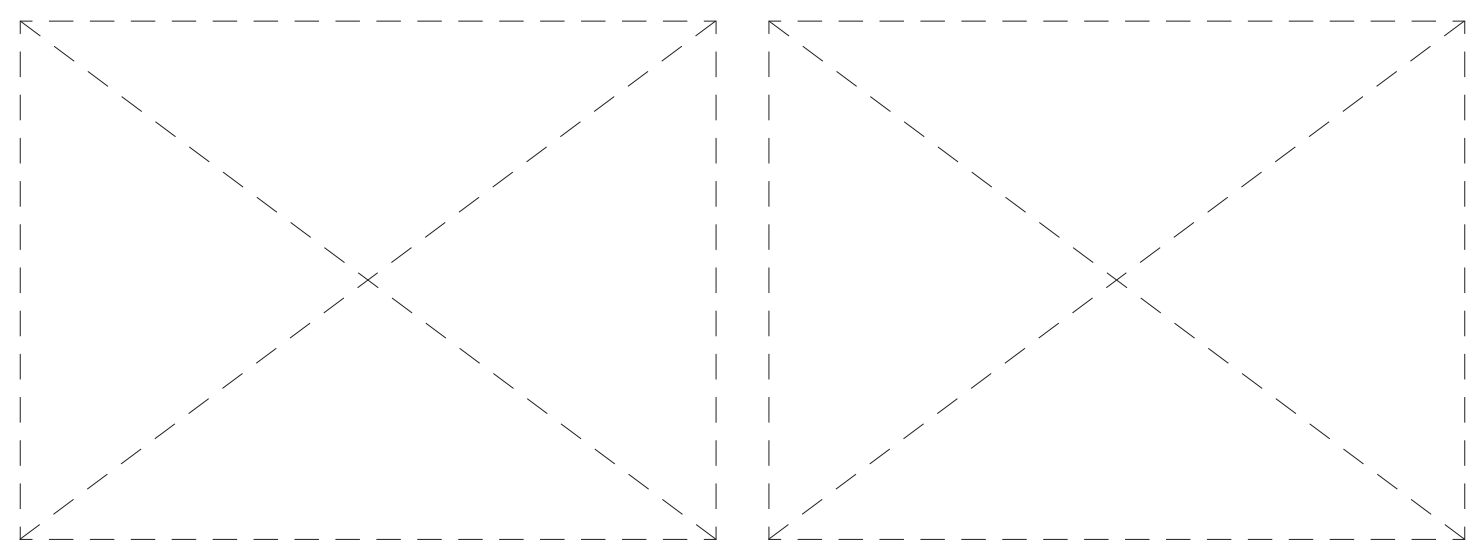

Figure 10 \& 11: Centraal Beheer, 1974 (Left), and Lloyd's of London, 1986 (Right). (Tumblr, 2013) \& (Reddit, 2019) respectively. 


\section{5}

\section{TECHNOLOGY AND THE CUBICLE (1980-2000)}

During the 1960s, designer Robert Propst created the 'Action Office'. The product of a large amount of research into office work processes, this set of furniture used modular and reconfigurable partition walls to increase the users "alertness, productivity and fluency" in their day to day work (Propst, 1966). The concept was successful, however during the 70s and 80s the idea was slowly drained of its flexibility. Owners and managers only saw partition walls and phased out the other more expensive aspects of the system. By the 1980s, the Action office had fossilised into what we know today as the cubicle. The advent of the desktop computer in the mid-1980s coupled well with the cubicle, leading to the widespread use of this kind of office environment. By 1998, 40 million people in the United States worked in cubicles (Gillen, 2019). This mass adoption did not please employees, with a survey by Steelcase the previous year revealing that 93 percent of cube dwellers would prefer a different workspace (Saval, 2014).

The mass adoption of information technologies such as the personal computer also saw other changes in the way people designed workspaces. Prior to the desktop computer, work processes still heavily revolved around typewriters and physical copies of documents. The word processing previously done physically could now be done completely digitally, giving rise to the idea of the 'paperless office' (Duffy, 2008). The computerisation of the office happened on a global scale, also effecting workspaces on a practical level, as cabling and cooling now had to be accounted for (van Meel, 2000). Richard Roger's design for Lloyds of London exemplified how these new technologies could change architecture (Figure 11). Completed in 1986, this building expressed a high-tech appearance that had not been seen prior. The office areas had raised floors and suspended ceilings to account for services. The building consisted of 6 towers, arranged around a large open atrium that let light deep into the building. All services such as stairwells and ducting were located on the outside of the building, allowing the office areas to remain open.

As technology continued to develop into the 1990s, it became possible for work to be conducted anywhere. Powerful laptop computers and the adoption of mobile phones allowed for workers to be freed from their fixed workspaces, becoming "footloose - free of place and time" (van Meel, 2000). This brought about new ideas of the role the office should play in work. 


\section{6}

\section{The Age of Autonomy \& Permeability (2000-)}

The turn of the century saw the blurring of what was considered an office. Fuelled by yet more technological advancements, many began experimenting with giving workers much more freedom. In the early 1990s, prominent Californian advertising firm Chiat/Day trailed 'deterritorialized' offices, also being called the 'virtual office' (Saval, 2014). Everyone was given a laptop computer and mobile phone, and were able to work wherever they wanted. Workers were given personal lockers for which to store their belongings, with personalisation being discouraged. This approach was far more radical than anything seen prior, and as a result the Chiat/ Day offices became "the talk of not just the industry but the entire world" (Saval, 2014). It was the first time these emerging technologies were fully incorporated into the management style of the workspace, and it would set the scene for the new millennium.

Numerous variations on the deterritorialized office gained popularity during the 2000s and 2010s. Hot-desking and activity-based working are prominent examples, with both relying on workers having no fixed desk and choosing where they want to work. Activity-based working is slightly different in that workspaces are set up with different activities in mind, meaning the worker chooses the space that best fits the work (Van Meel et al., 2010). This more autonomous management style has recently been coupled with rapid developments in information technology, resulting in designs such as The Edge, by PLP Architecture (Figure 12). Completed in 2015 for the global accounting firm Deliotte, this building sees workers have no assigned desks, they simply choose from the variety of spaces available. The building has an application that manages these spaces, so you can view what workspaces are in use and for how long. It also saves personal preferences such as light levels and temperature settings when you enter a space. The massive central atrium also serves to facilitate interaction.

Technology also allowed the city to become the office. The growing ubiquity of $\mathrm{Wi}-\mathrm{Fi}$, powerful mobile phones and portable computers in the 2000s resulted in public spaces such as cafes being used as workspaces. Although possible before, it was these improved technologies that made it much easier for anyone to work remotely. Freelancers, contractors and creatives were the primary groups to adopt this kind of public working (Gillen, 2019). This growing preference for complete autonomy coupled with the casual and informal atmosphere offered by cafes, resulted in the creation of purpose-built workplaces with these values in mind; called co-working spaces. Detailed more in chapter 2, this method of working sees workers occupying a shared, often open workspace with other freelancers or remote workers. Users can hire out office space as they need, whether this is week by week or hour by hour. It is often curated by a manager, to encourage interaction and the sharing of ideas between disparate groups (Kubátová, 2014).

The office is also becoming more a part of the city. Earlier examples such as Broadgate in London (completed 1995) see the breaking down of the barriers between office buildings and the wider urban context, incorporating courts and restaurants into the ground floor (Gillen, 2019). Skipping forward to the 2010s, this idea has 
grown, with companies leaning towards designing campuses that include these public amenities. Examples such as Google's Mountain View headquarters (completed in 2005, architect: Clive Wilkinson) in California mimic the layout of nearby Stanford University, having neighbourhoods and streets that house workspaces amongst gyms and outdoor areas. These campus-inspired workspaces are typically low rise and focus on facilitating the well-being of users, as this is known to aid in both the creativity and productivity of workers (Gillen, 2019). Nature is often incorporated as well, seen in Frank Ghery's design of MPK20 for Facebook in 2015, where a nine-acre park was situated on the roof of the long, two-storey building. Amazon's Spheres in Seattle also utilize nature as a key part of the design, fusing workspaces, public amenities and lush greenery in one building (Figure 13). All these designs focus on the user and incorporate public aspects into the ground floor. Workplace researcher Rob Harris states that "these trends suggest that buildings are becoming more "permeable" as distinct from the corporate monoliths of the past." (2015).

The office of today can be anywhere. Information technologies and looser ideas of what the office should be are allowing work to be blended more and more with the wider environment.
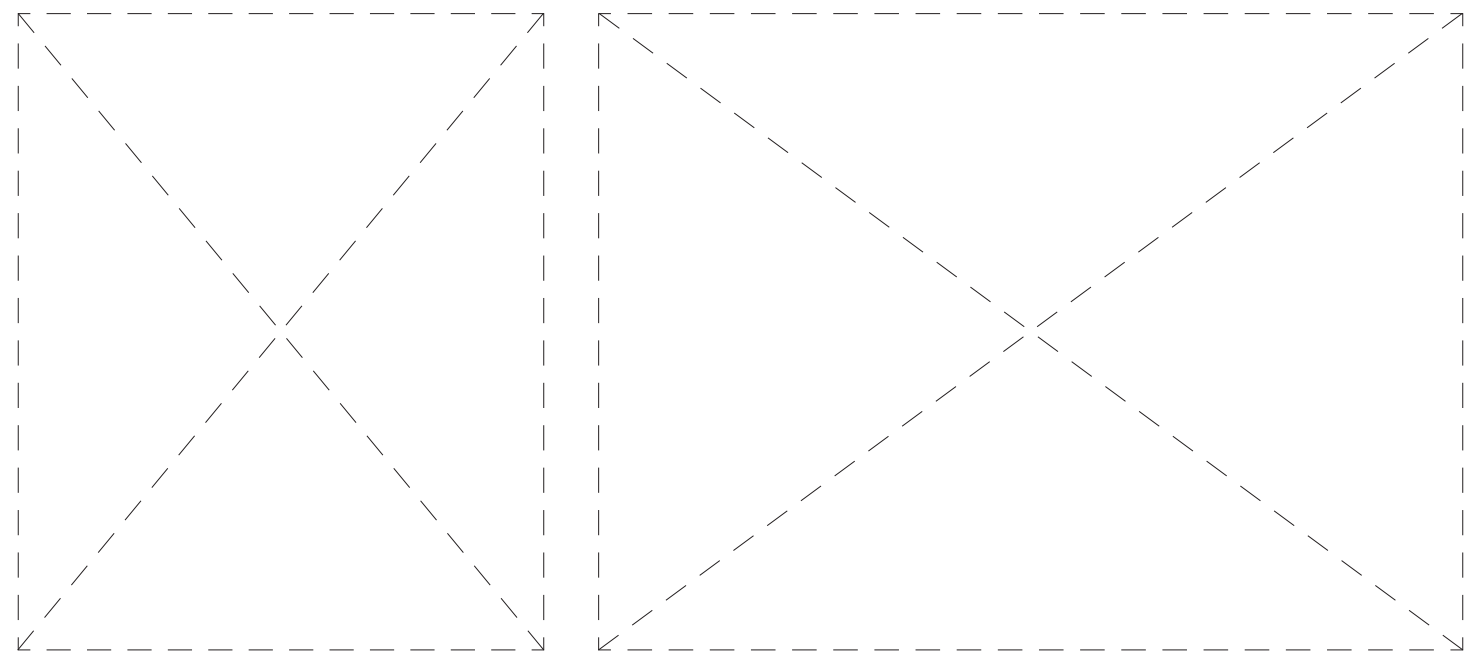

Figure 12 \& 13: The Edge, Amsterdam, 2015 (Left), and The Spheres, Seattle, 2018 (Right). (PLP Architecture, 2019) \& (NBBJ, 2019) respectively. 

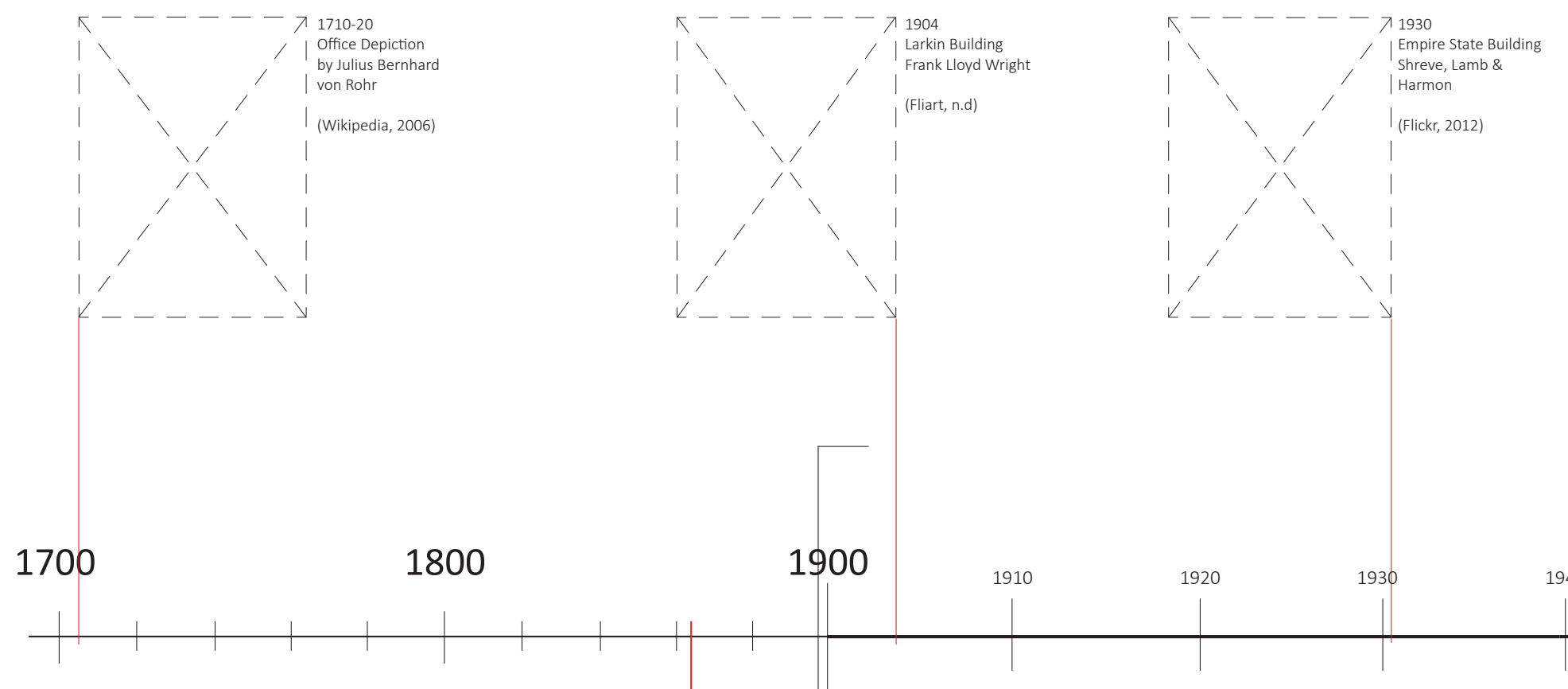

Early workplaces usually were heirachal, supervised 'white collar factories'.

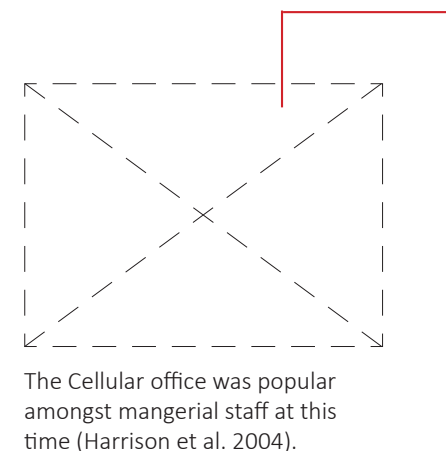

Figure 14: Timeline of prominent office developments throughout history. 


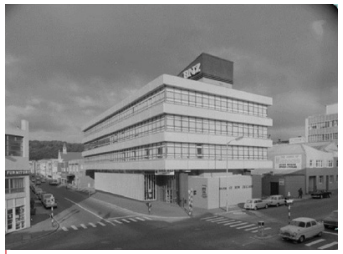

BNZ Computer Centre

(Ref: DW-3249-F Alexander Turnbull Library)

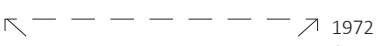

Centraal Beheer Herman Hertzberger

(Tumblr, 2013)
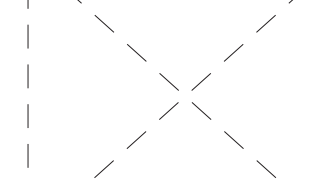

$$
\text { (1) }
$$
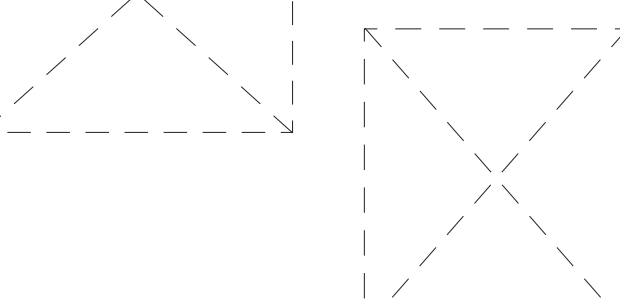

Richard Rogers \& Partners

(Reddit, 2019)
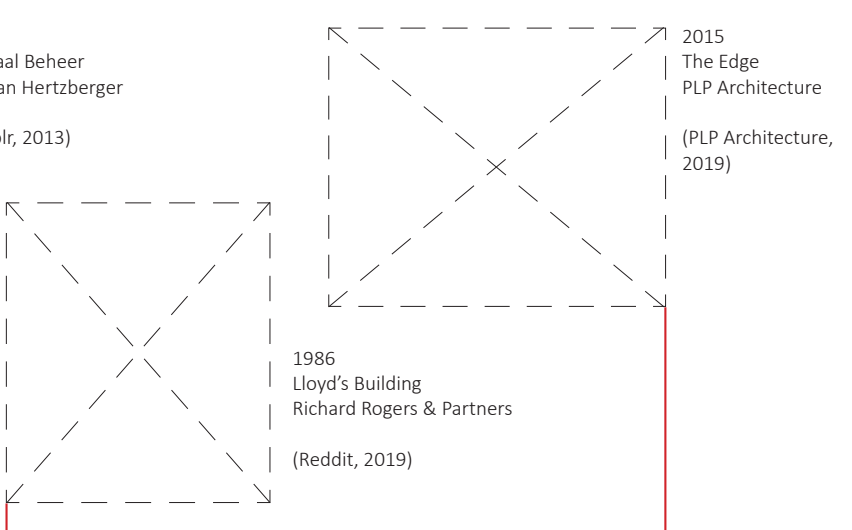

1980s

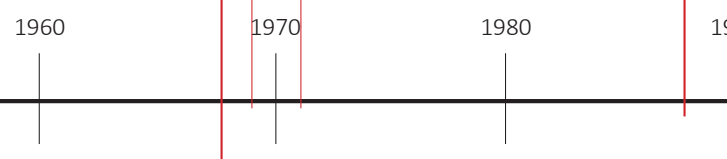

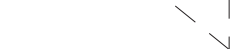

The landscaped office became popular in the 1960's, breaking the mold of Taylorism (Harrison et al. 2004).
Activity based working and other non-territorial office configurations become widely popular. Coworking explodes. 

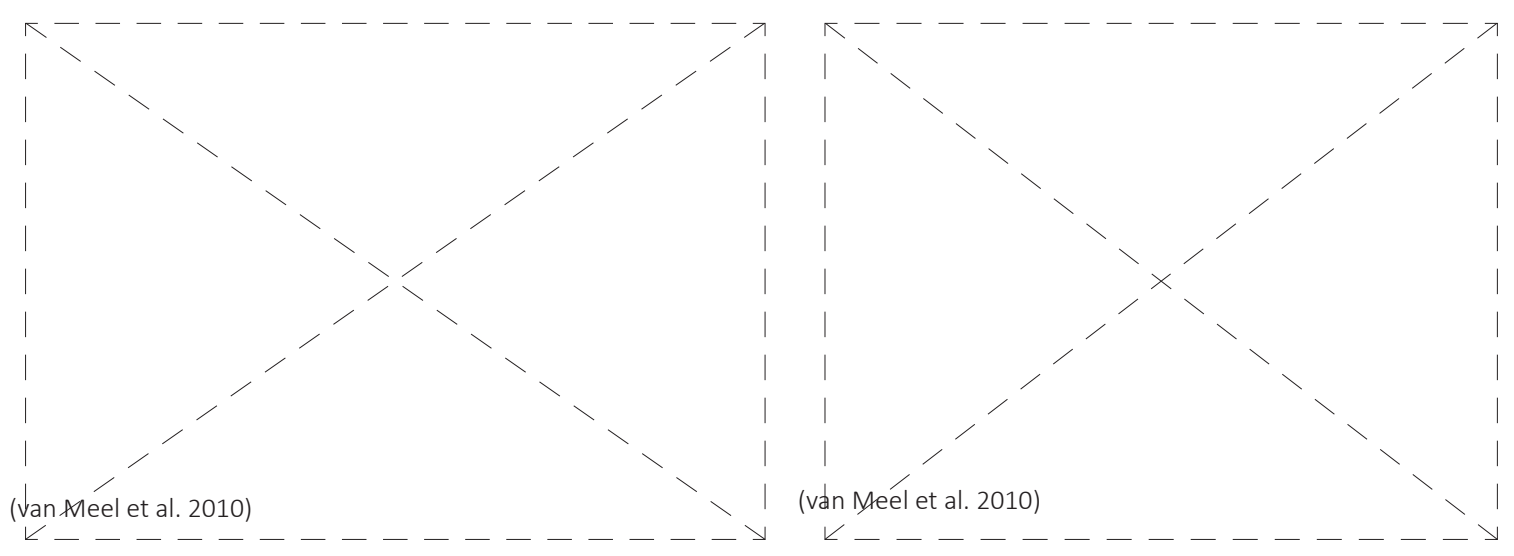

Advantages:

Advantages:

- Provides visual privacy

- Efficient in space utilization

- Complete control of ones climate (temperature, noise,

- Great flexibility in both density and layout of desks etc)

\section{ment}

Disadvantages:

- Very limited visual privacy

- Relatively expensive and inflexible when compared to

- No control over climate (temperature, noise, etc)

other configurations

- Adds a barrier between informal exchanges

- Danger of low utilization rate

- Segregates coworkers

Activity Based Offices/Non-territorial Offices

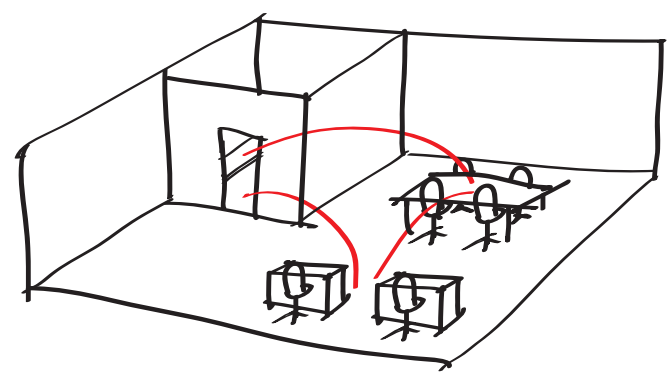

Advantages:

- Workers can choose their workspace to suit the task at hand and their own preferences

- Very efficient in space utilisation, less desks required

Disadvantages:

- Lack of personalization, loss of identity

- Potential for misuse as it relies on trusting employees to

organise themselves

- No way of guaranteeing the workspace you want will be available

Figure 15: Overview of the advantages and disadvantages of differing office configurations 


\section{7}

\section{Prominent OfFice Configurations And SizeS}

In the history of the office there have been many variations on the design of workspaces. However, most revolve around two primary configurations, the cellular office and the open plan. This section provides a brief overview of the primary advantages and disadvantages of these approaches, as well as a discussion of the typical amount of space provided.

The cellular office is a confined workspace that encloses the user. It is most suited to independent, concentrated work and gives the user complete control over their environment. As seen in the history section it can also be used to represent status. Its primary downside is that it segregates the user from their co-workers, impeding interaction. The cellular office is also relatively inflexible, often requiring expensive renovations to suit new arrangements. Privacy and concentration characterise the cellular office (Van Meel et al., 2010).

The open plan is an open space that houses all workers together. It is suited for creative and collaborative tasks, as it encourages informal interactions. It is also very efficient in the utilisation of space and greatly flexible. Its primary downsides are the loss of control of one's environment, which may hinder concentrated work (Van Meel et al., 2010). There is also little visual privacy, which may be required in some professions. Communication characterises the open plan.

Activity based working or non-territorial offices are not separate configurations, instead they provide choice between workspaces. The advantages of this include the user being able to choose the space that suits their preferences or specific tasks. It is also even more efficient than open plan in terms of space utilisation, with less desks being needed. Its main downsides are that there is no chance for personalization, and there is no way of guaranteeing the workspace you want will be available. Choice and variety characterise activity based working.

Although there are many other variations of office configurations, they all stem from the user's desire for either controlled individual environments or collaborative group spaces. Activity based working represents the desire to switch between to two as needed. Through this, we see the core needs of the office worker; concentration, collaboration and choice.

The amount of space given to each worker has also changed throughout history. During the times of 'white collar factories', the size of workspaces were determined by how many could be squeezed into one space, with the well-being of the user being an afterthought. This rationale of efficiency continued for quite some time, with the average American workspace in the 1960s only aiming for $5.0 \mathrm{~m}^{2}$ of space (Joedicke, 1962). This improved gradually over time, with design targets increasing to $10.0 \mathrm{~m}^{2}$ in $1990 \mathrm{~s}$ London. However, both of these averages are still relatively low when compared to today's workspaces, with Wellington averaging $16.4 \mathrm{~m}^{2}$ per person. Low unemployment is cited as a being motive for business owners to make working environments more attractive to users (Marriage, 2019). 


\section{8}

\section{CONCLUSION}

This chapter analysed how the office of today came to be and the forces that has shaped it. Through the growth and departure from Taylorism to the collaborative co-working facilities of today, we can see that social change and technological advancements have moulded the office into its current form. Control and hierarchy are seen to slowly give way to technologically-enabled autonomy. The core needs of concentration, collaboration and choice can also be observed, as well as the gradual increasing of space per worker. The next chapter looks forward, taking note of the key forces that have shown to have great influence on the design of contemporary workspaces, and analysing these to gauge the direction work may head in in the future. 

HOW IS WORK CHANGING?

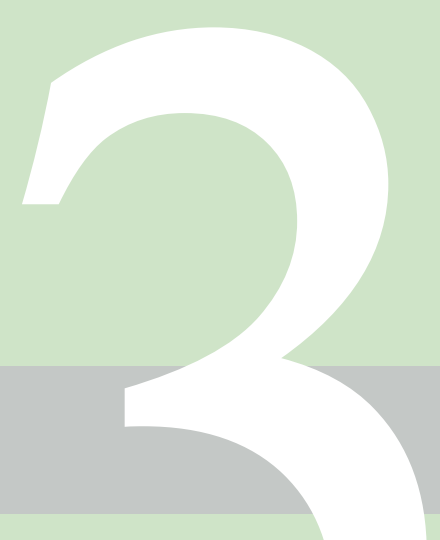


3.0

\section{INTRODUCTION}

The previous section highlighted the influence that social and technological forces have on the design of workspaces. This chapter examines how these forces are likely to change, with the aim of gauging the direction the future of the office is heading. Many experts and statistics do not refer to exact timeframes when discussing the future, instead they describe general trends that are likely to become prominent in the coming decades. This section analyses these wider trends, focussing on this same undefined range of the next two to three decades; with also some speculation on the far future. This relates to the second objective of this research:

2. Examine how these forces are changing and their potential implications on the future of workspaces 


\section{1}

\section{AUtOMATION AND ARTIFICIAL INTELLIGENCE}

To begin to explore the future of workspaces, an understanding must be gained of what the future of work in general might be. Just as in the past, the work people do and the way they do it will continue to change; with this all having implications on the kind of workspace required. Recently, technology has been at the forefront of discussions about the future of work, relating specifically to the growing advancements in artificial intelligence and its relationship with automation. The last two decades have seen the emergence and rapid development of artificial intelligence (Acemoglu \& Restrepo, 2018a). Artificial intelligence (A.I.) is the ability for machines or computers to mimic cognitive functions like those of the human brain (Poole et al., 1998). Algorithms are written that allow computers to learn and problem solve, rather than just simply following instructions. These are known as machine learning algorithms. Recent advancements in machine learning algorithms, through the use of deep neural networks, have made it possible for computers to learn and recognise abstract patterns much better than ever before (LeCun et al., 2015). These algorithms can be fed large amounts of data and learn for themselves how to complete different tasks. Machine learning algorithms already power many aspects of the modern world, from search engines to selfdriving cars; and the field is continually developing.

The reason A.I. is linked with the future of work is that it has the potential to rapidly speed up the process of automation. Although automation is a process that has been going on throughout history, with new machines routinely replacing humans in repetitive tasks, A.I is new in the sense that it can learn and problem solve (Acemoglu \& Restrepo, 2018a). This has the potential for much wider implications than the automation experienced previously, as it can be applied to almost any task. Professions that traditionally lay outside the capabilities of automation now seem at risk, such as lawyers and doctors, as an A.I. can be fed huge amounts of data on previous cases and build up a vast knowledge comparable to that of a professional in a fraction of the time (Susskind \& Susskind, 2016). This wide applicability may not be limited to computerized tasks. Continuing advancements in robotics could also be paired with A.I., resulting in a machine that could potentially interact with and learn from its environment. This leads to the debate currently taking place around the world, is there even a future of work? 


\section{2}

\section{POST-WORK SOCIETY}

It has long been theorised that computers will eventually take away our need to work. Influential economist John Maynard Keynes described such a situation in 1930, detailing what he called 'technological unemployment' as "unemployment due to our discovery of means of economising the use of labour outrunning the pace at which we can find new uses for labour" (Keynes, p. 2). With the advent of ever more powerful artificial intelligence, this post-work future seems closer than ever, but there is still much debate about the degree to which artificial intelligence and automation will impact work. In a recent study by the OECD, they estimated that $14 \%$ of jobs could be completely automated, with a further $32 \%$ of jobs having $50-70 \%$ of their daily work activities automated (2018). Mckinsey global institute carried out a similar study and estimated that $5 \%$ of jobs could become automated, while $60 \%$ of jobs could have $30 \%$ of their daily tasks automated (Manyika, 2017). Both studies predict that a notable portion of occupations could completely disappear, with a larger portion having their day to day work activities noticeably impacted.

Others are even less optimistic about the impact of automation. In 2013, Frey and Osborne published a now well-cited paper stating that $47 \%$ of jobs in the U.S are at risk of becoming automated, in "perhaps a decade or two" (p. 265). Authors such as Martin Ford echo this much more immediate view of automation, arguing in his book, Rise of the robots, that we are fast approaching the end of work as we know it (2015). His argument centres on how artificial intelligence not only has the ability the replace human labour in low skilled jobs, but also in higher-skilled professions. He also notes that these technological advancements are only accelerating, arguing that if we are not careful, the effects of this wave of automation could "disrupt our entire system to the point where a fundamental restructuring may be required" (p. 18).

$5 \%$

of occupations could be automated

$60 \%$

of occupations could have $30 \%$ of their daily tasks automated

Figure 16: Estimations of the impact of automation on occupations. (Manyika, 2017) 
These more alarming claims of the coming age of the robots has caused a large amount of automation anxiety, and many have contested these predictions. Carrying on from the work of Frey and Osborne, Acemoglu \& Restrepo took a closer look at the economic forces that underlie automation, gaining a clearer picture of its potential impacts on employment (2018b). In their paper, they acknowledge that automation does eliminate some jobs, causing a 'displacement effect'. However, there are numerous forces counteracting this effect. They highlight a number of primary 'countervailing forces'; namely the productivity effect and the 'deepening' of A.I (2018b). The productivity effect is where the reduced cost to produce goods, caused by automation, results in an increase of productivity, causing more demand for that now cheaper good and an increase in the jobs that come with it. The deepening of A.I describes how automated tasks get continually more efficient as A.I develops, resulting in an increase in productivity and no loss in jobs, which also feeds into the productivity effect. Acemoglu and Restrepo detail how these forces slow down and balance the displacement effect cause by automation, stating that it will be a slow and "painful" process adjusting to these changes, but work will likely not disappear (2018a, p. 32). Summarising the current state of A.I, automation and work, Mckinsey state that "a surplus of human labour is much less likely to occur than a deficit of human labour, unless automation is deployed widely. However, the nature of work will change" (2017a, p. 2).

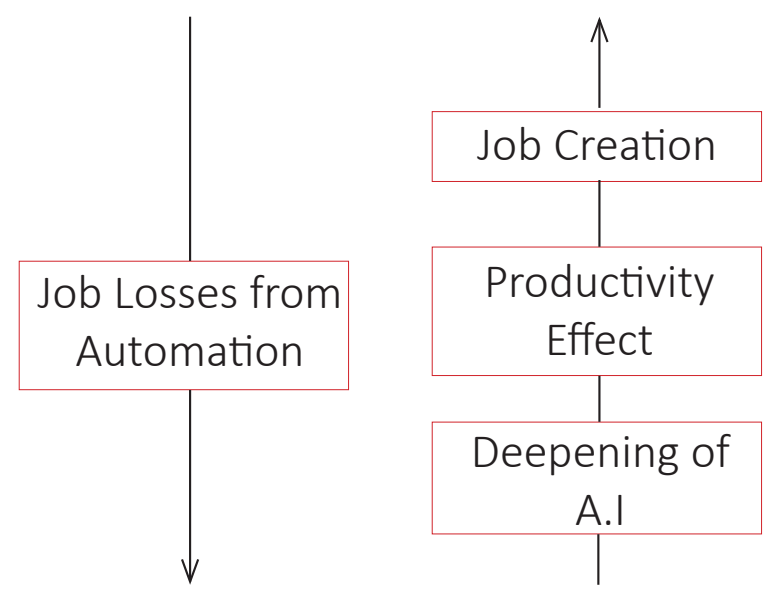

Figure 17: Simplified diagram of the balancing Forces of Automation, Acemoglu \& Restrepo, 2018. 


\section{3}

\section{IMPLICATIONS OF AUTOMATION \& DIGITAL TECHNOLOGIES}

Although there is no consensus about what the future of work is going to be, there is no doubt that automation and artificial intelligence will have a large effect on employment. As said before, work will change; but how? Although there will be many widely-varying implications of automation, this section discusses the most likely primary impacts. These are effects that have been identified by multiple sources and are almost certain to grow in significance in the future. The first effect many point to is the fact that large amounts of the population will need to be reskilled to meet the demands of the new economy. As seen from the OECD's and Mckinsey's research, a large amount of occupations will have roughly a third of their work tasks automated, with some being automated completely. It is estimated that globally, up to 375 million workers, or 14\% of the population, may need to switch occupations or retrain their skills (Mckinsey, 2017b). As a result, it is expected that companies will have difficulty retraining or hiring skilled staff fast enough in the coming decade. The World Economic Forum describes this growing skills instability, noting that "the skills required to perform most jobs will have shifted significantly" (2018, p. 8). They also hint towards a growing reliance on external talent by companies, as "between one-half and two-thirds are likely to turn to external contractors, temporary staff and freelancers to address their skills gaps" (2018, p. 9).

This trend towards utilising more freelancers and contractors is something that is already occurring in many developed nations, being known as the 'gig economy'; where 'gig' refers to short-term contract work (De Stefano, 2015). Resulting more from the development and adoption of new software than automation, this style of work acquisition is set to grow. Platforms such as Uber and Airbnb directly link workers or suppliers with clients, and many believe that in the future, much more work to be distributed like this. Workplace consultant Erik Veldhoen, who coined the term 'activity based working' in the 90s, believes heavily in this digitally-enabled restructuring of work. He argues that we will return to preindustrial times, stating that "we will go back to craftsmanship" (Saval, 2014, p. 297). He's referring to how before industrialisation, everyone worked for themselves and often pursued their craft. Digital technologies are allowing a return to this through directly connecting up workers with work. This direct kind of labour contract also allows greater freedom and autonomy, with the worker choosing what kind of work they take on and how they complete it. Veldhoen summarises this predicted rise in autonomy by stating that "in the future we don't need managers anymore" (Saval, 2014 , p. 298). However there are risks with this kind of arrangement, with there being no safety net for failure or shortages of work. Writer Richard Greenwald also believes in this return to older working styles of entrepreneurs pursuing their craft, but he acknowledges its inherent risks. Greenwald notes that the large corporations we have today will not disappear, but in fact grow, and suggests that these could be used as safety nets, with the worker taking on freelancing jobs as well as some fixed work (Saval, 2014). 
The most significant implication of the growth of artificial intelligence, digital technologies and automation is that they enable a single worker to do much more. Faster and increasingly more intuitive technologies, A.I assistants and the elimination of repetitive work will all allow workers to become more efficient with their time. Work in general will also become much more focussed on decision-making and creativity, as repetitive tasks will be automated out. Deloitte summarise this by stating that "automation, by removing routine work, actually makes jobs more human, enabling the role and contribution of people in work to rise in importance and value" (2019, p. 30).

\section{4}

\section{THE RISE OF CO-WORKING \& WORKPLACE INTERACTION}

So given these coming changes to work, what does this mean for the design of workspaces? With automation expected to cause reskilling and the utilisation of more freelancers, and with digital technologies changing the way work is acquired, it seems that the future of work is much more autonomous and focussed on the individual rather than a singular company. In this light, it is no surprise that we have seen an explosion recently in co-working, as these values lie at its heart. With the impacts of automation only encouraging more autonomy in the future, this explosion is very likely to continue.

As mentioned in chapter 1, co-working is the sharing of a single workspace between different users, often paid for as needed. The casual atmosphere coupled with the grouping of like-minded people counter the negative aspects associated with freelancing and remote working, namely professional isolation and the lack of networking opportunities (Spinuzzi, 2012). The first official co-working facility opened in 2005 (Kubátová, 2014), and since then it has exploded to an estimated 22,400 locations around the world in 2019 (Deskmag, 2019). Co-working companies such as WeWork have expanded globally to great success, with the company at one point being the most valuable tech startup in the U.S (Campbell, 2019). Although WeWork's valuation has dropped since then due to issues with its upper management, it shows the belief that people have in the idea of co-working. Coworking is also "evidence of a new attitude towards building use", as there is no one tenant, but many all coming and going as they please (Saval, 2014, p. 308).

The rise and current prominence of co-working reflect the growing desire by workers for autonomy and freedom. This desire will only grow given the forecasted developments that have been analysed. Although not all workplaces will become 
co-working spaces, these kinds of spaces will grow in appeal, as more and more people will be enabled by technology to follow their own craft or interests. These are also places where startups and creatives can gather and swap ideas, with many cities already seeing the benefit of this such as Auckland, who are using coworking spaces to create a "home of innovation" (Grid, 2019, p. 1). Because of this greater focus on both personal freedom and idea generation, the design of the space must focus on encouraging interaction, as collaboration aids in innovation and counters the isolation inherent in freelance work. This focus on interaction is key for the future workplace, with it being stated that "the purpose of the built environment is increasingly transforming towards providing a social setting where people meet and interact" (Petrulaitiene et al., 2017). With work in the future also being more human, as it is more focussed on the creation of ideas rather than carrying out repetitive tasks, the design of workspaces must prioritise the wellbeing of the user, as the worker is likely to be more productive and creative the happier they are. Workplace researcher and strategist Andrew Laing summarises this and calls for "flexible, diverse, human habits for electronically supported nomadic occupation" (2013).

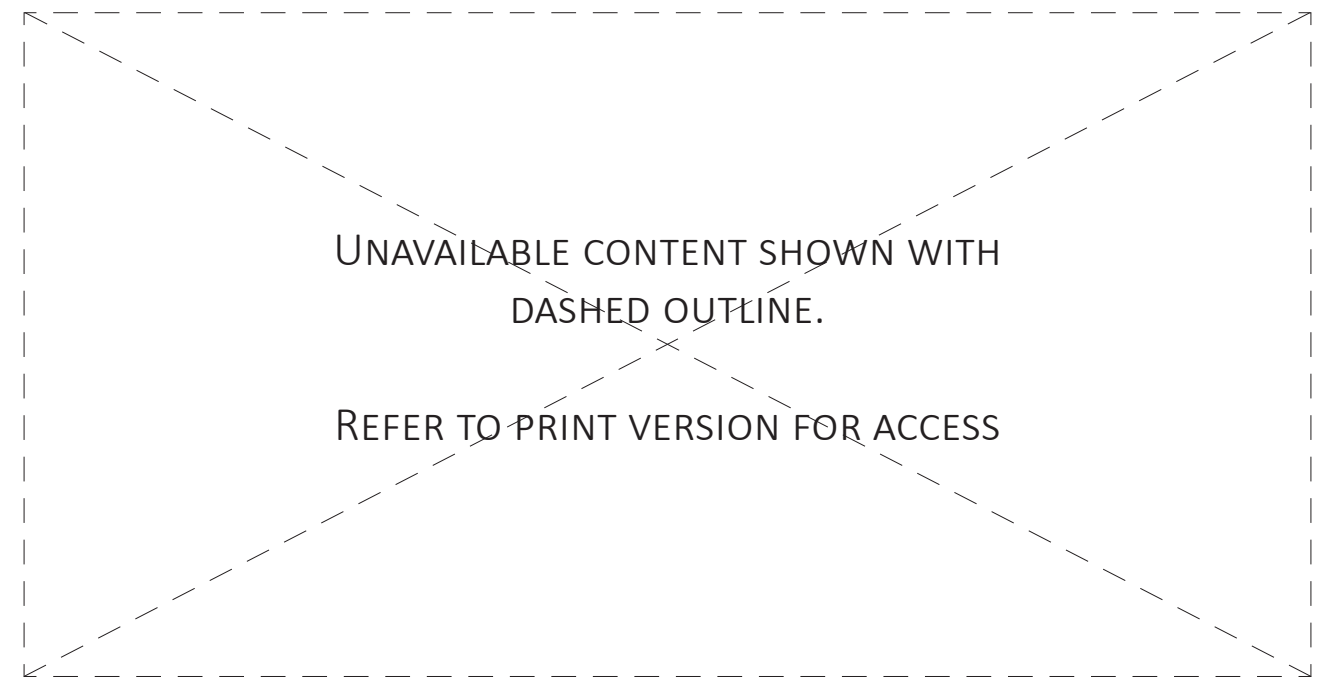

Figure 18: Number of Coworking Spaces Worldwide. (Coworking Resources, 2019) 


\section{5}

\section{TeCHNOLOGiCAL ChANGeS tO the WORKPLACE}

As seen throughout the history of the office, the development of new technologies often lead to significant changes in the design of workspaces. Having analysed the broader requirements of the future workplace, this section highlights possible technologies that could change the day to day work processes of the typical office worker.

Virtual reality (VR) has long been looked at as a revolutionary technology, and its potential to change the workplace has not gone unnoticed. Its ability to merge both the physical and digital realms gives it an advantage in that it can display much more information than a physical screen, with methods of extending desktop workspaces in VR being tested as early as 2006 (Hoffmann et al., 2006). Although not widely adopted due mainly to the cumbersome hardware currently available, virtual reality could become more useful when it becomes more seamlessly usable. Recent advances in augmented reality show promise, overlaying the digital world over the physical without the need for a full headset. The most ground breaking development in virtual and augmented reality is 'Holoportation' (Figure 19). Developed by Microsoft, this technology teleports a digital version of you and your surroundings to another location, where anyone wearing a virtual or augmented reality headset can see and interact with you (Orts et al., 2016). Once widely rolled out, this technology could have broad implications, connecting people face to face faster and easier than ever before.

Another technology that's impacting the workplace is the growing utilisation of the internet of things, as well as what's known as 'big data'. The internet of things is made up of all the different devices and objects that have electronics embedded in them, with the term describing how they act as sensors, giving a more digitally connected physical environment. Big data refers to how these sensors give large amounts of information about daily usage patterns, with machine learning algorithms now being able to sort and analyse this information quickly and efficiently (Gillen, 2019). WeWork utilise the internet of things and big data in the management of their co-working spaces. They do so by monitoring furniture and spaces, analysing what gets used and optimising their floor plans accordingly (Huet, 2019). This data is then used when designing a new fit out, and since an internet of things is implemented as well, WeWork continually build up a vast data set of user behaviours.

The field of robotics also has the potential to impact the future of work spaces. As mentioned previously, The Edge by PLP Architecture greatly incorporates technology into its design. Along with its application that manages the spaces and user preferences, the building also has robotic security in the form of autonomous roving bots (Figure 20). These robots patrol at night and scan for any intruders or disturbances, asking any passers-by for their work passes (Randall, 2015). As robotics develops further, the role of the robot in the workplace could change and evolve, although currently its uses are somewhat limited. Drones could also find a use in the workplace, as this technology has developed rapidly, becoming small, nimble and precise. 
An upcoming technology that is set to drastically change the way we work in the far future is Nueralink. Founded by entrepreneur Elon Musk, Nueralink is an implantable brain to machine interface, allowing humans and computers to exchange information without the need for input devices such as keyboards and mice (Musk \& Neuralink, 2019). Musk has stated that the ultimate goal of this technology is "some sort of symbiosis with artificial intelligence" (Johnson, 2019, p. 1). The implications of this could be very broad, as it calls into question everything about a typical workspace. The digital world would become fully integrated into the experience of the physical world, and humans would be able to augment their own brain, greatly improving their cognitive abilities. The impact of merging computer and brain would be huge, however, right now the concept is more science fiction than hard fact. Human trials of Neuralink begin in 2020, so it remains to be seen if this will become the distant future of work.

Technology has the potential to change the design of workspaces, so must be considered. In this increasingly digital age, this is even truer. As Andrew Laing summarised; "buildings and places are therefore becoming sites for integrated, embedded technologies, in which the distinctions between architecture, media and computing are increasingly blurred" (Laing, 2013, p. 11).

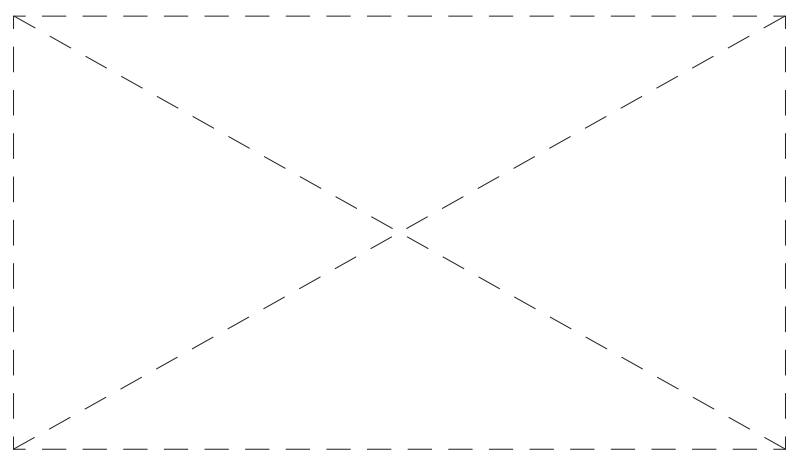

Figure 19: Demonstration of holoportation. (Microsoft Research, 2016)

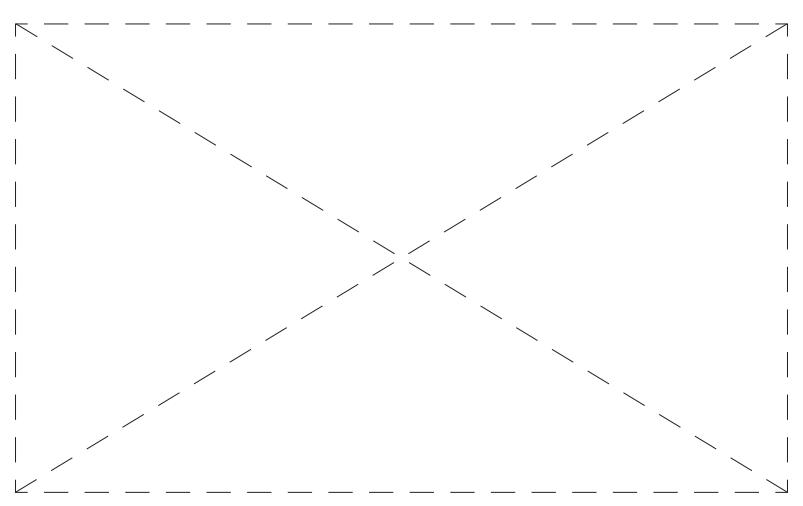

Figure 20: Robotic security at The Edge. (Randall, 2015) 


\section{6}

\section{KEY DRIVERS FOR THE FUTURE WORKPLACE}

This chapter examined the primary forces that have historically impacted the design of work spaces, analysing how they are likely to change in the future. Throughout this analysis, it became clear that there were certain issues that the workplace of the future must respond to. A set of 4 key drivers were developed, informed primarily from both the history of the workplace and how it is expected to change. These key drivers were also informed by those outlined in Andrew Laing's Work and Workplaces in the Digital City (2013, p.23), and The Distributed Workplace (Harrison et al., 2003). These drivers include:

Interaction - Technology has allowed work to be done anywhere, so why come to the office? It is increasingly focussed on interaction, with this being an even greater focus in a co-working facility.

Flexibility - Automation and technological development are constantly changing the work people do and the way they do it. Future workspaces must be able to adapt to these changes.

User Wellbeing - Companies and individuals realise that they work better when they are happier, with the workspace itself being able to aid in this.

Technological Integration - Technology will continue to become a bigger and bigger part of modern life, which must be reflected in workspaces. 


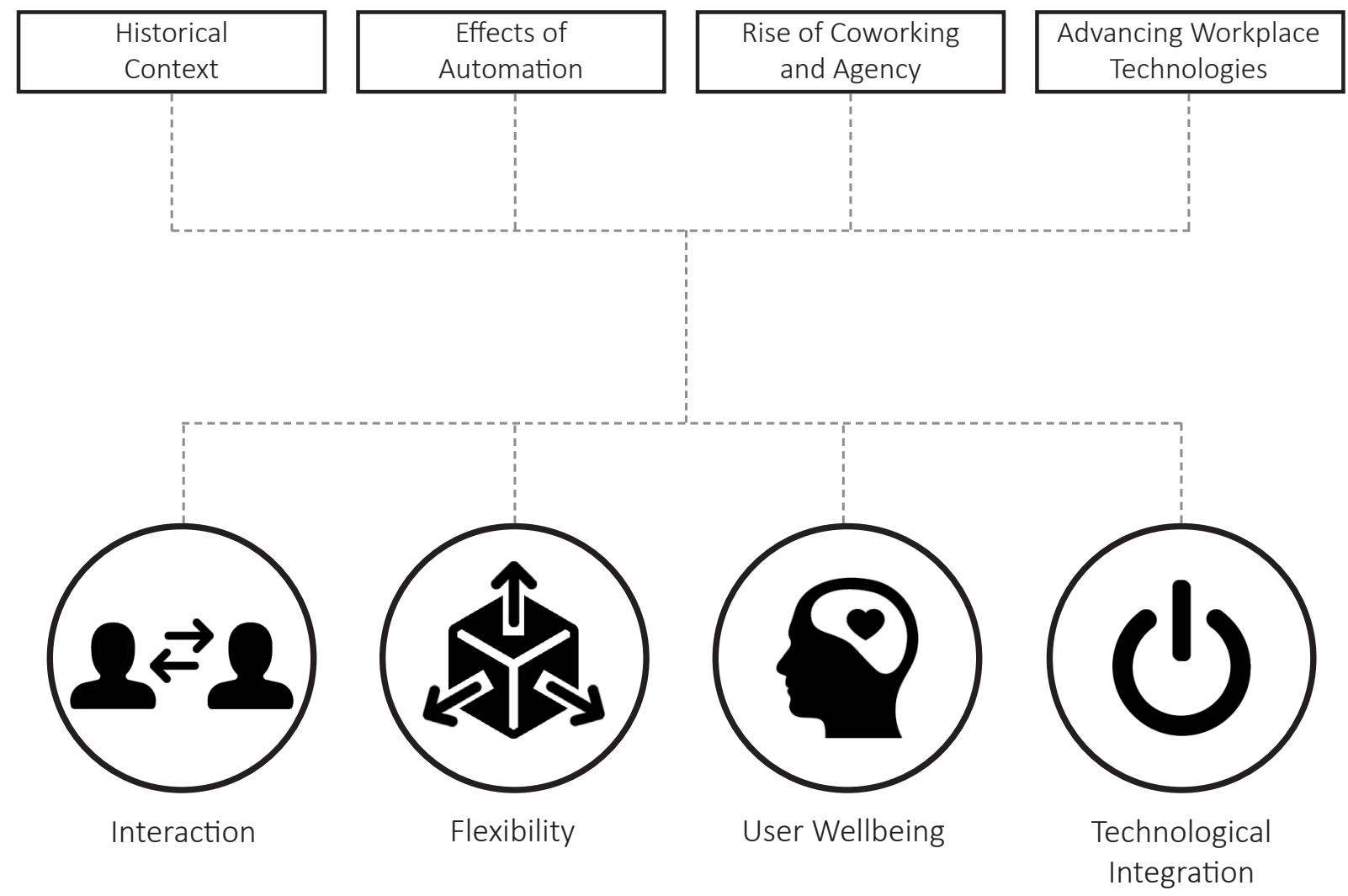

Figure 21: Diagram showing the forces that led to the development of the key drivers. 


\section{7}

\section{CONCLUSION}

This chapter highlights how the forces that influence workspace design are likely to change. The impact of automation and advancing technologies are set to change the way work is acquired and completed. A greater focus on short-term work could lead to a greater utilisation of co-working spaces, as their values and function align with those desired by freelancers and remote workers. The 4 key drivers outline the main issues that affect the design of a future workspace. The next section evaluates global and local precedents, examining how architects and designers are approaching the problem of designing workspaces in these changing times. 

PROJECT REVIEW 


\section{0}

\section{INTRODUCTION}

This chapter looks at global and local precedents, examining how architects and designers are responding to current workplace issues. The aim of this is to gather strategies and approaches that can be used to design a workplace of the future, showing what a future office might look like in a New Zealand context. The precedents chosen best exemplify the key drivers indicated in the previous section. Although co-working spaces were highlighted in the previous chapter, these examples include conventional single-tenant workplaces, as the scope of this research includes wider trends of workplace design, not just co-working. 


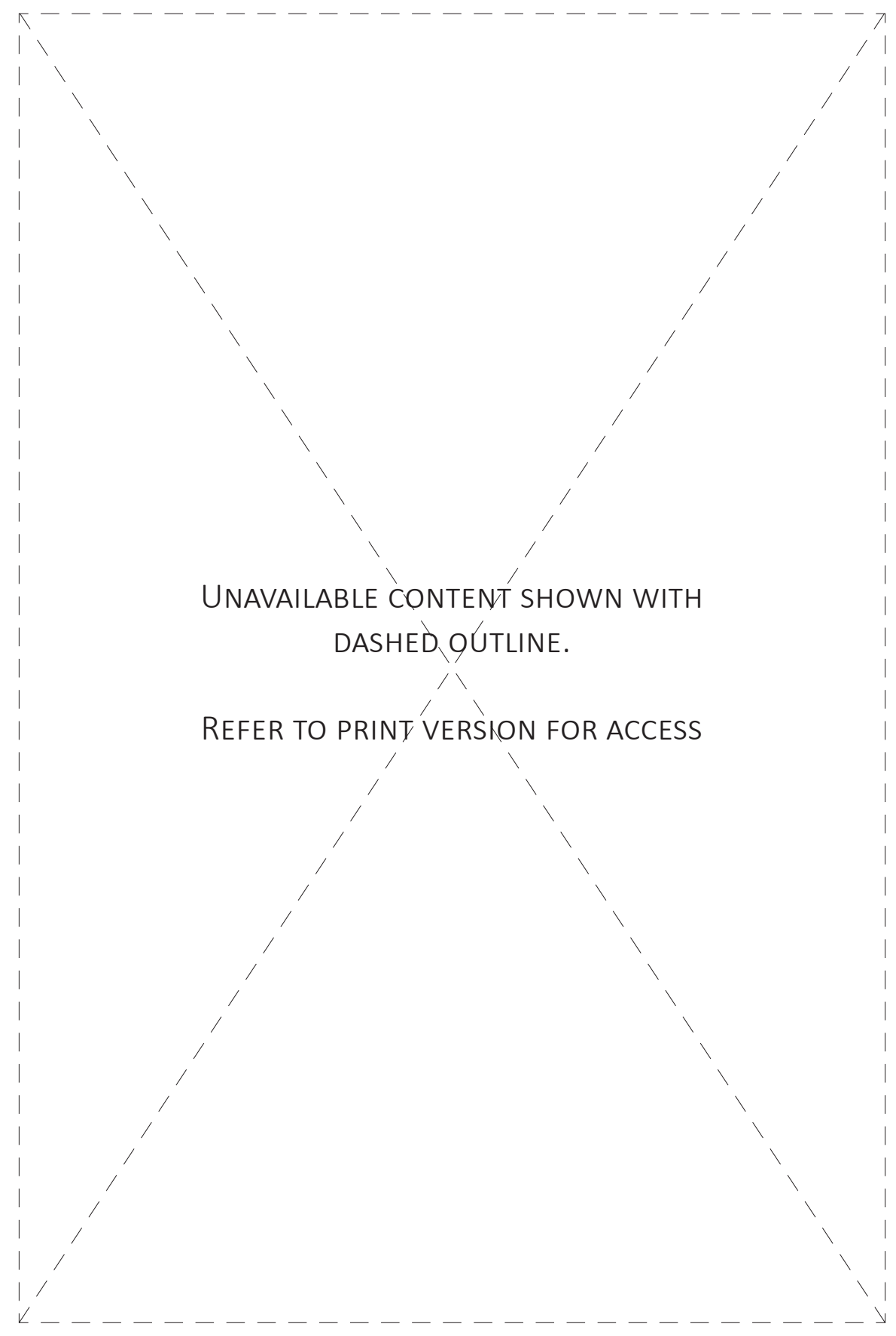

Figure 22: Central stair and atrium. (3XN, 2019) 


\section{1}

\section{GLobAl CASE Studies}

UN City, Copenhagen- 3XN

2013

Client: United Nations

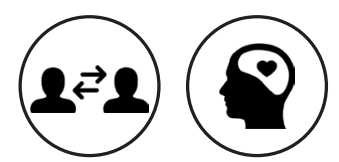

For their design for the United Nations in 2013, 3XN focussed on interaction as a key design driver. Their approach resulted in the creation of a large atrium, with a flowing, sculptural stair at its centre. The cutting of the atrium provides visual connectivity, allowing workers to see into more of the building. The stair provides physical connectivity, encouraging workers to move through the space. These visual and physical connections facilitate interaction through opening up the building, allowing people to see and meet one another much more organically. The stair itself is interesting in the fact that it connects the opposing sides of the atrium by walkways, with the stairs being attached to the side of these. This provides a place for people to meet and interact that isn't in the middle of a stair. It also allows more of the atrium to be accessible, utilising the most out of this usually empty area. This design approach rethinks the role a central stair has in the design of a space, and plays with the arrangement of the stairs components to great effect. The abundance of natural light and warm materials also aid in wellbeing.

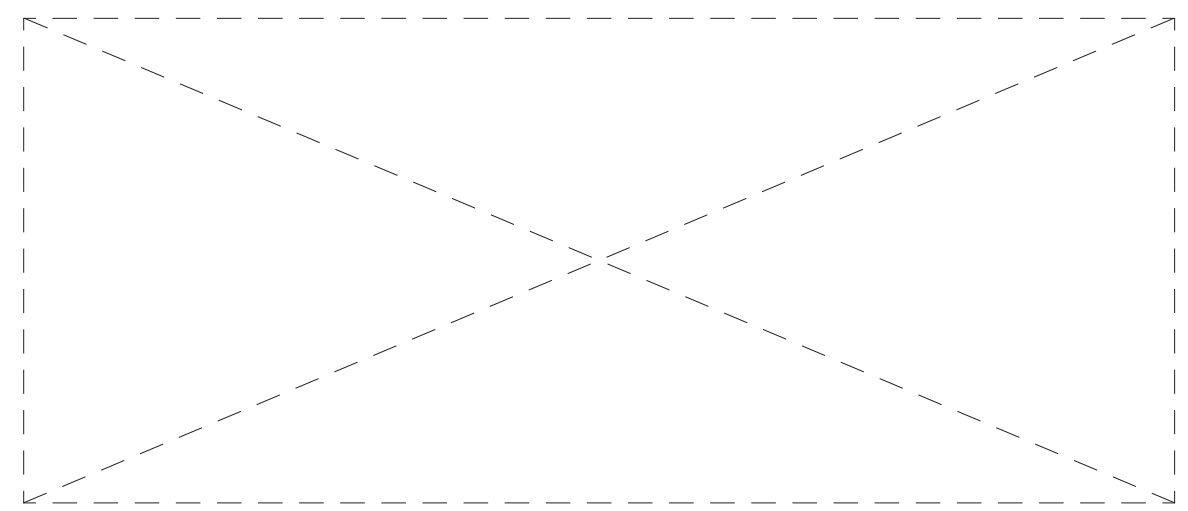

Figure 23: Exterior of UN City. (3XN, 2019) 


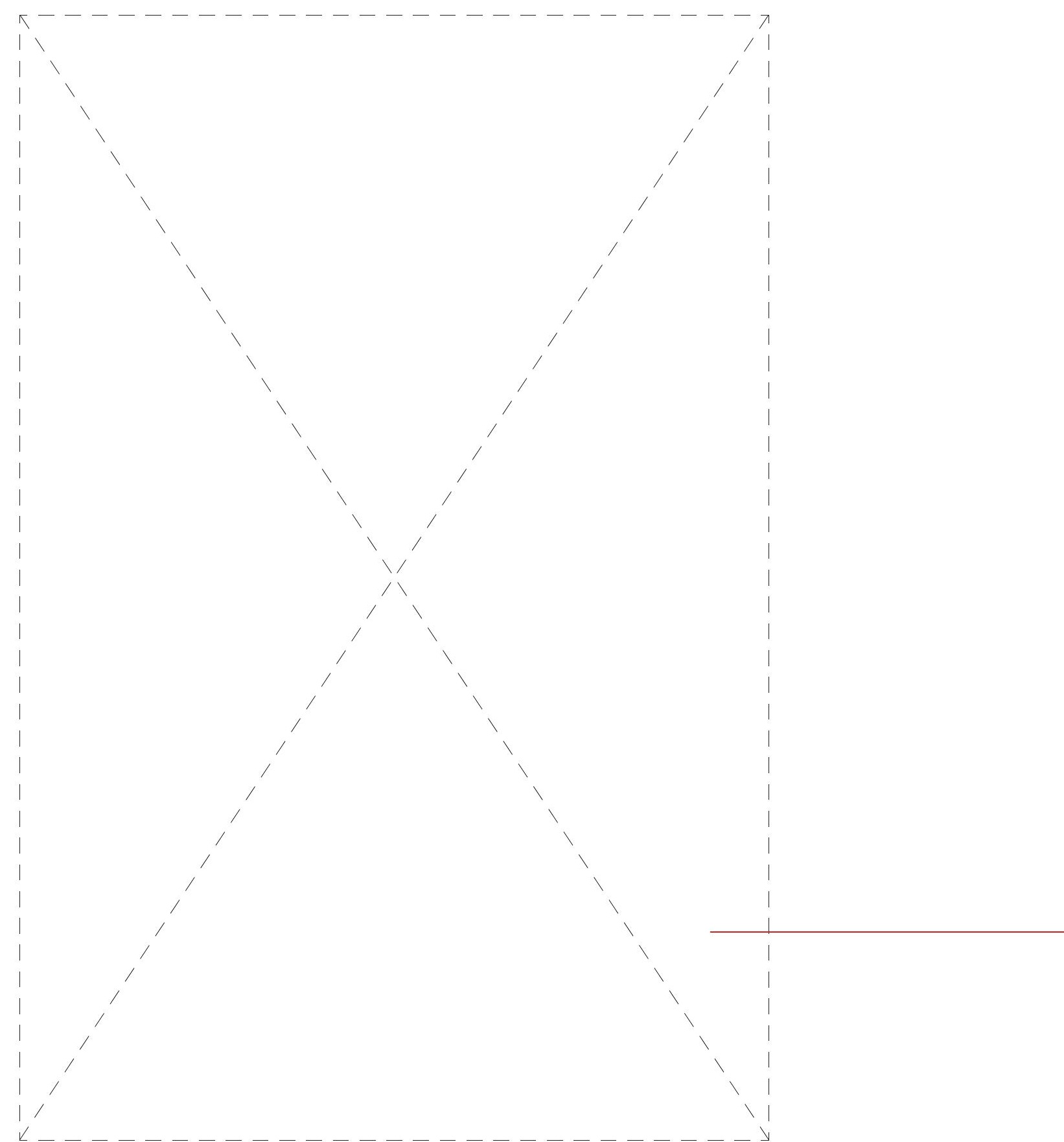

Figure 24: Central stair in atrium. (AHMM, 2016) 
6 Pancras Square, London- AHMM

2016

Client: Google

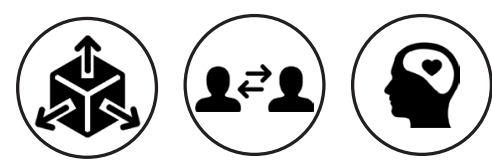

Designed for Google, 6 Pancras Square tackles many issues affecting contemporary and future workplace design. Just as with 3XN's UN City, AHMM have cut a large atrium and included a central sculptural stair. This visually and physically connects the building together, encouraging interaction between co-workers and allowing more of the atrium to be accessible. Another focus for AHMM was flexibility, which resulted in Project Jack, a modular meeting room or workspace that can be fully taken down and reassembled at will (Figure 25). A response to Google's constantly changing business processes and team structures, this approach shows how typically static spaces, such as meeting rooms, can be rethought to produce something innovative. Wellbeing is also considered in their design, with facilities such as gyms, cafes and generous break areas being incorporated throughout.

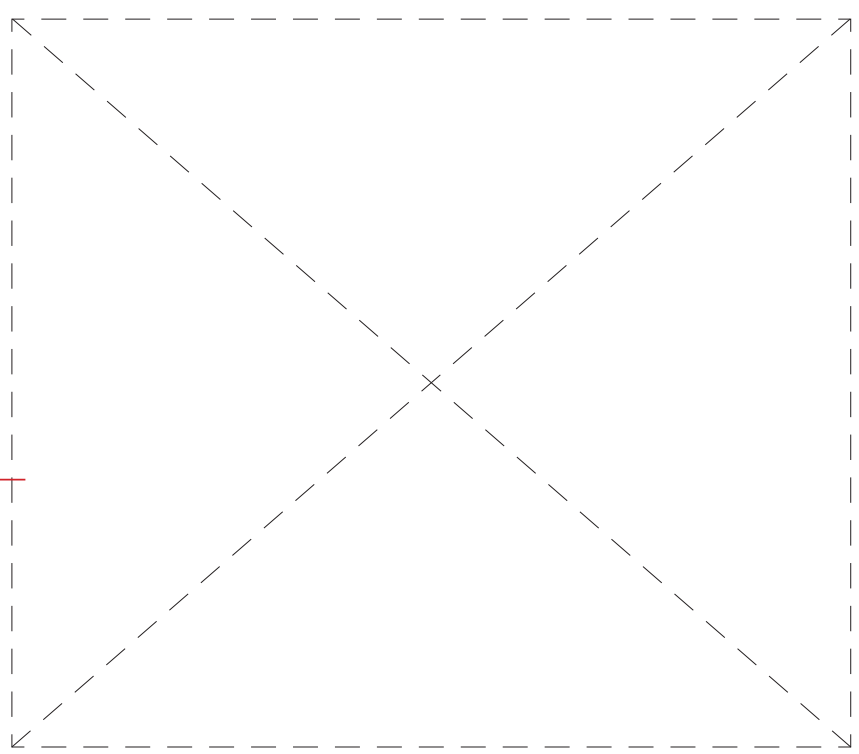

Figure 25: Project Jack (AHMM, 2016) 


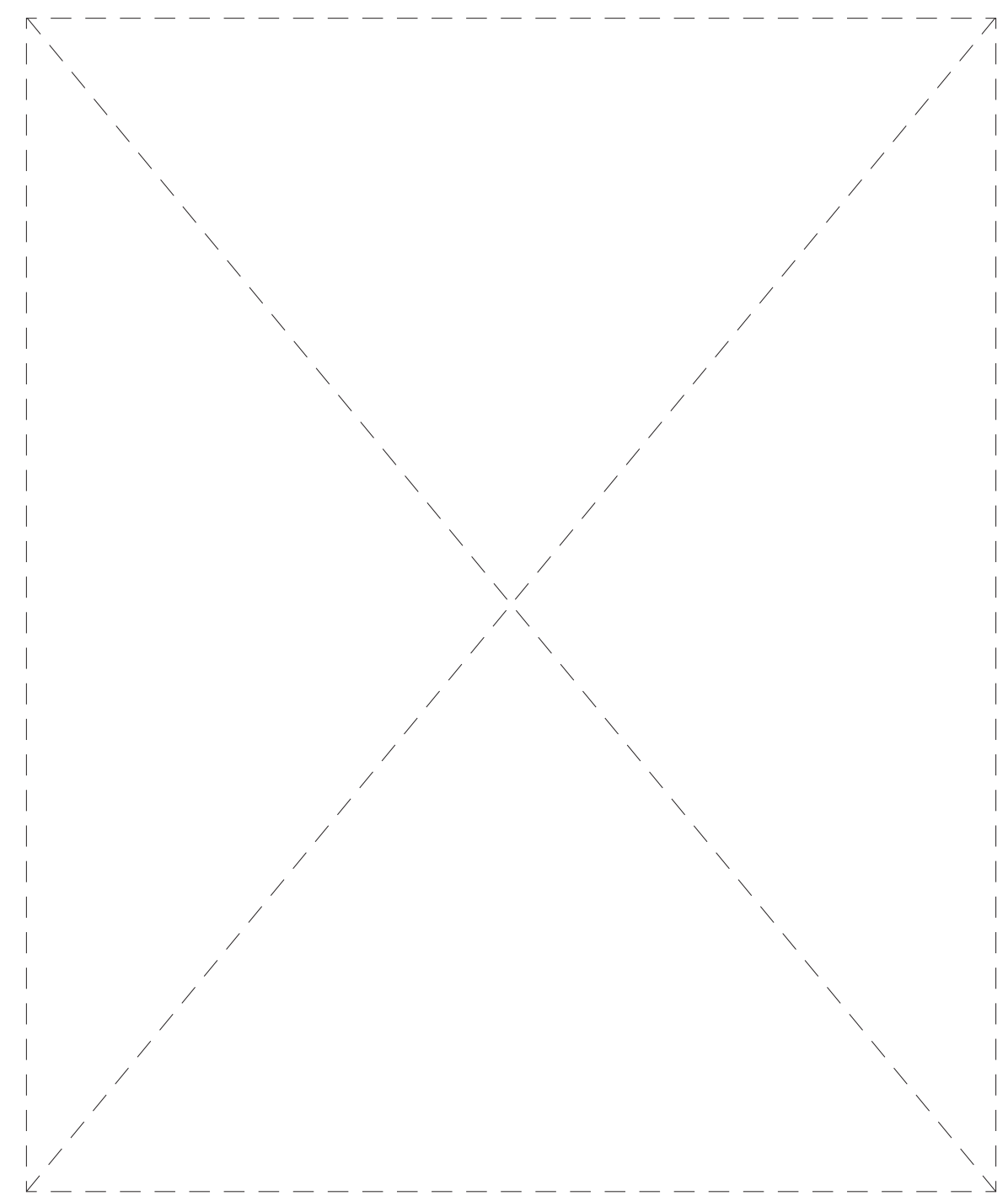

Figure 26: Central Atrium (PLP Architecture, 2016) 
The Edge, Amsterdam- PLP Architecture 2015

Client: Deloitte

As mentioned in previous chapters, PLP Architecture focussed greatly on the integration of current technologies in their design of The Edge. Designed for Deloitte, this building features an application that manages its spaces and user preferences, as well as roving robotic security guards. Being called "the smartest building in the world" by Bloomberg, The Edge has sensors embedded throughout its roof panels, turning the whole building into a sort of internet of things; being entirely connected (Randall, 2015). As a result, spaces are monitored and adjusted as needed. This approach to incorporating as much up-to-date technology as possible in the building has garnered unique results, bringing new ideas to the design of workspaces. The design also features a large, open atrium, used to encourage interaction as well as providing an informal workspace for workers. The variety of workspaces in The Edge is also of note, as there are numerous types of different work stations that the user can choose from.

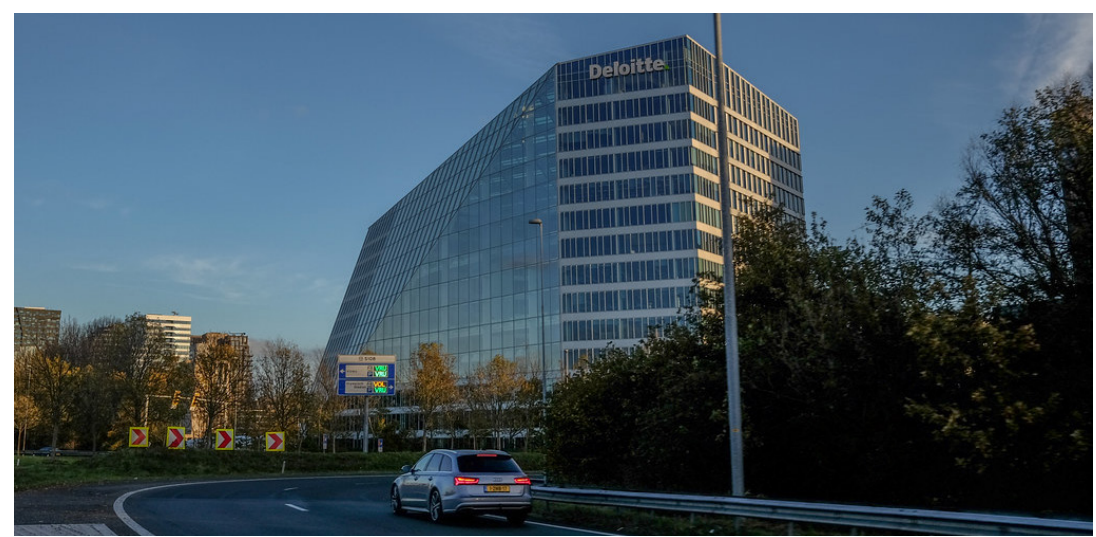

Figure 27: Exterior view (CCSearch, 2019a) 


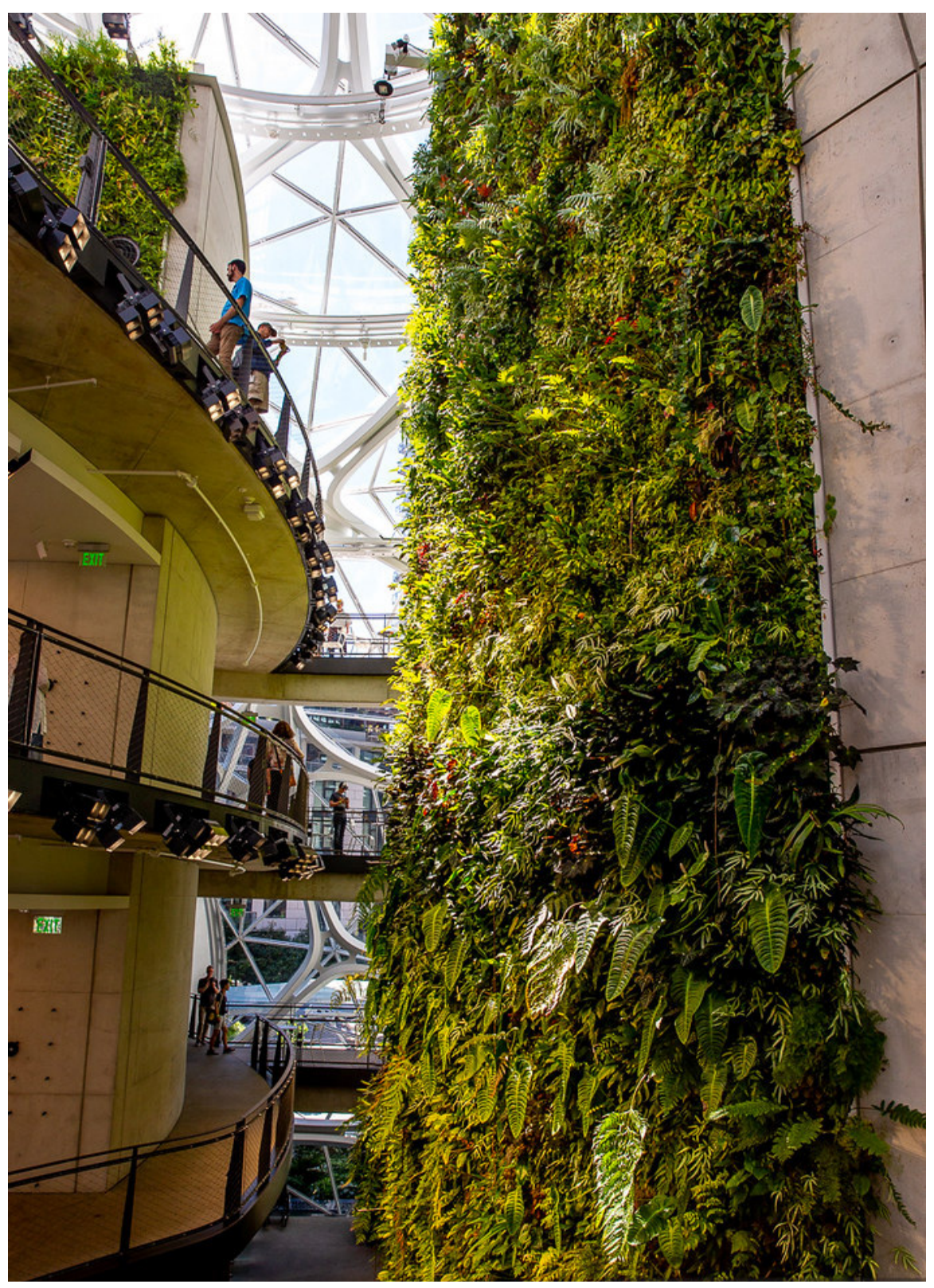

Figure 28: Interior green spaces in The Spheres (CCSearch, 2019b) 
The Spheres, Seattle - NBBJ

2018

Client: Amazon

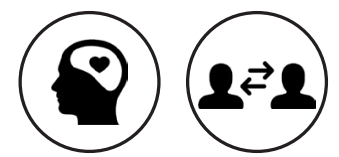

NBBJ's design for The Spheres is one that fully embraces wellbeing as its main design driver. Being part of Amazon's Seattle Campus, this glass covered workplace houses workspaces, public amenities and most notably an abundance of nature from around the world. The Spheres are designed around the fact that the presence of visible nature has been proven to have significant psychological benefits (Kaplan, 1993). As a result, workers are enveloped in lush greenery, with the aim of making the employees "feel and work their best" (NBBJ, 2019). This bold approach to cater for wellbeing is very successful, being not only a refreshing place to work but a local landmark, standing out from its context. The permeability of the building is also noteworthy, as it encourages interaction between workers and members of the public.

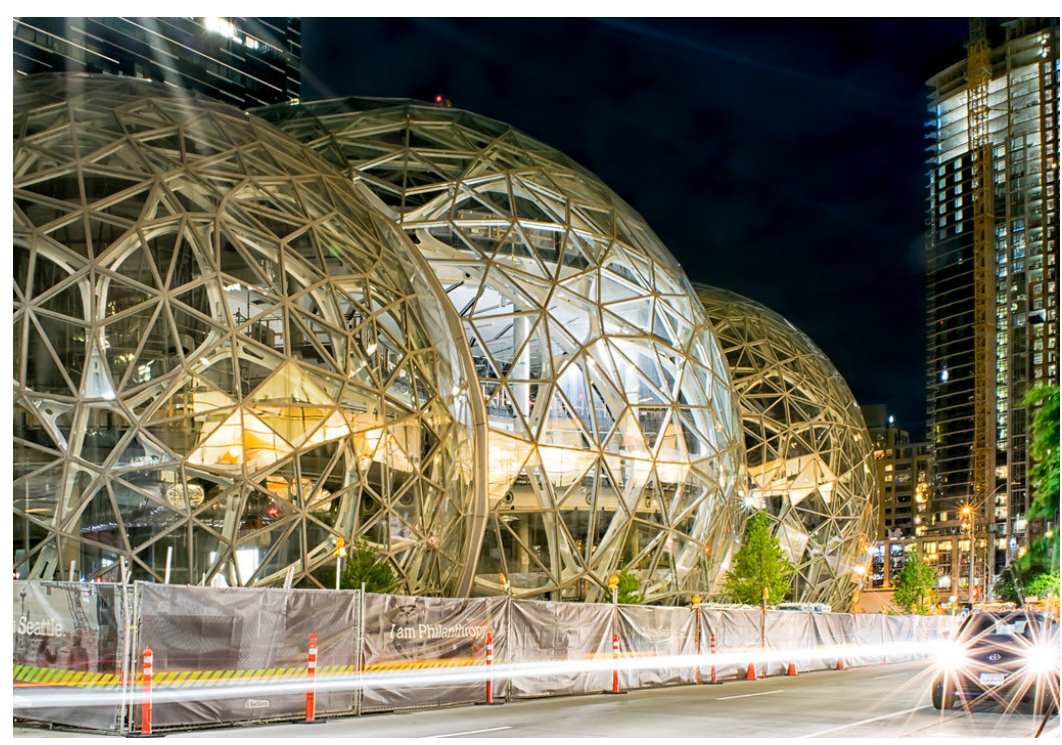

Figure 29: Exterior view (CCSearch, 2019c) 


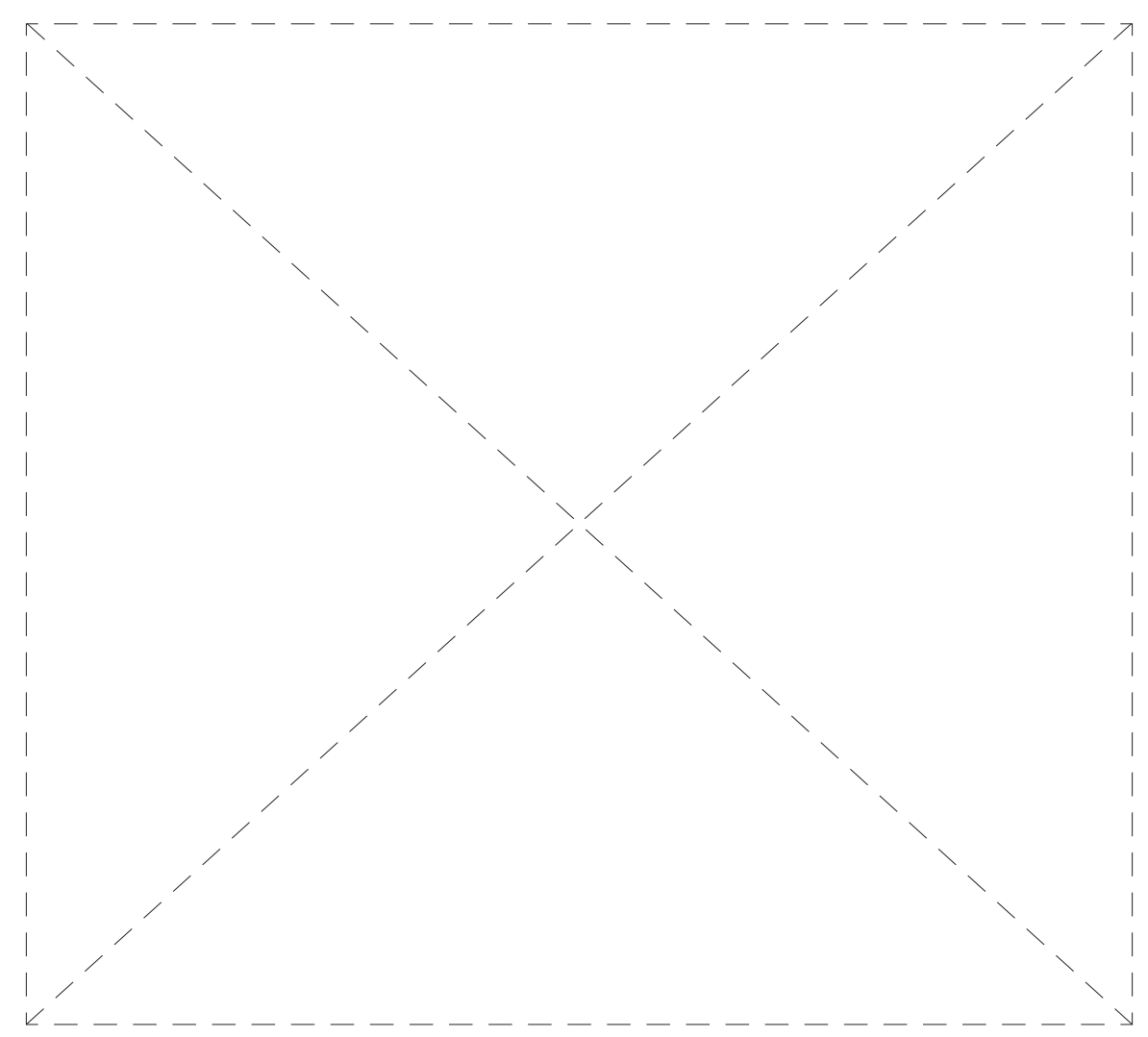

Figure 30: Exterior view showing the connecting laneways (Precinct, 2019) 


\section{2}

\section{LOCAL CASE STUDIES}

40 \& 44 Bowen Street, Wellington- Tennant Brown Architects Late 2021

Client: Pending

A local example of a workplace responding to the key drivers of the future is 40 and 44 Bowen Street by Tennant Brown Architects. Expected to complete in late 2021, this building is designed for use by corporate and government agencies, meaning that it is an example of what the near future of work will look like in Wellington (Precinct Properties, 2019). Consisting of two buildings, the complex features a network of connecting laneways that offer retail, café and other amenities; allowing for interaction between workers. This design gives a good insight into how local architects are addressing the issues of designing for the future.

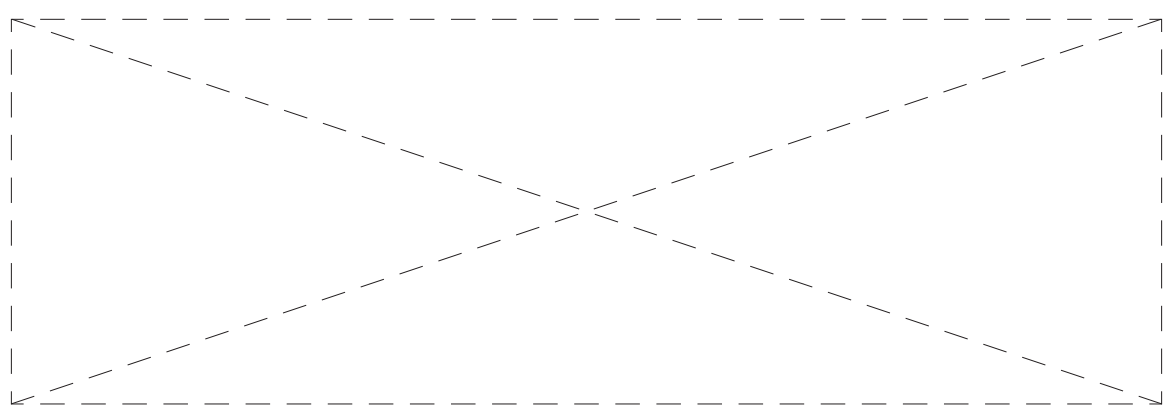

Figure 31: Exterior view from highway. (Precinct, 2019) 


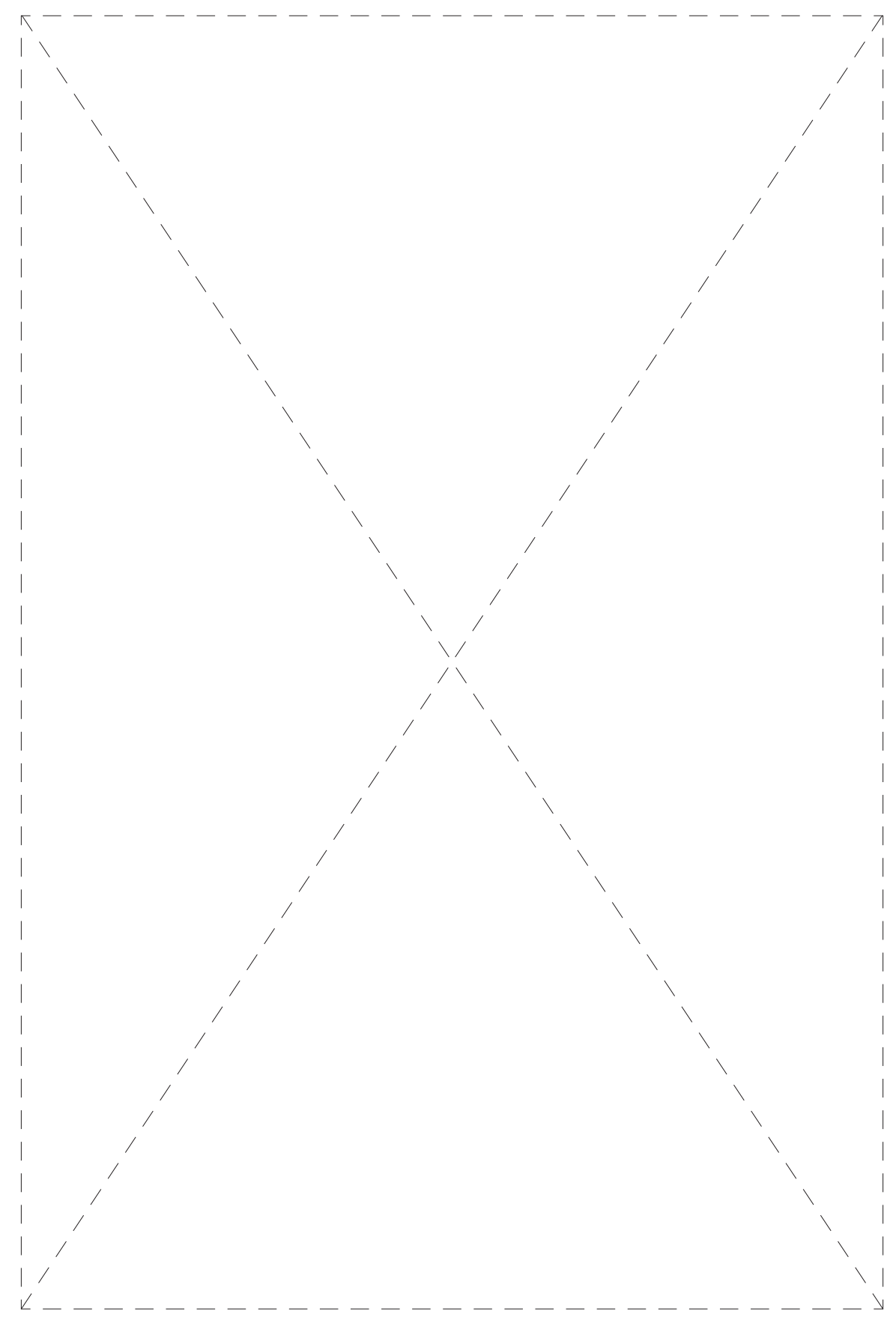

Figure 32: Sculptural stair in the centre of the B:Hive. (Jasmax, 2019) 
B:Hive, Auckland- BVN \& Jasmax

2018

Client: Multiple Tenancies

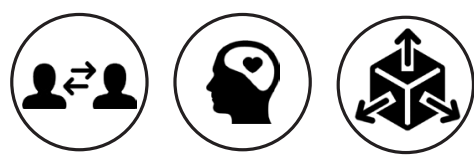

One of the most up-to-date workplaces in New Zealand is the B:Hive in Smales Farm, Auckland. Typically co-working spaces are fit-outs of existing buildings, but this is purpose built with co-working in mind. Winning the NZIA interior award in late 2019, and taking home the title of 'best office in the world' at the 2019 World Architecture Festival, the B:Hive is described as "a state-of-the-art workplace; it signals what the future of work might look like" (North, 2019). The building houses freelancers and remote workers, small to medium sized businesses, and even departments of large international companies such as ASB, Deliotte and ANZ. The design centres on the open, flowing atrium that houses a vibrantly orange sculptural stair. Much like with the approaches taken by 3XN and AHMM, this atrium and central stair open up the building, providing visual and physical connections, encouraging interaction between co-workers as they can see and access more of the building with ease. Jasmax and BVN also focussed on flexibility in their design. Their approach to housing differently sized businesses in one building resulted in the use of movable partition walls, making the whole outer ring of team spaces adjustable. Wellbeing was also a consideration by the architects. Prioritising "holistic wellness", the B:Hive includes lush greenery, cafes \& restaurants and generous social spaces (Jasmax, 2019). The approaches and strategies Jasmax and BVN have used to design their version of the future of work have been celebrated internationally, with their consideration of concepts such as interaction, flexibility and user wellbeing all blending together to create a very successful design. Its local context and current success make it an excellent gauge of the direction workplace design is heading both globally and in New Zealand.

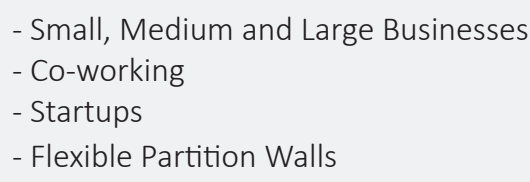

Established International Businesses at the B:Hive:

\section{ASB Bank Deloitte ANZ Bank}




\section{3}

\section{CONCLUSION}

This section highlights how different designers globally and locally are tackling the issues present in contemporary and future workplace design. Through analysing the projects in relation to the 4 key drivers identified in the previous chapter, different strategies for considering these drivers were observed. Interaction was encouraged through the use of open atria, flowing, sculptural stairs and the inclusion of generous social spaces. Flexibility was achieved through the use of modular systems and movable partitions. User wellbeing was considered through the inclusion of amenities such as gyms and cafes, as well as lush greenery. Technology was integrated much more subtly than the other drivers, being woven deeply into buildings and augmenting the management of its facilities.

The B:Hive also stands out as an internationally recognised local example of the direction workplace design is heading. The design strategies observed here will be used in the design phase of the research, relating to the third objective of exploring the potential implications of these future changes to work. The next chapter focusses on the local context of Wellington. 

CONTEXT ANALYSIS 


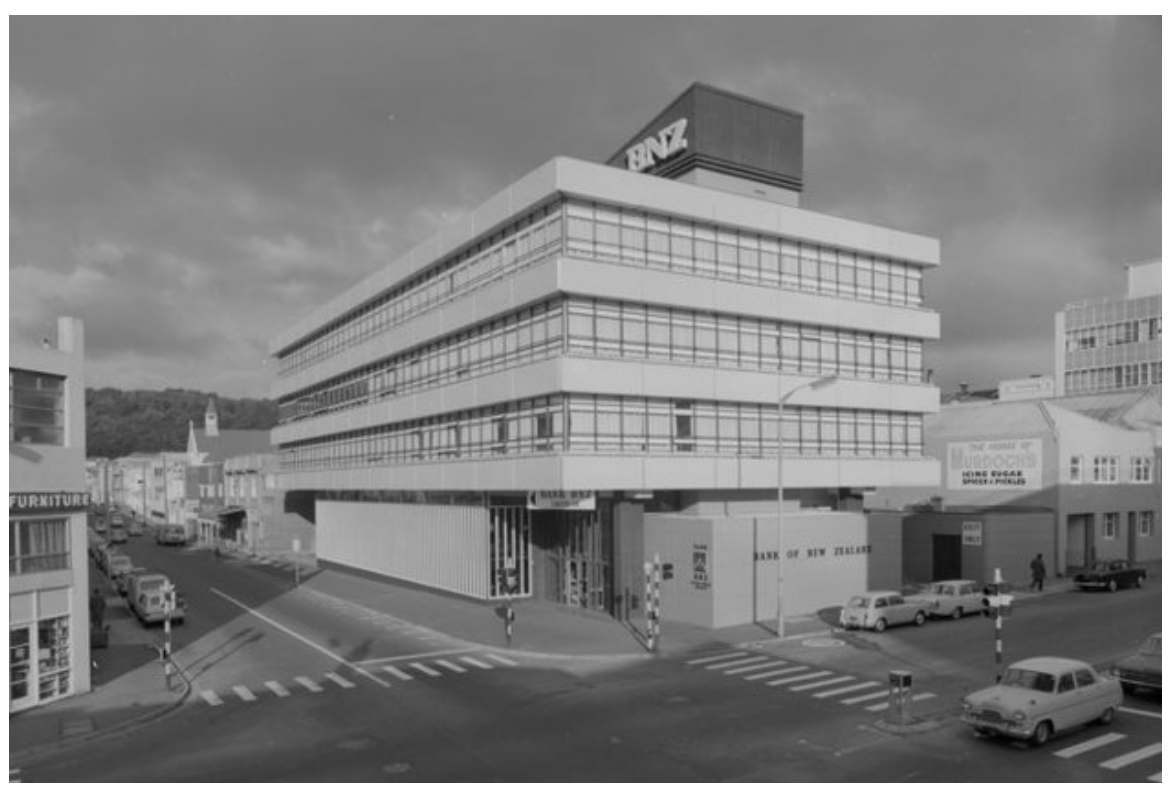

Figure 33: The BNZ Computer Centre, 1968. (Ref: DW-3249-F Alexander Turnbull Library)

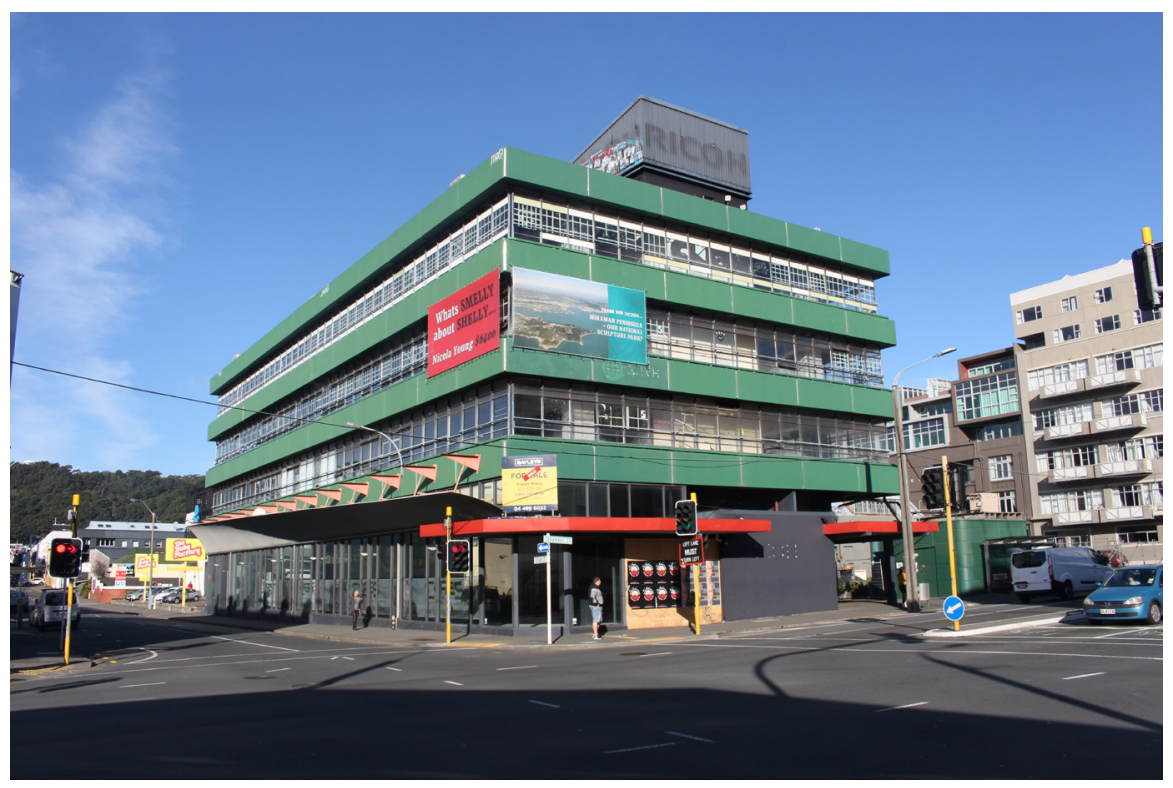

Figure 34: 123 Taranaki Street, 2019. (Author) 


\section{0}

INTRODUCTION

This chapter examines the local context of Wellington, with the goal of assessing the opportunities present for both a specific site and the wider urban fabric. Wellington as a city has unique qualities, and these could result in an office design that differs from other cities. Workplace expert Juriaan van Meel emphasises the importance of national and local context, stating that office design is not only influenced by function, but the national context in which it takes place; with this being "crucial for a general understanding of office design" (2000, p.14). To answer the research question, the context of Wellington must be taken into account when exploring the future of workspaces, as these buildings would not exist in isolation. This chapter relates to the third objective of this research:

3. Explore these potential implications in a specific context, resulting in a speculative example of what the future of work spaces could be 

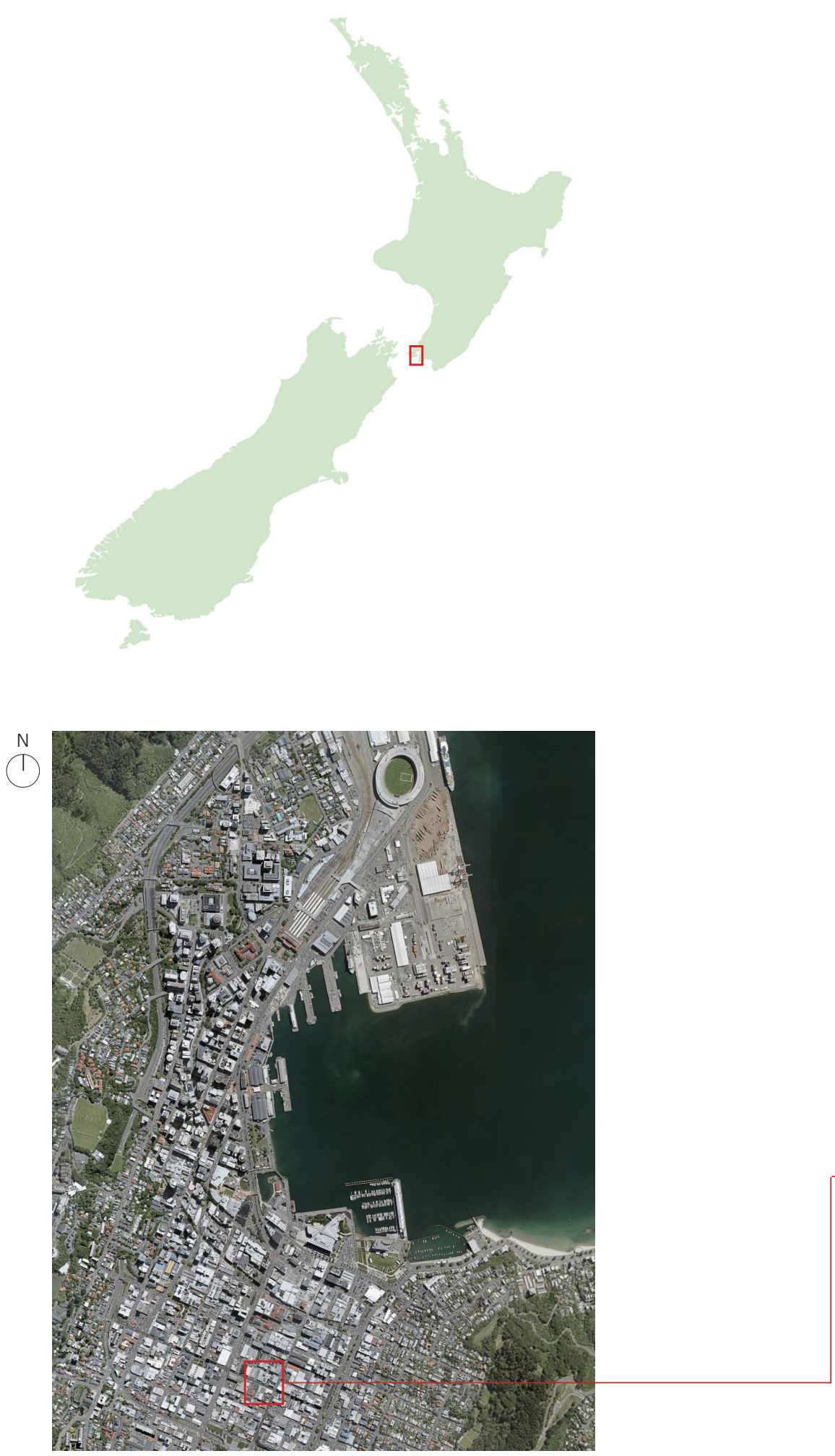

Figure 35: Loaction of 123 Taranaki in relation to the city centre. 


\subsection{1}

\section{TARANAKI STREET}

To explore the architectural implications of the future of work in Wellington, a site was chosen that had opportunities uniquely relevant to the research. Hailed as "the future of work" when it was first constructed, 123 Taranaki Street is a now abandoned office building that was completed in 1966. Originally called the BNZ Computer Centre, this building is located in central Wellington and is adjacent to an empty plot of land (Figure 36). It is situated on the corner of two busy streets, Vivian and Taranaki, as well as being around the corner from the Victoria University School of Architecture and Design. The reason that this site was chosen is that although other sites were considered, 123 Taranaki Street had a history that related directly to the topic of the future of workspaces. It gave the opportunity to reinterpret the buildings original brief, whilst providing space for something new to be added. No other site offered this level of historical and functional relevance to the topic.

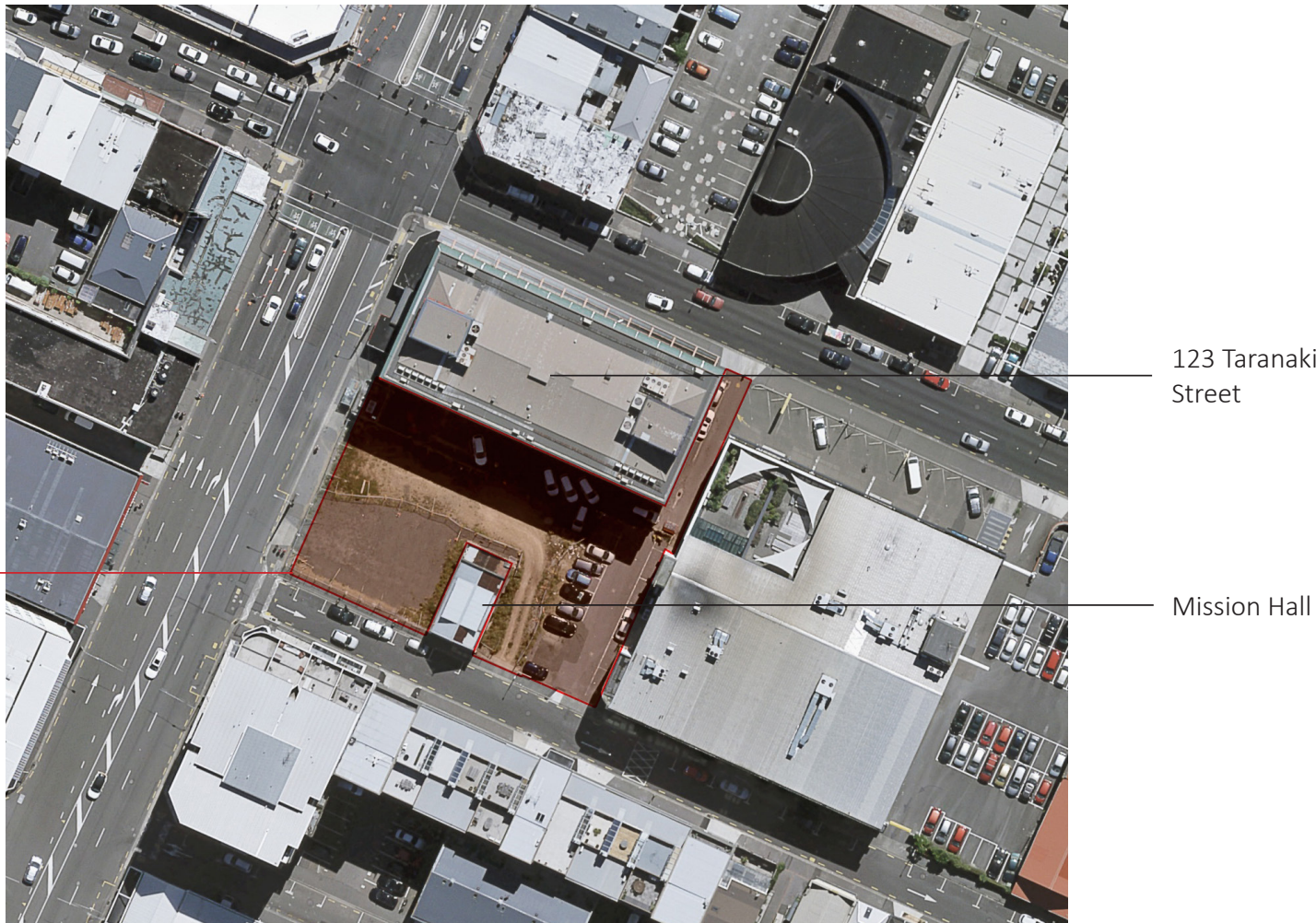

Figure 36: Map showing 123 Taranaki, the adjacent empty plot, and the Chinese Mission Hall. 


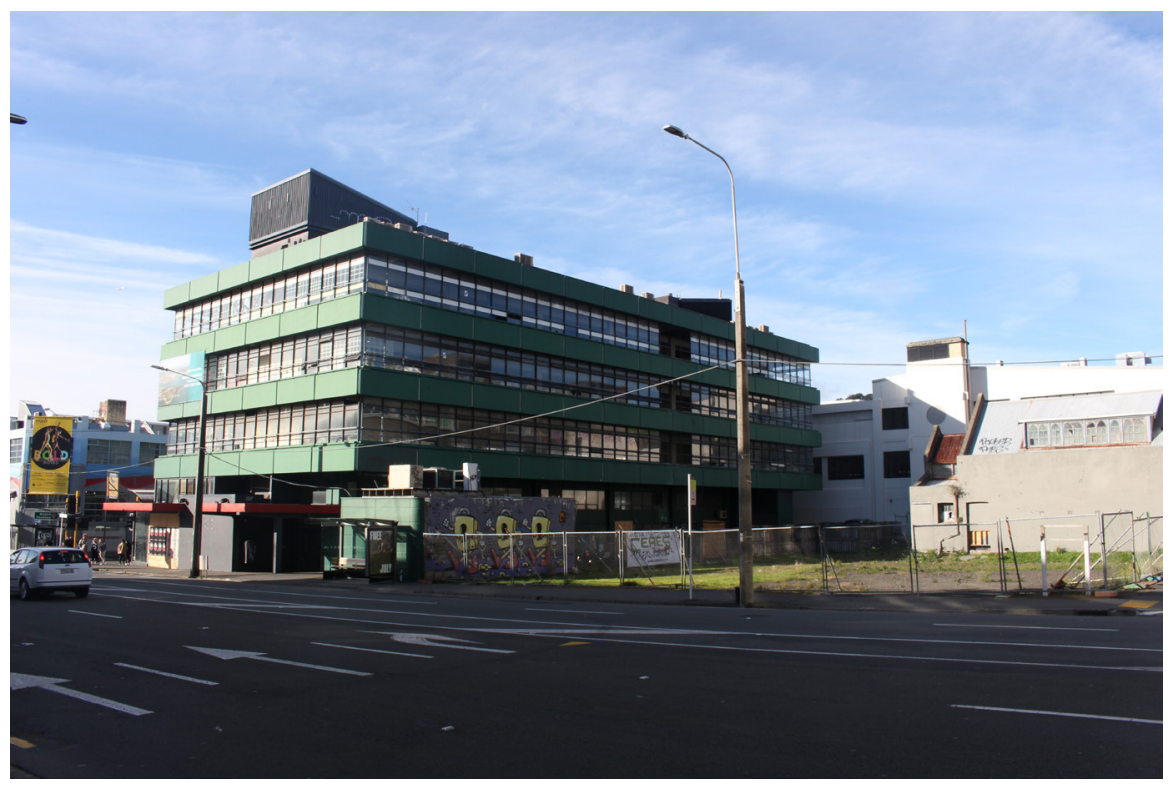

Figure 37: View looking north-east (Author)

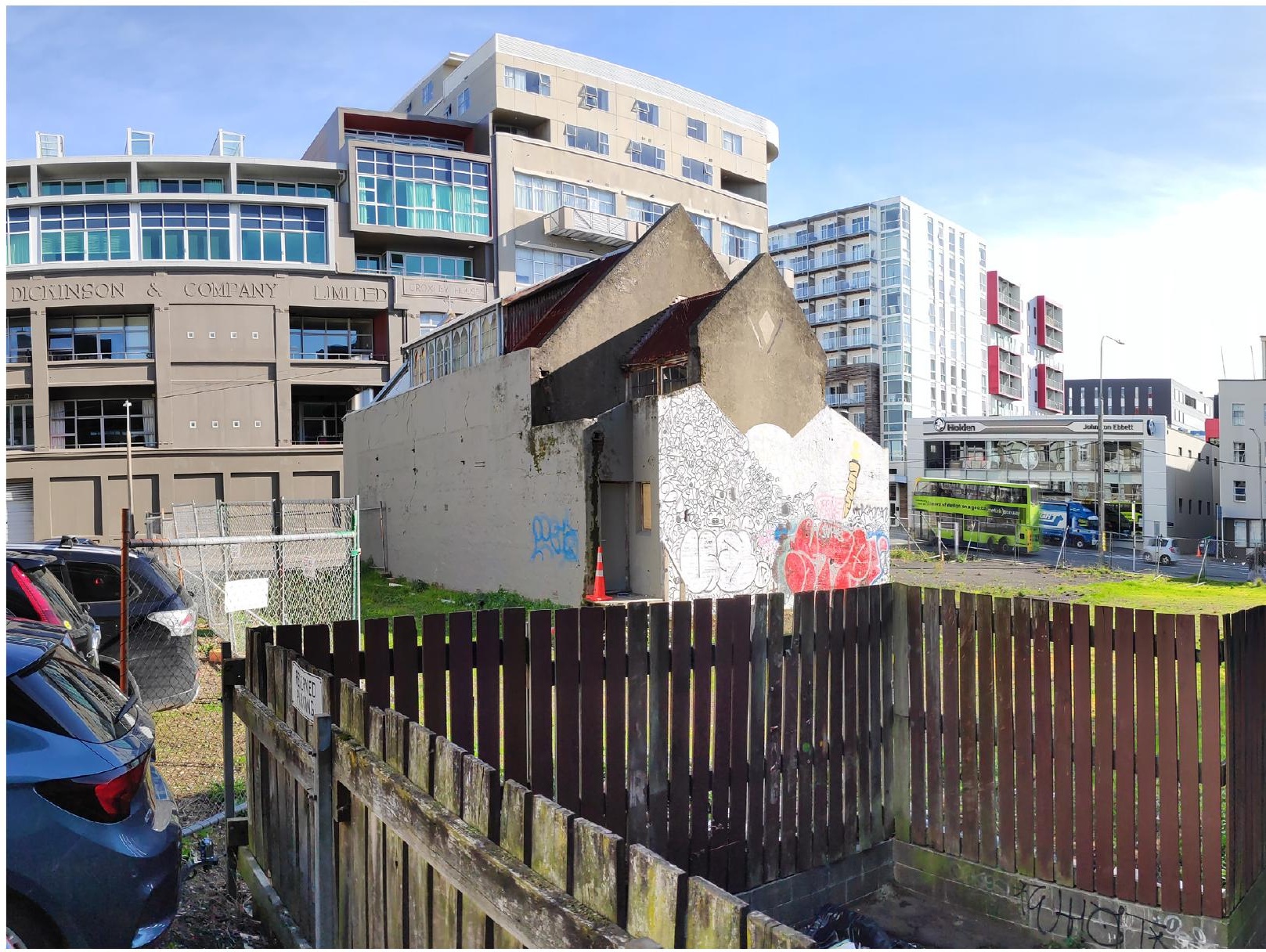

Figure 38: Panorama showing how 123 Taranaki, the empty plot of land and the Chinese Mission Hall relate to each other spatially. (Author) 


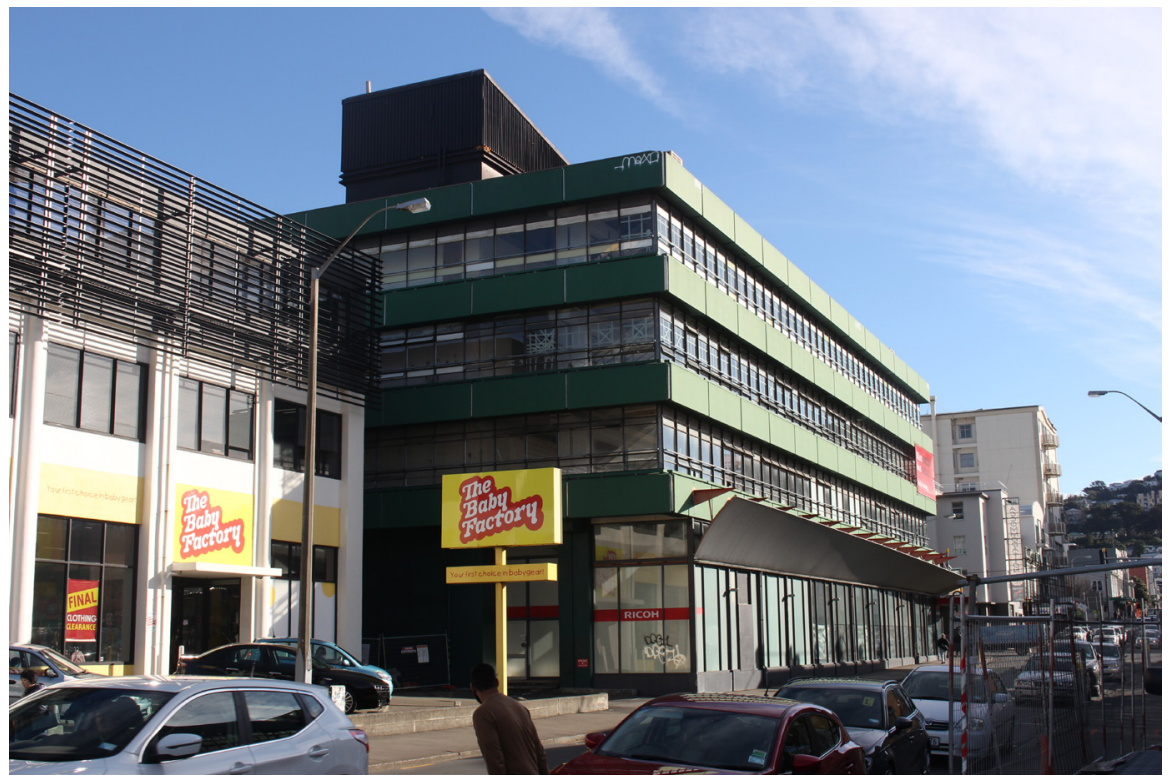

Figure 39: Photo showing the Vivian Street entrance to the former drive-through. (Author)

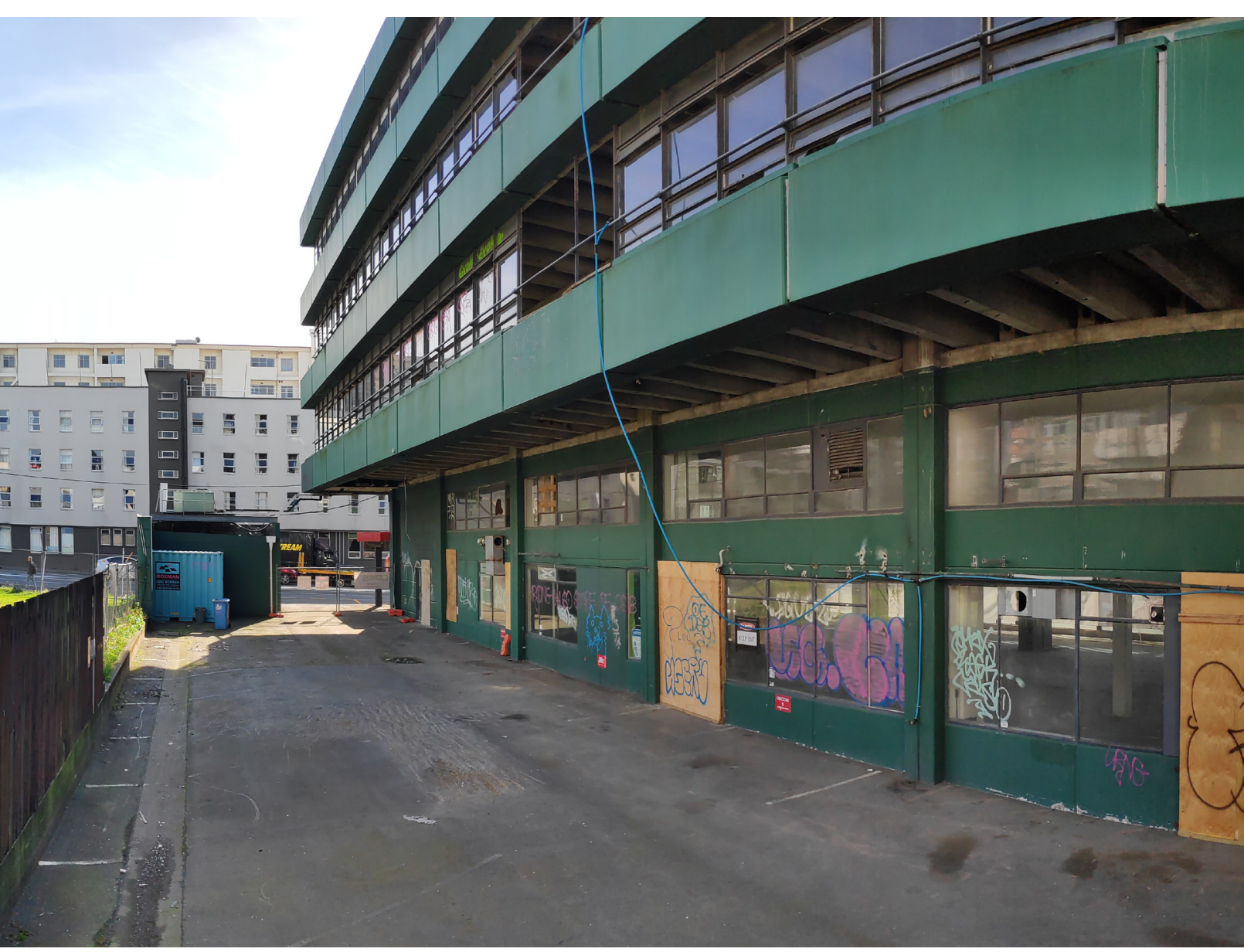




\section{$\mathbf{5 . 0 . 2}$}

\section{HISTORY OF THE SITE}

Opening in 1966, the BNZ Computer Centre served as the first workplace in New Zealand to introduce computers into the world of banking (BNZ, 2019). Designed by the firm Kingston, Reynolds, Thom and Allardice (KRTA), the floor plan of the building was made open and spacious to house the then new technology. Being designed around the same time as the ideas of Taylorism were starting to be questioned and egalitarian concepts such as Burolandschaft were emerging, the building focusses more on the integration of the technologies of time rather than ideas of freedom or control. Photographs taken by Duncan Winder during the construction of the building shows its unique structure (Figure 41-46). The design also included a drive through, where people could deposit their bank slips without leaving the comfort of their car (Figure 40). The BNZ Computer Centre was quite well received in its day, being awarded the NZIA Merit Award in 1970 (Haarhoff, 2016).

The building remained with BNZ until it was acquired by the international printing company, Ricoh. Renovated in 1996, then again in 2007 for the engineering firm $\mathrm{MWH}$ to move in, the building remained in use until Ricoh moved most of their operations to the much larger Ricoh House at 1 Victoria Street (Ricoh, 2019). No new tenant was found for the upper floors of 123 Taranaki Street, and when MWH vacated the ground and mezzanine floors in 2017, the building became completely abandoned. During the course of this research in late 2019, it was announced that 123 Taranaki Street would be developed by into a luxury hotel and apartment complex (Ramada, 2019). The empty adjacent site remains undeveloped.

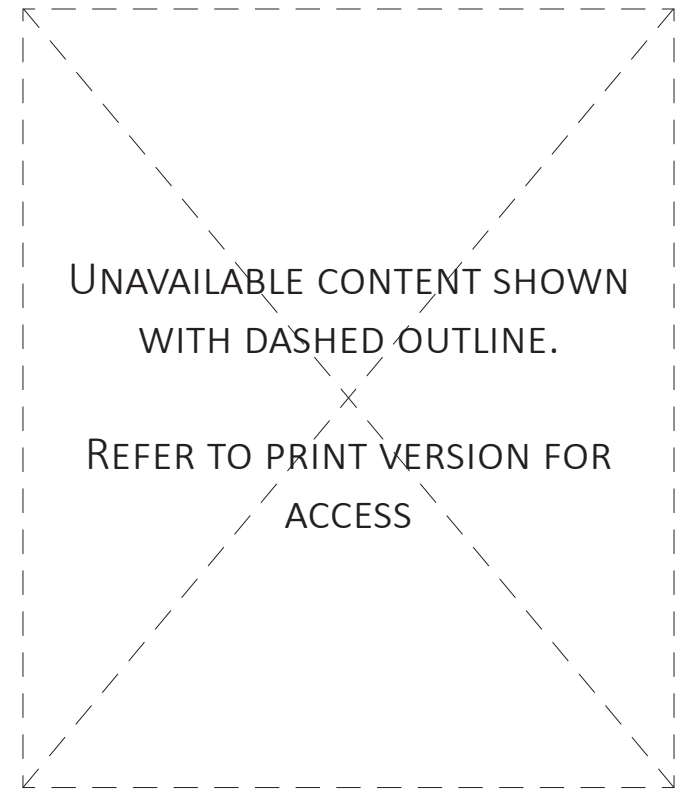

Figure 40: Photograph of the drive-through, 1968. (Pinterest, 2017) 


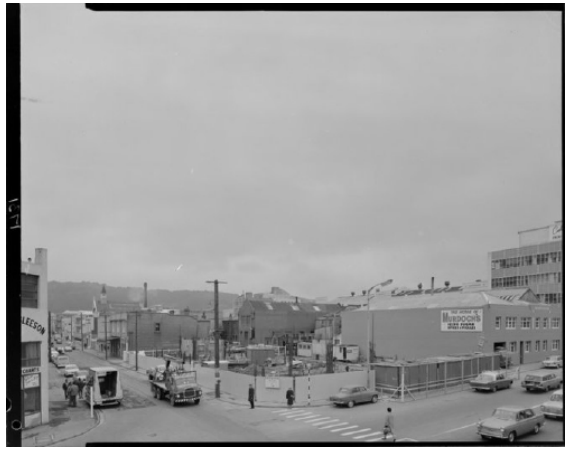

27 Oct 1965

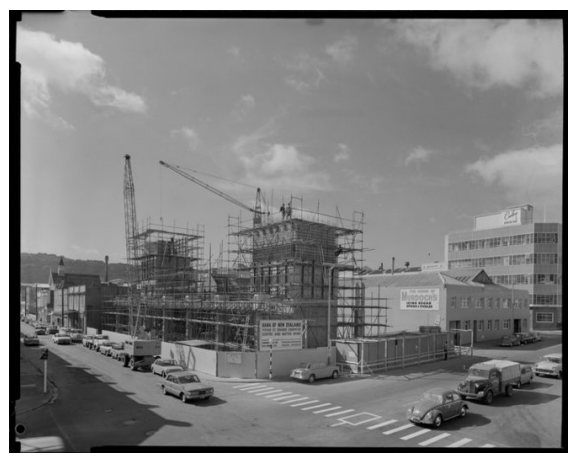

27 Jan 1966

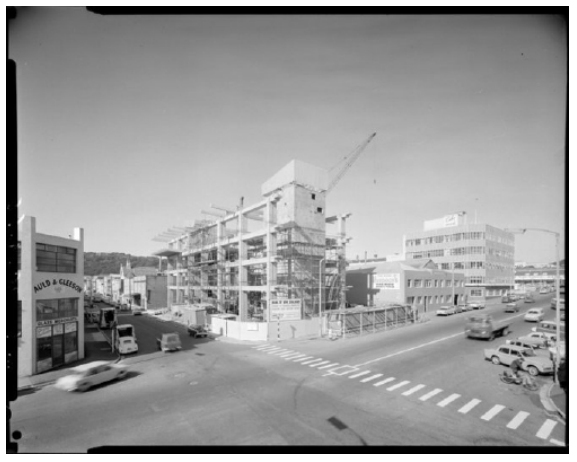

28 Apr 1966

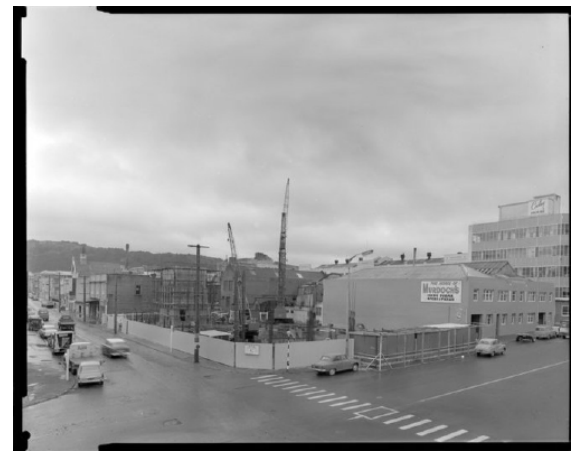

26 Nov 1965

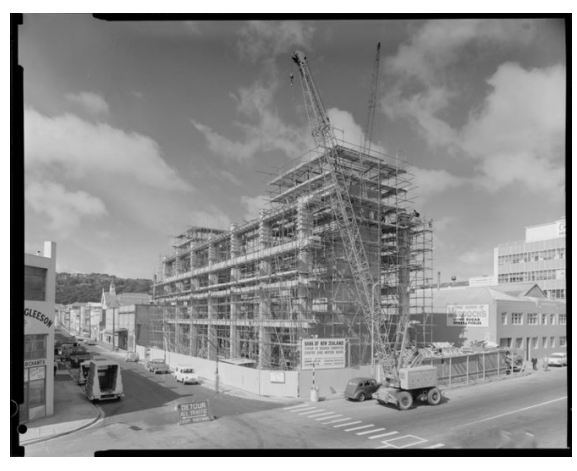

25 Mar 1966

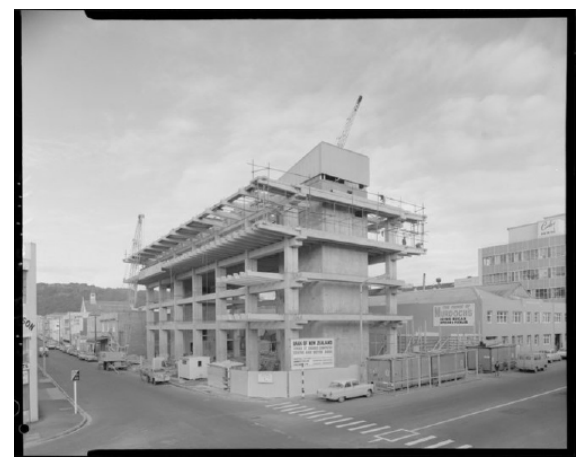

30 May 1966

Figure 41-46: Periodic photos of the construction of the BNZ Computer Centre. (Ref: DW2065-F Alexander Turnbull Library) 


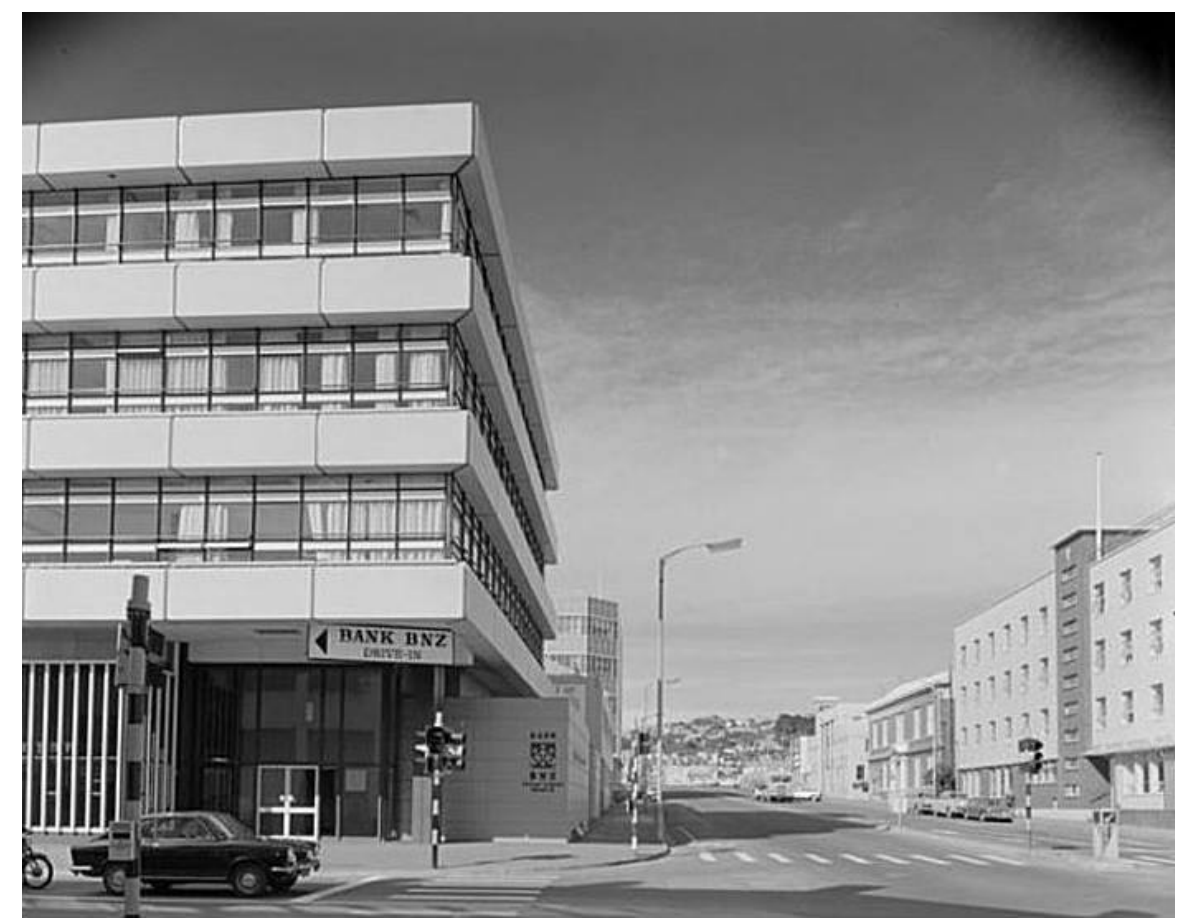

Figure 47: (Ref: DW-3985-F Alexander Turnbull Library)

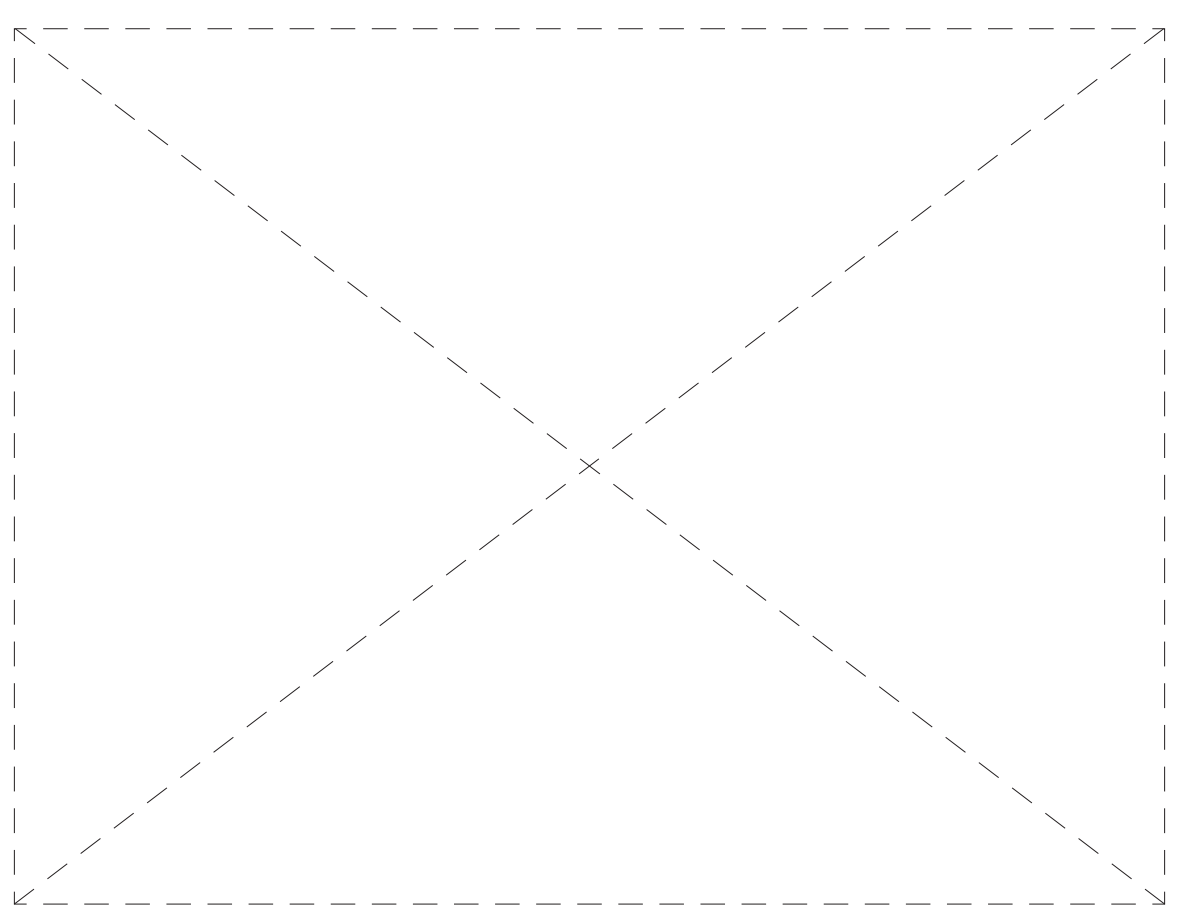

Figure 48: (BNZ, 2019) 


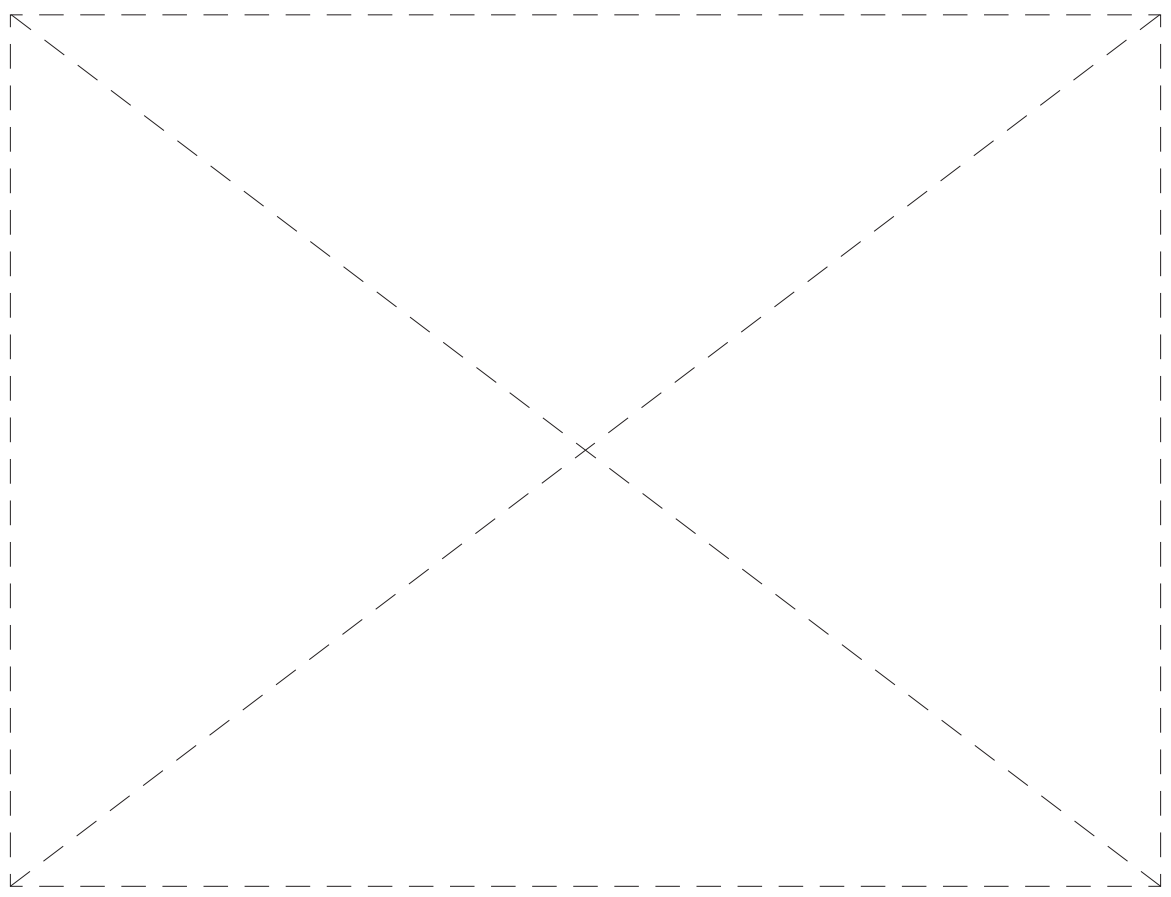

Figure 49: (BNZ, 2019)

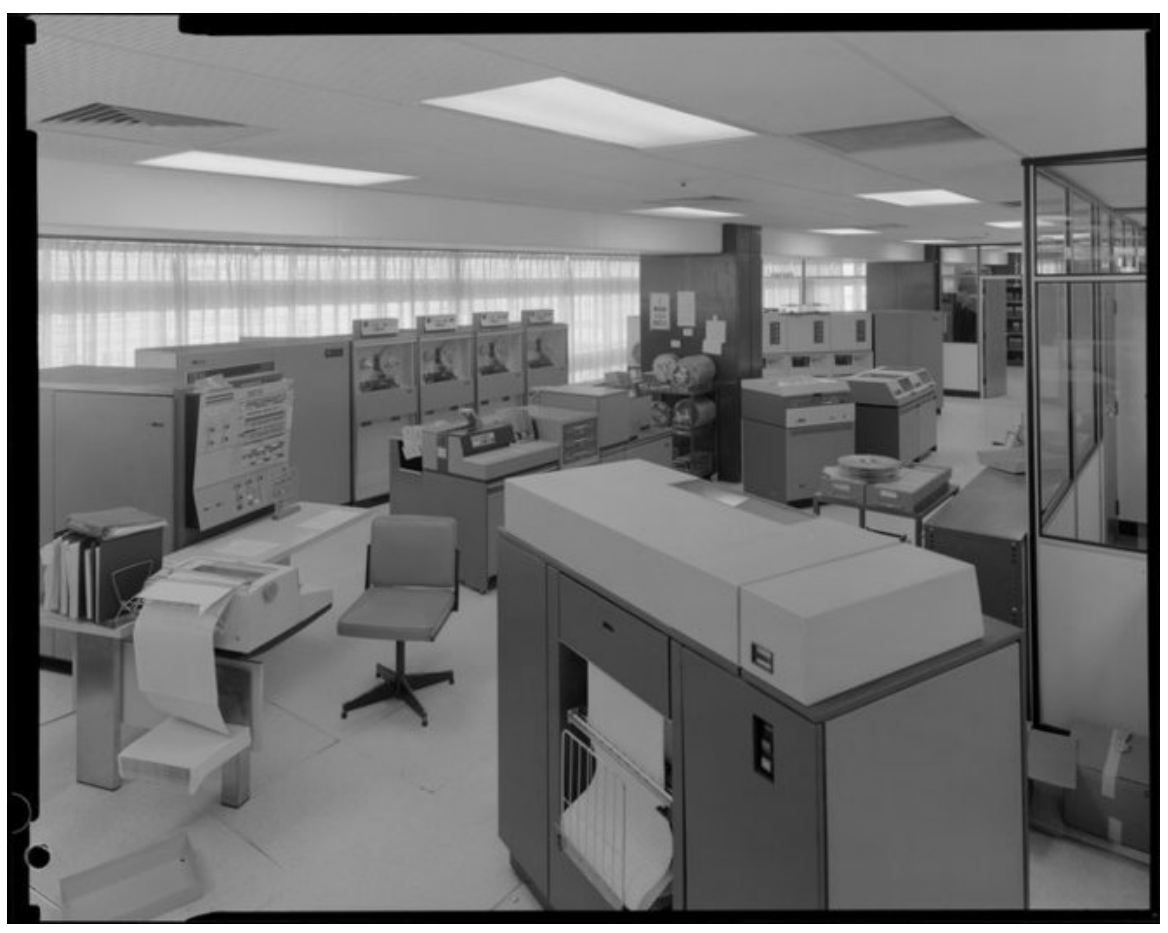

Figure 50: (Ref: DW-3987-F Alexander Turnbull Library) 


\subsection{3}

\section{EXISTING BUILDINGS ON SITE}

Occupying this undeveloped site is a small, abandoned hall, called the City Mission Hall (Figure 51). Designed by accomplished Wellington architect Frederick de Jersey Clere in 1906, this small building is a remnant of the Chinese community that used to occupy Fredrick and Haining street (Maclean, 2002). A modest variation of Gothic Revival, the hall became vacant after the church moved from Frederick Street, ending 50 years of use. Interestingly, from 2009 to 2012 it was used a music and exhibition venue, being known as 'Fred's' (WCC, 2015). It remains vacant today, with much of the roof becoming deteriorated.

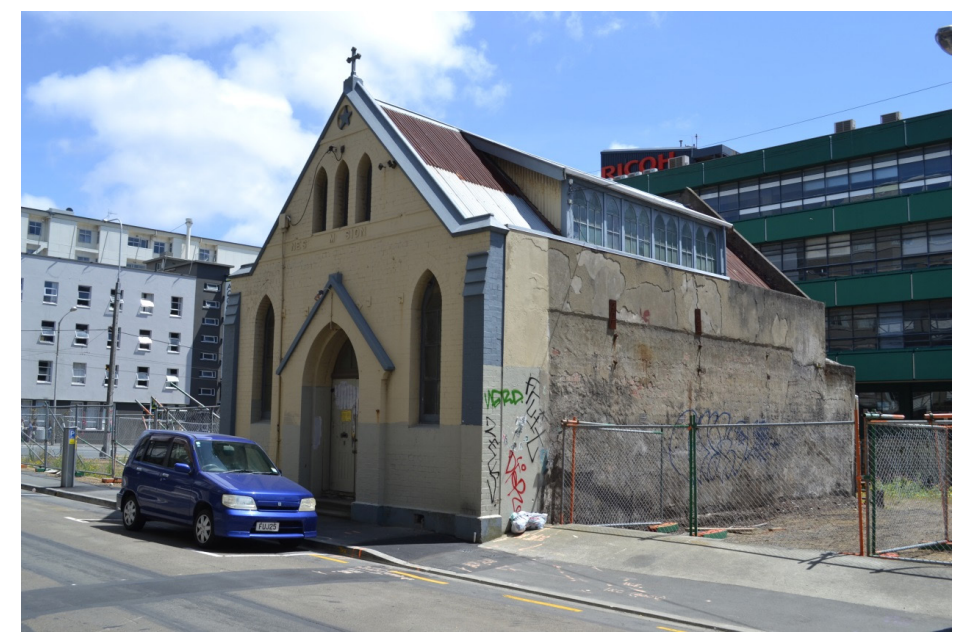

Figure 51: The front facade is the only ornate feature, the other faces of the building are blankly planned for an urban situation. (Author)

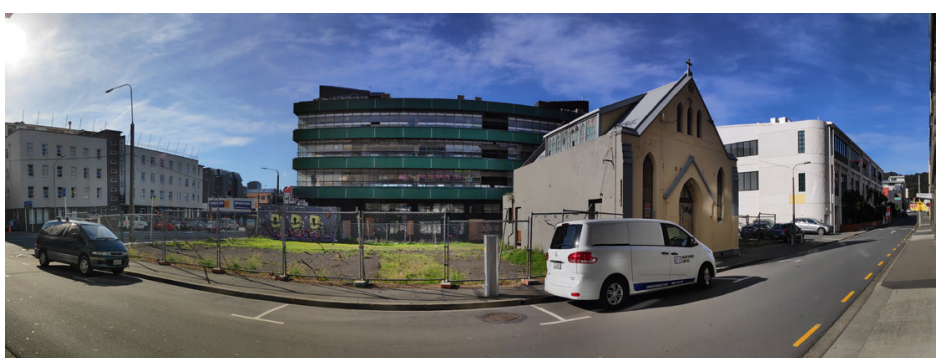

Figure 52: Panorama showing the empty space beside the mission hall (Author) 
The building that previously occupied the empty lot was a warehouse for the company Murdoch's (Figure 53). Built in 1919, it was demolished in 2011 due to being an earthquake hazard.

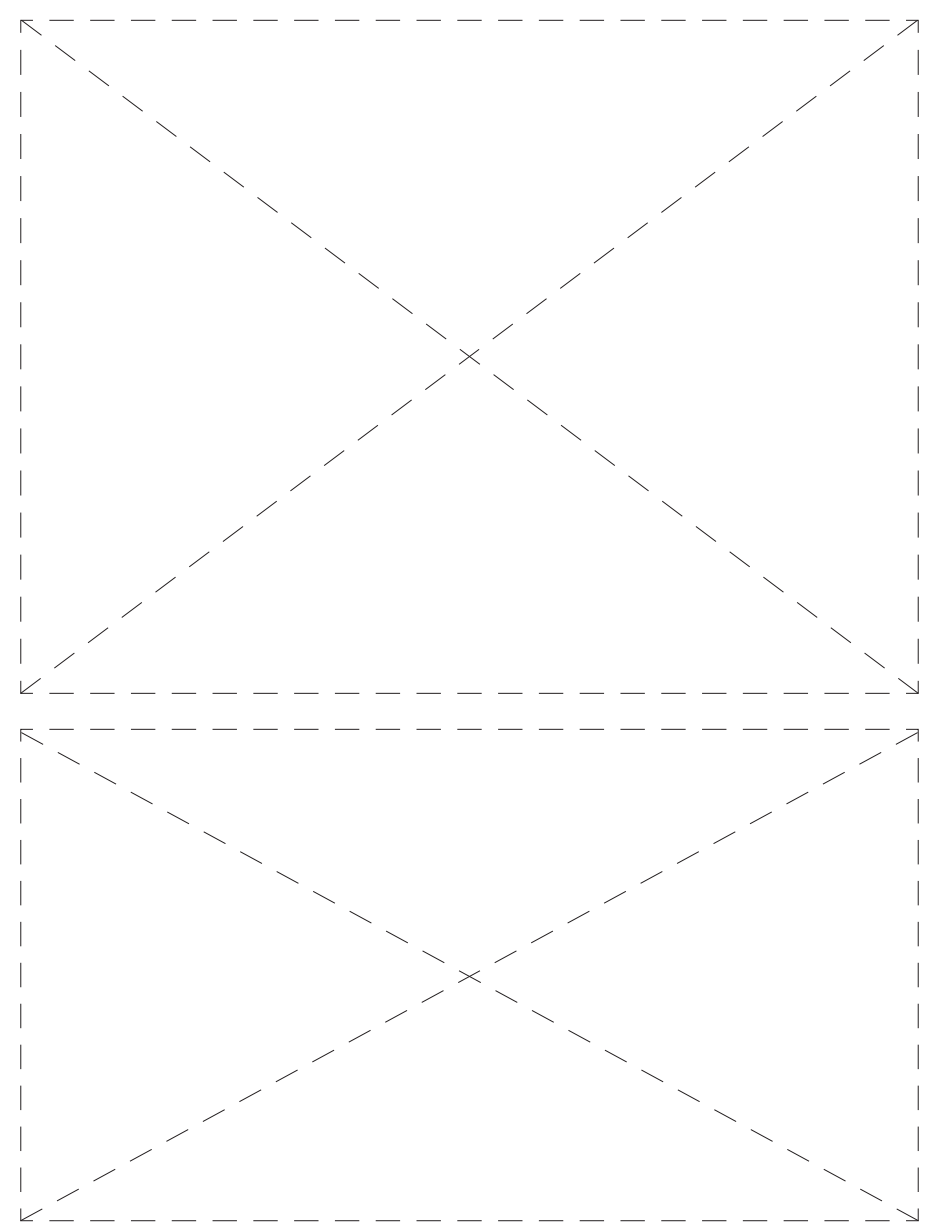

Figure 53: Murdochs warehouse that was demolished in 2011. (What's it Worth, 2019) 


\subsection{4}

\section{EXISTING STRUCTURE}

Looking more closely as the existing structure of 123 Taranaki Street, it is quite unique, consisting of two rows of thick columns and beams and two concrete cores. The central floor beams span the 13 metres from primary beam to primary beam, with the outer floor beams cantilevering on each side to support the floor. This creates a 13 metre open space in the centre of the floors. From looking at the photos from when it first opened, it seems that this space housed the computer equipment, as it is away from the window. The ceiling height is also relatively low in some areas, with the thick primary beams resulting in a height of only 2.3 metres in places. The ground floor is also noteworthy, housing a mezzanine floor and being 6.5 metres high.

Section AA 1:200 (All dimensions in $\mathrm{mm}$ )

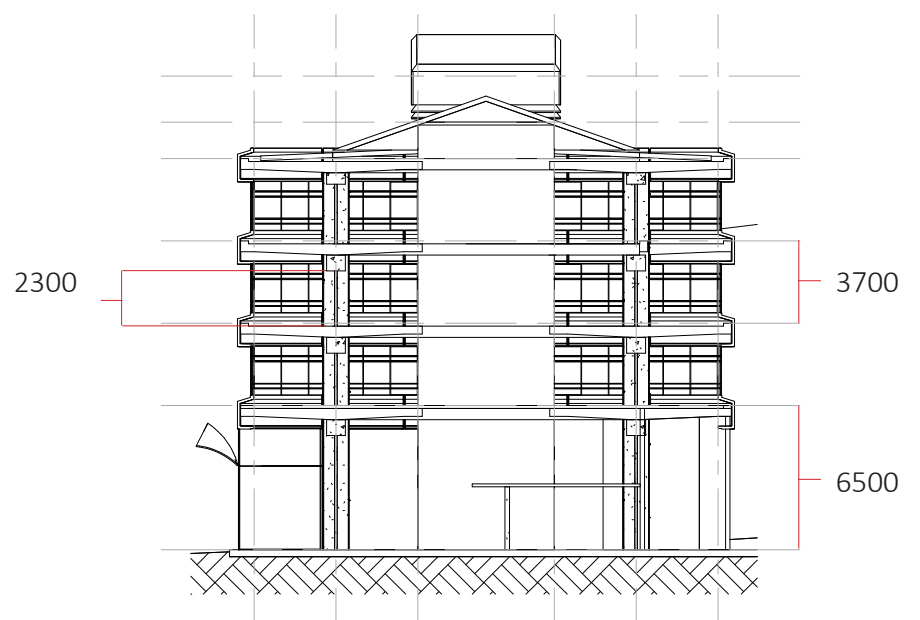

Level 1 Floor Plan 1:200

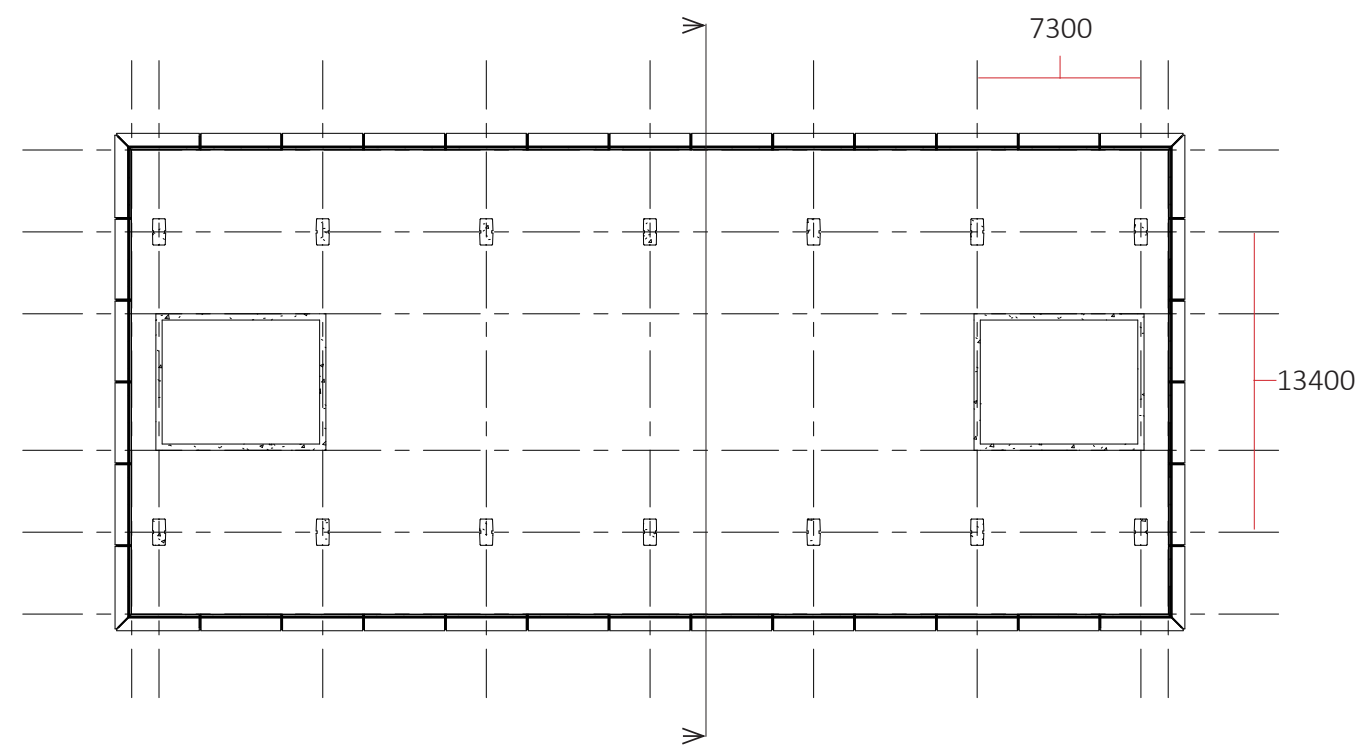




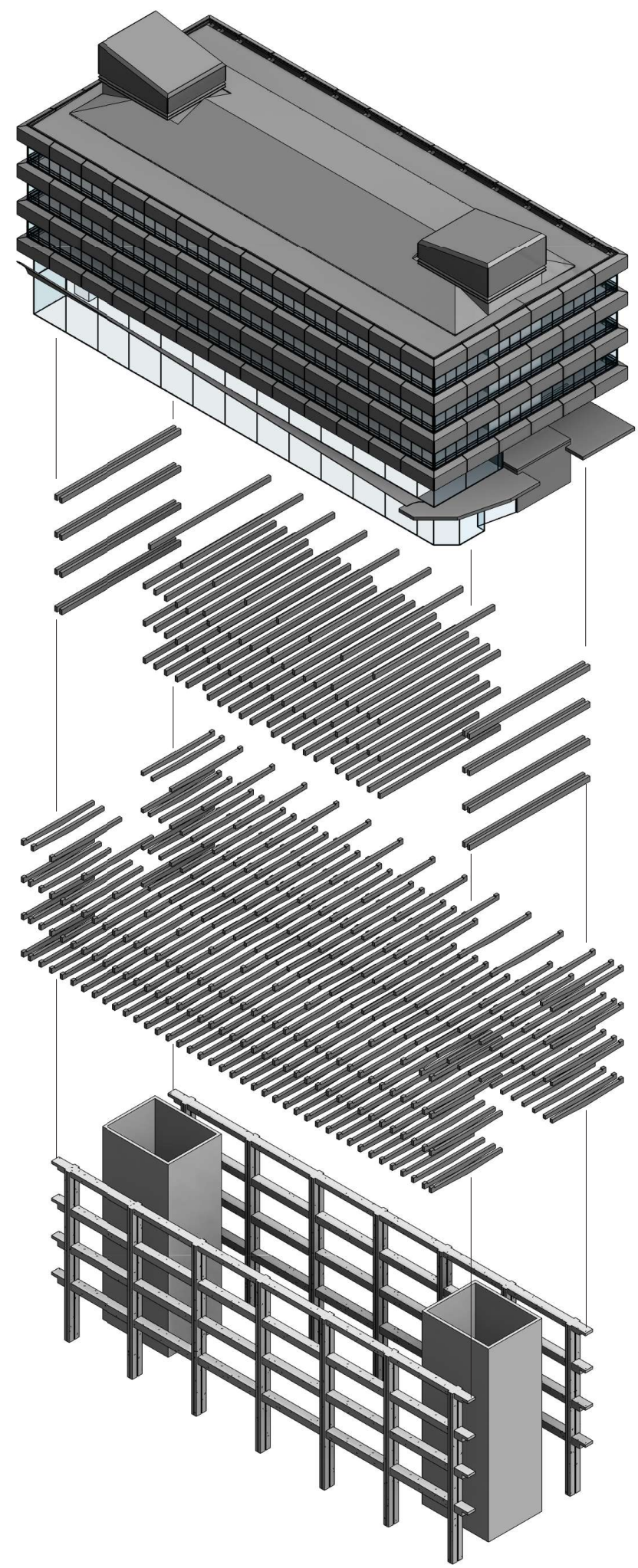

Figure 54: Exploded view of 123 Taranaki Street. 


\section{$\mathbf{5 . 0 . 5}$}

\section{SUN ANALYSIS}

From visiting the site and doing sun shading simulations (figure 56), it was recognised that when it came to sun on the site, the existing building had a large impact. In discussions with architect John Melluish, the architect who designed one of the previously proposed redevelopments of 123 Taranaki, he emphasized that the northern face of the building was very prone to overheating. With no obstructions in front of it and it facing almost directly north, this face receives direct sunlight all day. A shading system would need to be implemented to reduce the effect of this. Another consequence of this large surface facing the sun is that the rest of the site remains shaded for most of the time, especially during winter. If another building was to go behind 123 Taranaki, making the most of the sun that is not obstructed would be key in getting sunlight deep into the building.

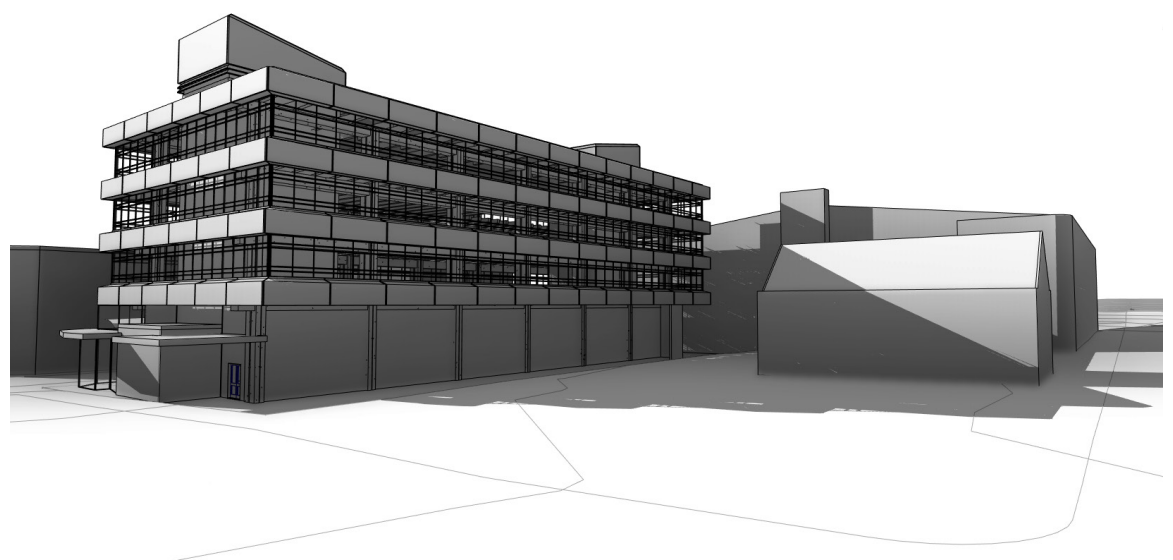

Figure 55: Sun shading for $12 \mathrm{pm}$ in winter. Even in winter, this part of this site is not blocked by 123 Taranaki Street. 
$N$
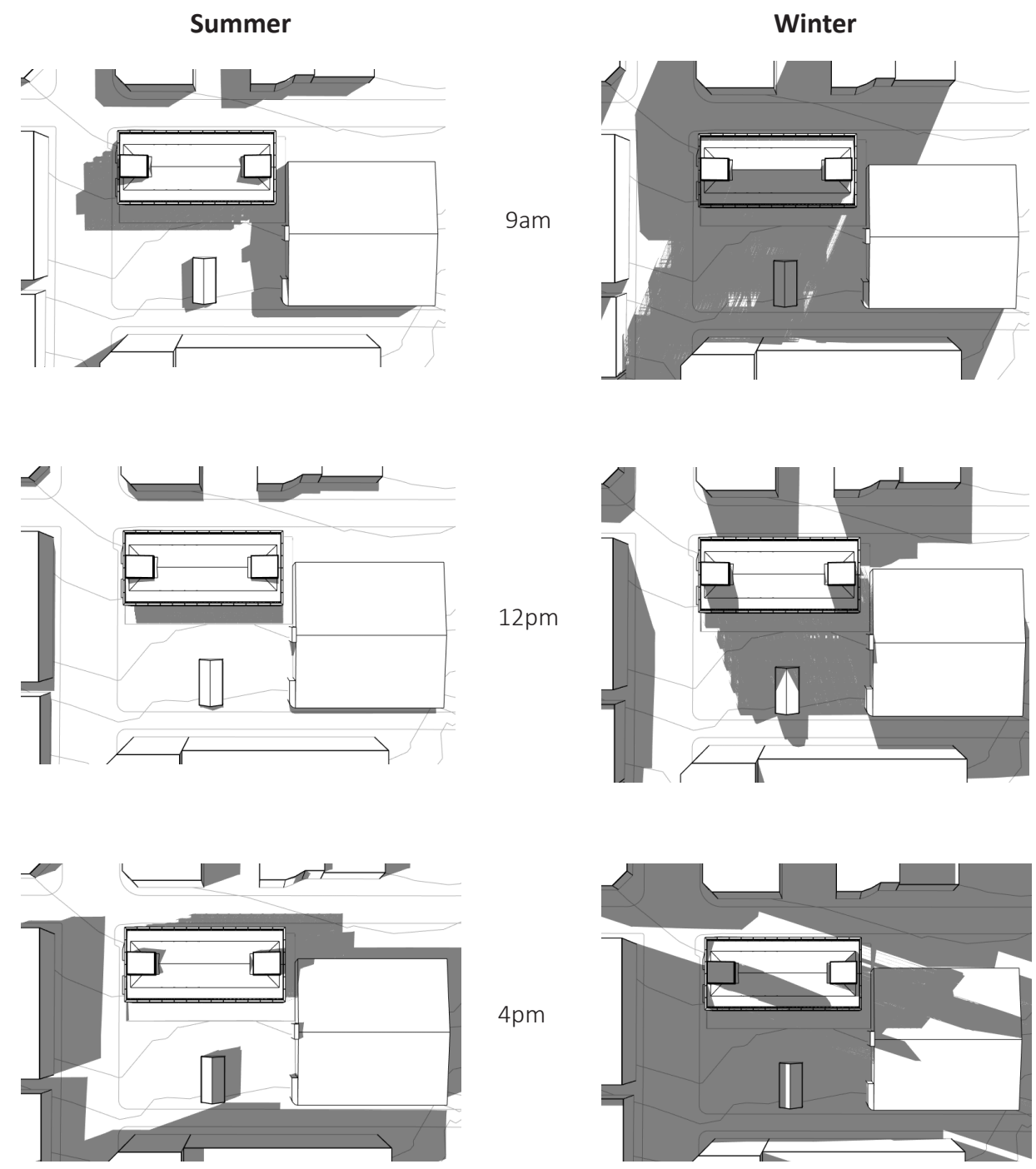

Figure 56: Sun shading diagrams at different times of day for winter and summer 


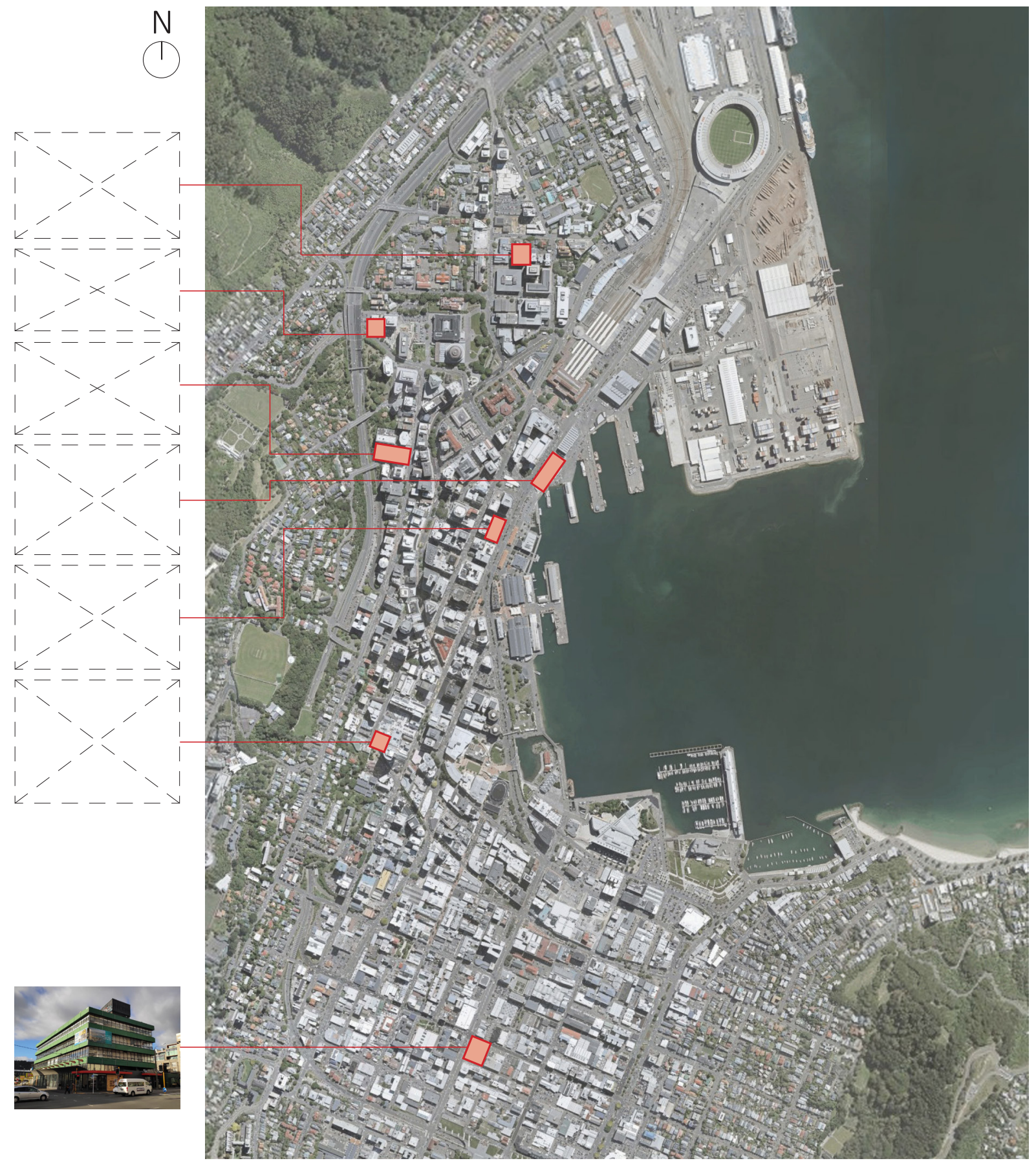

Figure 57: Map showing contemporary office developments in Wellington. Pictures relate to the table on the next page. 


\section{1}

\section{PROGRAMME ASSESSMENT}

Having analysed the site for opportunities, the rest of the chapter focusses on the wider urban context of Wellington, seeing where a potential office development would fit in in the current and future landscape of the city.

\subsection{1}

\section{ReCENT WelLington OfFice DeVELOPMENTS}

This map shows where the latest office developments are located in Wellington, and their proximity to 123 Taranaki Street (figure 57). As can be seen, many of the contemporary offices being built are located in the city centre. Being closer to government and other business headquarters, this corporate-oriented area differs greatly from the area 123 Taranaki Street resides in. 


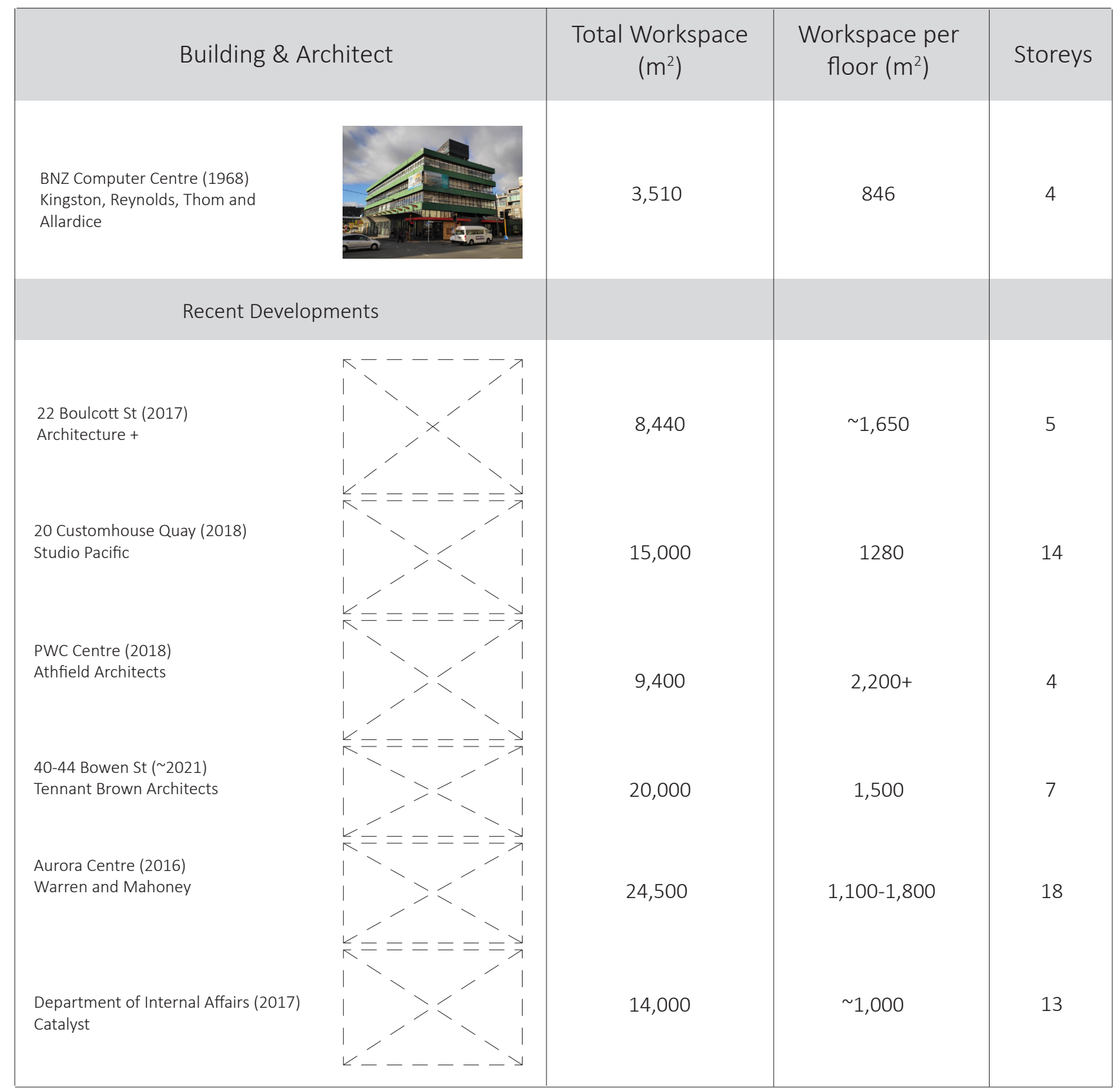

Figure 58: A breakdown of different Wellington office buildings and the amount of workspace they provide

When analysing these contemporary offices for the amount of workspace they provide, similarities started to arise (figure 58 \& 59). Newer developments tend to have floor plates of at least 1000 sqm, which is most likely due to government agencies preferring to have this size of floor plate to allow rapid workforce 


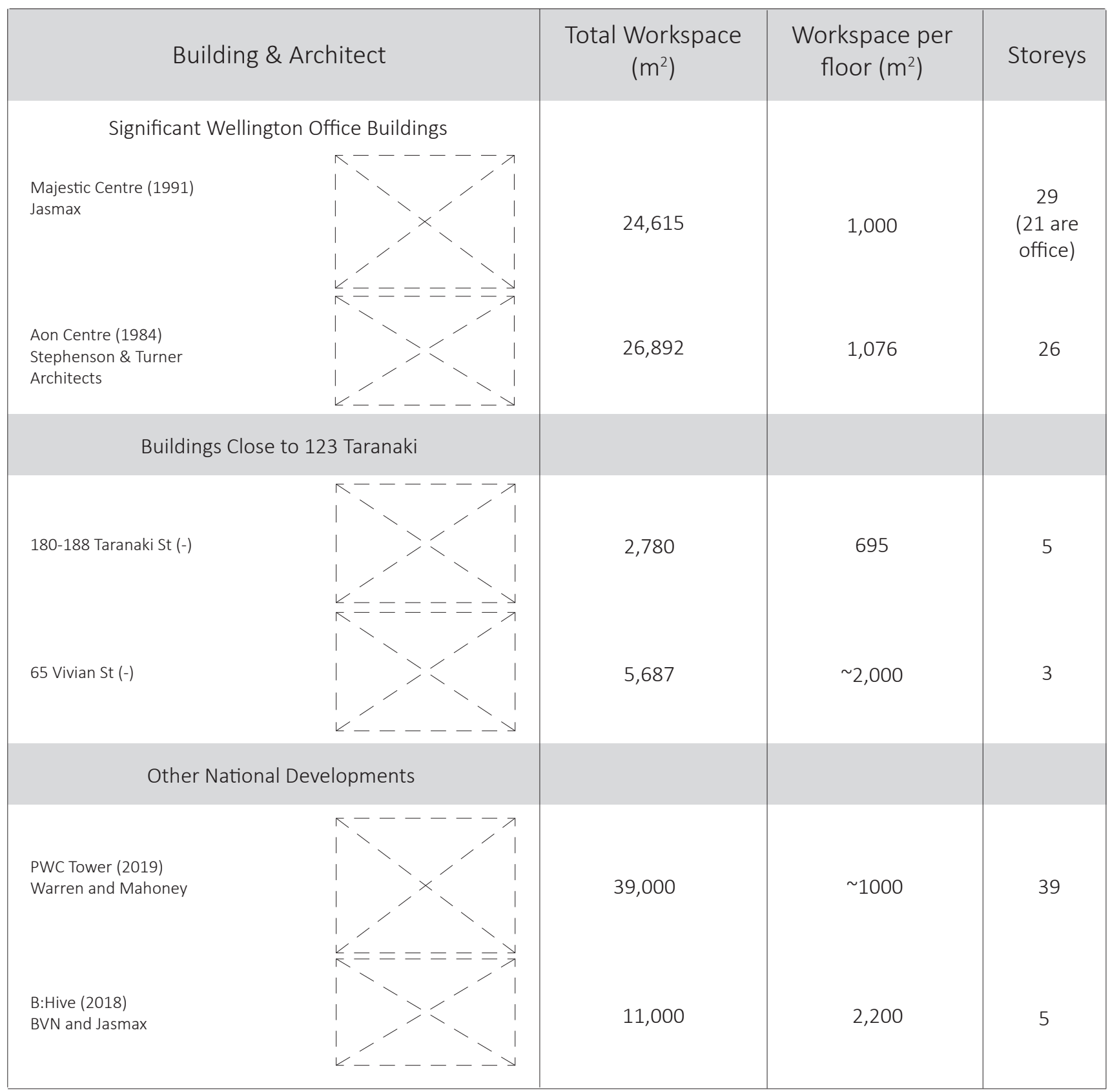

Figure 59: A breakdown of other office developments for comparison

reorganisation for non-government clients. Newer developments such as the PWC Centre and the B:Hive go even further, having upwards of 2000 sqm on each floor. 


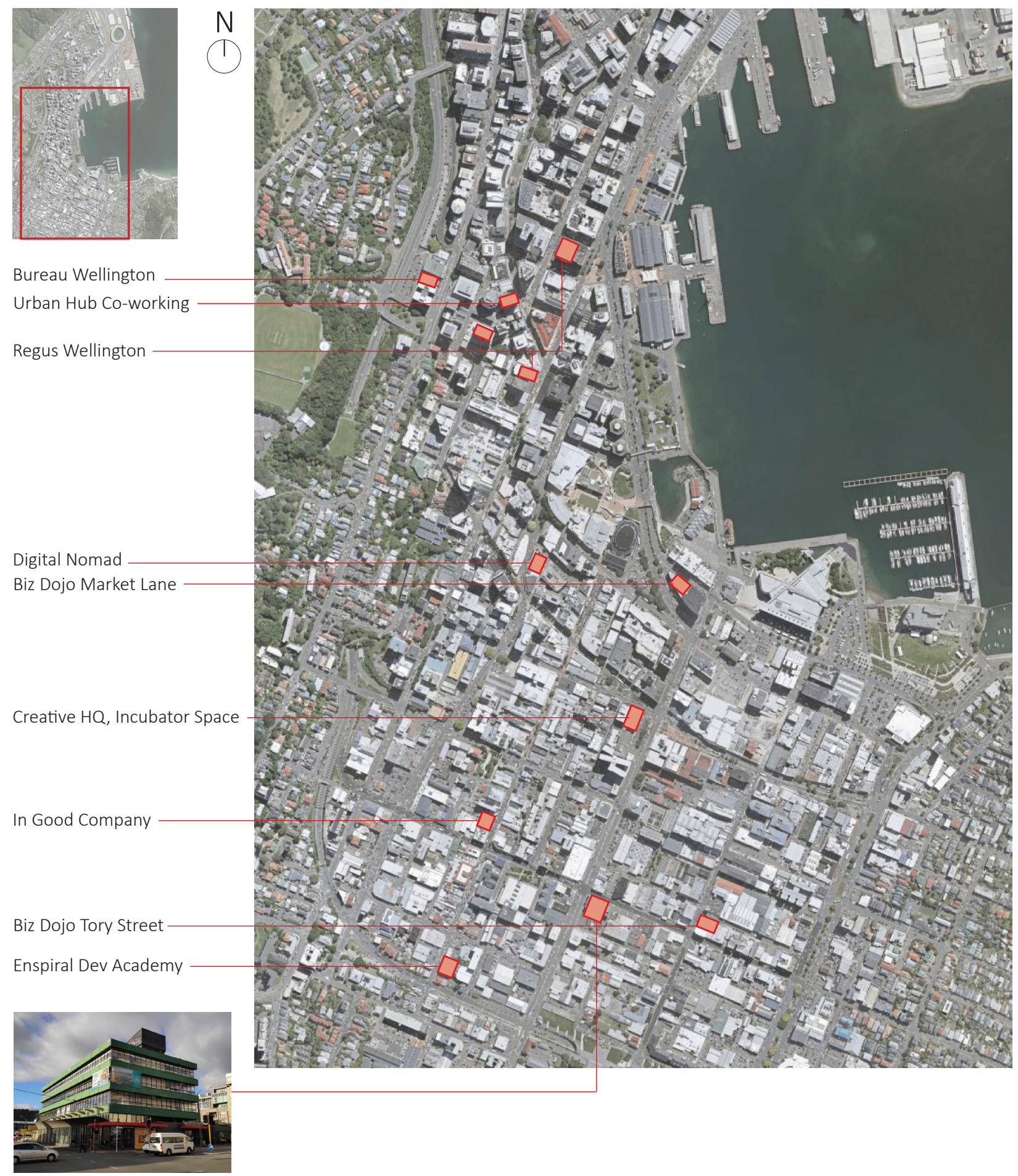

Figure 60: Map showing where co-working and startup communities are located in relation to 123 Taranaki Street 


\section{1 .2}

STARTUP WORKSPACES AND COMMUNITIES

Although my site is not closely located in the corporate centre of Wellington, it is located in the more creative side of the city. This can be seen when looking at the location of various co-working and start-up incubator spaces. Other than the clustering of the corporate co-working spaces of Regus and Bureau in the central city, the other community workspaces are located in the Te Aro area, being in the same neighbourhood as 123 Tarananki. Biz Dojo Tory Street is situated just down the street, and at one point was New Zealand's most successful co-working space. In discussion with Paul Swift, who previously ran Biz Dojo Tory Street, he described how recently Regus (a large multinational co-working company) had purchased the local coworking space. He mentioned that it had gone into a state of decline as a result. Citing their lack of ability to foster a community through engaging with their users, Regus's more corporate focussed way of operating the space has resulted in the dissolution of the community that had been built there. The Te Aro area of Wellington has no large hub for co-working, with there being only small groups of spaces dotted around. 


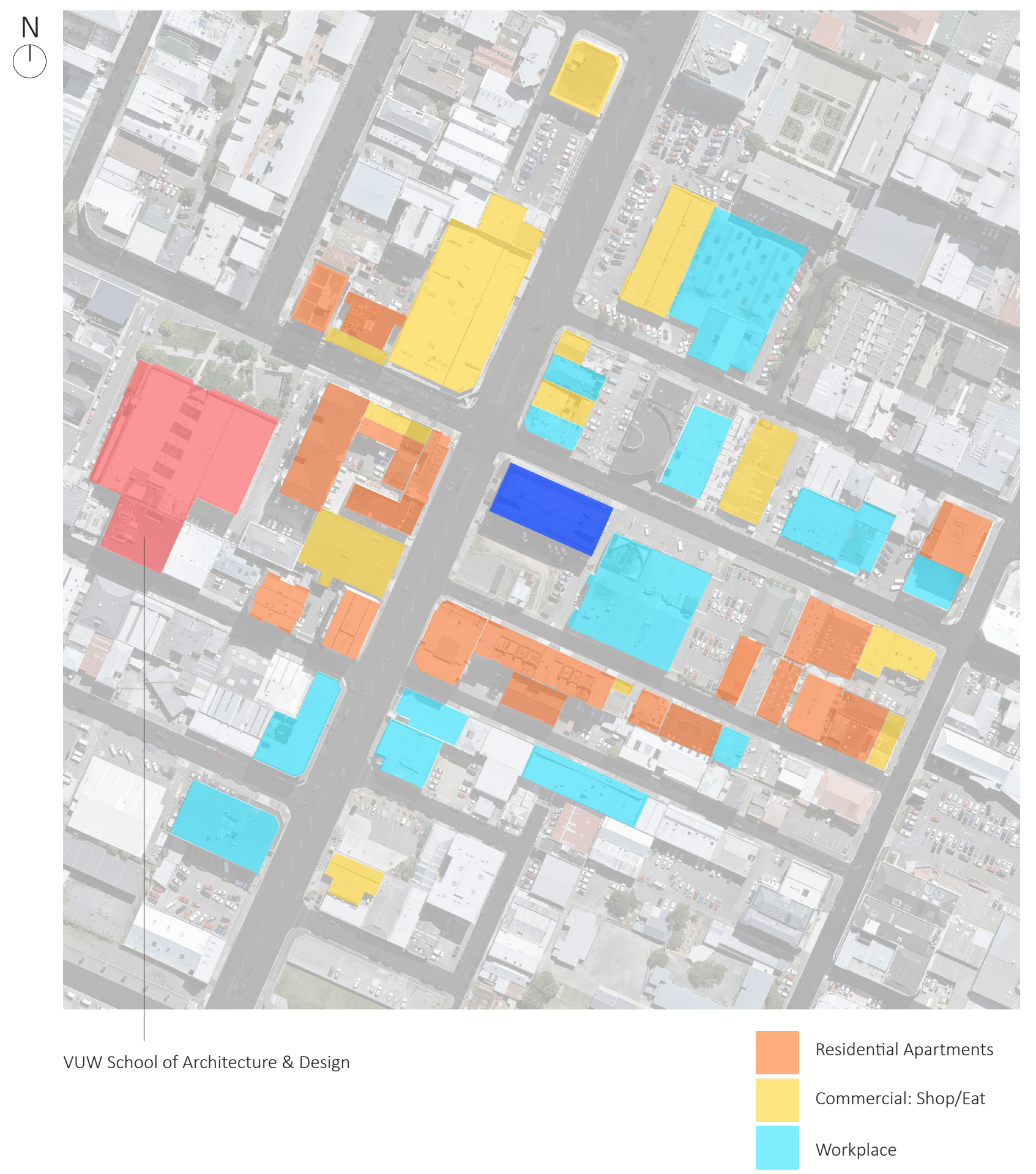

Figure 61: Map showing the diversity of buildings around 123 Taranaki (in blue). 


\section{1 .3}

LOCAL COMMUNITY

Looking more closely at the immediate context of 123 Taranaki Street, there is a large amount of diversity in the function of the surrounding buildings. With a mixture of residential, commercial, workplaces and the School of Architecture and Design, this area is a mix of everything. A design placed in this context would have to consider this, as the building would not only serve workers, but the surrounding community of people who live, work and study there. The opportunity to incorporate the university into the design would also be worth pursuing, as students may also have a use for such a workspace. 


\section{1 .4}

\section{LOCAL BUSINESSES}

When observing what businesses occupy the area around 123 Taranaki, a few notable examples emerged. Wrestler is an international advertising company based here in Wellington. Forbes magazine has noted the business as being one of the fastest growing in the Asia-Pacific region, with it specializing in video production and augmented and virtual reality media (Slade, 2019). When asked what sets Wellington apart from other cities, co-founder Ben Forman stated that "where Wellington can offer something different is in doing work that is slightly more human-centred" (Slade, 2019). He cites how Auckland and the US are 'too profit driven', when compared to the capital. Wrestler has recently moved to Vivian Street, across the road from 123 Taranaki, reportedly to fit up to 100 employees. This exemplifies the kind of clientele this area draws, as well as the kind of work Wellington could specialise in.

\section{"Where Wellington can offer something different is in doing work that is slightly more human-centred"}

Wrestler Co-Founder Ben Forman. (Slade, 2019)

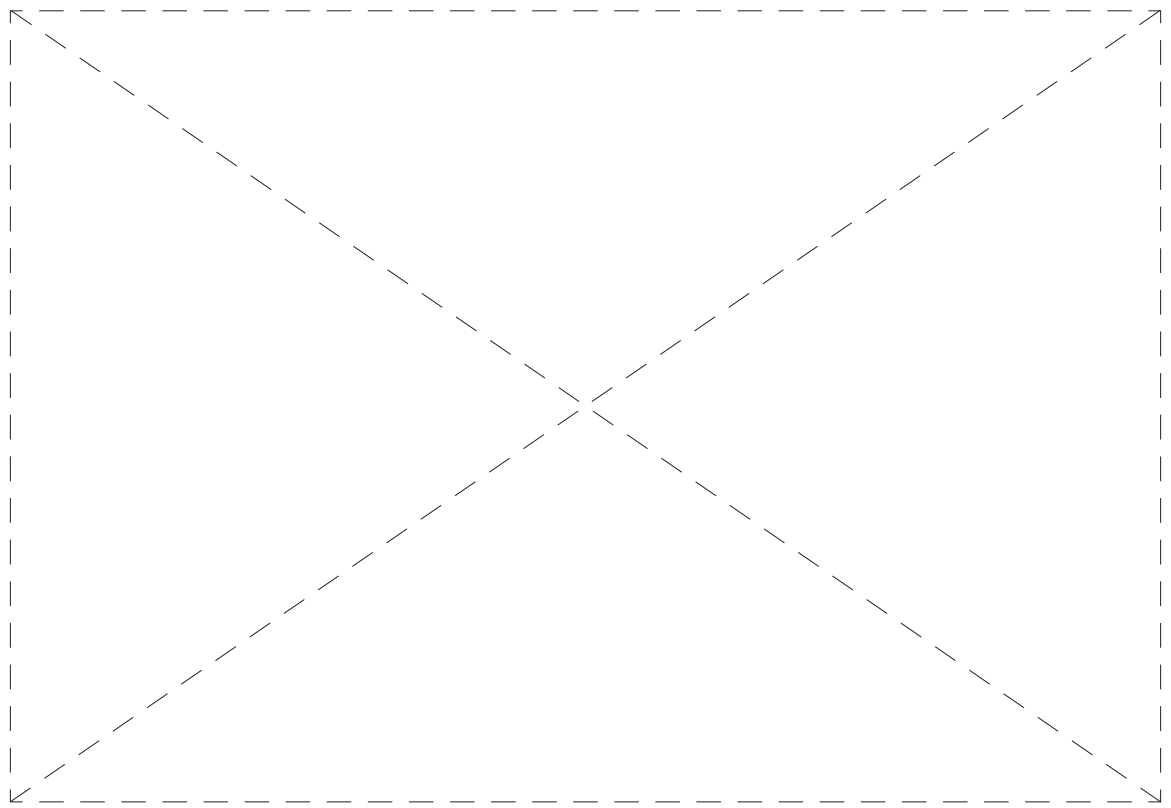

Figure 62: Wrestler's new headquarters, across the road from 123 Taranaki (Author) 


\section{MAKERS' SPACES}

The immediate area was also once home to a small community of makers' spaces. These spaces are shared workshops where people pay and use the facilities as they need. Makerspace NZ used to be located down Vivian Street, until it closed down years ago due to the economic difficulty of running such a space (figure 63). Relying on subscription fees to stay afloat, there is only one other makers space left in Wellington that's publicly open, with this being the Massey University run Fab Lab. This is located further up Taranaki Street. Wellington has the creative reputation to support these spaces, they are just not well-known and rely on subscription fees to survive. There is great opportunity to embed a makers' space into the redesign of 123 Taranaki.

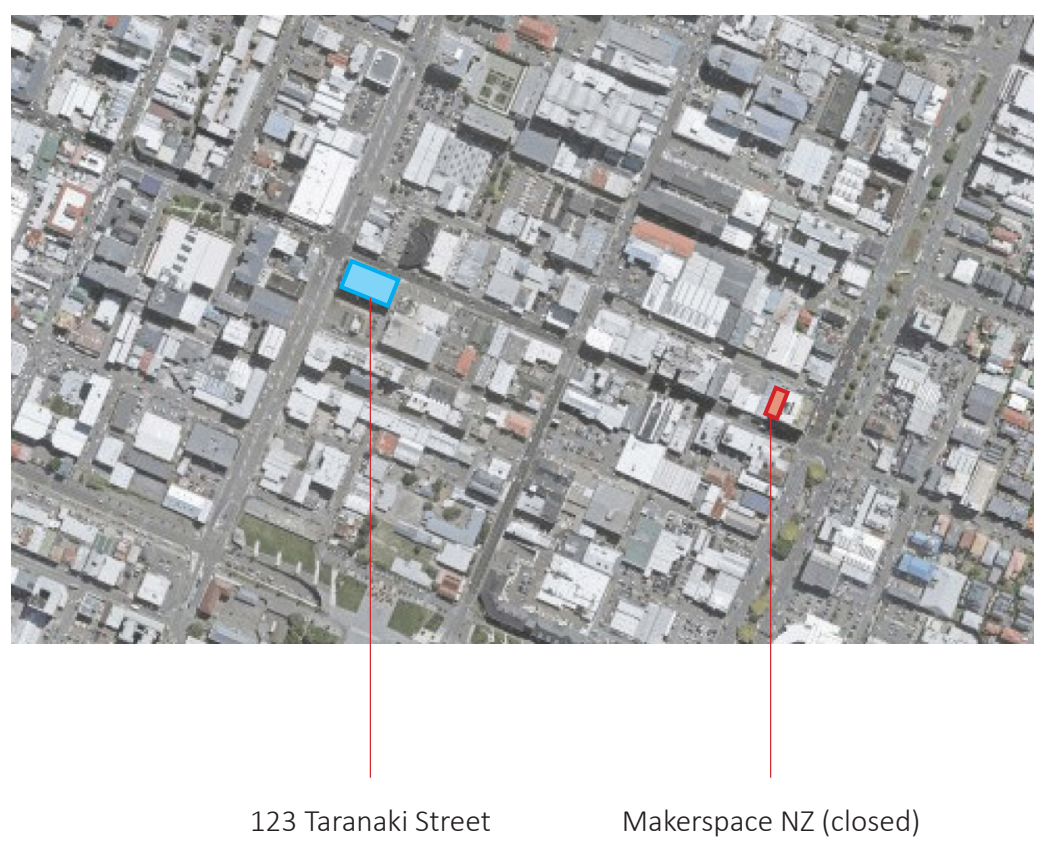

Figure 63: Map showing the former makers' space in Wellington. 


\subsection{5}

\section{INTEGRATION OF INFRASTRUCTURE}

In 2019, the Wellington City Council and the NZTA announced the 'Let's Get Wellington Moving' programme. The plan consists of $\$ 6.4$ Billion dollars of upgrades to the transport system, potentially including a mass transit system such as light rail (George, 2019). In their plan they include visualisations of Taranaki Street, as well as there being a proposed light rail route that could pass through it (figure 65). The future of this street could become a lot busier, with more people being able to easily get in and out of the city. At the very least it can be seen that Taranaki Street is on the council's radar for future improvements.

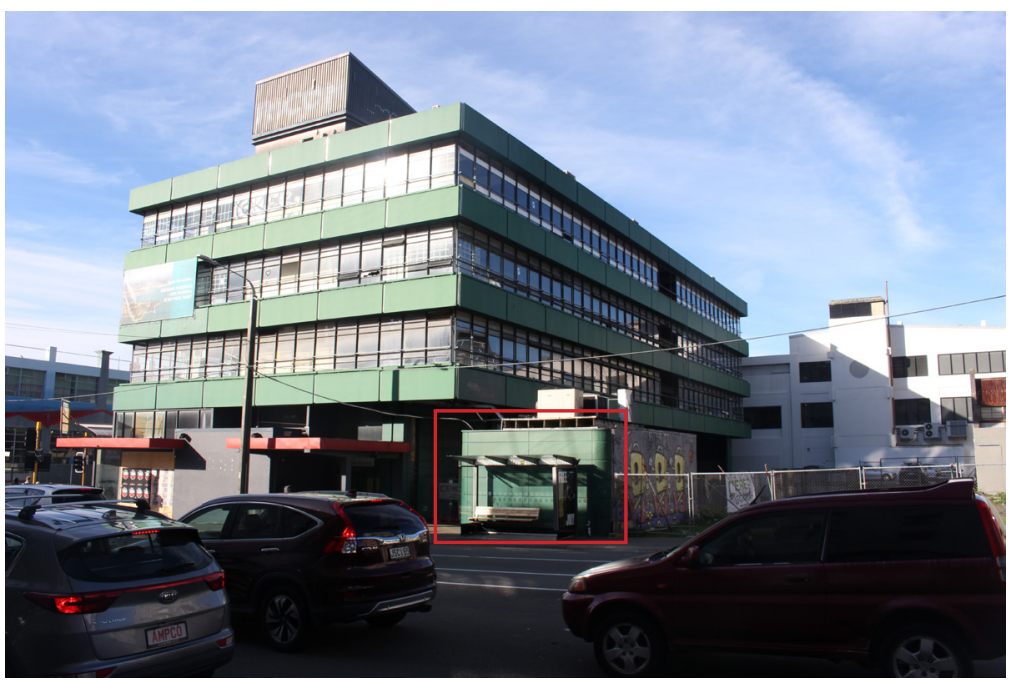

Figure 64: Bus stop at 123 Taranaki Street, it is already well used (Author)

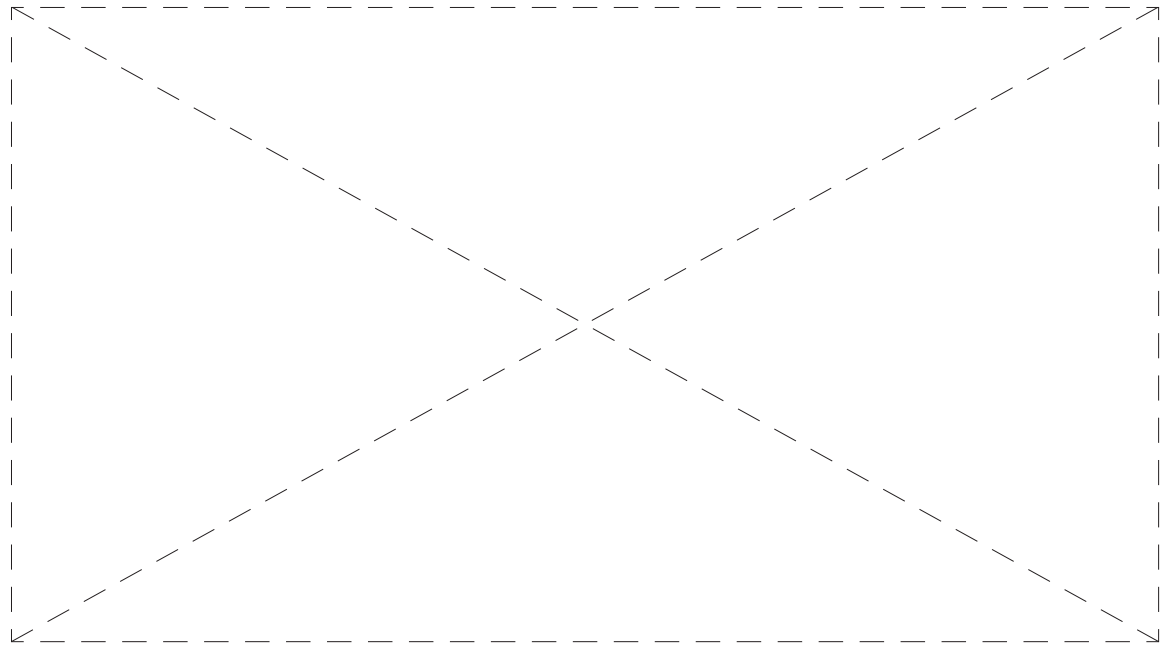

Figure 65. Visualisation of proposed transport changes to Taranaki Street (George, 2019) 


\subsection{6}

\section{RELEVANT Planned DeVElopments}

A medium density apartment complex is set to be built very close to 123 Taranaki. Known as The Paddington, this low-rise housing development will house a large amount of up-market tenants. This will affect the amount of people in the proximity of the new redesign, meaning it could service even more people.

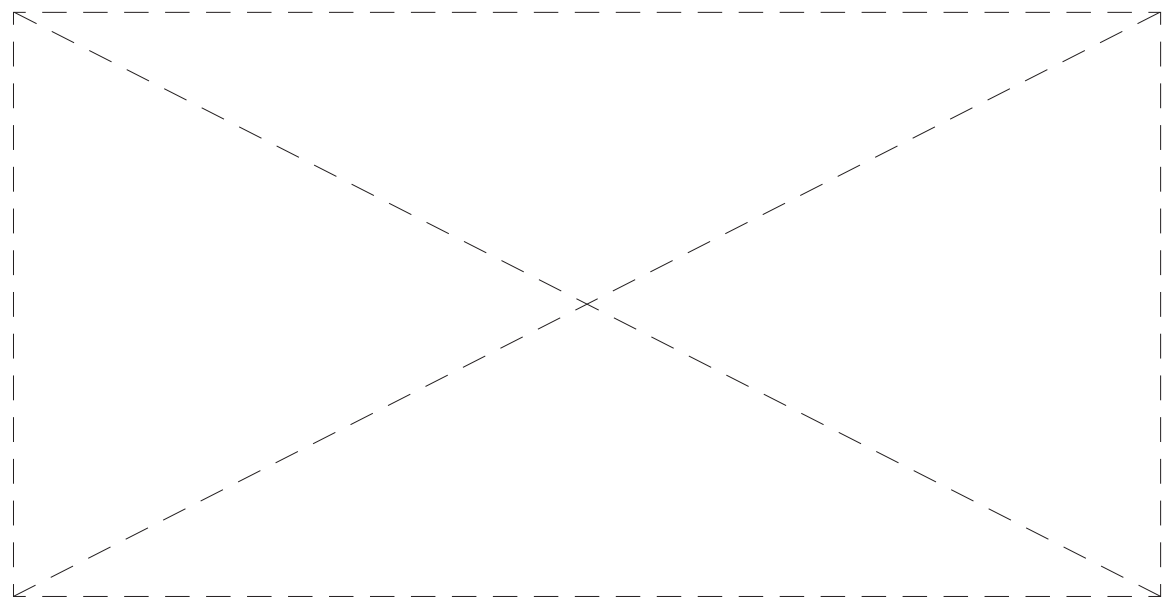

Figure 66: Visualisation of The Paddington (Thames Pacific, 2019)

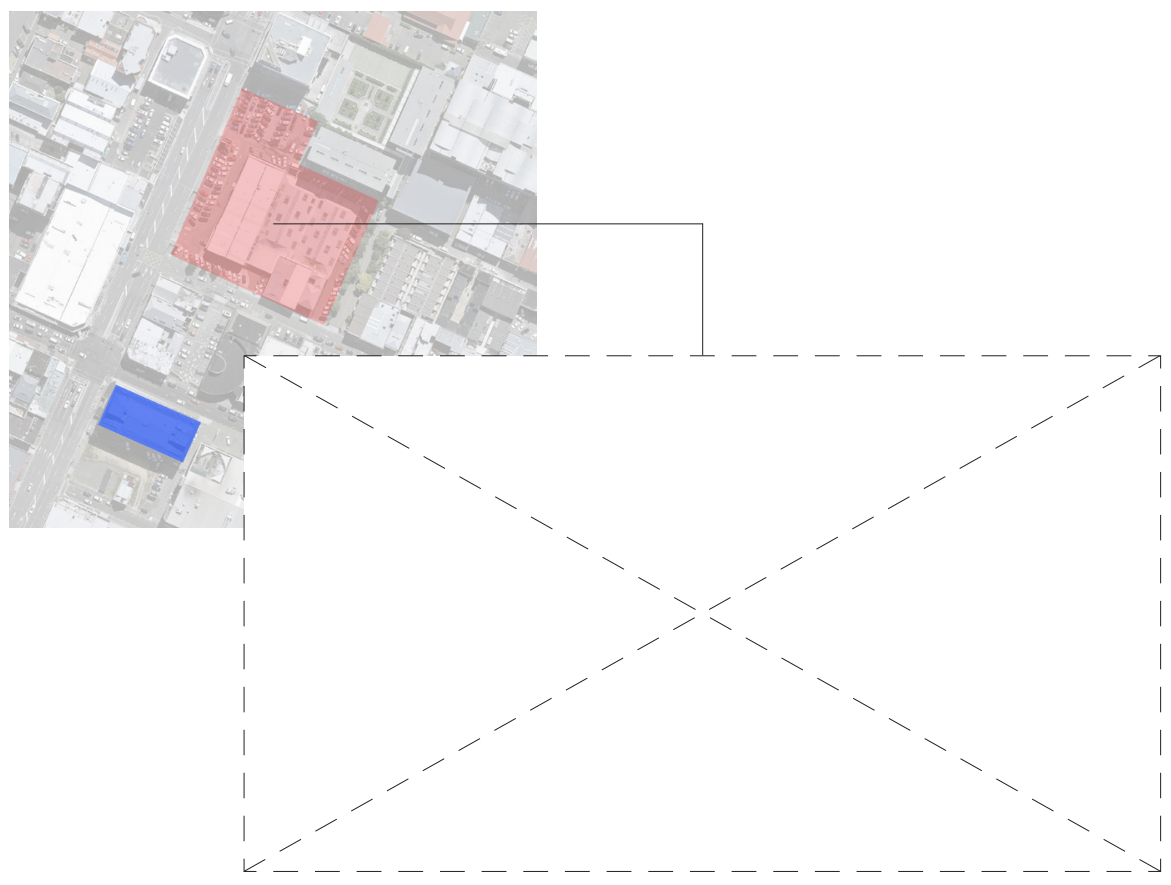

Figure 67: The Paddingtons proximity to 123 Taranaki, in blue. (Thames Pacific, 2019) 


\subsection{7}

\section{WelLINGTON'S PRIMARY GROWTH SECTORS}

Looking at the wider trends of the type of work Wellington is growing in, it can be observed that the city specialises in creative, digital media, as well as the gaming sector and business process operations (NZTE, 2016). Being described in the New Zealand Trade and Enterprise 2016 report as a "high tech hub", the city also has a highly educated workforce and a unique focus on the creative industries such as film, in part due to the success of Sir Peter Jackson's Lord of the Rings (NZTE, 2016). This focus on the creation of ideas aligns well with the direction work is heading in general (discussed in chapter 2), putting Wellington in a prime position to capitalize on its reputation in the future; if it was so inclined.

of New Zealand's

digital media revenue

Creative Digitech Industry:

"The Wellington region has the highest concentration of web-based and digital technology companies per capita in New Zealand"

(New Zealand Trade and Enterpise Regional Report, 2016)

Screen Sector:

Wellington is known for its post production for film and television, with companies from the U.S outsourcing their work here. Weta etc.

(WellingtonNZ, 2019)
Game Development Sector:

"Our creative and digital scene has attracted masses of tech talent to Wellington, leading to niche digital startups emerging across the city"

(WellingtonNZ, 2019)

Business Process Operations:

"Wellington is a world-class, cost-effective location to establish higher value customer service, technical support and business"

(New Zealand Trade and Enterpise Regional Report, 2016)

Figure 68: Summary of New Zealand Trade and Enterprise 2016 Regional Report. (NZTE, 


\section{2}

\section{CONCLUSION}

This chapter set to find out the opportunities present in a specific site and the wider Wellington context, with the goal of incorporating these into a holistic design that shows what the future of work could be for the city. 123 Taranaki Street was chosen due its historic and functional relevance to the research area, with the surrounding site offering a wide range of considerations. Other new office developments were analysed, with the amount of workspace they provided being reviewed. The surrounding businesses were also examined, with it being identified that creative companies, co-working spaces and makers' spaces all lay in close proximity to 123 Taranaki. The creative and digital sectors of Wellington are also growing, putting the city in a good place, given the expected changes to work in the future.

The next chapter focusses on incorporating all that has been learnt from the previous chapters, utilizing a broad range of iterative design experiments to test how best to express the key drivers, and also how to capitalise on the opportunities present on the site. 

PRELIMINARY DESIGN 


\section{0}

\section{INTRODUCTION}

This chapter brings together the lessons from the literature, the project review and the opportunities present on the site, with the goal of creating a speculative preliminary design that represents what the future of workspaces could be for the city of Wellington. This chapter documents and reflects on the process of design experiments that were conducted in the pursuit of this goal. This relates to the third objective of this research:

3. Explore these potential implications in a specific context, resulting in a speculative example of what the future of work spaces could be 


\section{1}

\section{PRIMARY DESIGN DRIVERS}

Throughout the design process, the key drivers identified in chapter 3 were used to inform the different approaches that were taken. The architectural implications of these drivers are explored in throughout this chapter. The key drivers include:

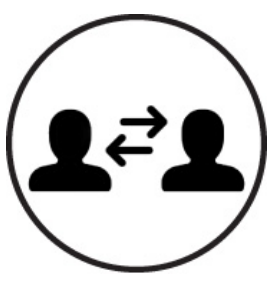

Interaction

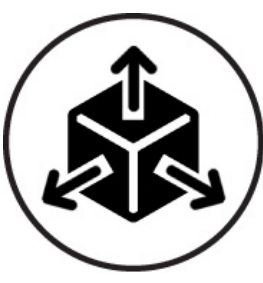

Flexibility

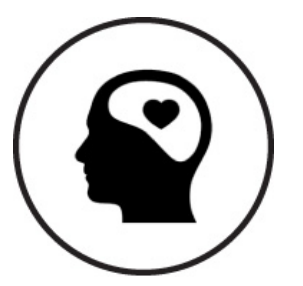

User Wellbeing

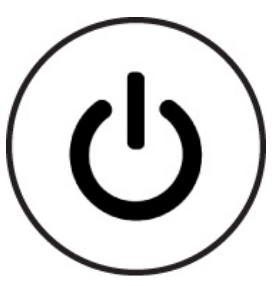

Technological Integration

Interaction was used as a starting point for the design, as throughout the project review chapter it was observed that this driver had the most impact on the spatial arrangement of the building. 


\section{2}

\section{INTERACTION EXPERIMENTATION}

Throughout the project review it became clear that one of the primary methods used by designers of encouraging interaction, was the incorporation of an open atrium and a central stair. Buildings such as the B:Hive (figure 32) show how effective this feature is in not just aiding in co-worker interaction, but also in creating a focal point for the central area of the building. Drawing inspiration directly from the approaches taken by $3 \mathrm{XN}$ in their design for UN city, and Jasmax and BVN in their design for the B:Hive, two different stair designs were tested in the existing structure of 123 Taranaki Street. The goal of this was to test how these approaches of encouraging interaction would work the existing context.
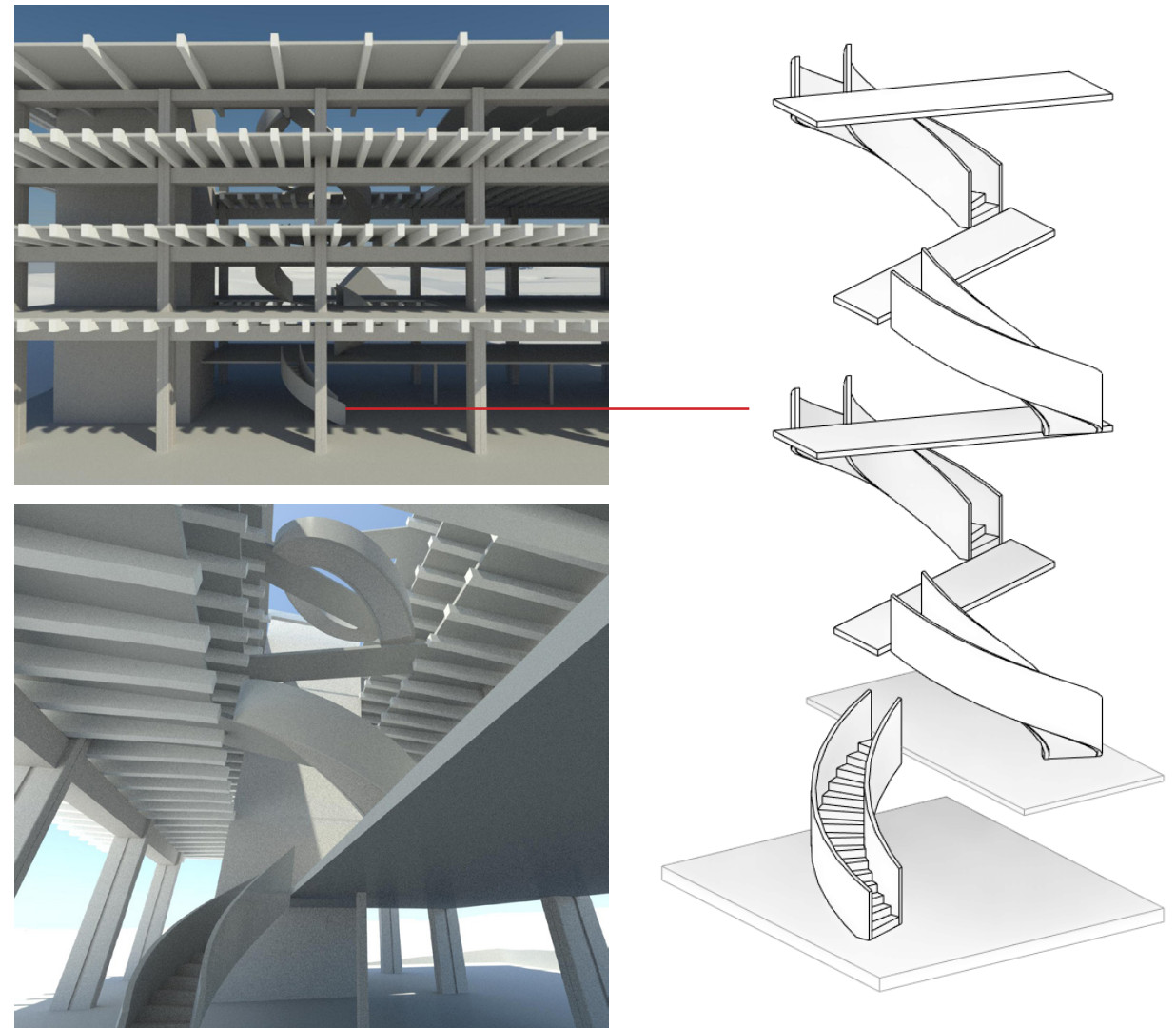

Figure 69: Sketch renders and drawing showing how the 3XN-inspired stair would fit into the structure of 123 Taranaki Street. 

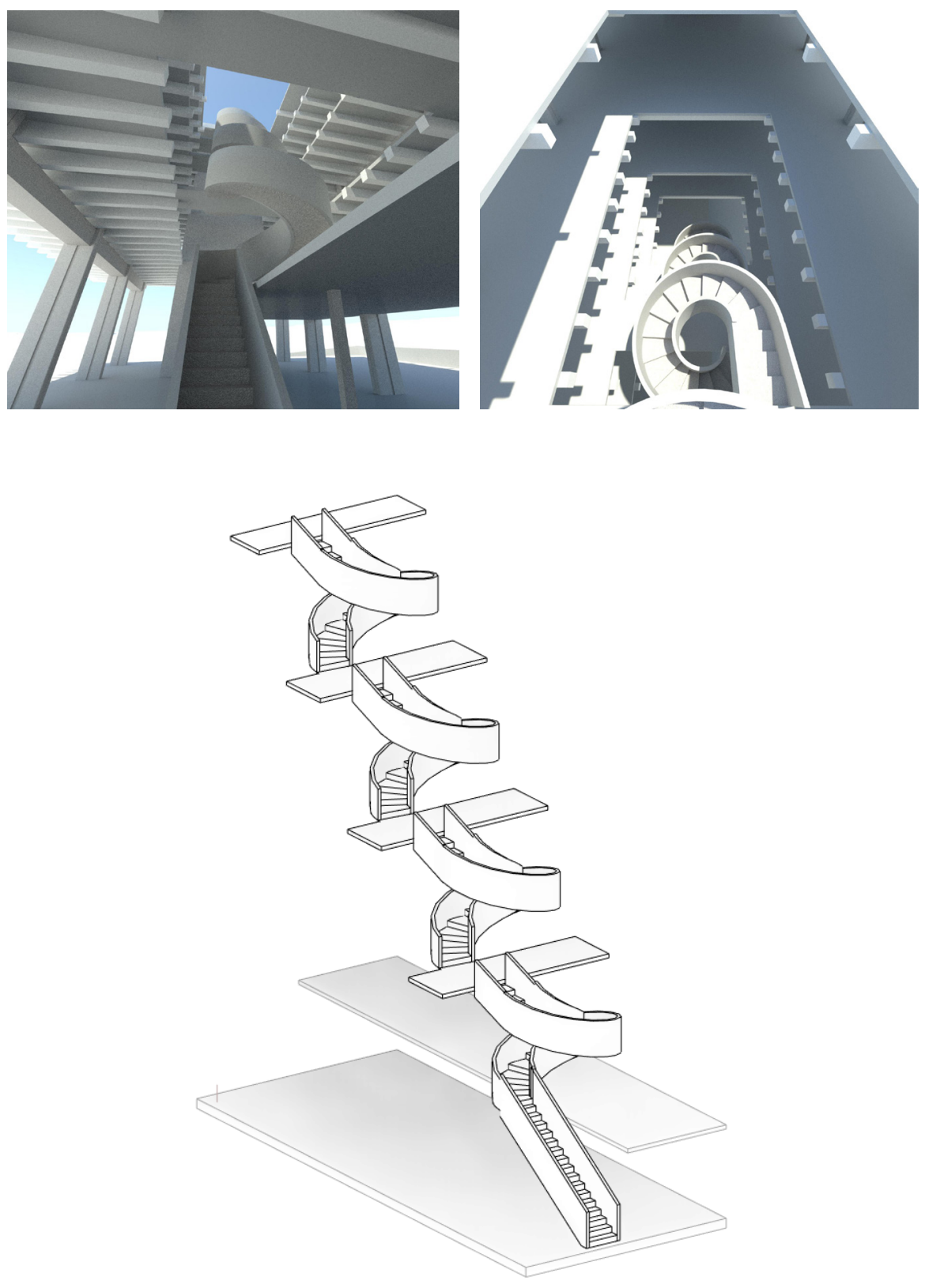

Figure 70: Sketch renders and drawing showing how the Jasmax and BVN-inspired stair would fit into the existing structure. 


\section{3}

\section{QUANTIFYING INTERACTION}

From the previous experiments it was observed that these sculptural stairs occupy a lot of room, and this would likely impact the functionality of the existing space. Some way of quantifying the effects of these experiments had to be employed. Physical and visual connectivity is key in encouraging interaction between coworkers, as more of the building can be seen and accessed by a larger portion of its users, increasing the likelihood of an informal encounter. UCL Depthmap is a software that analyses a spaces visual and physical connectivity, assessing the integration of its spaces (Turner, 2004). This software was used to quantify the impact design interventions had on the physical and visual connectivity of a space.

The graphs below (figure 71) show the visual integration of different areas in a space. These are generated using visibility graph analysis (VGA), in which a grid of points is overlaid on a plan, then every point is connected to every other point (Turner, 2004). Points that are not very connected to other points in the space show up as blue, with highly connected points showing up as red.

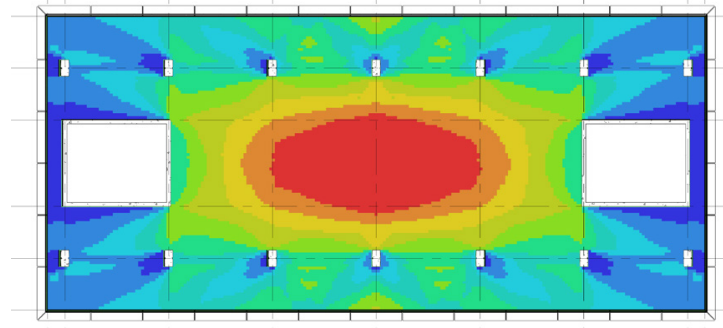

Figure 71a: VGA graph of the level 1 plan of 123 Taranaki Street

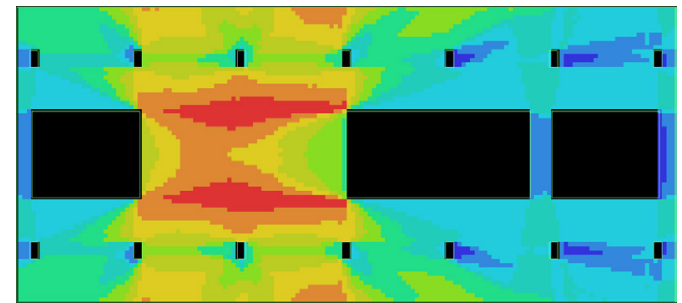

Figure 71b: VGA graph of level 1 plan, with hole cut in floor plate to test stair experiments in previous section.

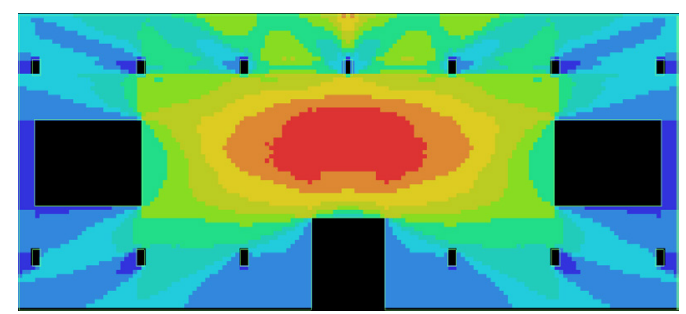

Figure 71c: VGA graph of level 1 plan, testing the impact of adding a stair in a different area. 
Testing the impact different arrangements of stairs have on the connectivity of the space found that the existing space is already highly connected, due to the structure of the building meaning there are no central columns. This shifted the focus away from altering 123 Taranaki Street, to augmenting it by occupying the surrounding site. The next set of Depthmap VGA graphs show tests that were carried out that gradually increased the size of a central open area, and seeing the impact this had on visual connectivity (figure 72). The bigger the red and orange areas in the centre meant a bigger amount of visually connected space, which would help encourage interaction between co-workers. What was found was that the larger the central space was made, the more visually connected it became.
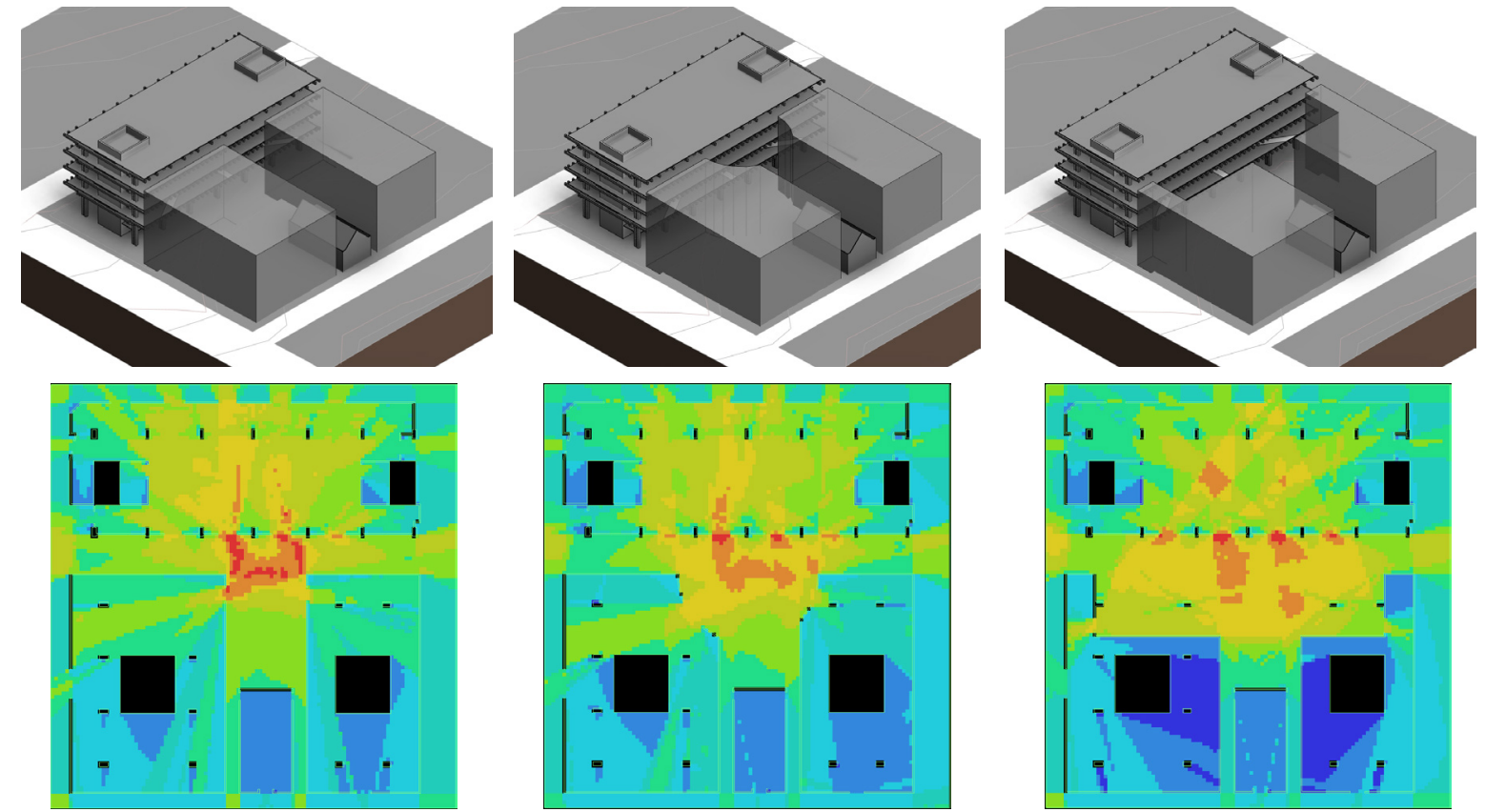

Figure 72: VGA graphs of different arrangements of the ground floor and surrounding site of 123 Taranaki. Graphs correspond to the arrangments above them. 


\section{4}

\section{SIZE INVESTIGATION}

Through using Depthmap, it was found that interaction could be encouraged better through augmenting the existing structure of 123 Taranaki Street, rather than altering it. It was also found that the larger a central open atrium space was, the more visually connected it became, making it a space that more easily aids in coworker interaction.

Now knowing that the surrounding site was to be occupied to augment 123 Taranaki, the next question became; how big should this future workplace be? Looking at other local and national contemporary office developments in section 5.1.1, it was observed that floor plates are usually over $1000 \mathrm{~m} 2$, with some such as the B:Hive going over $2000 \mathrm{~m} 2$. The total workspace provided in these developments ranged from around $8,000 \mathrm{~m} 2$ to upwards of $20,000 \mathrm{~m} 2$. The starting figure of $9,000 \mathrm{~m} 2$ was chosen for the total workspace provided by the design. This was primarily informed by buildings such as the B:Hive, as this is a recent example that has been critically well received.

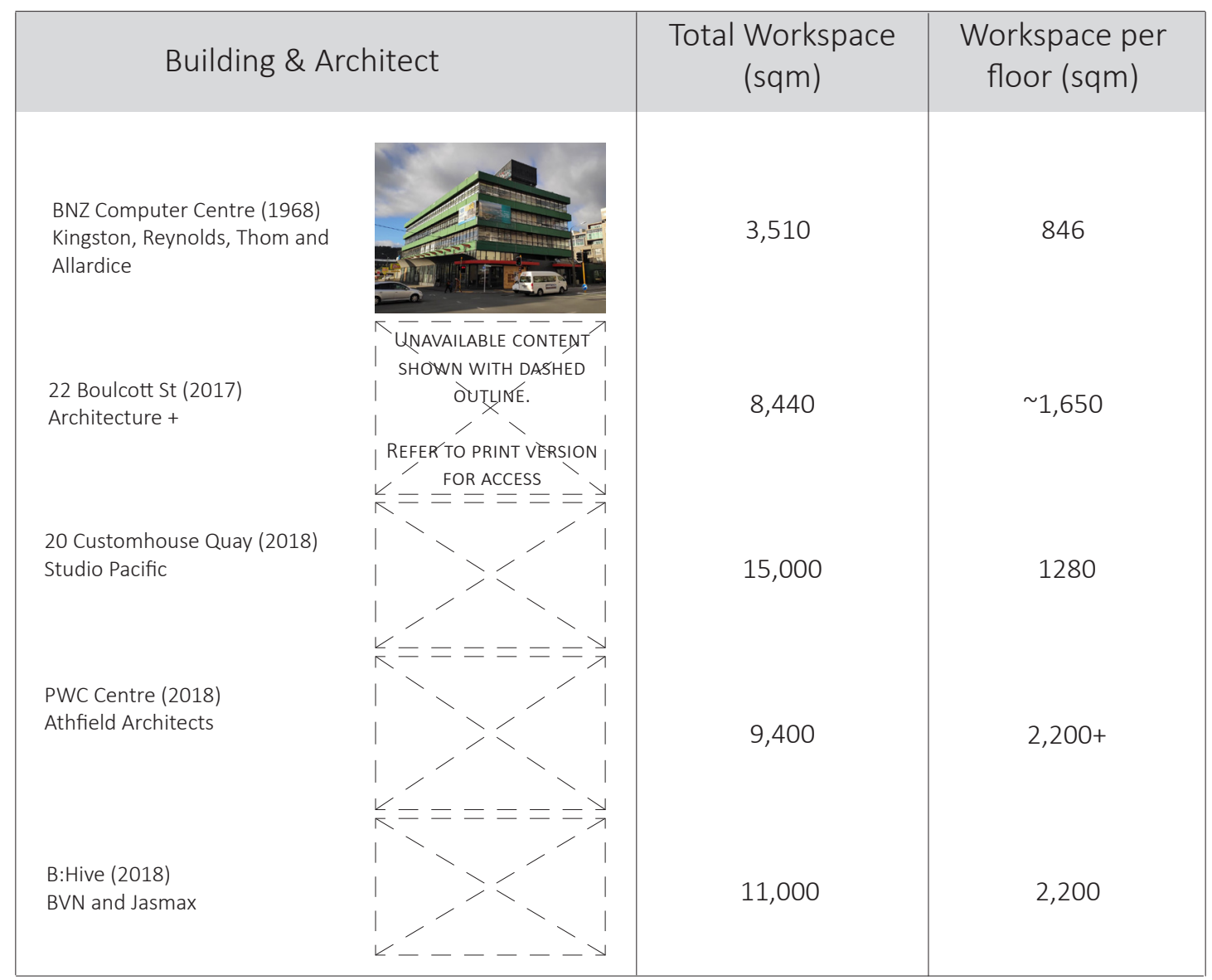

Figure 73: Summary of figure 58 in section 5.1.1, comparing various amounts of workspaces provided by contemporary developments. 
The effect of reaching $9,000 \mathrm{~m}^{2}$ of workspace was assessed through a series of sketch designs.

\section{Existing Total Workspace area: $\mathbf{3 5 1 0 \mathrm { m } ^ { 2 }}$}

Total Workspace area required to reach 9,000m2: 5490m²

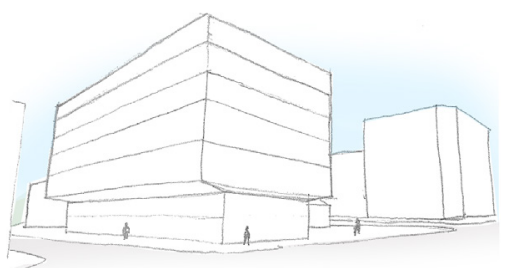

Workspace area per floor: $846 \mathrm{~m} 2$ 2 floors: $1692 \mathrm{~m}^{2}$

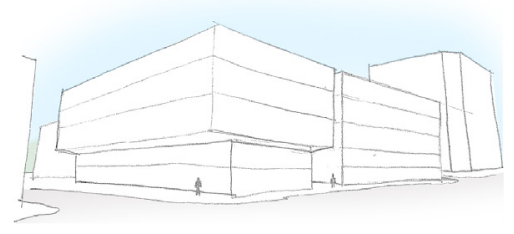

Workspace area per floor: $700 \mathrm{~m} 2$ 4 floors: $2,800 \mathrm{~m}^{\mathbf{2}}$

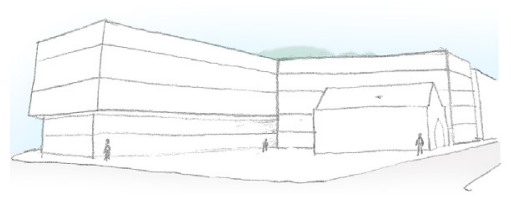

Workspace area per floor: $600 \mathrm{~m} 2$ 4 floors: $\mathbf{2 , 4 0 0 m ^ { 2 }}$

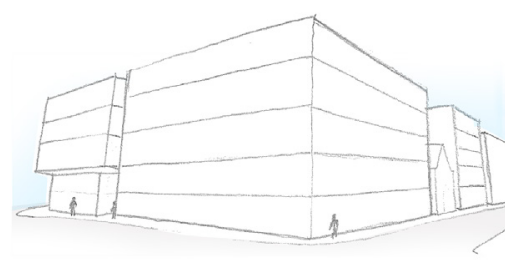

Workspace area per floor: $1,300 \mathrm{~m} 2$ 4 floors: $\mathbf{5 , 2 0 0 m ^ { 2 }}$
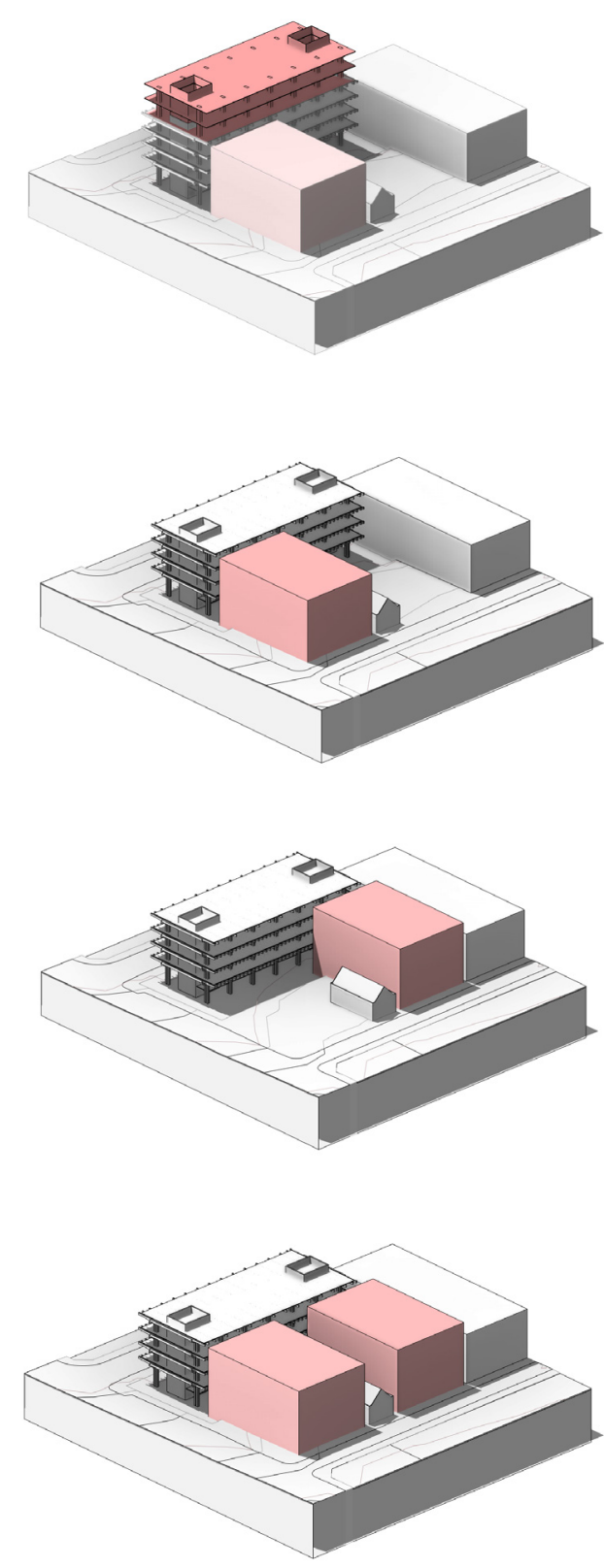

Figure 74: Sketches and isometric views of how different strategies of adding workspace impact the site. 


\section{5}

\section{CONCEPTUAL SKETCHES}

From the size investigation it was observed that to provide a comparable amount of workspace to contemporary developments, the entire empty site would need to be occupied. It was also possible to reach the target of $9,000 \mathrm{~m}^{2}$ through the combination of different approaches. The possible approaches were explored primarily through sketching and modelling.

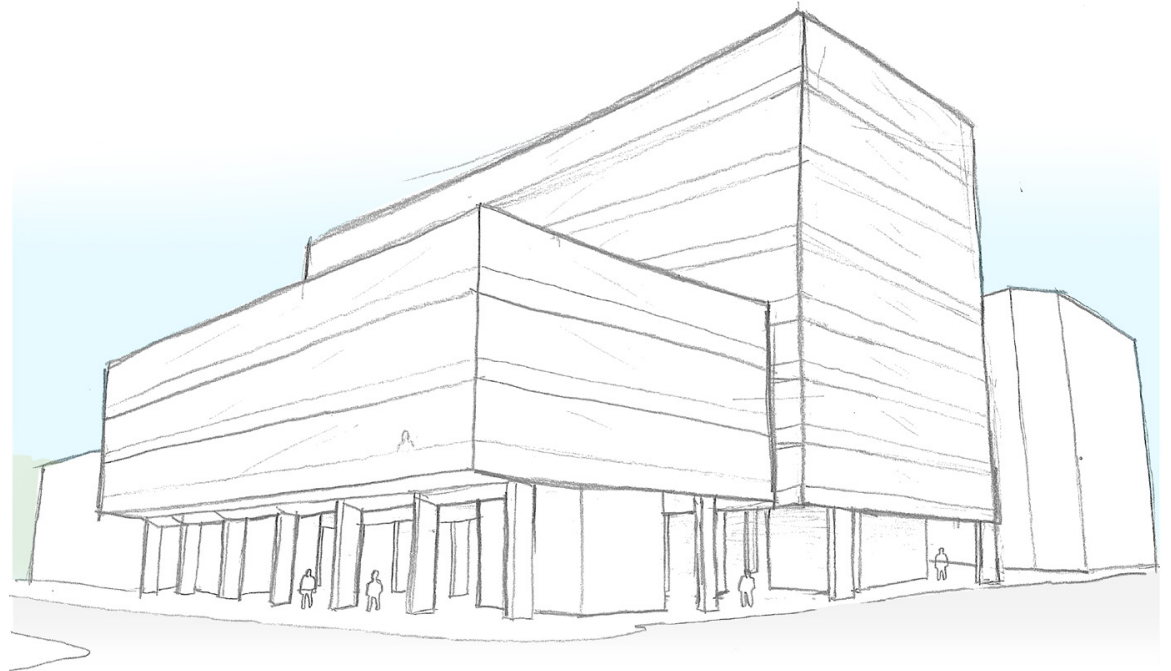

Figure 75: Sketch of an arrangement that prioritises the southern building, improving the amount of sun it gets, but at the cost of shading nearby buildings.

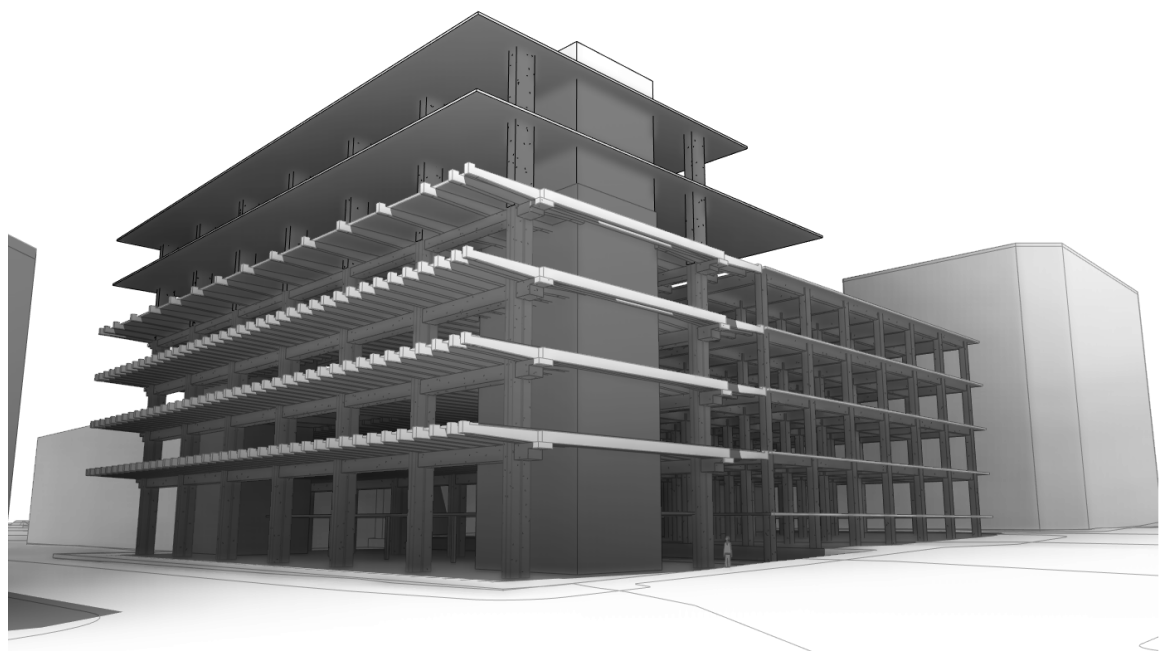

Figure 76: Model showing the reverse approach. However now the southern building will be heavily shaded. 
PRELIMINARY DESIGN

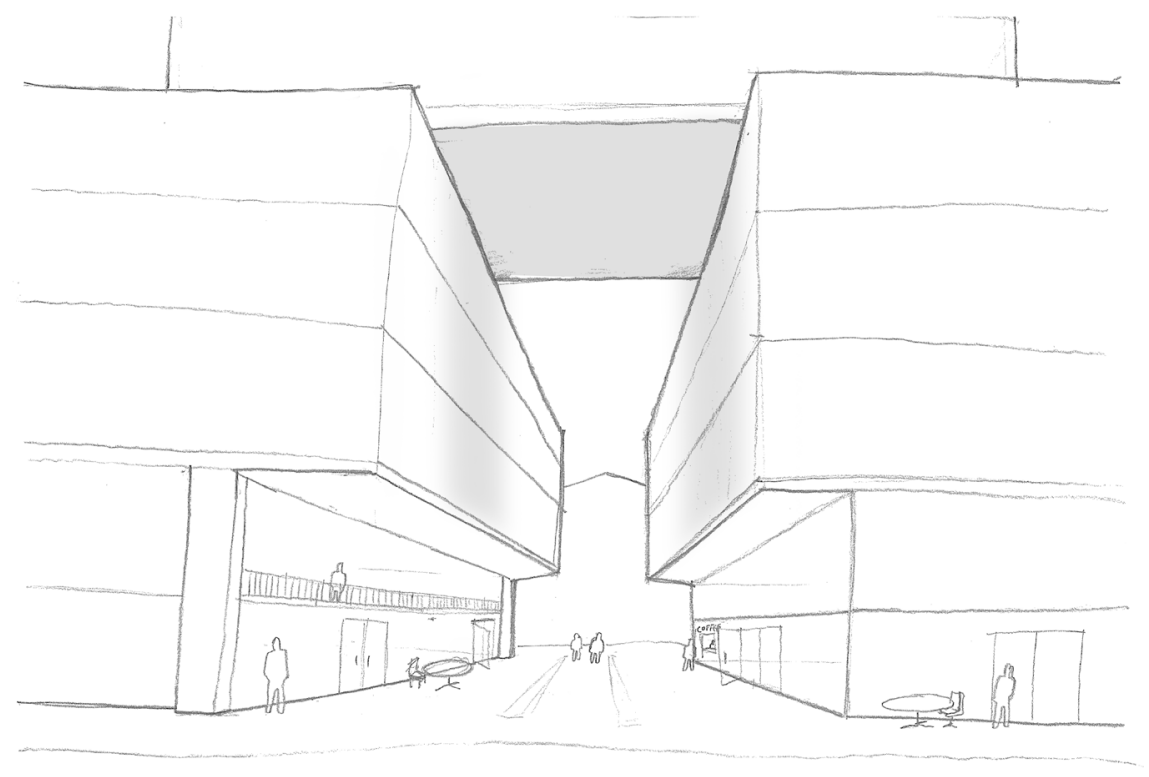

Figure 77: Concept sketch of a 'spanning' approach.

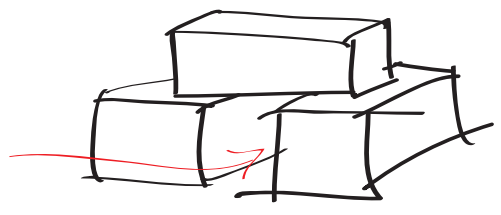

105 
Having done some very preliminary tests of the different possible arrangements, it was then time to reintroduce the key driver of interaction, to see how the arrangement of the building could aid in encouraging interaction. A creative approach was taken as it was noted that interaction-inducing atria and stairs often take on the role as a focal point of the building.

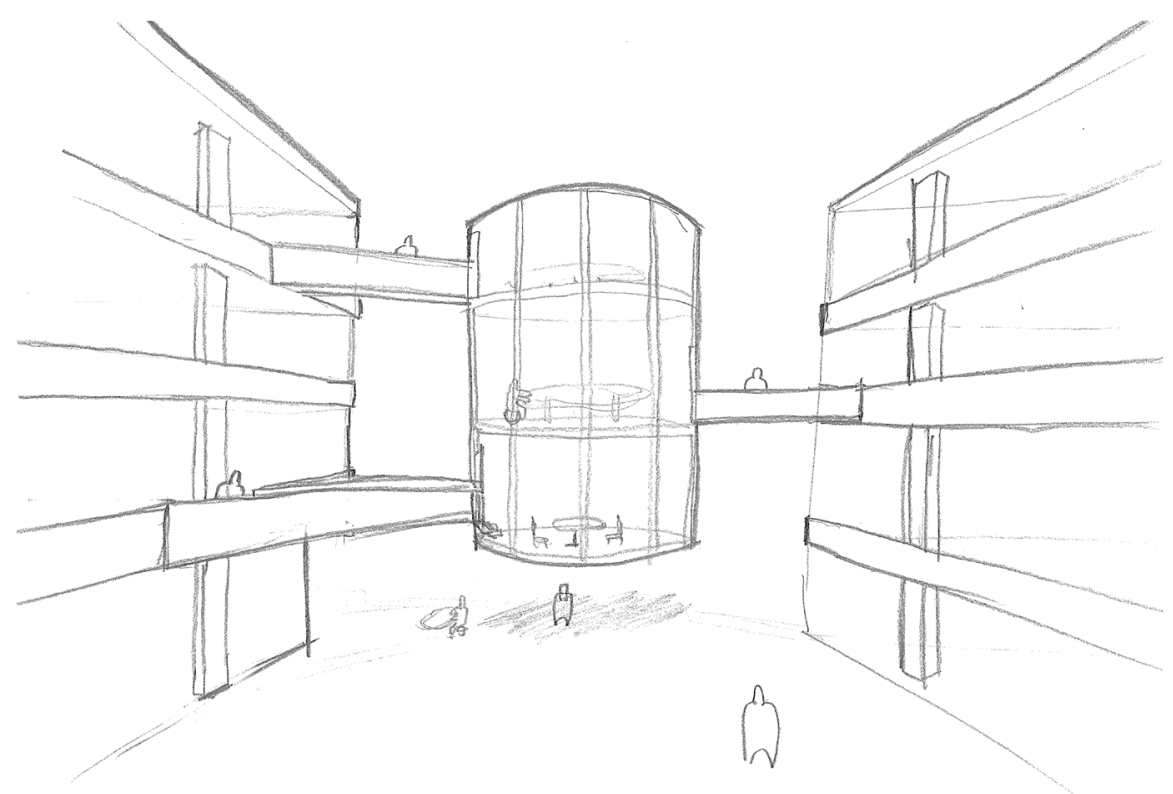

Figure 78: Sketch of a stack of meeting rooms that are supported by the walkways themselves. 


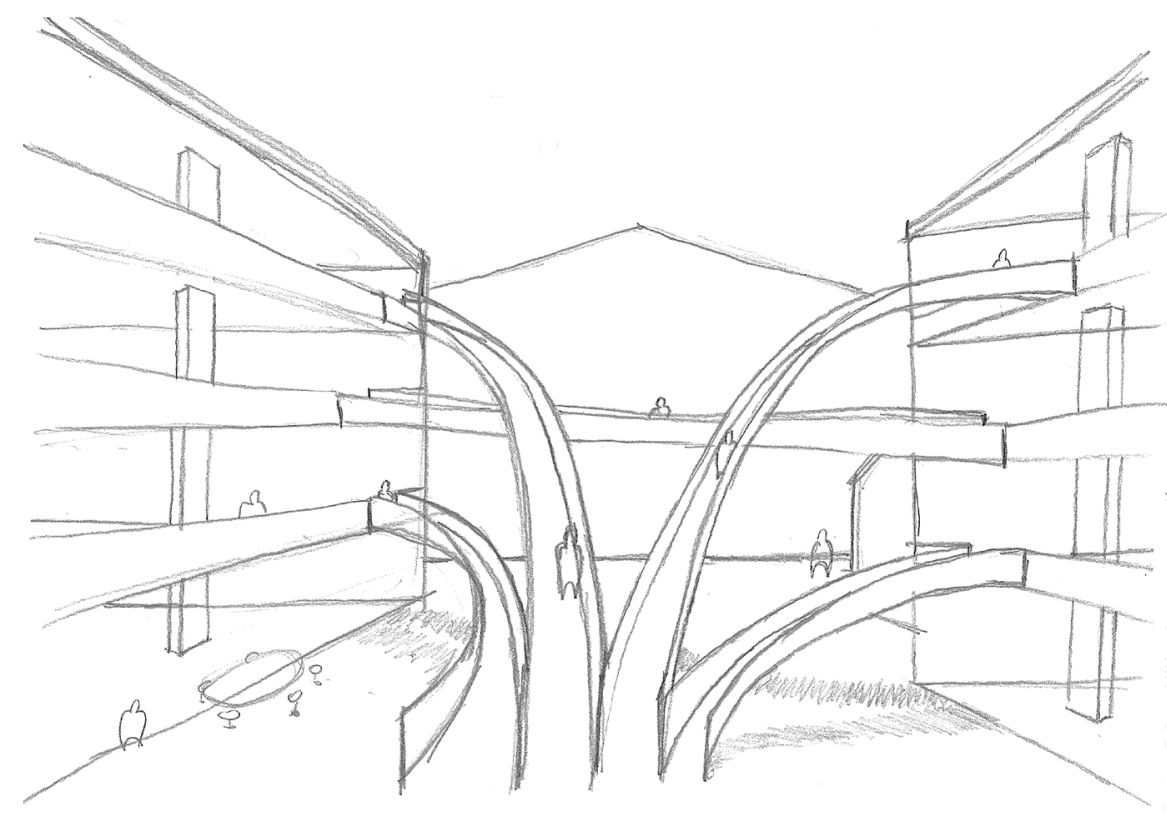

Figure 79: Sketch showing a spreading of walkways.

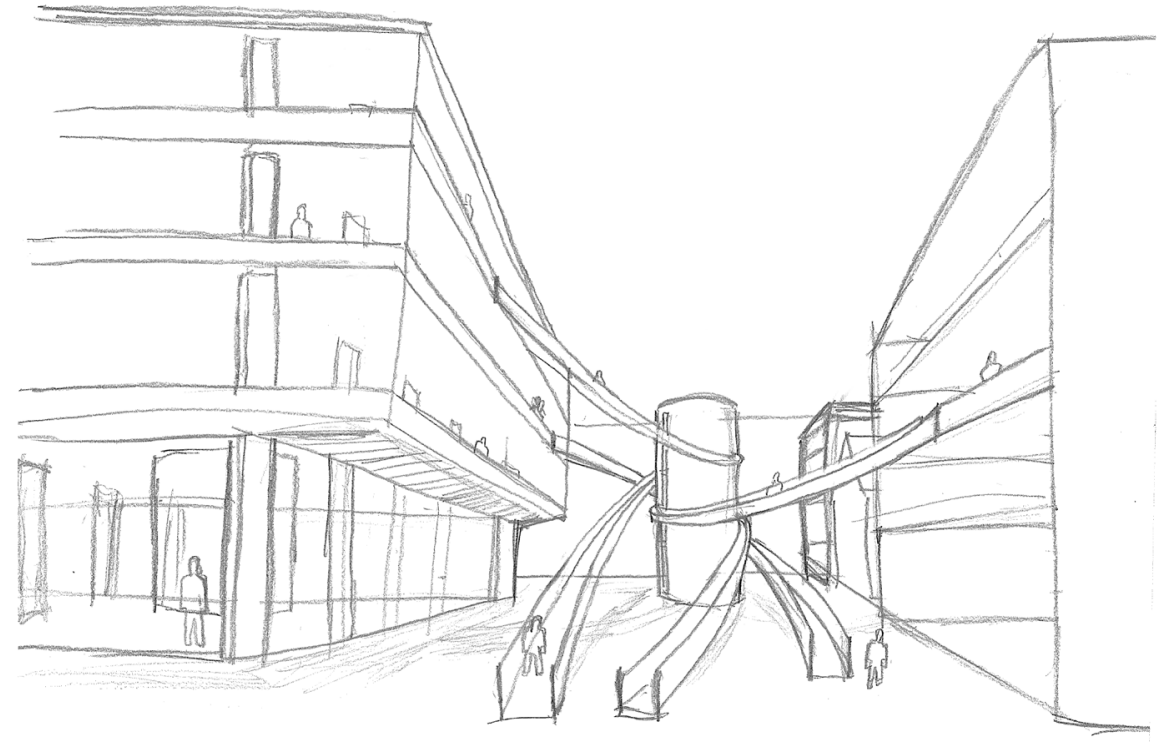

Figure 80: A concept where walkways encircle a 'tube' of meeting rooms. 


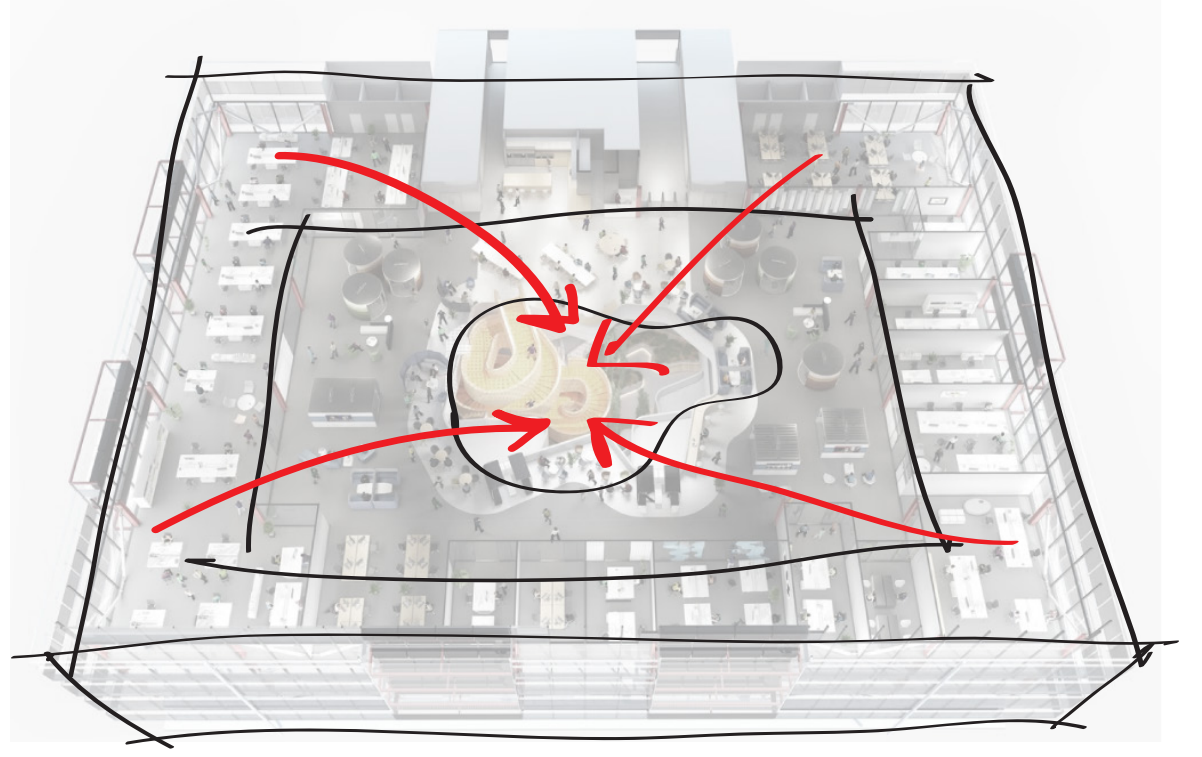

Figure 81: Sketch over the level 2 plan of the B:Hive, showing how everything is centred around the stair \& atrium.

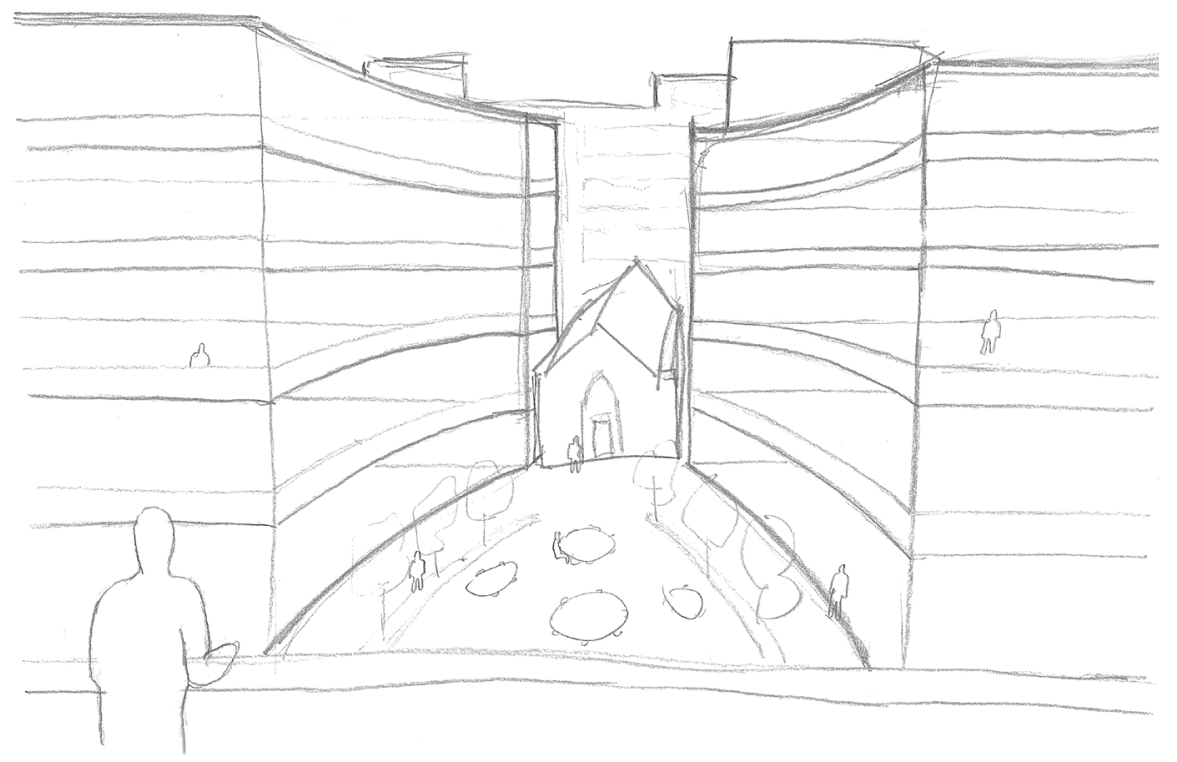

Figure 82: Concept inspired by the arrangment of the B:Hive, instead centring on the back of the mission hall. 

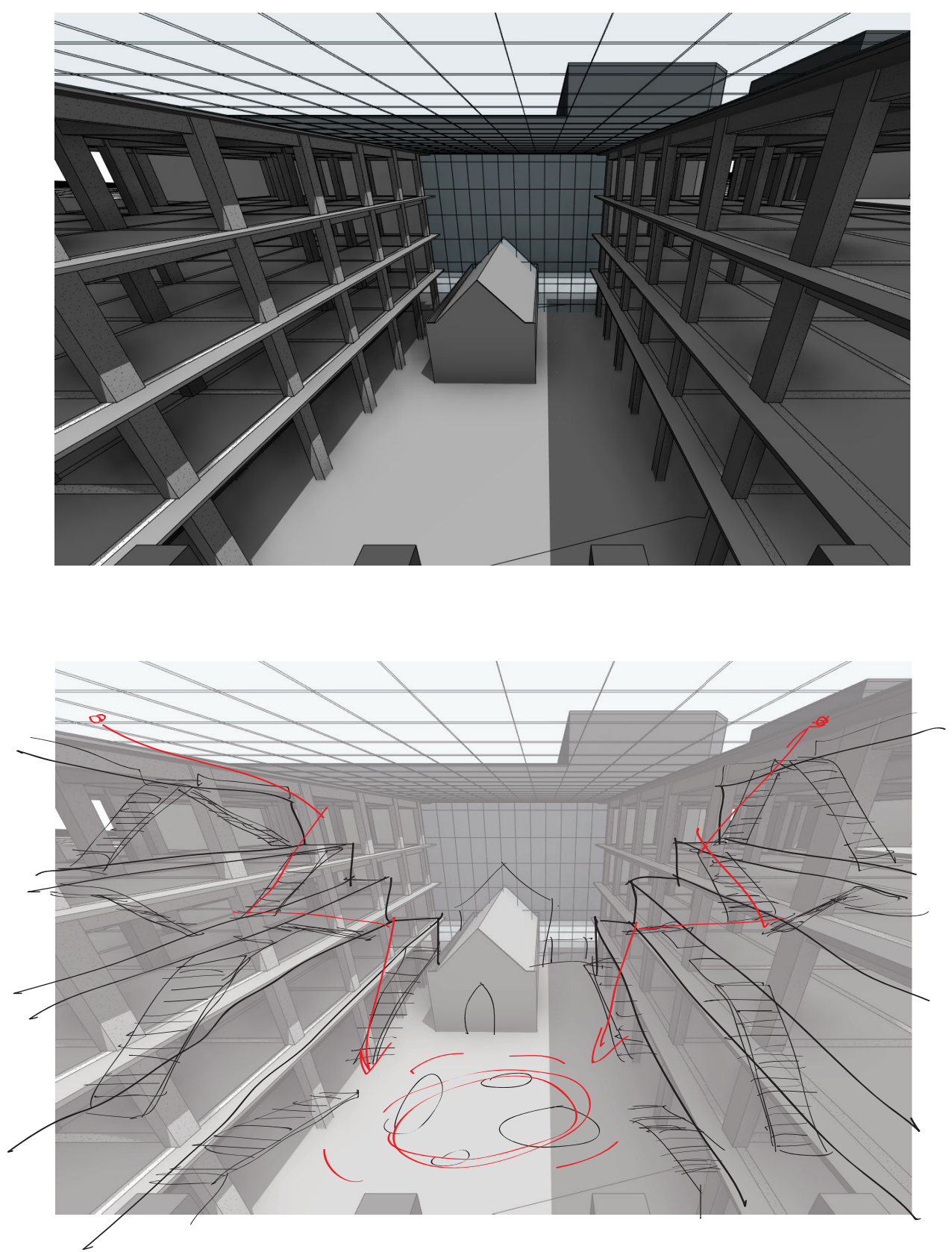

Figure 83: This idea of centring around the mission hall was expanded upon, including vertical circulation for more physical connections. 
Combining elements from figure 76 and 82 , the idea of centring on the mission hall and terracing the floor plates downward to the centre of the space was explored (figure 84). This gesturing towards the mission hall was in an attempt to celebrate the heritage of the humble building, whilst also visually connecting the floor plates through opening up the building gradually. What was learnt was that this arrangement puts too much focus on the neighbouring residential buildings, Croxley Mills and Marickian Apartments. Also it misses the opportunity of facing the busy Taranaki Street, instead it faces the one-way Frederick Street.
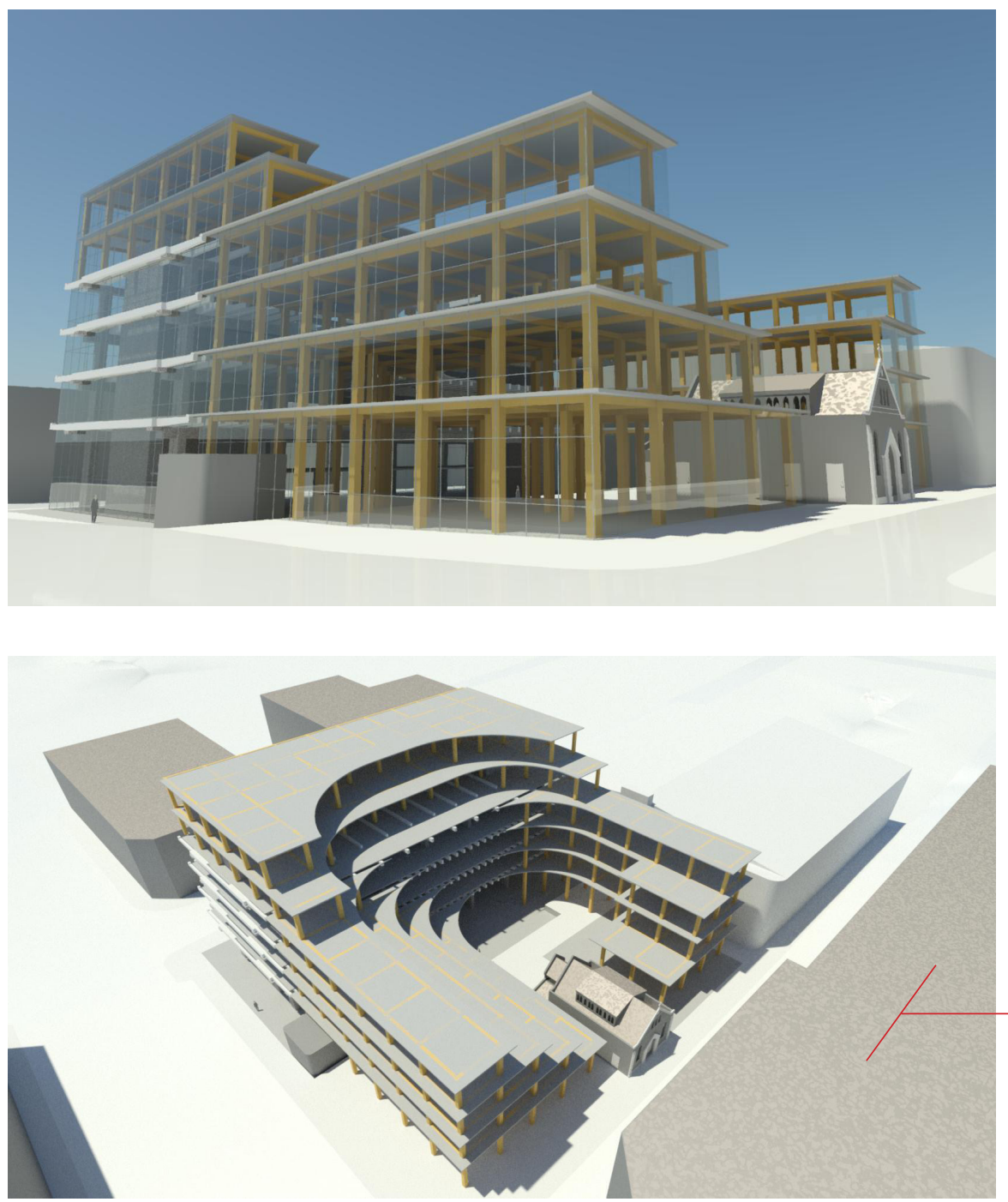

Croxley Mills \& Marickian Apartments

Figure 84: Exploration of terracing the floor plates and focussing on the Mission Hall. 


\section{6}

\section{PRELIMINARY WORKSPACE DESIGN}

It became clear that the workspaces themselves needed to be considered in the preliminary design process, rather than letting interaction solely guide the arrangement of the building. To do this, a concept brief was developed to explore what kind of workspaces would need to be provided. As this was still early in the design process, the brief was simple, having the objective of cohabiting start-ups, established businesses and freelance/remote-workers in one coworking complex. This decision to design a coworking facility that houses different sizes of teams reflects the findings present in chapter 3 , which shows that these spaces are likely to grow in relevance. The goal of this was to see how businesses and coworkers could work together, with the architecture of the preliminary design encouraging interaction between the disparate groups.

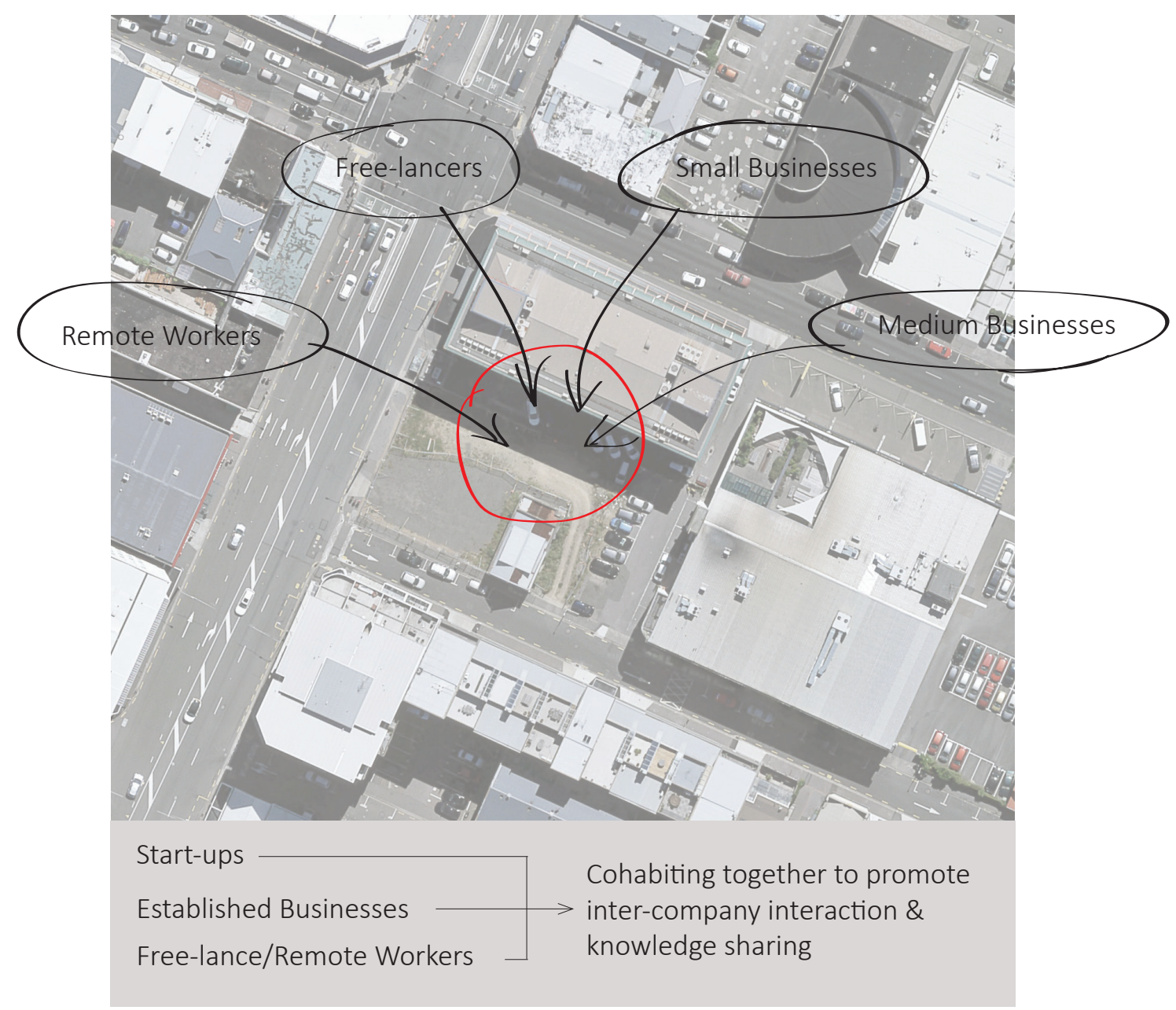

Figure 85: Diagram representing the concept brief that was developed. 
To accomplish this goal of housing different teams and encouraging interaction between them, a similar approach to UN City, the B:Hive and The Edge was used, with the central atrium serving as a hub for social interaction. The concept design that was developed revolves around having core team spaces that are connected into shared social spaces, with these all being connected to the larger central atrium (figure 87).

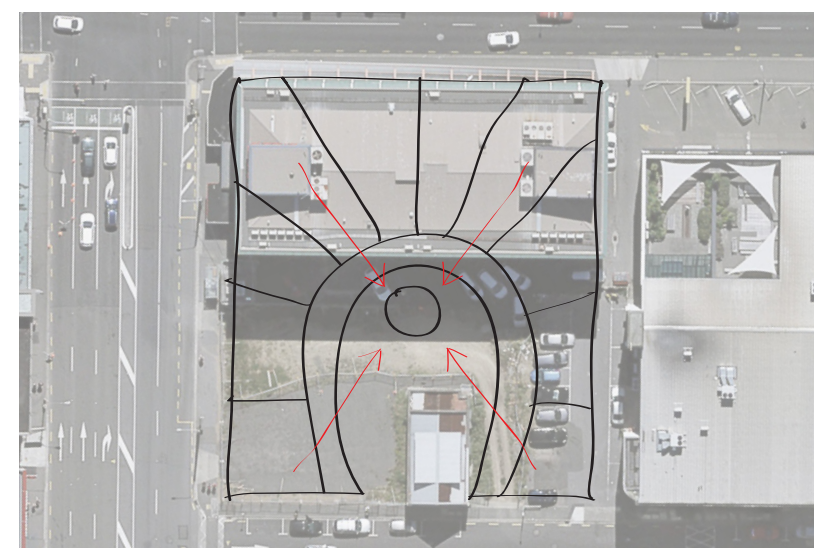

Figure 86: Initial sketch showing the focus on the central atrium.
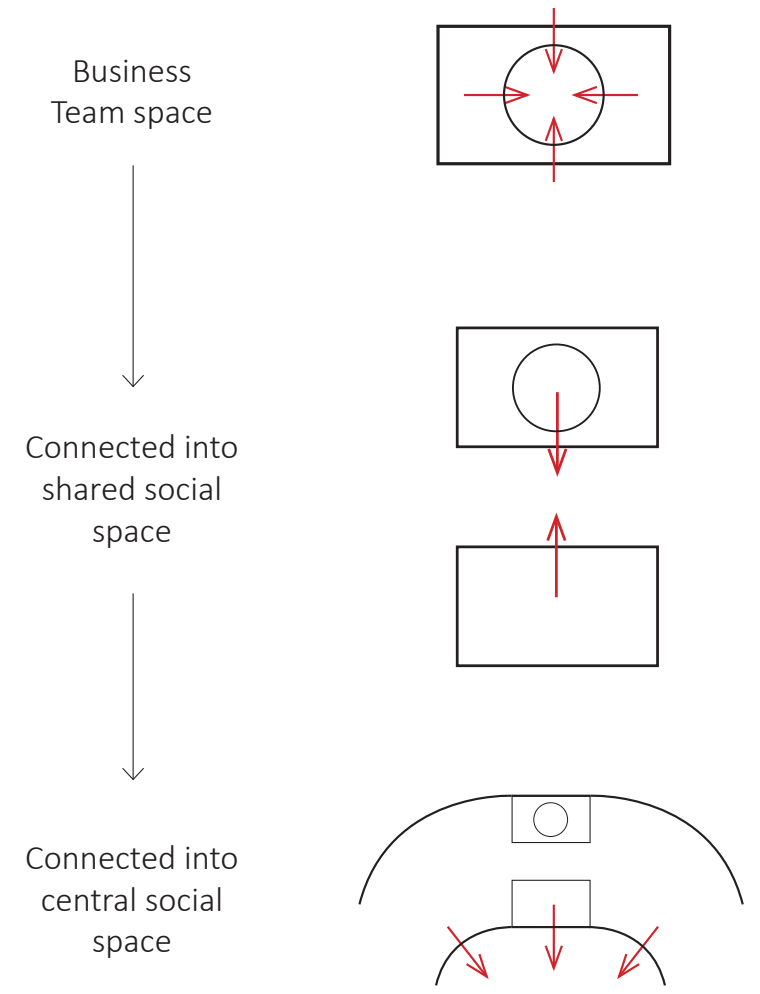

Figure 87: Diagram showing the relationship between team spaces and the connecting social spaces 
The other key drivers were also considered in this concept design. The approach used by NBBJ in The Spheres of incorporating an abundance of nature to aid user wellbeing was explored. Images of native New Zealand forest were collaged onto a sketch model (figure 88). The visual effect of this was significant, making the space much more aesthetically pleasing and as visible nature has beneficial psychological effects, presumably it would help with workers' wellbeing.

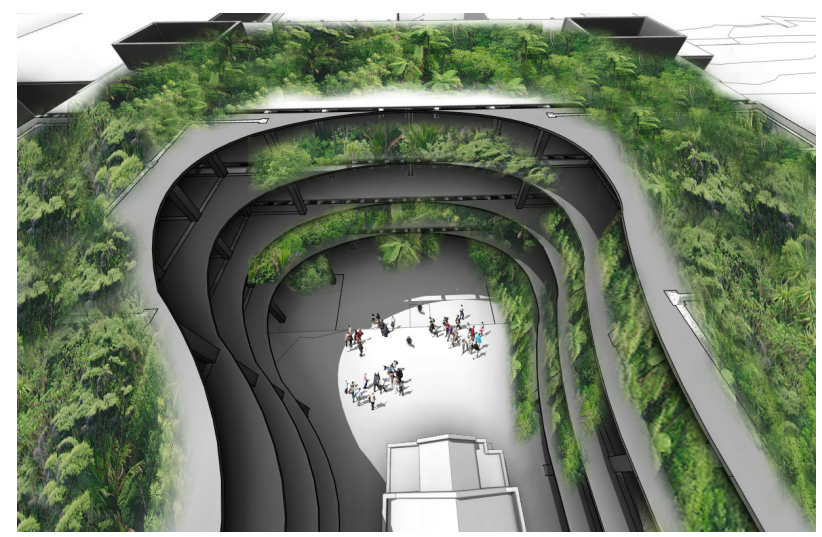

Figure 88: Collage of native NZ forest onto a previous sketch model.

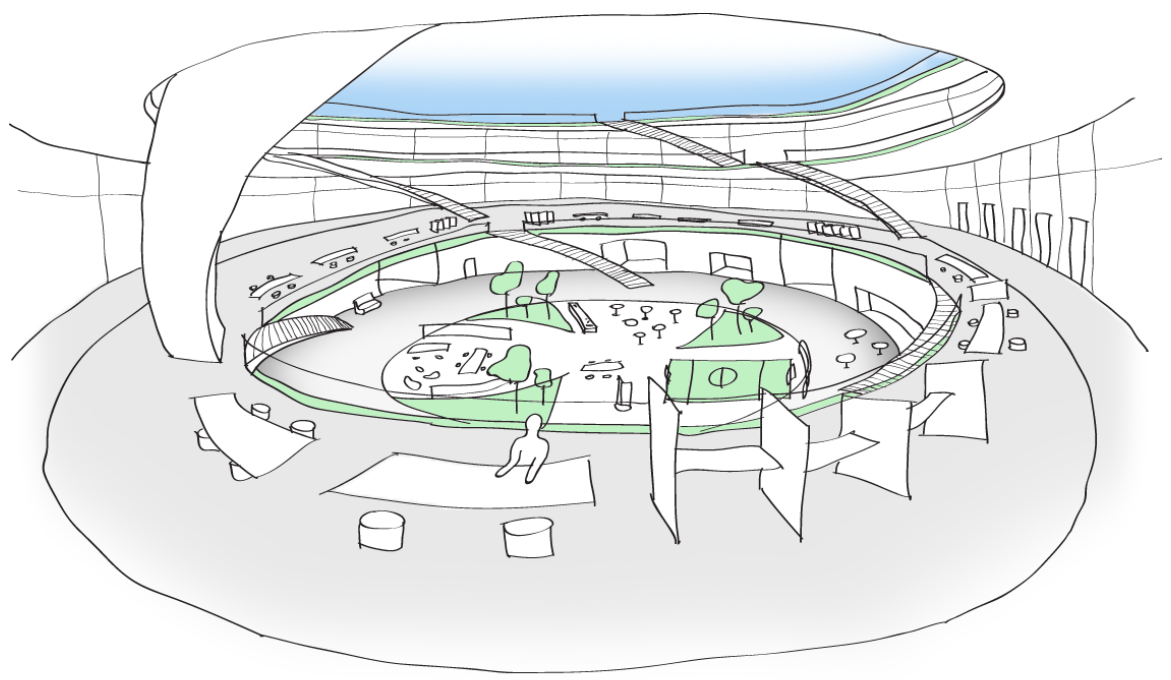

Figure 89: Conceptual sketch of how the connected central atrium might look. The key drivers being explored here are interaction and user wellbeing. 
The resulting preliminary design responds to the key drivers of interaction, user wellbeing and flexibility. Technology was considered but as seen in the incorporation of technology in The Edge (section 4.1), this usually takes the form of a digital layer that is added to the building. It was too early in the design process to do this effectively. The design consists of a team space, which opens out onto a social space that is shared with a co-working space. These all border the core social space (figure 92). This would allow for the slow refreshing of new workers outside of team spaces, which because of the social spaces that they share, could result in more informal interactions with a continually varied group of people.

The design would also have personalisable doors that could be decorated, allowing businesses to curate their own spaces, potentially using it to draw in the right kind of coworkers (figure 90). If a business is larger than one team space, multiple spaces could be used, potentially creating distinct business areas (figure 91).

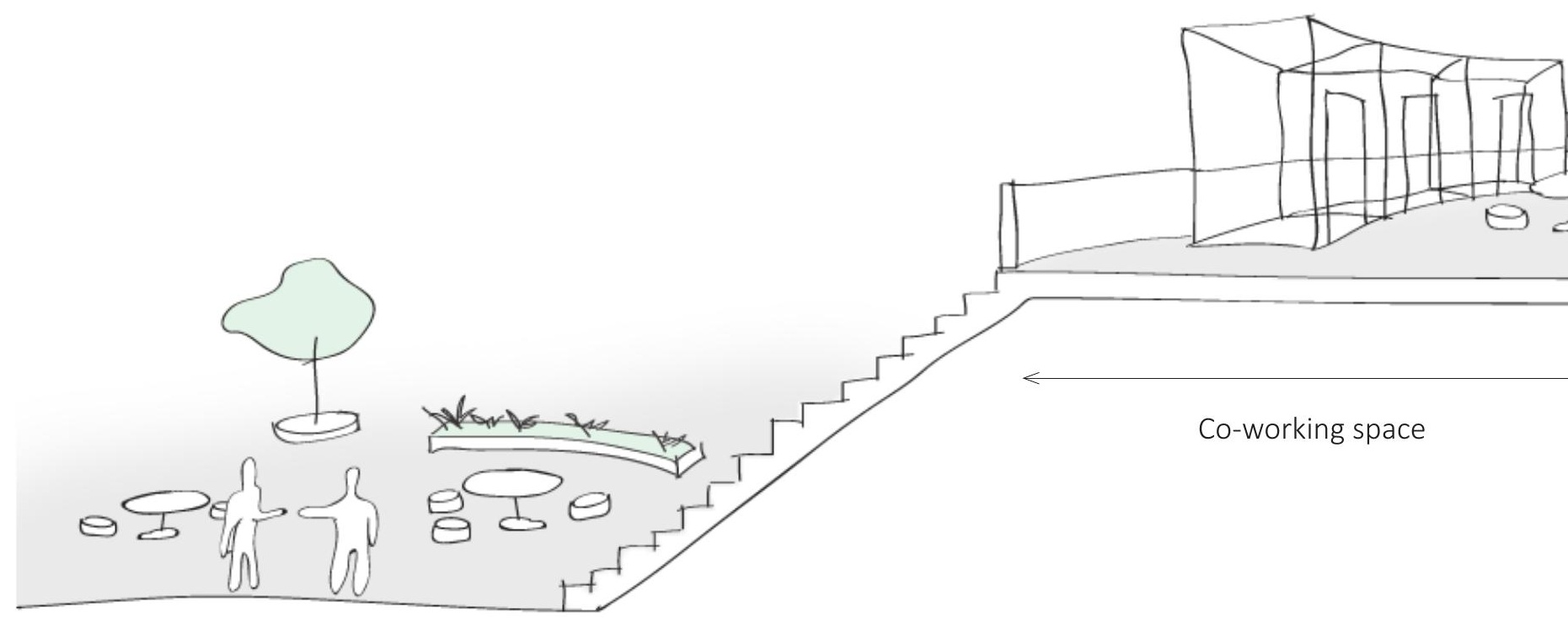

Core Social Space 

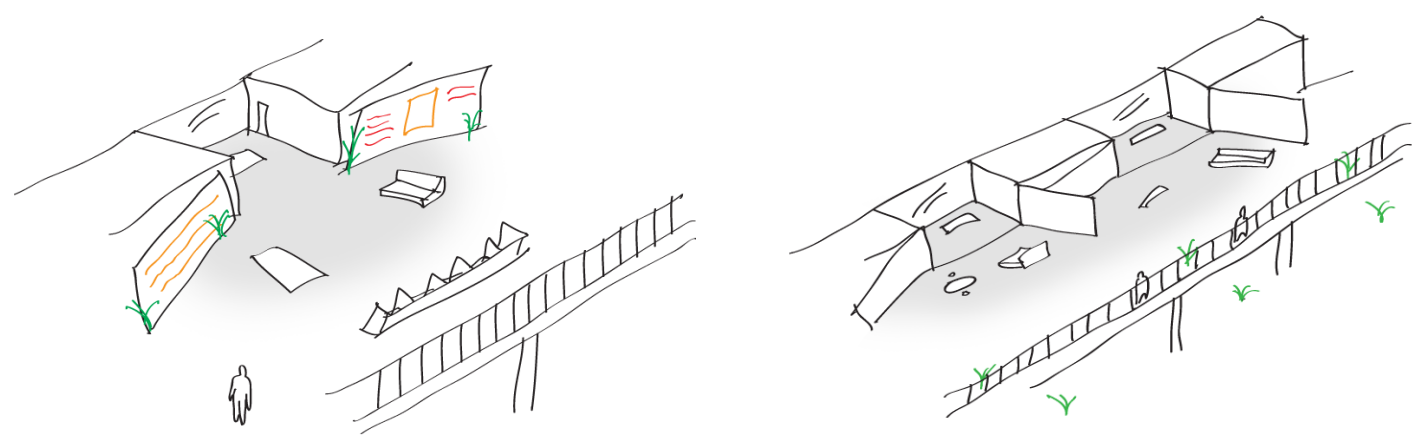

Figure 90 (left) \& 91 (right): Illustrations of personalisable doors and multiple team spaces.

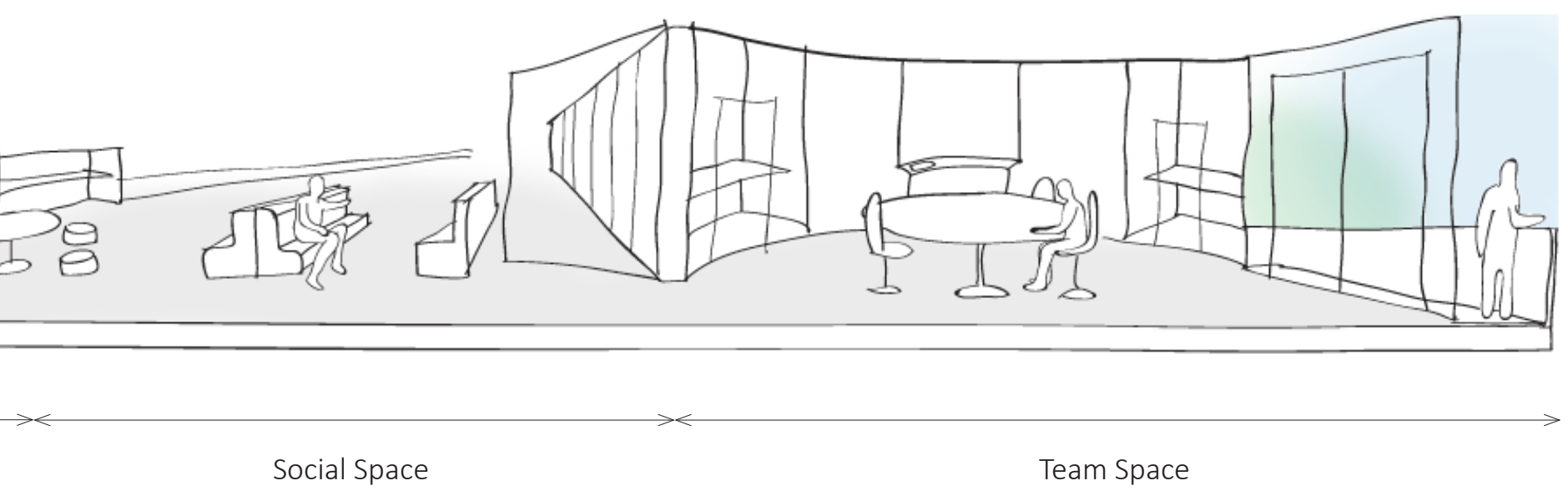

Figure 92: Sketch showing the progression from team spaces to coworking spaces, then to the core social space. 
The team spaces themselves consist of a six person central table that is flanked by private work booths. Six was chosen as the team size as this number falls within the range of what is considered optimal for decision making (Aubé et al., 2011). Other sources also hover around this number, with the 'rule of seven' being touted as ideal for team size (Blenko et al., 2010). The team spaces also have a small kitchenette and an outdoor area, as well as backing onto the informal social space (figure 94).

The idea behind this kind of workspace came from the core needs of the worker that were identified in section 2.7, with those being privacy, communication and choice (figure 93). Workers can choose to work in their team space, or in the work booths. They could also choose any workspace around the building if they wanted. The personalisable doors are included to counteract the lack of personalisation inherent in activity-based working. Flexibility was also considered, with the privacy booths being movable to suite different configurations (figure 95).

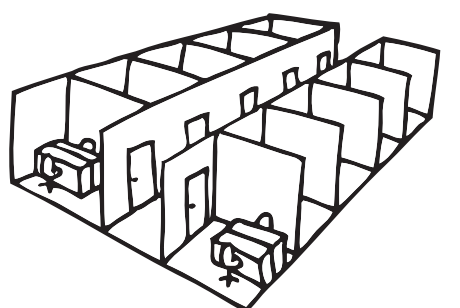

Open Plan Offices

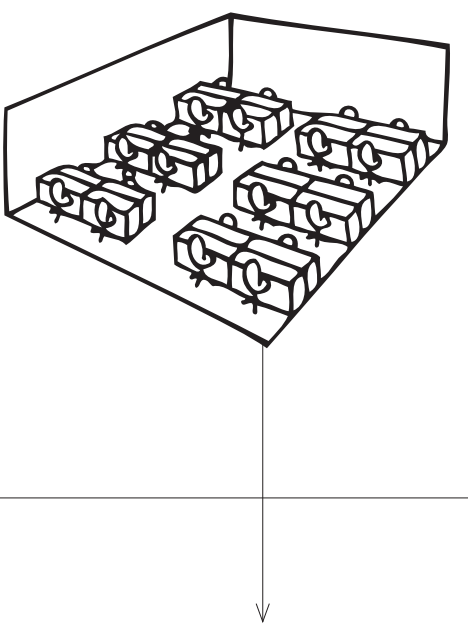

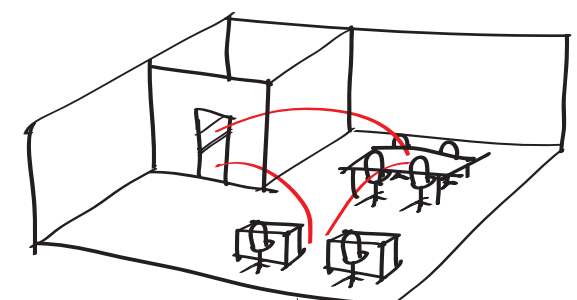

\section{Privacy + Communication + Choice}

Figure 93: Diagram summarising the core needs of the worker, as discussed in section 2.7. 


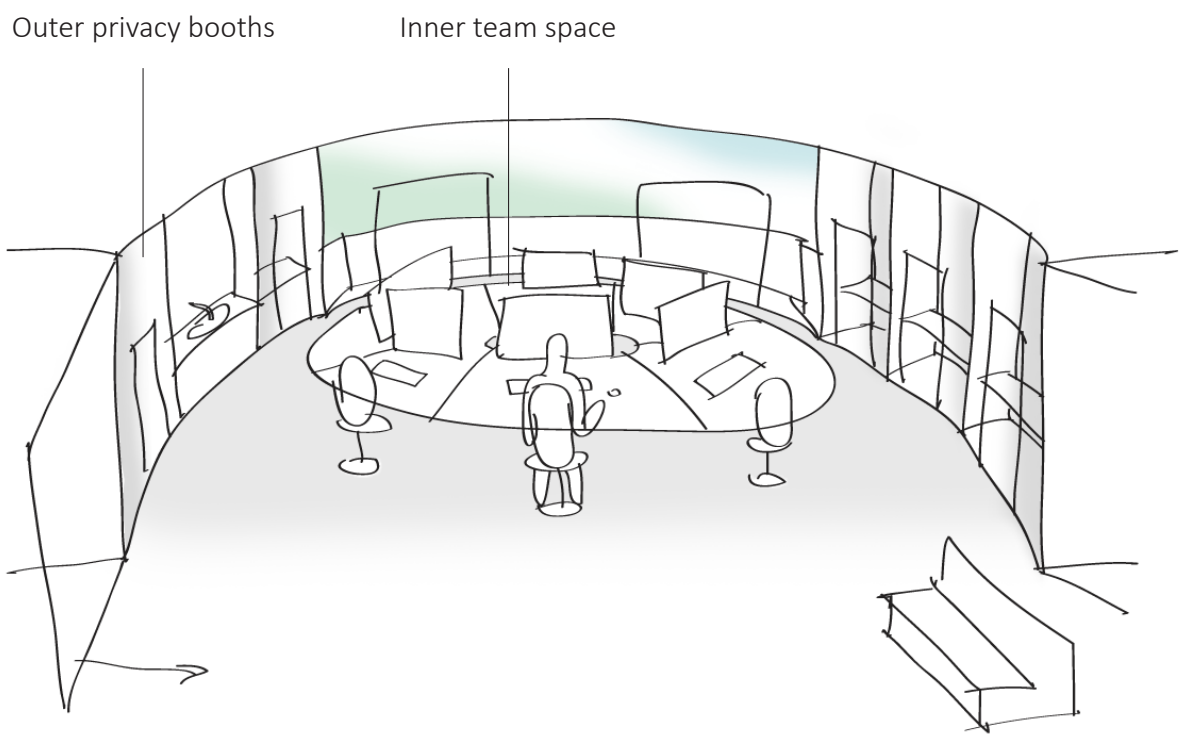

Figure 94: View of team space, which backs onto the social space.
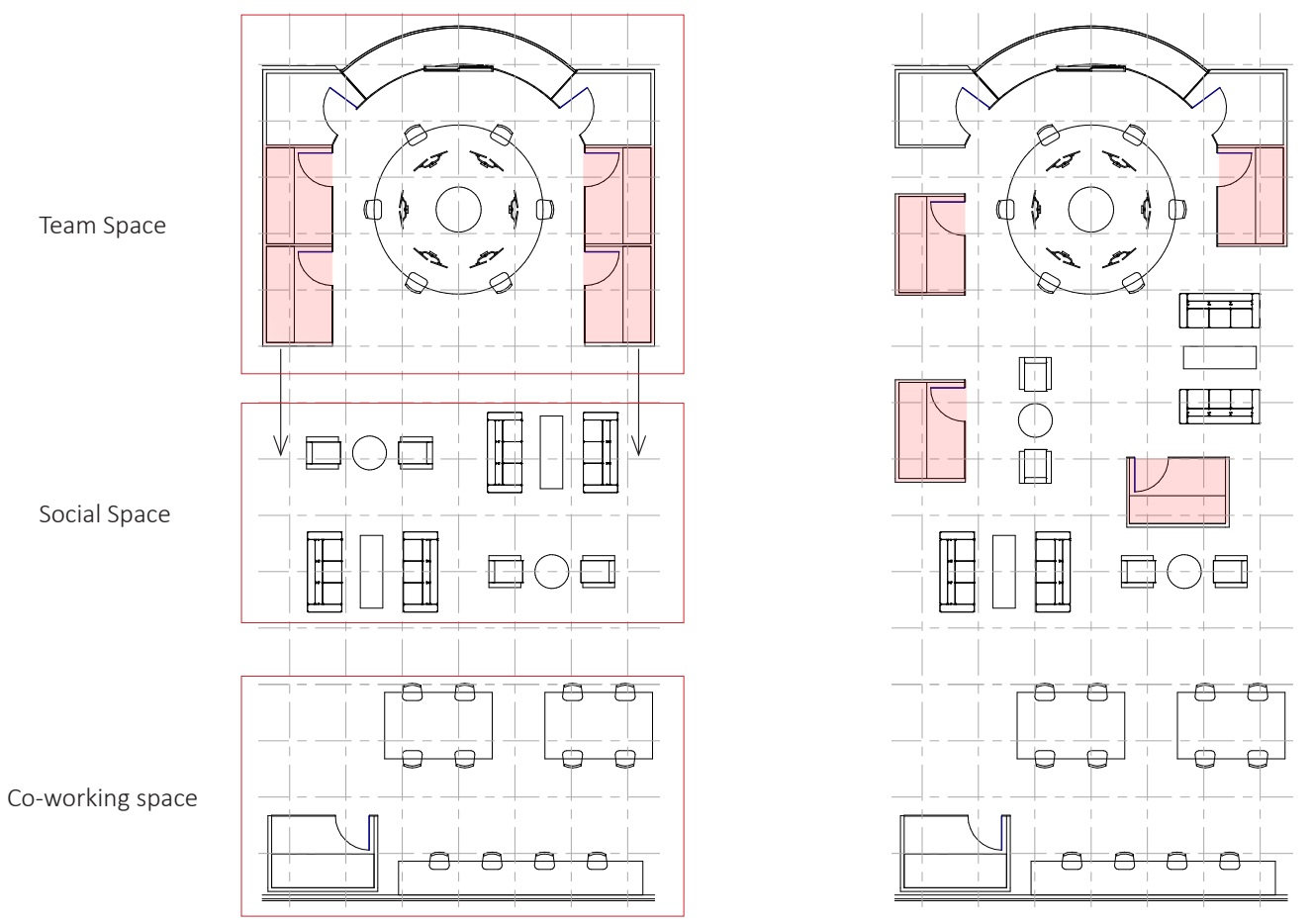

Figure 95: Plan of team, social and coworking spaces, showing how the privacy booths can be rearranged 


\section{7}

\section{PRELIMINARY DESIGN REFLECTION}

The resulting concept design integrates quite well the different considerations of the key drivers and the core needs of the worker of privacy, communication and choice. However, the more functional aspects of the scheme were much too vague, with also the resulting images being not too far of a departure from current workplace design. To satisfy the objective of exploring what the future of workspaces might be, the design had to be pushed further. This meant examining how better to consider the key drivers and the opportunities present on the site.

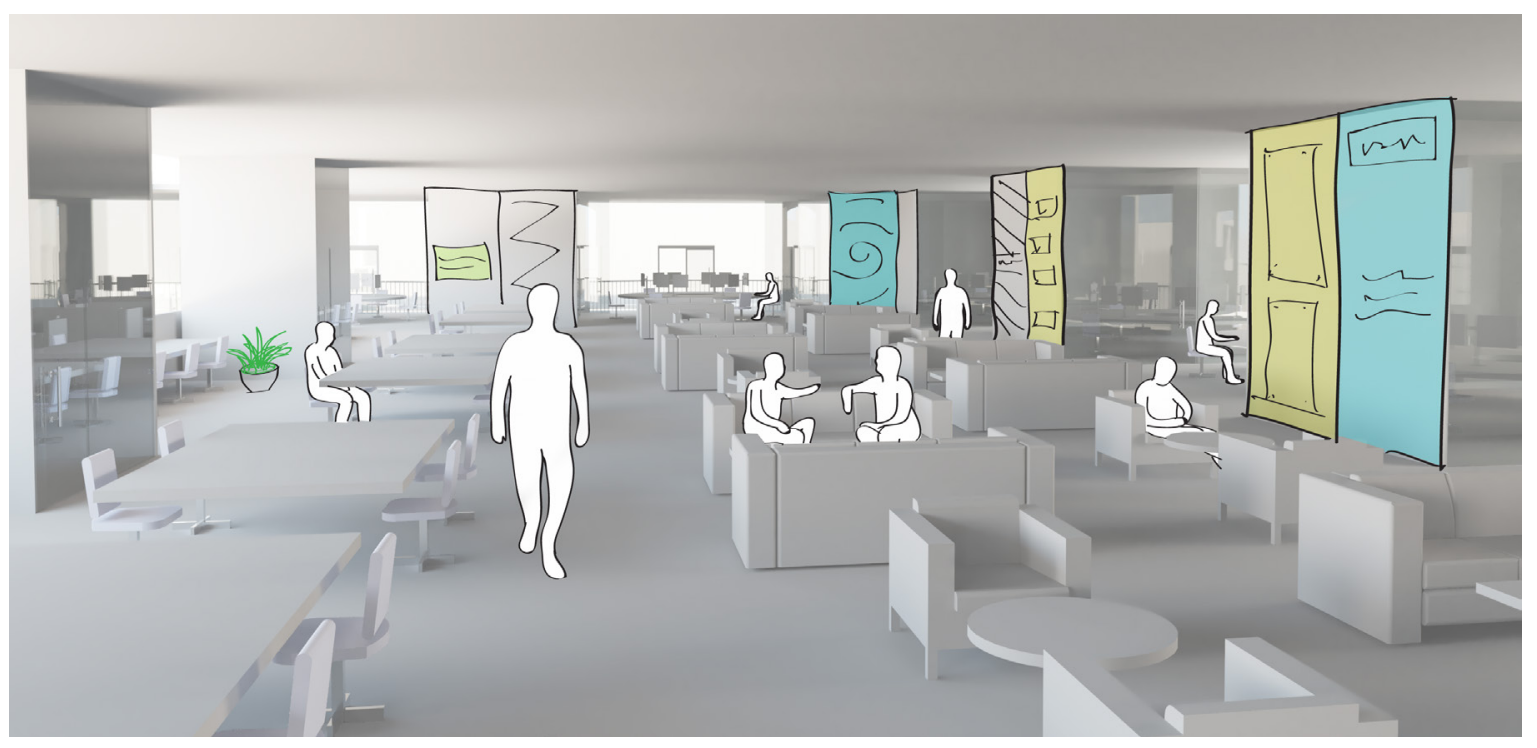

Figure 96: Render and collage of the social space, showing the mixing of teams and coworkers. It also shows the personalisable door panels. 

DEVELOPED DESIGN

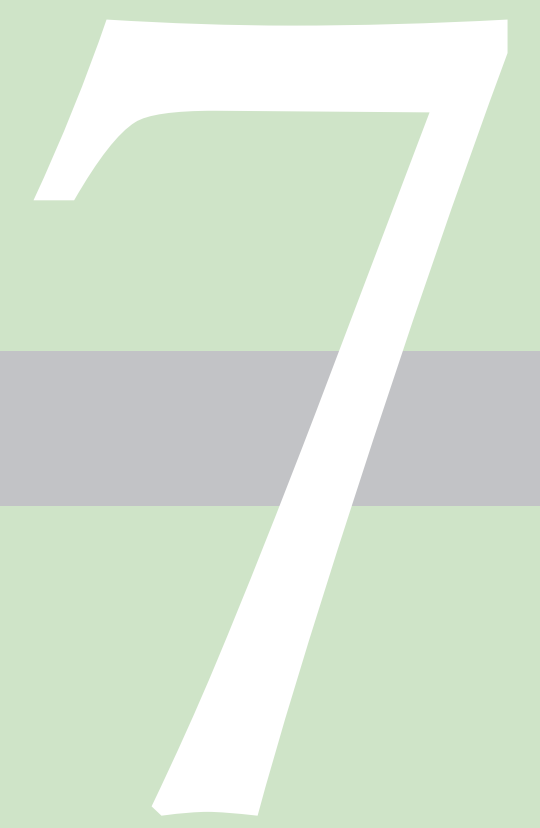


7.0

INTRODUCTION

This chapter builds upon what was learnt from the preliminary design phase, taking note of the successes and shortcomings of the initial conceptual design. This chapter details how the consideration of the key drivers and the findings from the literature were incorporated alongside the functional requirements of a coworking space. The goal of this was to create a speculative developed design that conveys how the future of work spaces might evolve for the city of Wellington. 

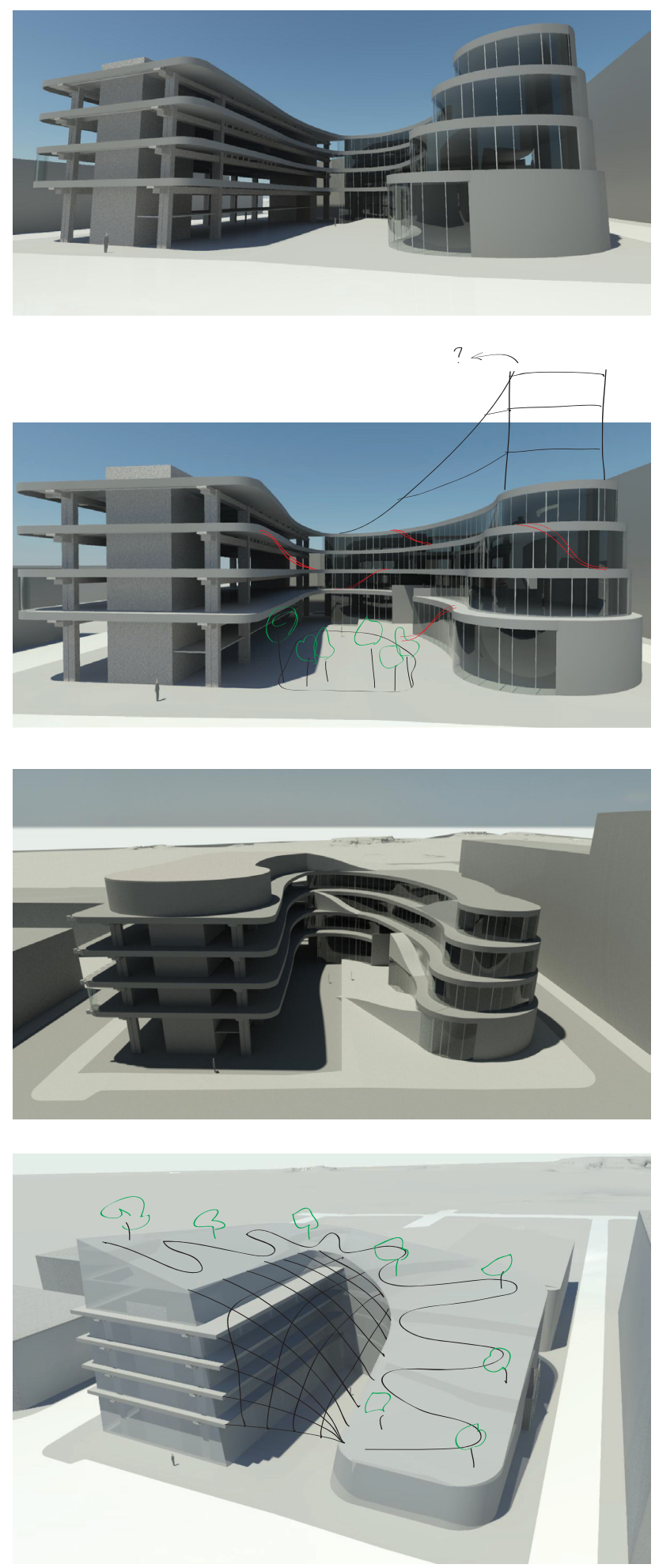

Figure 97: Series of sketch designs that show the testing of organic forms, leading to the idea of a flowing rooftop garden to aid in user well-being. 


\section{1}

\section{Site ARRANGement}

The preliminary design section explored different on-site configurations and the incorporation of key drivers in the design of a workspace. Reflecting on the results, it was observed that the key drivers could be pushed further, being expressed more in different aspects of the design. Interaction was mostly used as the metric from which the arrangement of the building was tested. Through a series of design experiments, user wellbeing was also used a driver (figure 97). For this research, the way an intervention is considered to aid in user well-being is if its intended purpose is to reduce the amount of stress and fatigue experienced by the worker. As seen in section 4.1, this can take the form of the inclusion of gyms, cafes and social spaces. Plants and organic shapes also fulfil this requirement, due to the presence of nature and natural forms having "positive effects on health and well-being" (Grinde \& Patil, 2009).

With this in mind, the idea of having a flowing design that supported a hill-like walking track and garden was tested. The resulting sketch designs also faced Taranaki Street, as in the previous chapter this was seen to have the advantage of catching the eye of a greater amount of passers-by. As these were exploratory in nature, the functional aspects of the workplace were not prioritised. 


\section{2}

\section{FUNCTIONAL CONSIDERATIONS}

Having explored how to incorporate more of the key drivers in the arrangement of the building, a review of the functional requirements needed in the speculative future workplace was undertaken. As discussed in section 6.6, coworking was chosen as the type of complex required. Shown in the context analysis chapter, the community surrounding 123 Taranaki Street is primarily creative, with Wellington as a city growing in the digital and creative media sectors. Due to this, these knowledge-based creative companies became the target users for the design, as well as freelancers and remote workers; as these groups were identified in chapter 3 as likely to grow in prominence in the future.

A brief was developed to specify the functional and spatial requirements needed (figure 98). The goal of this brief was to design a creative media headquarters that brings together the disparate businesses and coworking groups around 123 Taranaki Street. The key drivers also informed the brief, with user wellbeing being considered through the inclusion of green space and cafes/restaurants. The integration of technology was also considered through the inclusion of a holoportation space and virtual reality workstations.

$\begin{array}{ll}\text { General Requirements: } & \\ -\sim 9,000 \text { sqm (like the B:Hive and other developments) } & \\ \text { - Promotes informal interaction and allows for worker autonomy } \\ \\ \text { Spatial Requirements: } & \\ \text {-75\% businesses, 6-49 workers per business } & \sim 6750 \text { sqm } \\ \text {-25\% coworkers } & \sim 2250 \mathrm{sqm} \\ \text {-1 Makers' space/workshop } & \sim 650 \mathrm{sqm} \\ \text {-1 Restaurant/Bar } & \sim 260 \mathrm{sqm} \\ \text {-1-2 Cafes } & \sim 120 \mathrm{sqm} \\ \text {-1 Prominent Green Space } & - \text { Rooftop area } \\ \text {-1 Retail or Pop-up Space } & \sim 150 \mathrm{sqm} \\ \text {-1 Presentation/Conference Space } & \sim 350 \mathrm{~m}^{2} \\ \text {-1 Holoportation Space + VR workstations } & \sim 60 \mathrm{~m}^{2}\end{array}$

Figure 98: The developed brief that considers the funtional and spatial requirements of the proposed future workplace. 
A review of the workspaces currently being used by the different businesses that the brief targets was also undertaken. What was found was that the offices of the different creative businesses are quite similar in their motivations, with these being to create an open space that allows for easy reorganisation and team communication (figure 99). This aligns with what start-ups require, with coworking spaces also being designed around this. A noteworthy characteristic of coworking spaces is the range of different workspaces available, offering users' variety.
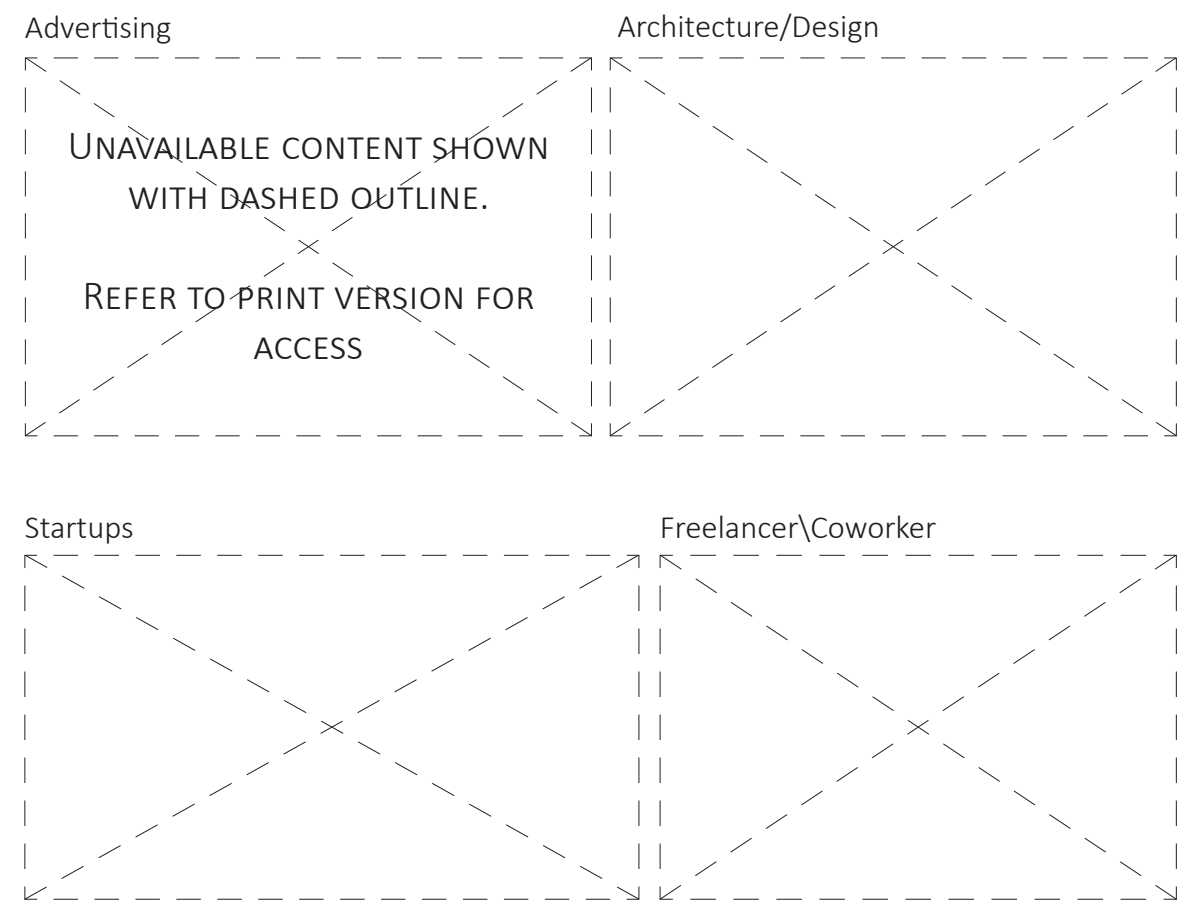

Figure 99: Examples of different Wellington workspaces of different businesses and groups. 
Using the module of the team space that was developed during preliminary design, an arrangement was created that consolidated the functional requirements of the brief, and the spatial arrangement that was developed in section 7.1 (figure 100). What was learnt from this was that the arrangement needed adjusting, with it being observed that not many workspaces would fit into the half of the building that occupies the empty site.

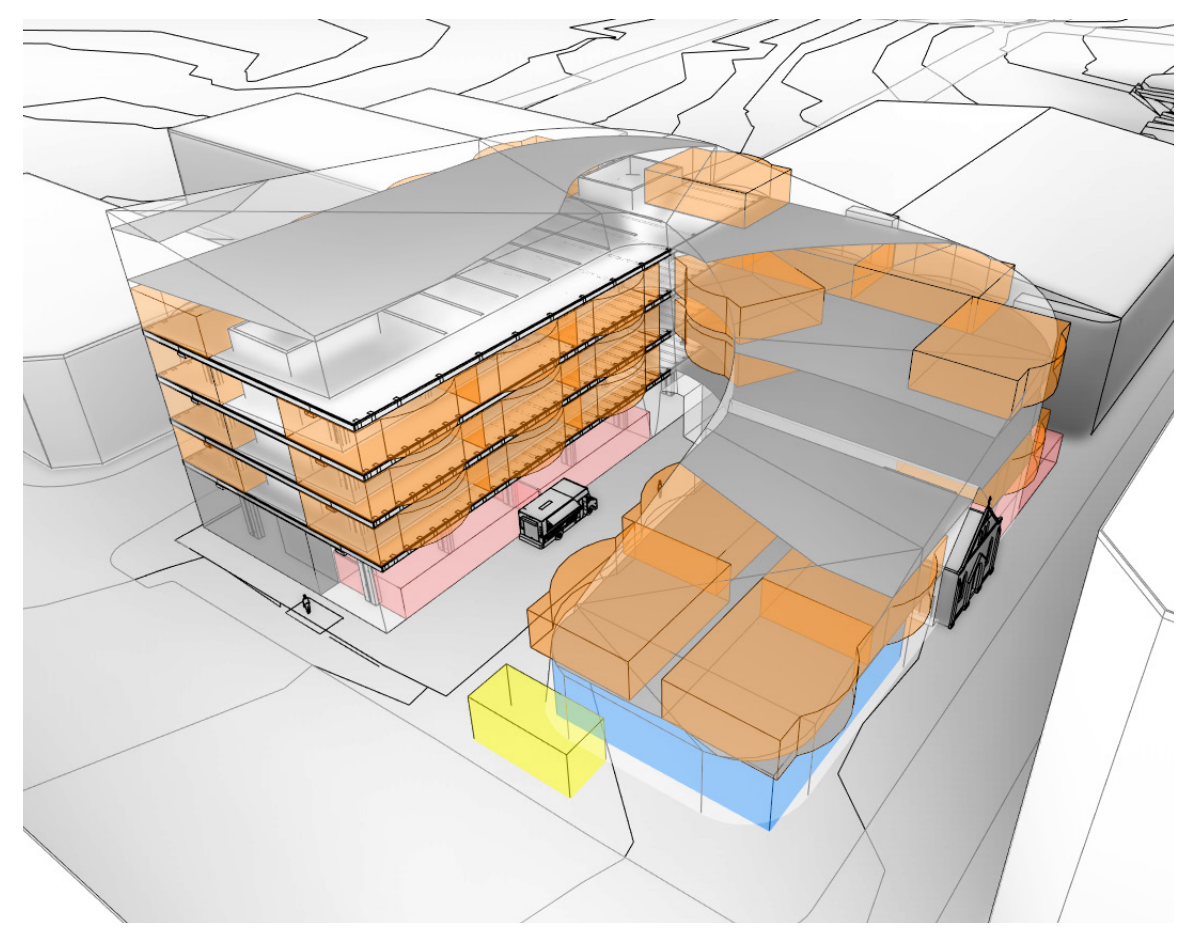

Figure 100: Arrangment of functional requirements in spatial arrangement. Orange masses represent the team space module, red is retail space, and blue is a restaurant. The yellow is a repurposed bus stop, but this did not get carried through into the rest of the design. 
Adjusting the massing of the building allowed for more workspaces to be located in the newer part of the building, whilst also negating the negative sun shading effects that would have been caused by having the northern side of building at the previous height.

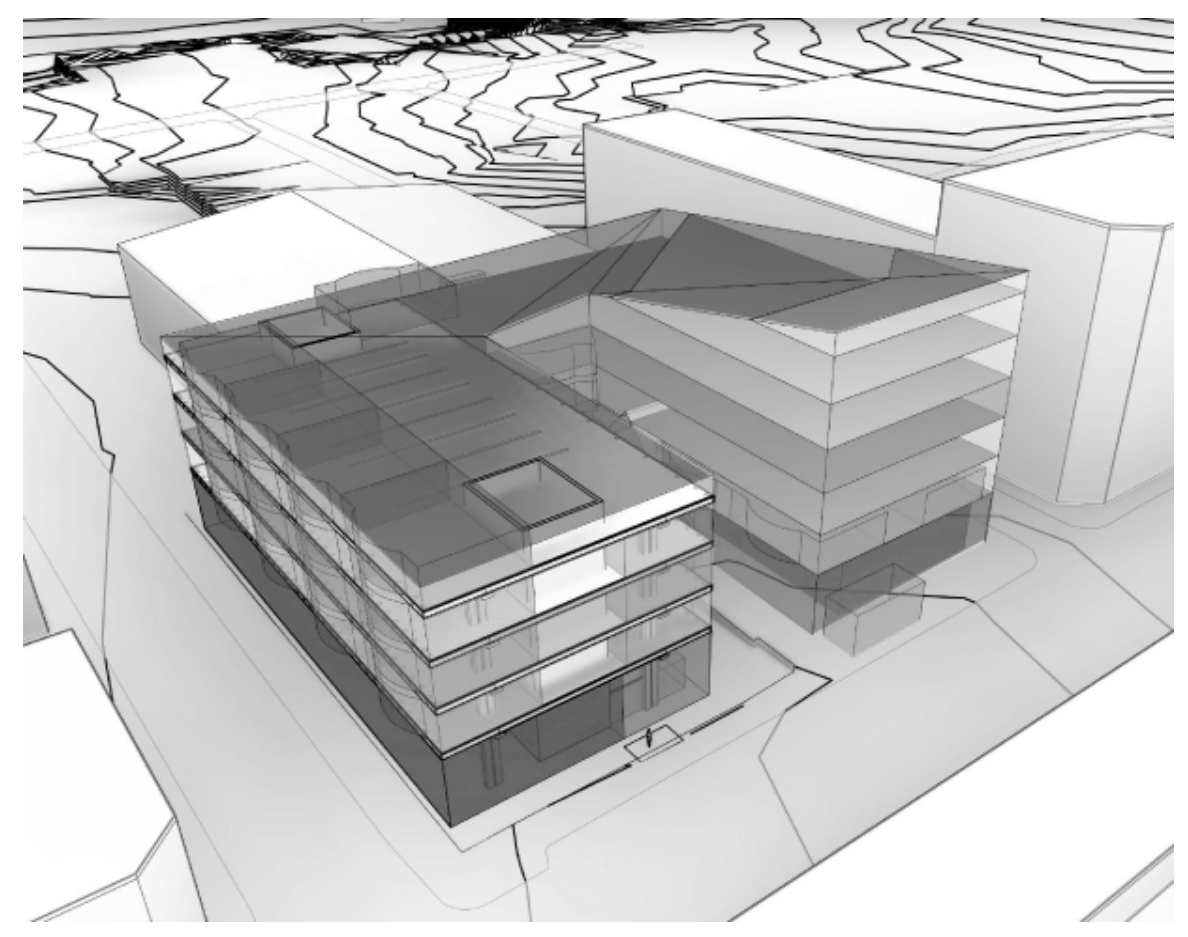

Figure 101. Simple mass model showing the adjusted arrangement. 


\section{3}

\section{FUNCTIONAL DEVELOPMENT}

Having altered the arrangement of the building to take better advantage of the sun and the empty site, another exploration was carried out of how the key drivers could be integrated further into the design. Drawing, rendering and collaging was used to create visualisations of how the different spaces around the building would operate. The consideration of respecting the heritage of the Mission Hall led to the idea of having an 8 metre-high space that acts as the central social/conference space of the building (figure 102). The central atrium space has a flowing stair that curves around the atrium, having meeting rooms attached to the side of it, so when informal interactions do occur, the stair is not blocked (figure 103). Flexibility was considered through the incorporation of a variety of spaces, having both open coworking floors as well as banks of cellular workstations.

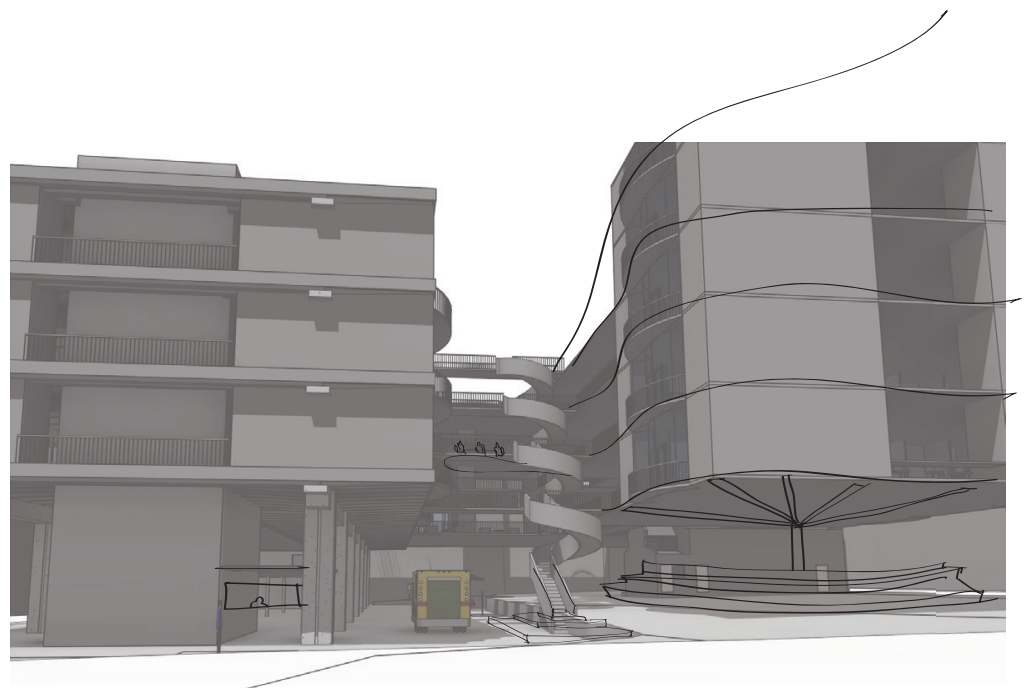

Figure 102: Sketch that led to the idea of having a 8m-high space that houses the Mission Hall.

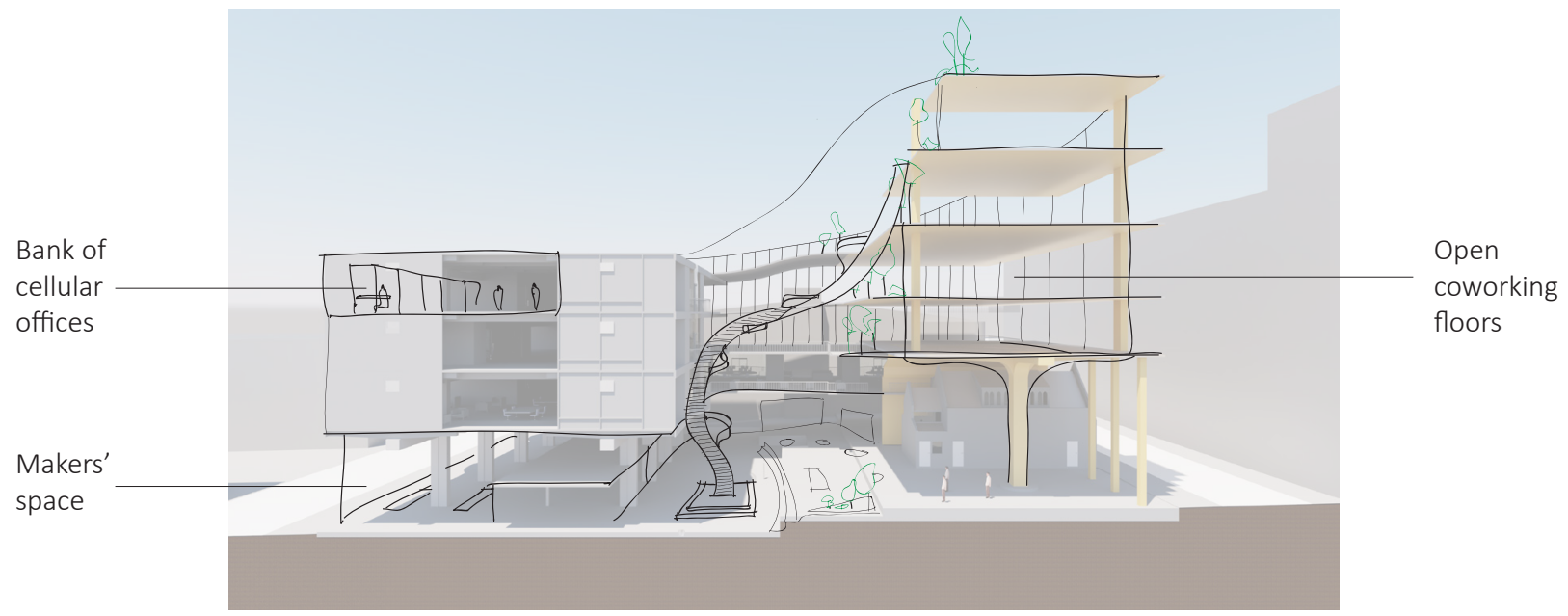

Figure 103: Visualisation of how the variety of workspaces could work. 


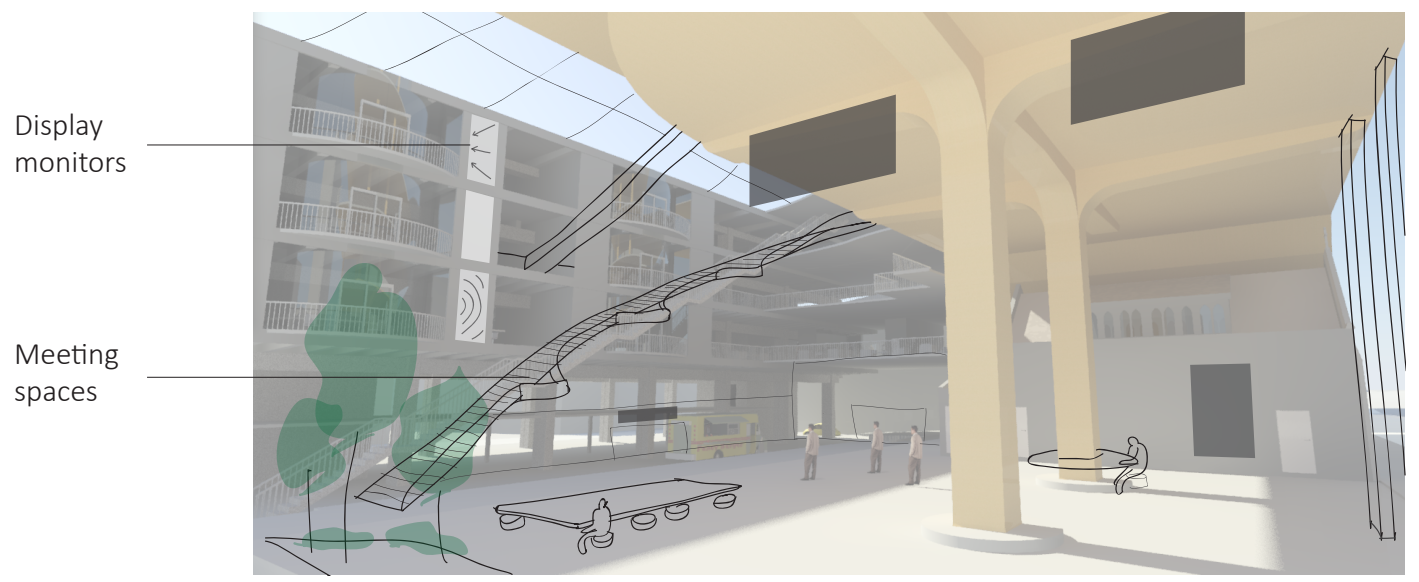

Figure 104: View of social/conference space.

Technology was incorporated through the inclusion of monitors and screens throughout the atrium, which is a digital reinterpretation of the personalisable door panels that were developed in the preliminary design (figure 104). Workers could display their work, upcoming events, or general information to the other inhabitants of the complex. User wellbeing was also considered through the incorporation of plants, user amenities such as cafes, and the large rooftop garden (figure 105).

Upon reflecting on this design, it was observed that it successfully incorporated the key drivers through a variety of interventions. Some needed improving upon however, with the central social/conference space and atrium being much too large and empty, potentially having the opposite effect on encouraging interaction. In discussion with Paul Swift about the design, who formerly ran BizDojo Tory Street, he emphasized that the spaces should be more intimate and personal, with a close-knit community atmosphere being essential in determining the success of a coworking space. To achieve this, it was suggested that the building be slightly scaled back in size.

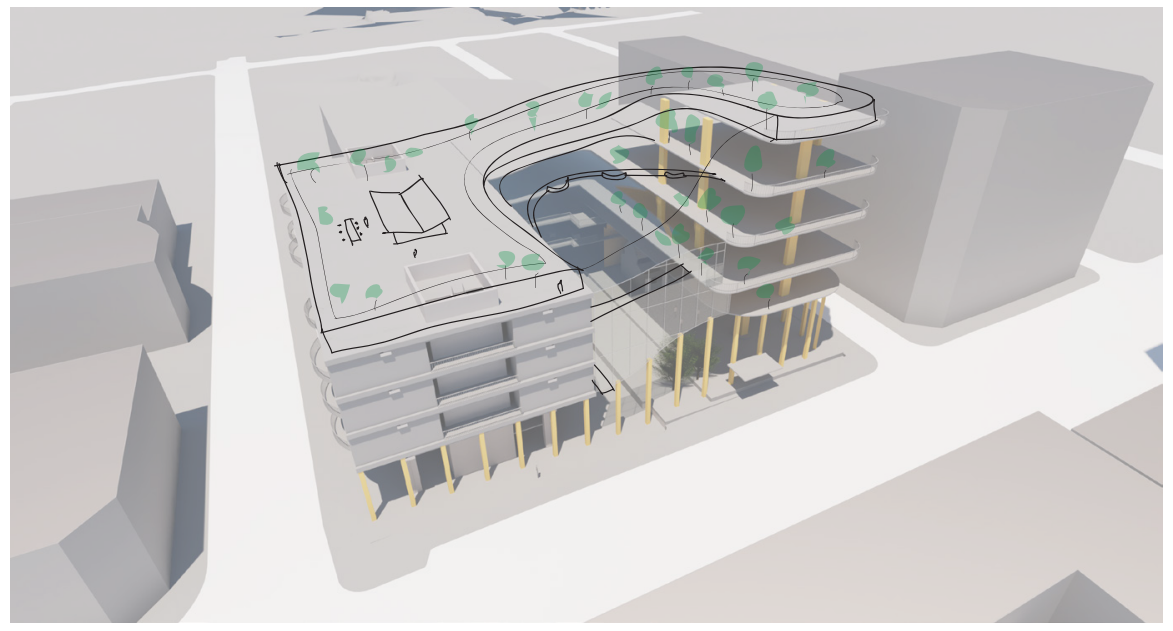

Figure 105: Overview of the design. 


\section{4}

\section{STRUCTURAL DEVELOPMENT}

As seen in the visualisations of the design in the previous section, timber was chosen as the material from which the new portion of the complex would be constructed of. This decision was informed by looking at the recent explosion in the use of laminated timber products in the construction industry both locally and globally. Property investor Sir Bob Jones proposed to build the world's tallest timber office building in Featherston Street in Wellington, taking advantage of New Zealand's substantial forestry industry (Iles, 2018). Although no updates have been given on whether this development will continue, it still shows the belief people have in the material of laminated timber products.

There are also proven psychological benefits of the material, with a 2017 study revealing that touching wood with the palm "calms prefrontal cortex activity" and induces "physiological relaxation" (Ikei et al.). These effects along with timber being anticipated to grow in use around the world, make it align with both the key driver of user wellbeing and the objective of speculating what the future of work spaces might be.

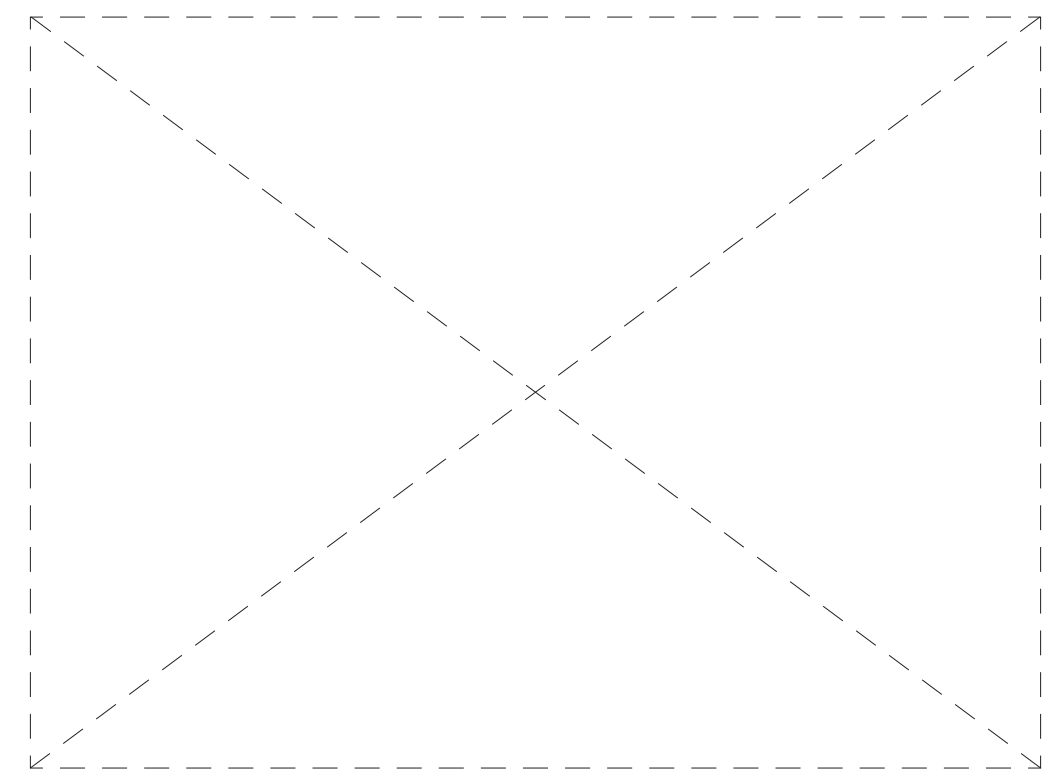

Figure 106: The Nelson Marlborough Institute of Technology, 2011. An early example of how structural timber products are being used in New Zealand (Nelson Pine, 2019). 


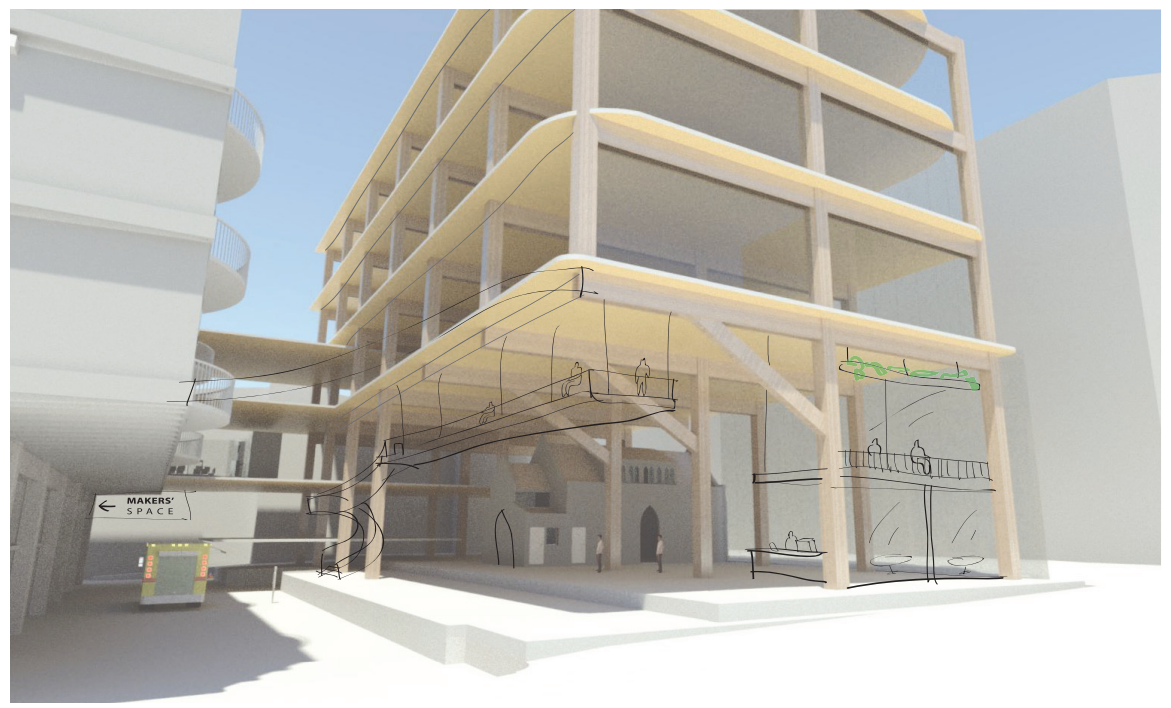

Figure 107: Early sketch testing the opportunities present with the timber structure.

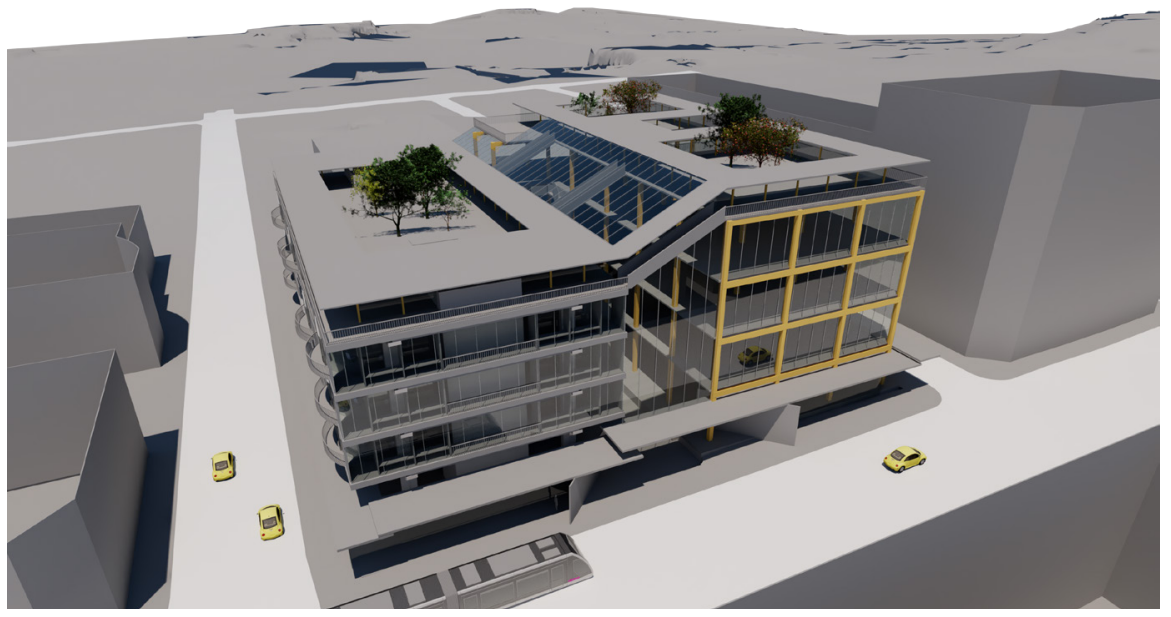

Figure 108: Later model that shows the use of 3 bays, matching the width of 123 Taranaki Street. 


\section{5}

\section{ROOFTOP GARDEN}

From reflecting on the previous design, it became clear that the rooftop garden needed to be condensed down, as the size of the facility also needed reducing. Other outdoor gardens that are incorporated with workspaces were reviewed, with Goodside at the B:Hive standing out as a notable example (figure 109). Using simple timber members to cover the users, an intimate space is created that allows for informal arrangements of seats and tables, as well as the presence of natural foliage. This kind of space became the inspiration for the development of the rooftop garden.

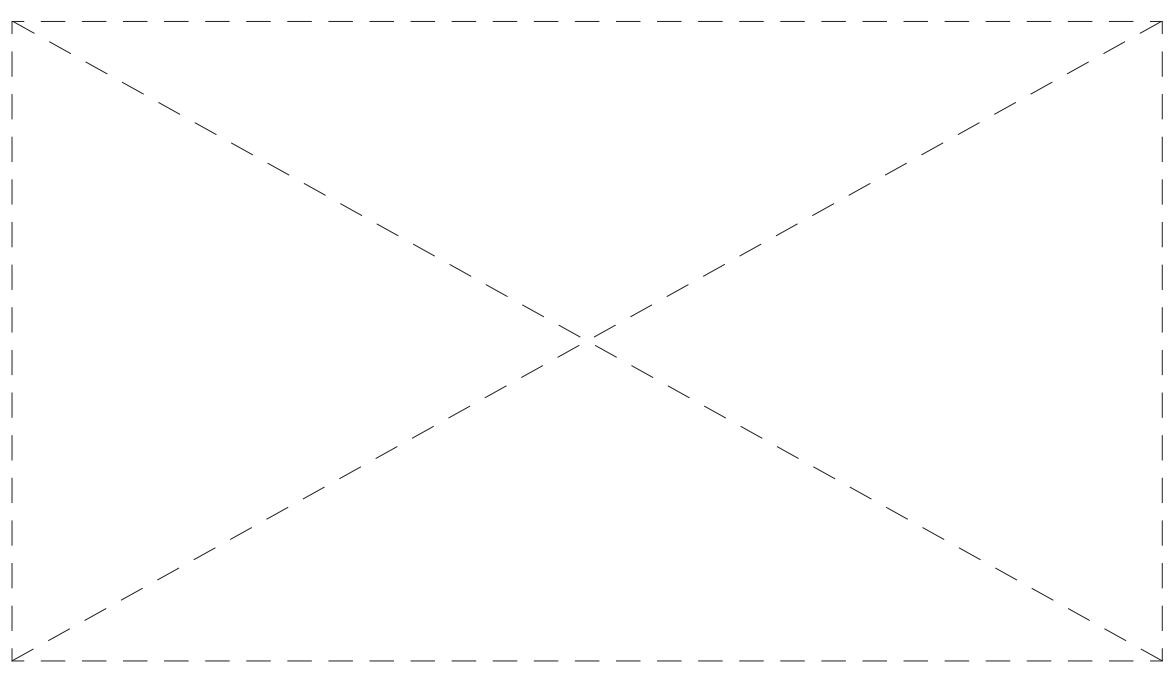

Figure 109: Goodside at the B:Hive, Auckland. (Smales Farm, 2019)

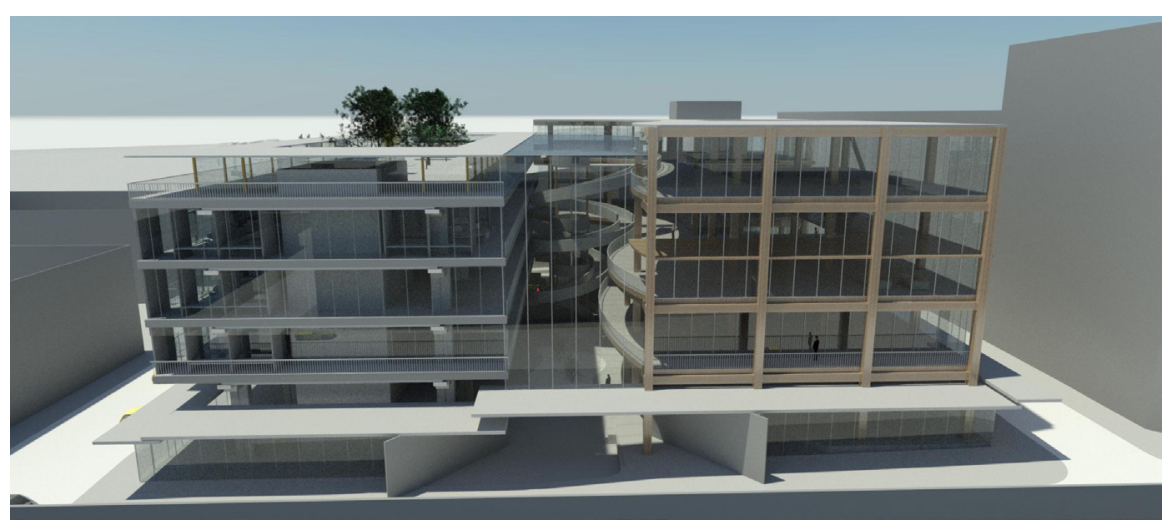

Figure 110: Render showing the removal of the southern roof garden. 


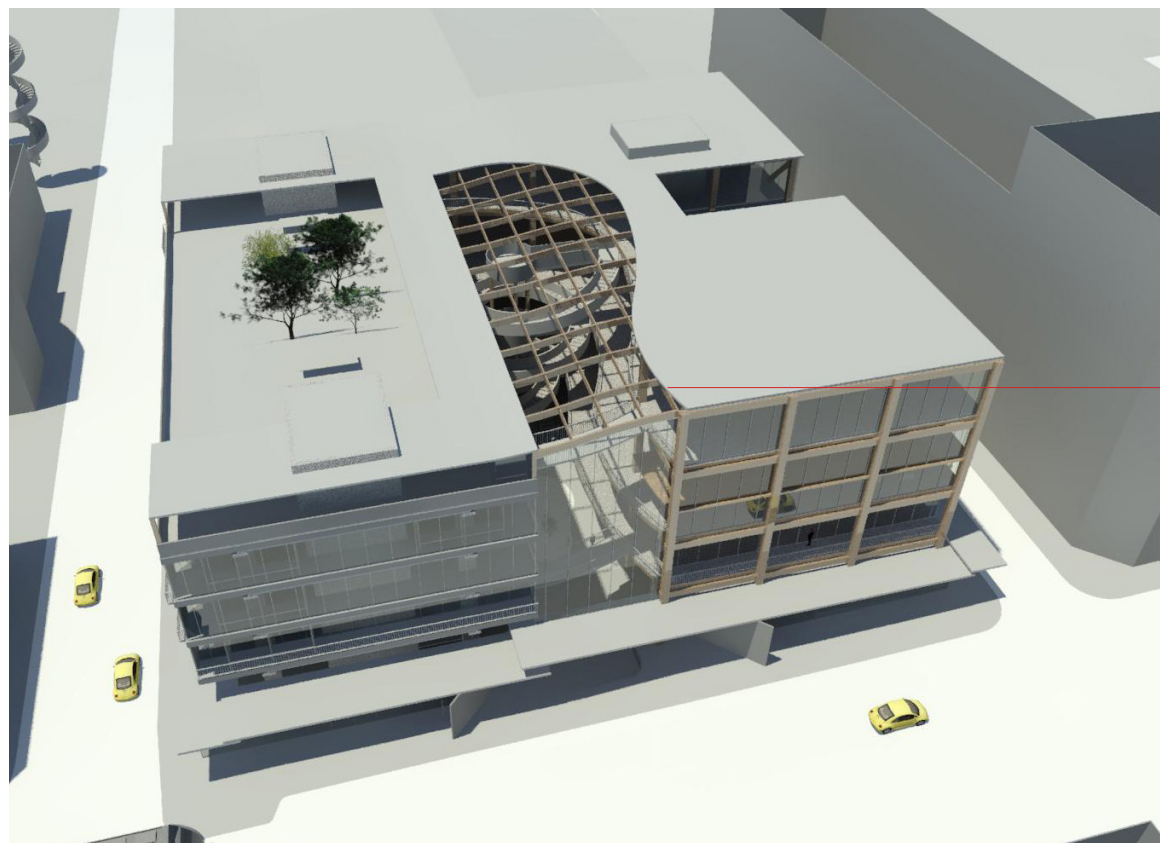

Figure 111: To span the atrium and let in natural sunlight deep into the workspaces, a grid of curved LVL beams were used.

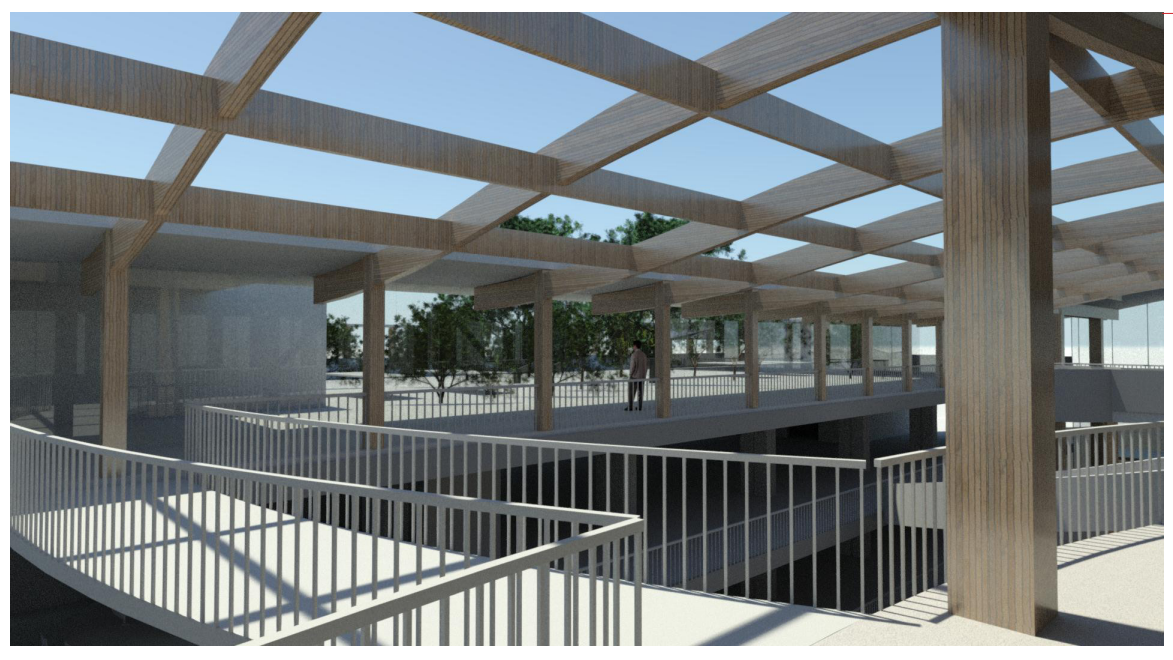

Figure 112: These LVL roof beams also provided a smooth aesthetic transition from the upper workspace to the rooftop garden. 
$0^{N}$

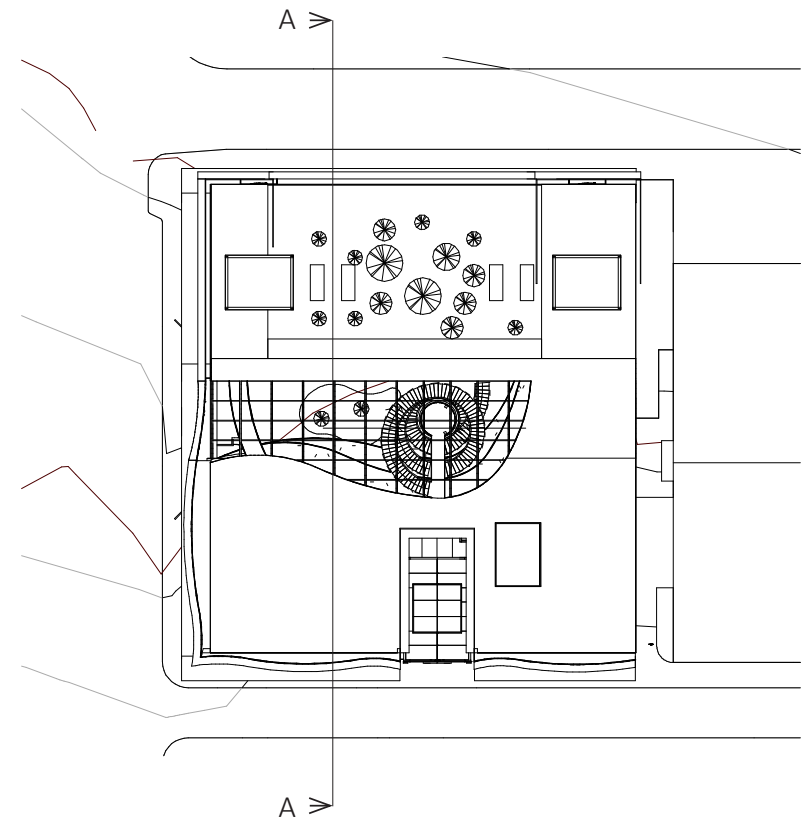

Figure 113: Site plan of developed design, 1:1000.

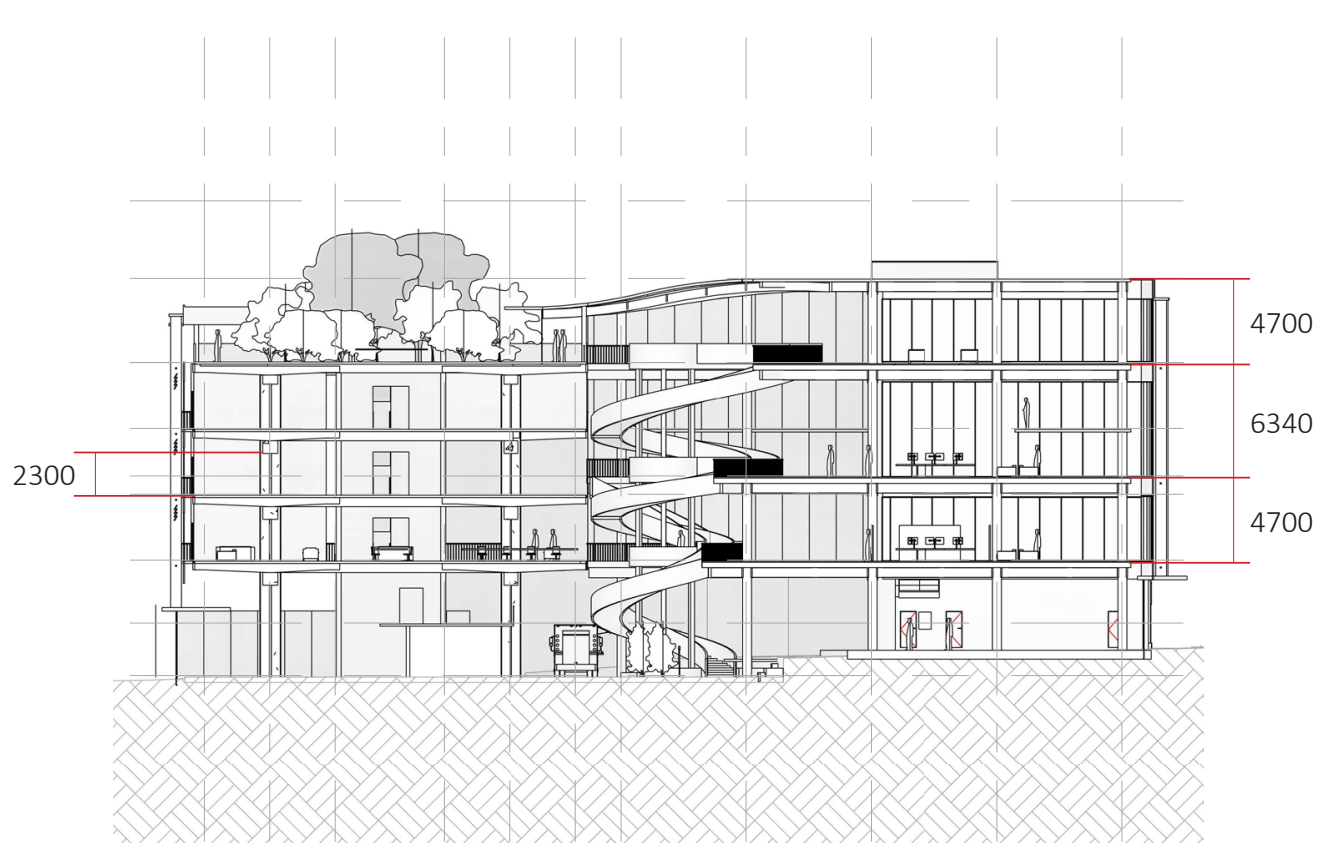

Figure 114: Section AA, 1:500, showing the level variations. (all dimensions in mm) 


\section{6}

\section{WORKSPACE DEVELOPMENT}

In the preliminary design phase, the workspaces themselves catered to the core needs of the user; with those being concentration, communication, and choice. Through observing how buildings such as The Edge and coworking spaces such as the BizDojo offer a variety of spaces for workers to choose from, it was decided that a variation of workspaces was to be incorporated into the design. To best take advantage of the existing structure of 123 Taranaki Street, a range of different spaces were created through the use of adjusting the ceiling height.

Due to the existing structure having a height of only 2.3 metres in some places, it was decided that the new structure would have much higher floor to ceiling heights. There is some research to suggest that ceiling height has an impact on the way people think and process information, with a study in 2007 stating that people in higher ceiling rooms think in "non-traditional, more creative ways" (Meyers-Levy \& Zhu, 2007). Informed by this and noting that higher-end offices typically have higher ceilings, the floor-to-floor heights of the new timber structure were set as 4.7 metres, with the central floor being at 6.3 metres to house a mezzanine floor. This provided a wide variety of different types of workspaces. The existing concrete structure would house more concentrated workstations, whilst the southern timber structure would house the more open, creative workspaces. The mezzanine floor would offer an even more bustling work environment, with the top floor offering a view to nature as it opposing the rooftop garden (figure 114).

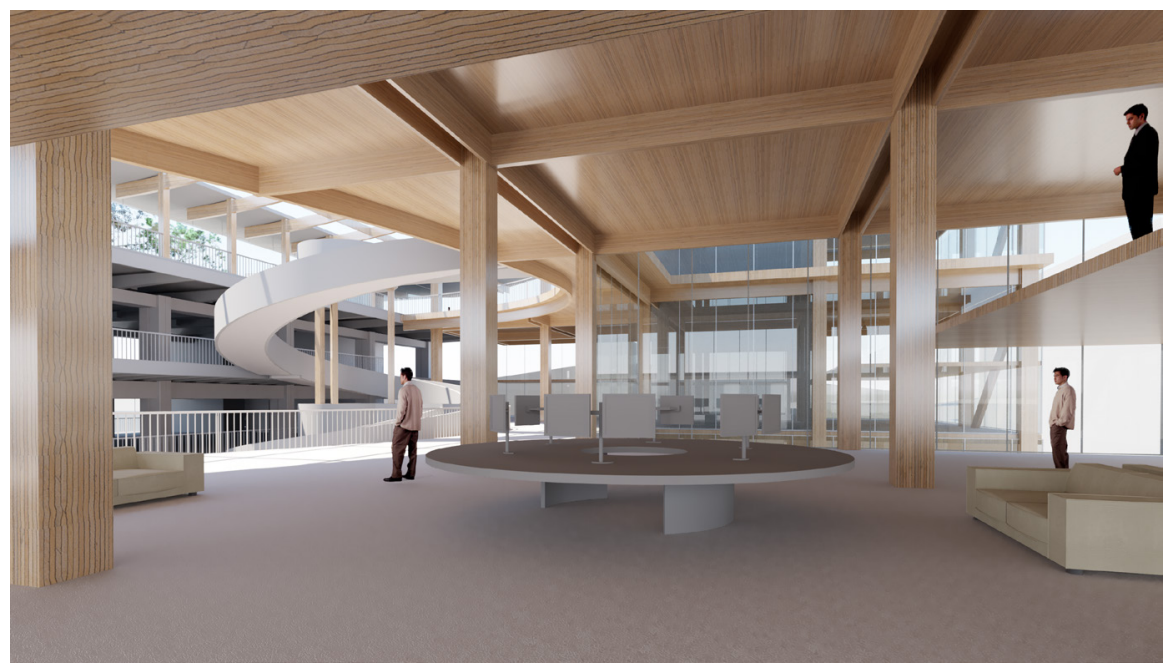

Figure 115: Sketch render of mezzanine floor, showing how much more light is let into the taller space. 


\section{7}

\section{INTERACTION}

As seen in the majority of projects analysed in chapter 4, the central stair lies at the heart of many contemporary workplaces, and serves to facilitate interaction between coworkers, as well as being a sculptural focal point for the building. Throughout the design process, many different kinds of stair were trailed (figure 116). The measure of how successful each stair was how well it connected the atrium space, as well as it needing to somehow incorporate meeting spaces into its design. What resulted was the development of a spiral stair case that gradually expands as it rises upwards (figure 117). Meeting spaces were situated within the spiral, so when people run into each other on the stair, they can interact without impeding other users.
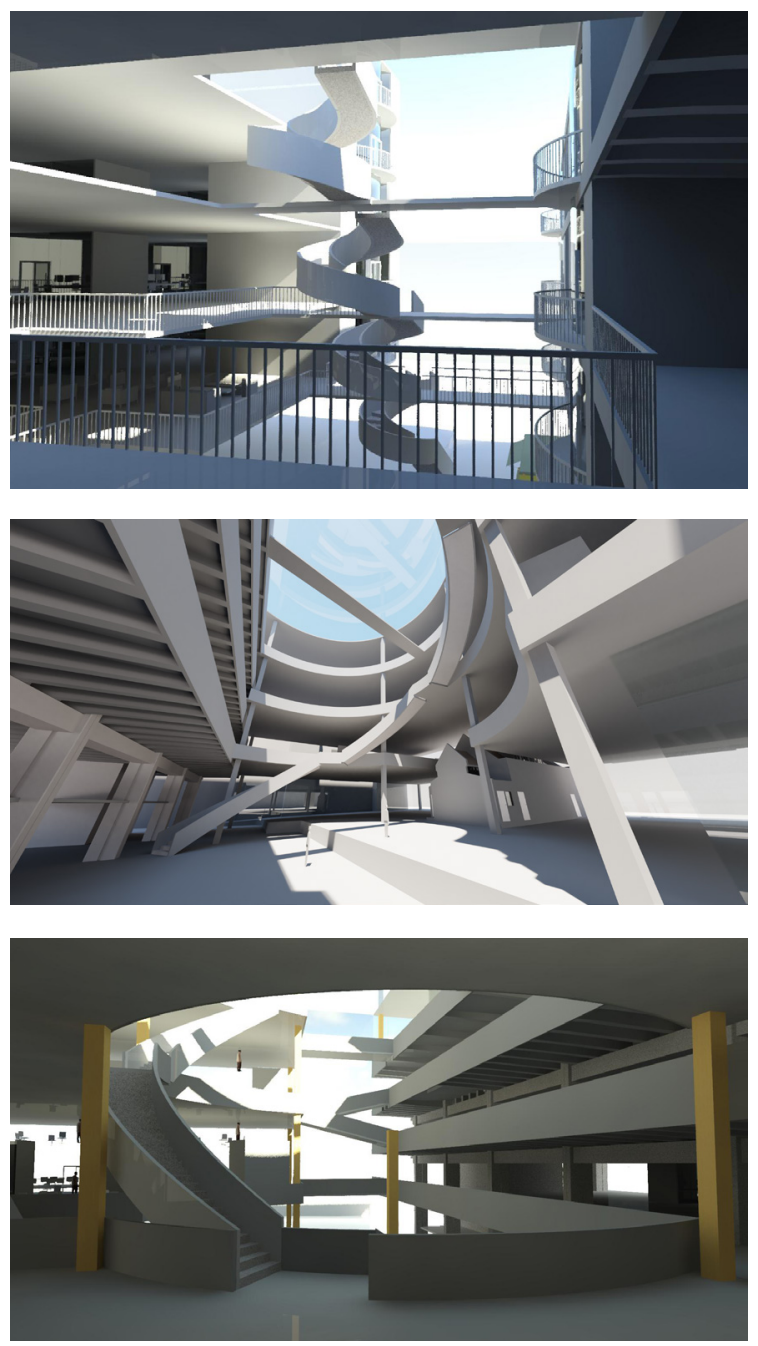

Figure 116: A variety of stair experiments that led to the developed design. 

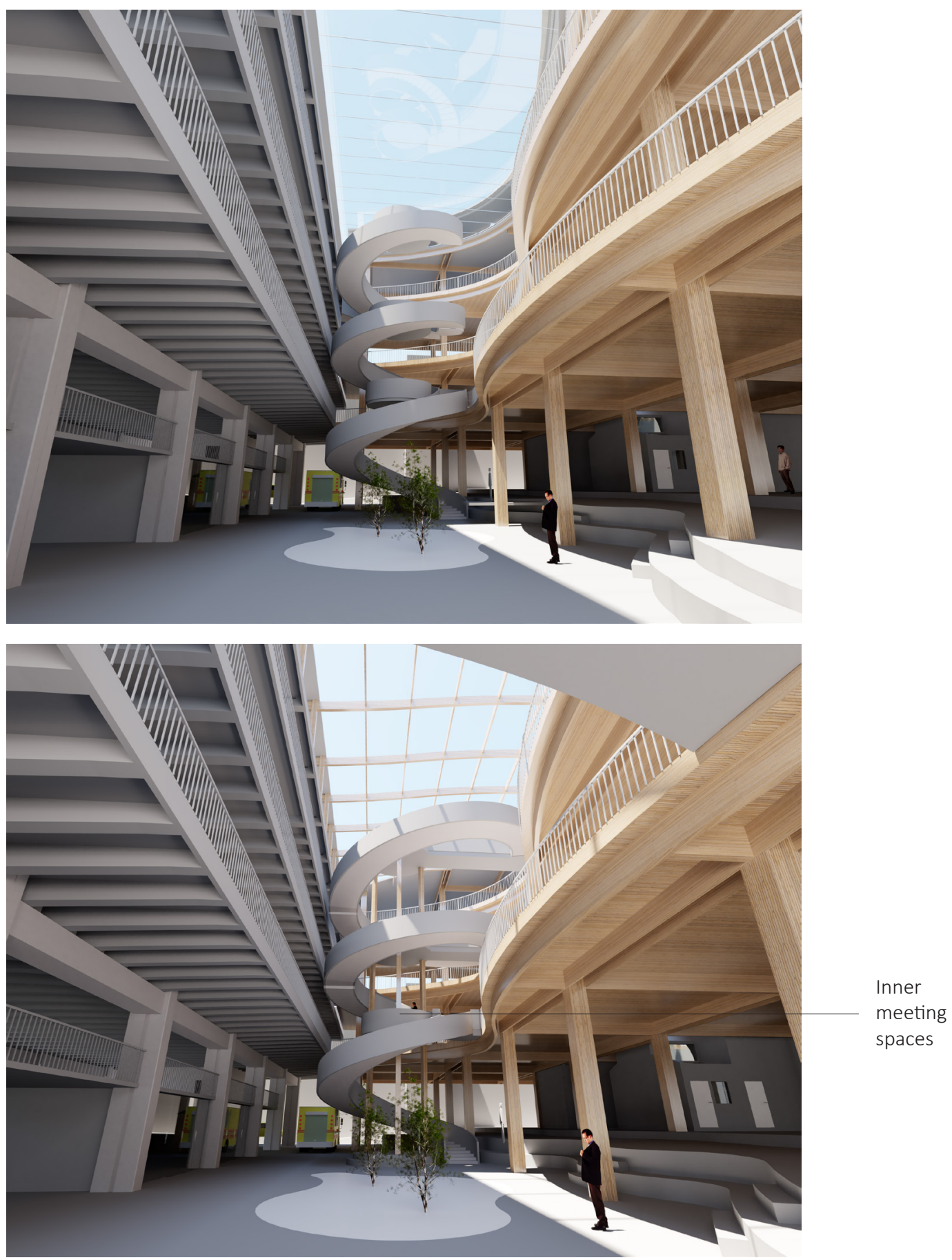

Figure 117: Renders showing the development of the gradually expanding spiral stair. 


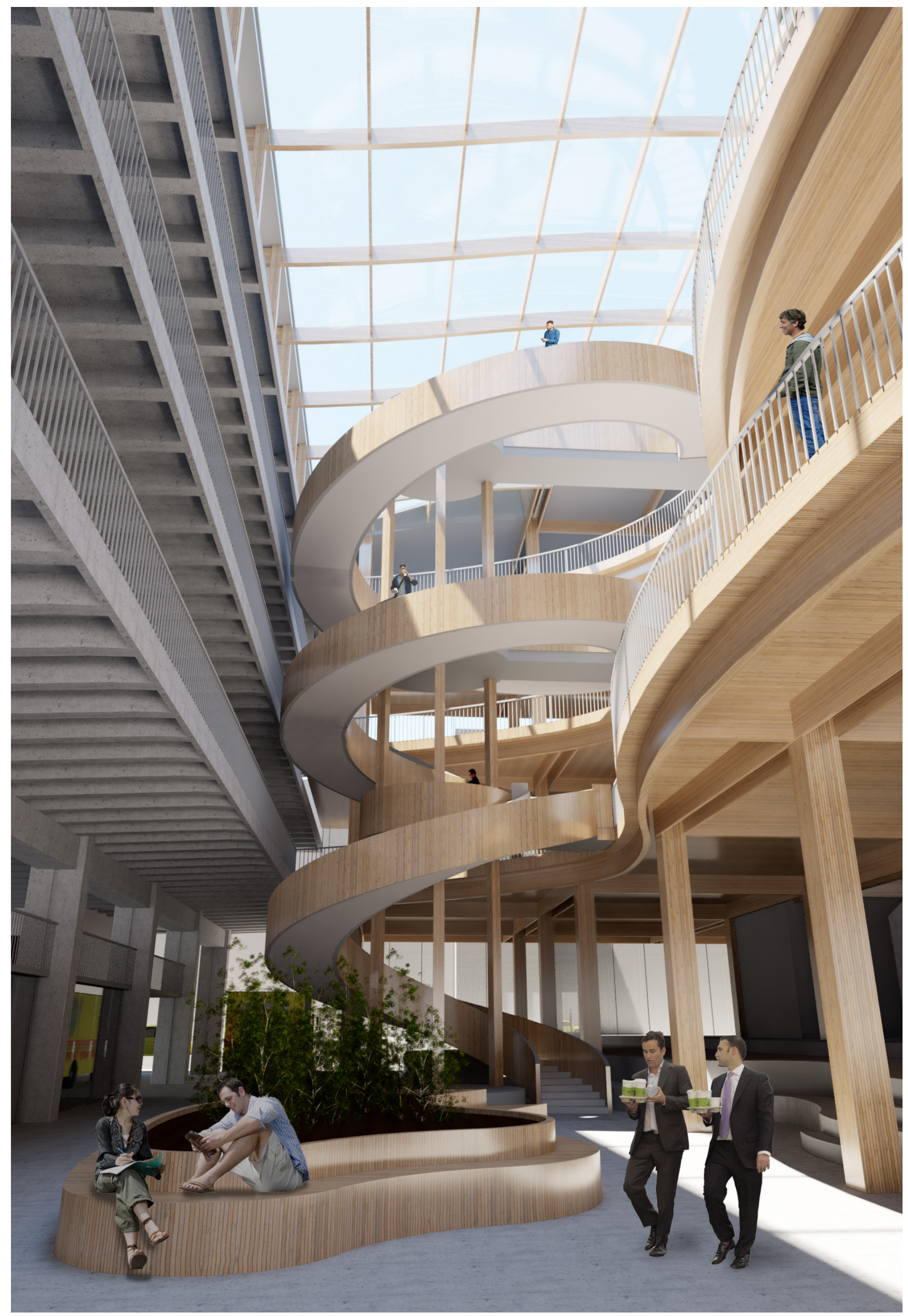




\section{8}

\section{FINAL DESIGN}

The final design features a flowing stair that connects the workspaces together. The rooftop workspace faces the rooftop garden, giving a visual connection to nature. The space opens up a to allow more natural light into the timber workspaces. A makers' space also occupies the ground floor of the existing 123 Taranaki street, with the opportunity being present to have the nearby Victoria University sponsor or buy into the venture, benefitting the complex and the students of the school.

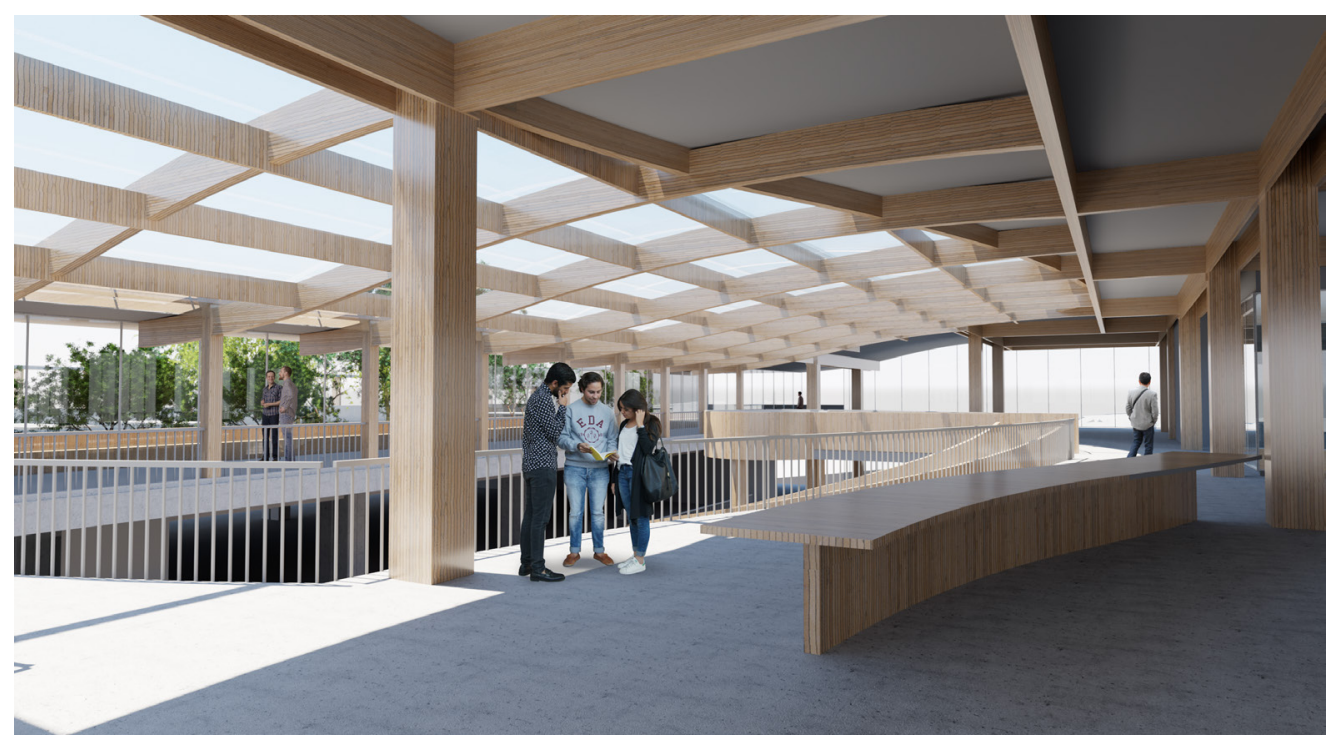

Figure 119: View of rooftop workspace.

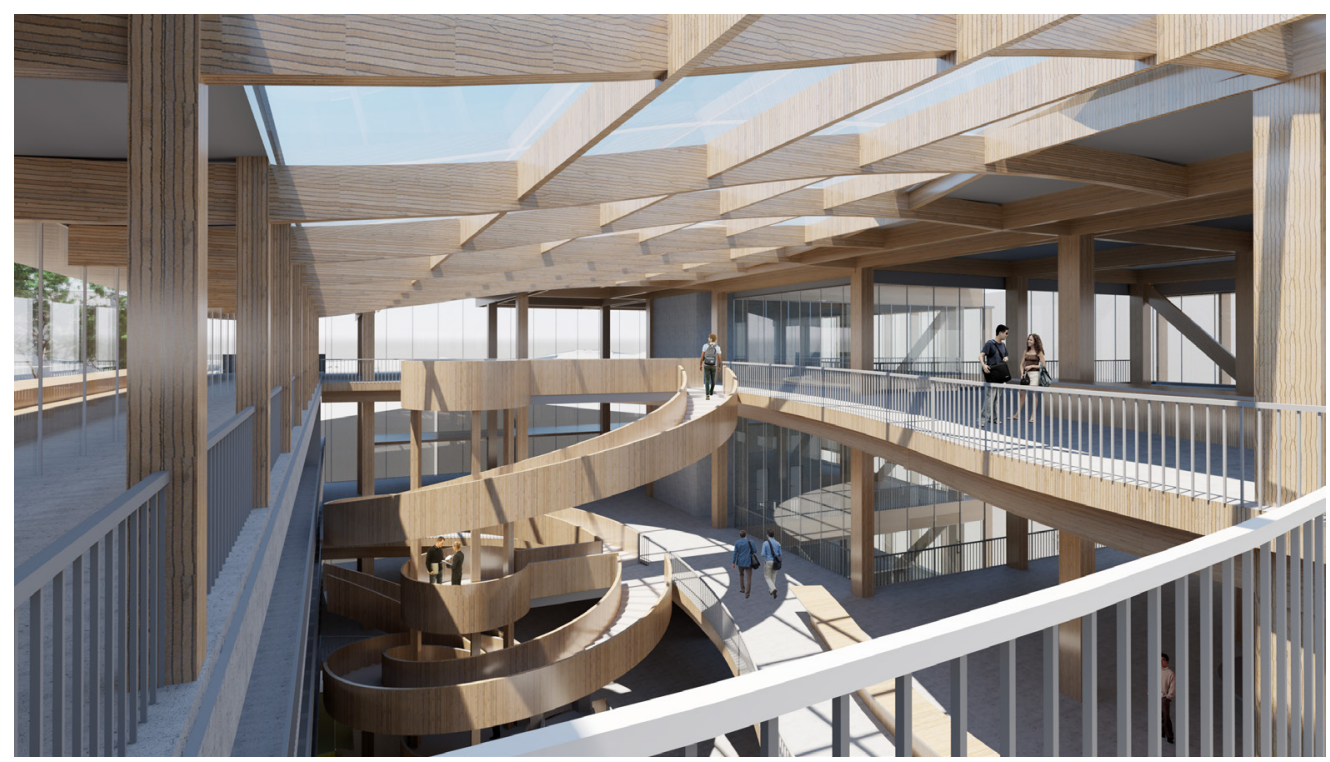

Figure 120: View of rooftop workspace and central stair with inner meeting rooms. 


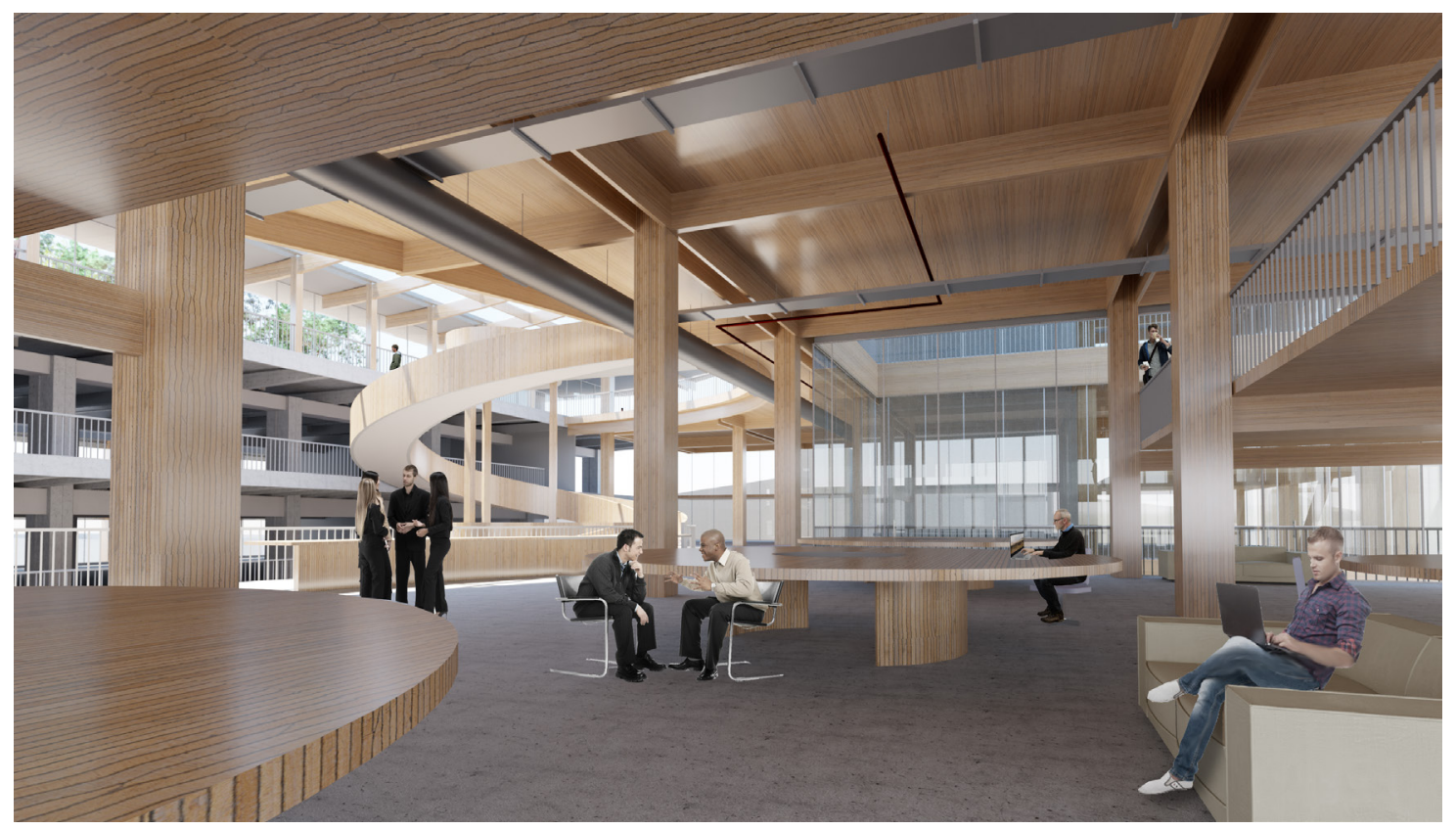

Figure 121: View of mezzanine workspace.

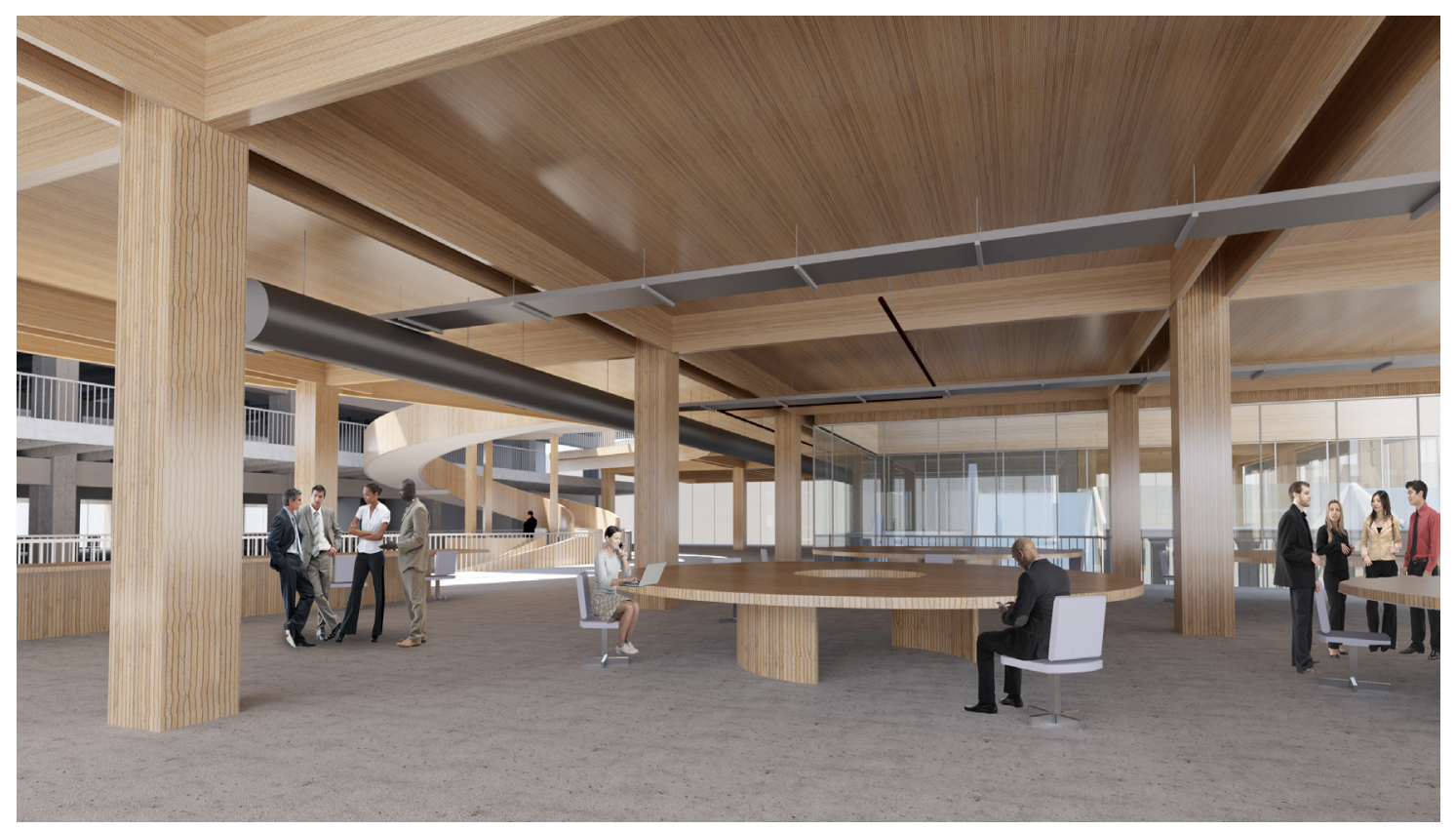

Figure 122: View of level 1 workspace. 
The workspaces vary in ceiling height, with the same 6 person team space being applied to these open coworking floors. The plan below shows the maximum number of team tables that can fit into the space, however these can be replaced and reorganised to suite, as the floor plate is flexibly large. VR workstations are hidden in the corners of the building, as privacy whilst wearing such a device is needed. The drive through is also reinstated on the ground floor, with food trucks being able to drive in and back out of the space.
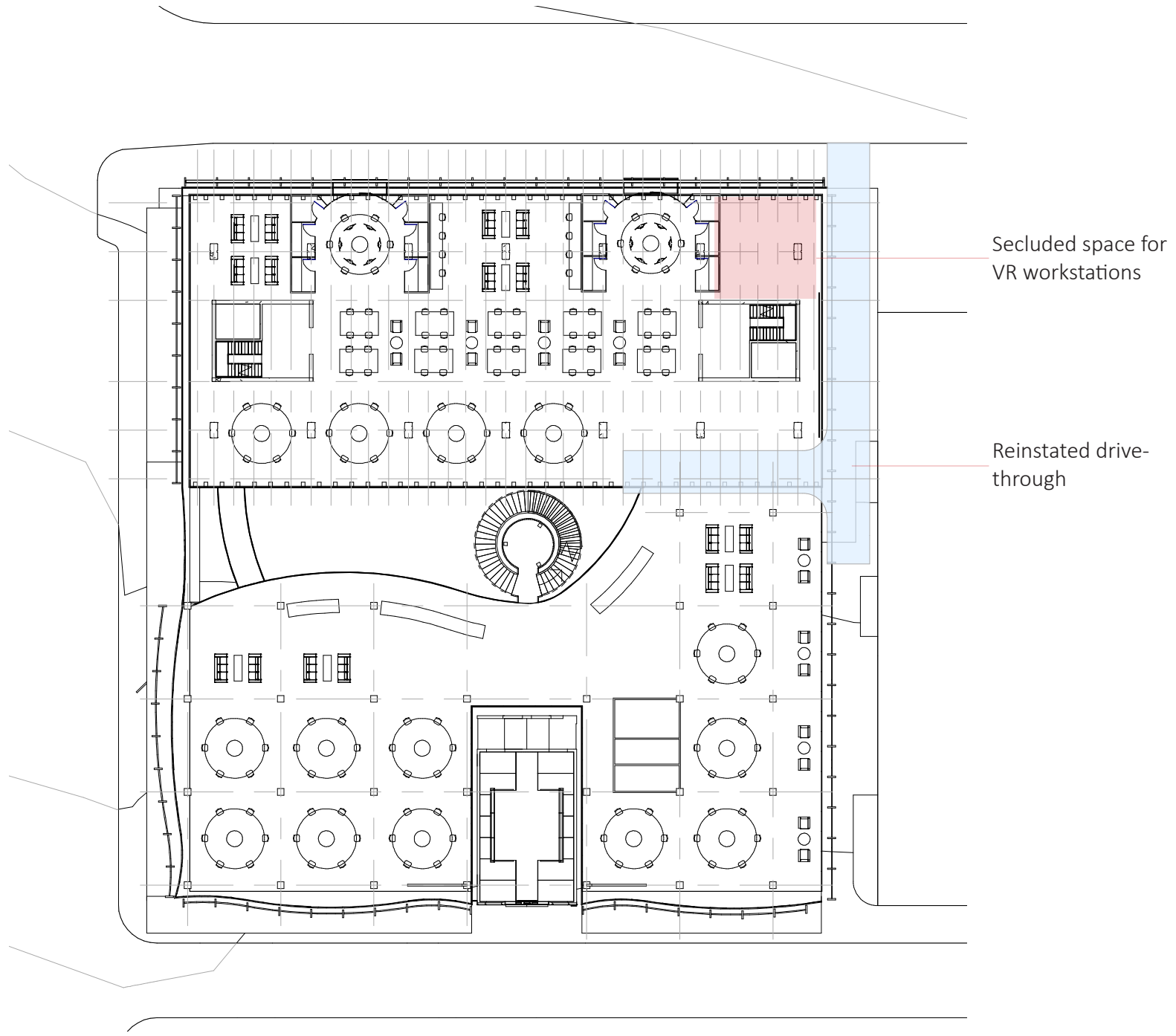

Figure 123: Level 1 plan, 1:500. 


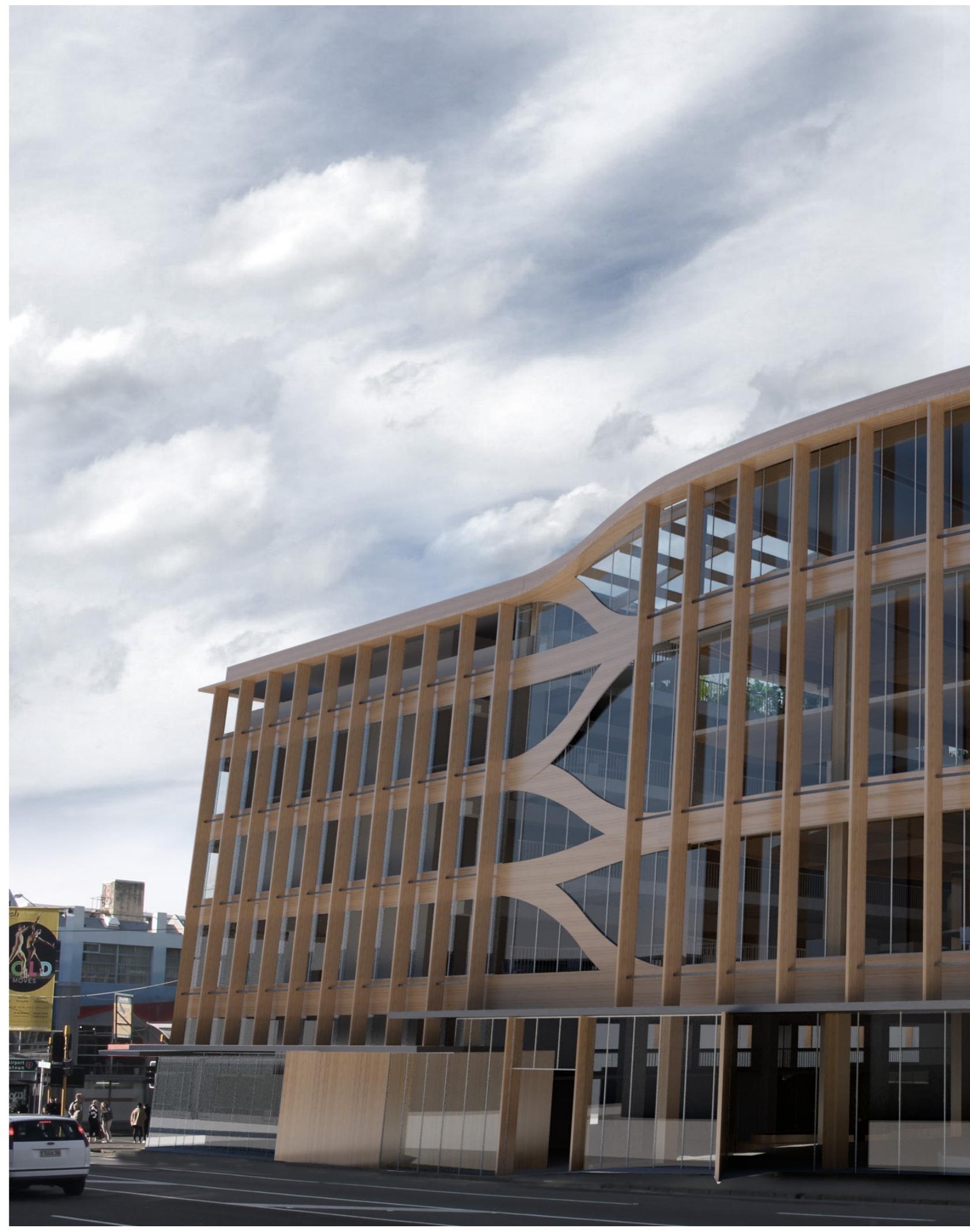

Figure 124: Exterior view of final design, looking at the corner of Taranaki and Frederick Street. 


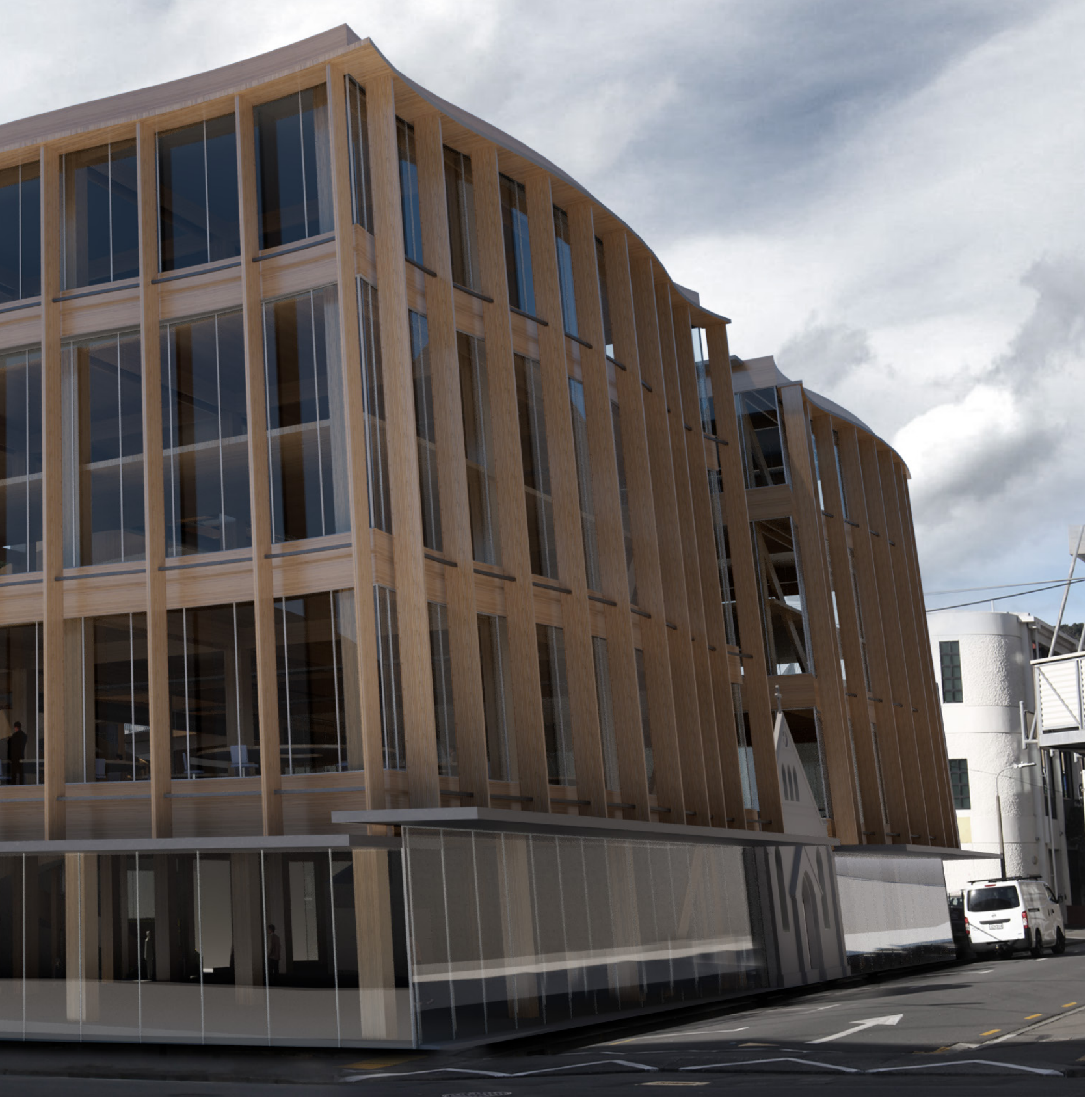




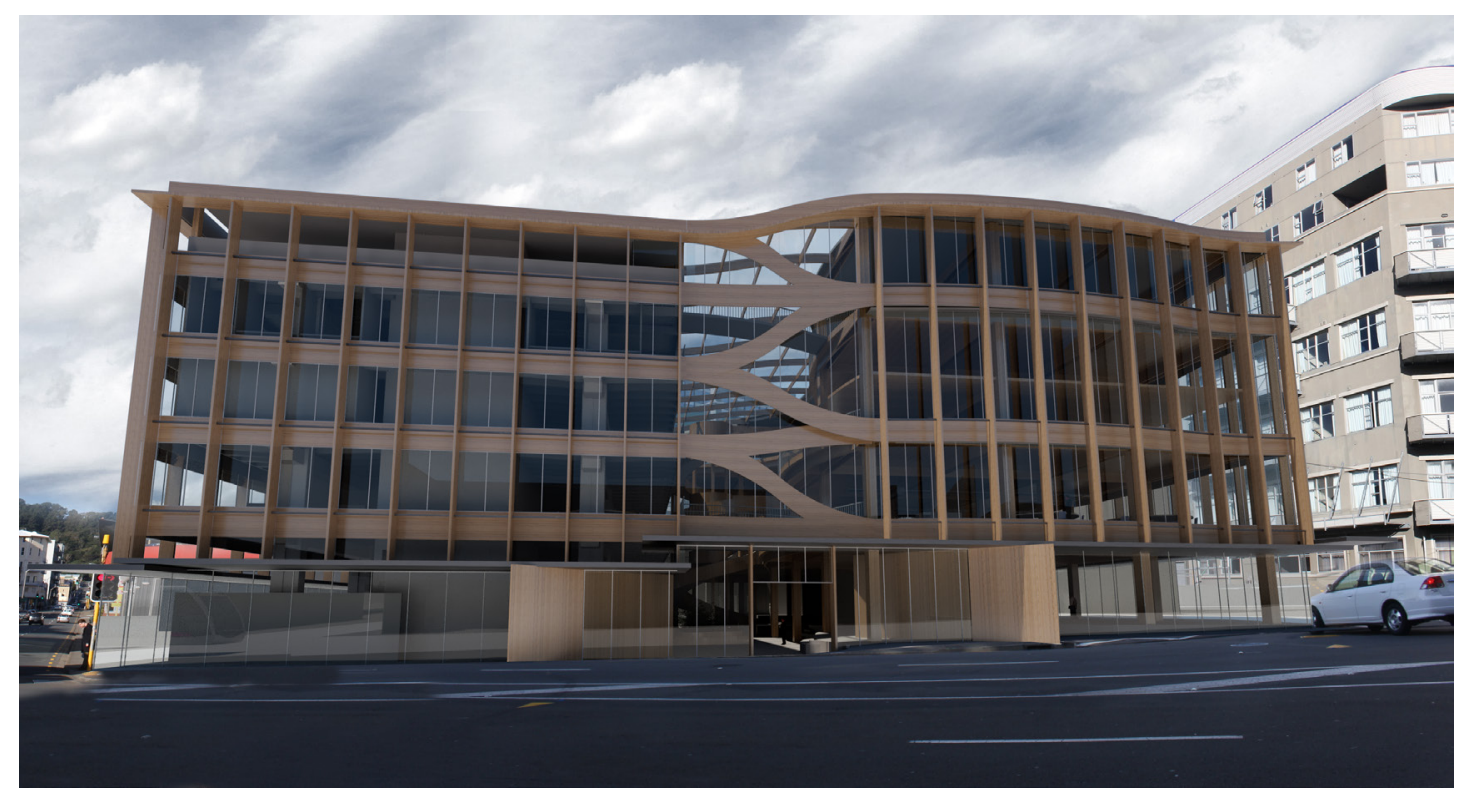

Figure 125: Exterior view, facing east.

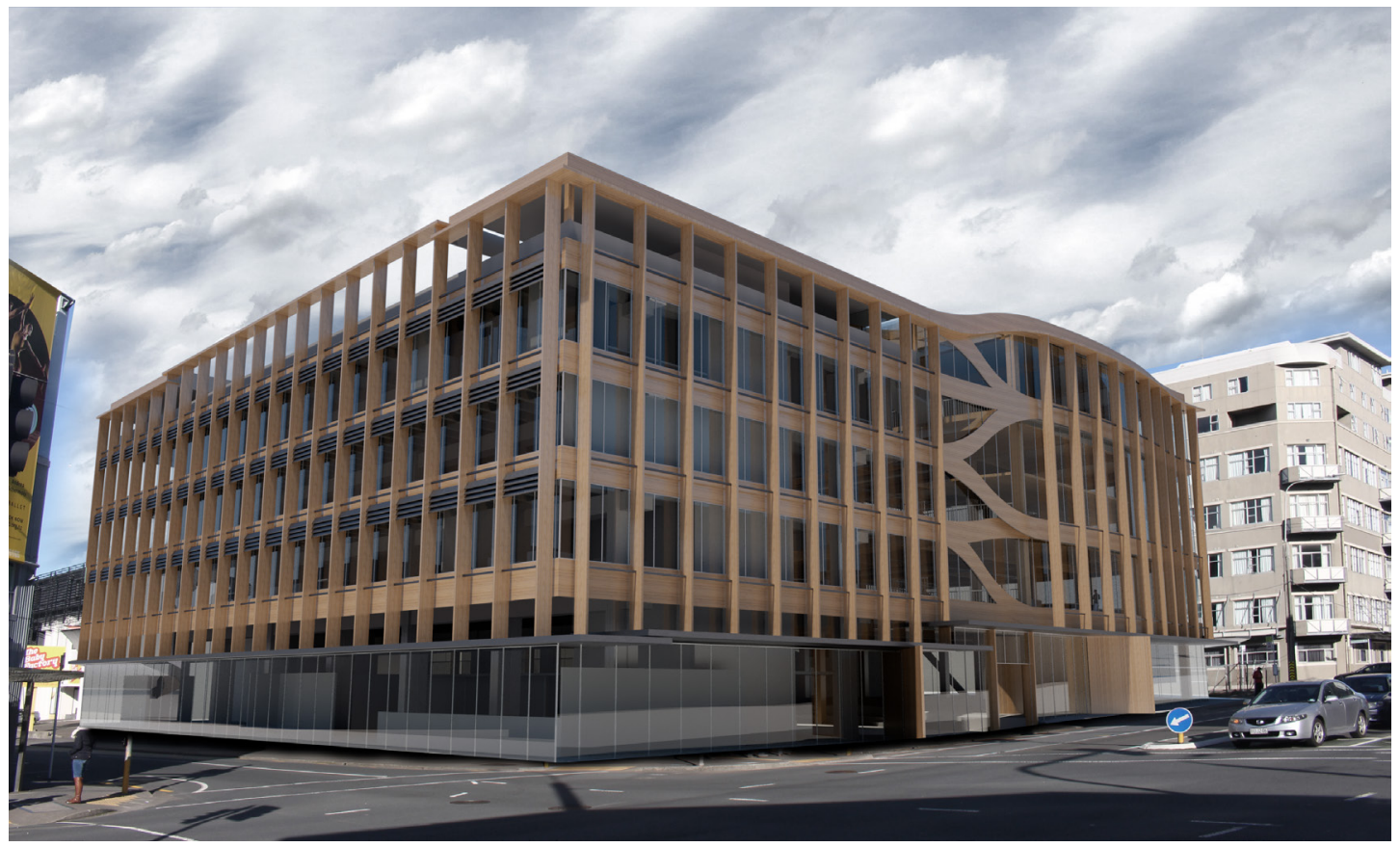

Figure 126: View from the corner of Taranaki and Vivian. 
With the main idea of the building being to connect disparate groups together, this needed to be reflected in the aesthetic of the building (figure 125). Timber slats and aluminum louvres were used to shield against the sun on the northern face. The Mission Hall was also incorporated into the design. As the roof of the building was deteriorated, a glass roof was fitted and the old function of the space being an exhinition space was reinstated. Exhibiting the work created in the complex, the glass roof would allow people on higher floors to look out over the balcony and potentially view something that might inspire their own work.

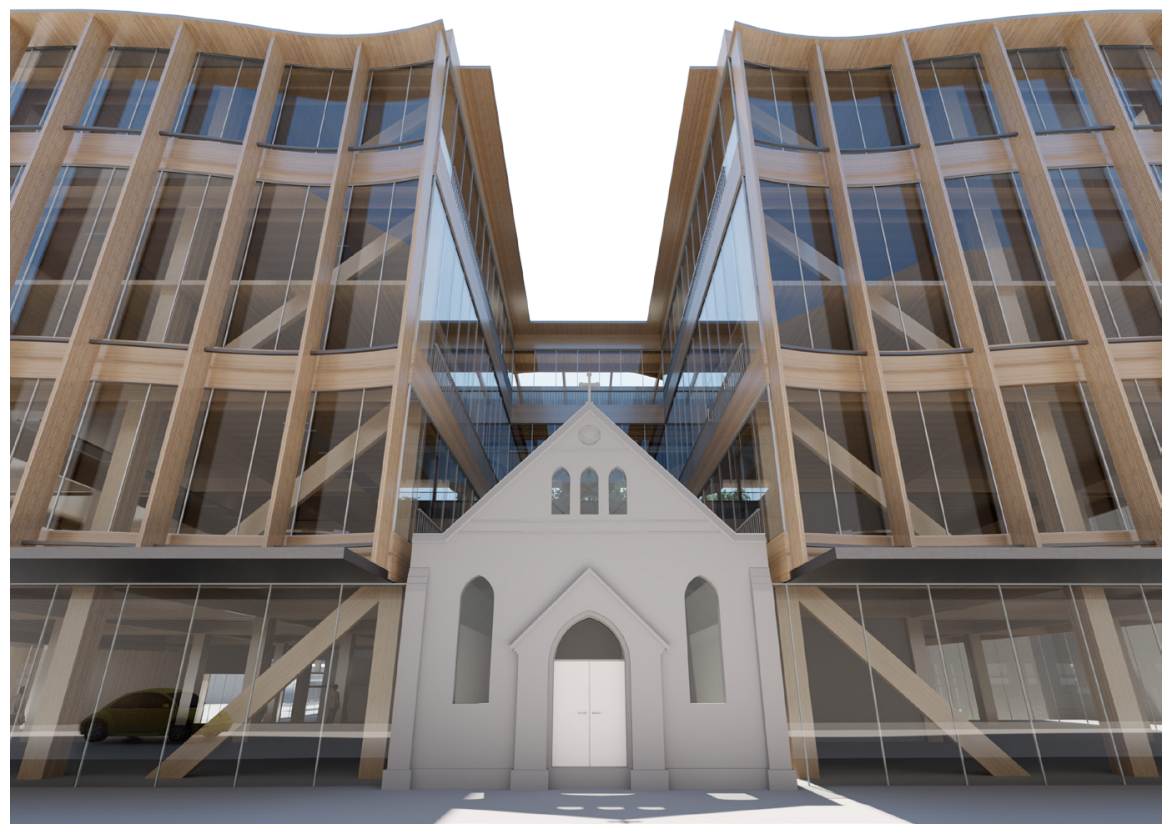

Figure 127: View from Frederick Street, showing how the Mission Hall is embedded in the design. 
7.9

Final DeVeloped Design

This chapter brought together the lessons learnt from the literature, the context of the site and the functional requirements of a coworking facility, culminating in a representation of what the future of workspaces could be for the city of Wellington. The next chapter reflects on how well the design met the overall objectives of the research, as well as discussing how well the methodology worked in answering the research question. 

CONCLUSION 
How will the future of work spaces evolve in the context of Wellington?

Research Aim: To evaluate the changing nature of work in urban settings, and explore its architectural implications.

OBJECTIVES:

1. Analyse the forces that have influenced the design of workspaces today

2. Examine how these forces are changing and their potential implications on the future of workspaces

3. Explore these potential implications in a specific context, resulting in a speculative example of what the future of work spaces could be

Figure 128: Summary of the research aims and obectives. 


\section{0}

\section{CRITICAL REFLECTION}

The aim of this research was to evaluate the changing nature of work in urban settings, exploring the implications of this in the local context of Wellington. Through examining the history of the office, it was observed that work has been continually changing, with the primary forces of social and technological change being identified. This met the first objective of the research, which was to identify the main forces impacting the design of workspaces. This objective was comprehensively met, with the summary of the entire history of workspaces providing great insight into how the office has evolved over time.

The second objective of this research was to analyse how these forces are changing, examining what impacts this might have on work in the future. Through analysing automation and its likely impacts on the global economy, it was discovered that work in the future will likely involve more freelancers, as technology is allowing work to be distributed like never before. Coworking spaces were identified as facilities that are exploding in popularity recently, and with the coming changes to work, this rise is expected to continue. Interaction was also shown to be crucial for the future workplace as a result of the way work is changing, as automation will automate out repetitive work, the creation of ideas and decision making will become more of a focus; both of which are aided by interaction between coworkers. These finding are very relevant to contemporary workplace design, as facilities such as the B:Hive are already beginning to head in this direction. 
Four key drivers were developed from this analysis, being Interaction, Flexibility, User Wellbeing and Technological Integration. In the project review chapter, the different approaches being used by architects and designers were identified in relation to these key drivers. The drivers of flexibility and technological development could have been examined closer, as the resulting approaches did not become incorporated very deeply into the design.

The third objective of this research was to explore the potential implications of these coming changes, resulting in a speculative example of what the future of work may look like. With the research question relating specifically to city of Wellington, the local context became a focus for the design. The context analysis chapter found that Wellington as a city is growing in the creative sectors, with the context around the site of 123 Taranaki Street being diverse and full of coworking communities. This chapter found that Wellington could be poised to capitalise on its creative reputation in the future, as automation increases the value of idea creation. The opportunity for a coworking space to bring together the disparate working groups around Wellington was a significant finding, as it brought together what was learnt from the literature and the context analysis.

The incorporation of the key drivers in the design could have been developed further. Although interaction and user wellbeing were explored heavily in the design experiments, it was difficult to incorporate flexibility and technological integration alongside this. One solution to this would have been to just focus on one or two key drivers, exploring them fully. However, as workplaces are a result of a multitude of different motivations, these drivers would not exist in isolation in reality. For example, a workplace designed around interaction would likely end up having elements of technological integration, as this is the direction the future is heading. Although it may have been more beneficial to explore just one or two key drivers, this narrowed scope would have left out considerations that are required to gain a holistic view of the direction work is heading. 
The resulting spaces give a good indication of how workspaces are changing, both locally and globally. The informal and open spaces reflect the growing desire by workers for autonomy and choice. The choice of developing a structural timber coworking facility in central Wellington is well substantiated by the findings in the earlier chapters. The central sculptural stair also effectively integrates interaction in an elegant yet functional manner.

The primary limitations of this research is that the topic of work in general is vast, with there being many contributing factors. This resulted in aspects such as technological integration and flexibility being explored in limited ways, as it was difficult to balance the varying key drivers. This research has great potential to be applied to the city of Wellington, as it has been shown that the city is in need of a facility like the one developed.

Further research would look further into the future, analysing how emerging technologies would affect the design of workspaces. Technologies such as Neuralink could have massive implications to the way people work, as well as other yet uninvented technologies. 

CITATIONS 
3XN, A. (2019). UN City-The regional head office. 3XN.Com. https://3xn.com/ project/un-city

Acemoglu, D., \& Restrepo, P. (2018a). Artificial Intelligence, Automation and Work (Working Paper No. 24196). National Bureau of Economic Research. https://doi. org/10.3386/w24196

Acemoglu, D., \& Restrepo, P. (2018b). Low-Skill and High-Skill Automation. Journal of Human Capital, 12(2), 204-232. https://doi.org/10.1086/697242

AHMM. (2019). Google, Pancras Square. Allford Hall Monaghan Morris. https:// www.ahmm.co.uk/projectDetails/168/Google-Pancras-Square\#

Archdaily. (2015, February 27). See BIG \& Heatherwick's Design for Google's California Headquarters. ArchDaily. http://www.archdaily.com/603947/see-big-andheatherwick-s-design-for-google-s-california-headquarters/

Aubé, C., Rousseau, V., \& Tremblay, S. (2011). Team size and quality of group experience: The more the merrier? Group Dynamics: Theory, Research, and Practice, 15(4), 357-375. http://dx.doi.org/10.1037/a0025400

Blenko, M. W., Mankins, M. C., \& Rogers, P. (2010). Decide \& Deliver: 5 Steps to Breakthrough Performance in Your Organization. Harvard Business Press.

BNZ. (2019). They said it couldn't be done! BNZ Heritage.Com. https://www.bnzheritage.co.nz/archives/story/they-said-it-couldnt-be-done

Campbell, D. (2019, September 29). How WeWork went from $\$ 47$ billion valuation to bankruptcy talk in 6 weeks -Business Insider. https://www.businessinsider.com/ weworks-nightmare-ipo/?r=AU\&IR=T

CCSearch. (2019b). Seattle Spheres Interior. CC Search. https://search.creativecommons.org/photos/c79ea4e7-2954-4415-84a8-fcf943c05630

CCSearch. (2019c). Spheres Exterior. CC Search. https://search.creativecommons. org/photos/c79ea4e7-2954-4415-84a8-fcf943c05630

CCSearch. (2019a). The Edge Exterior. CC Search. https://search.creativecommons. org/photos/c79ea4e7-2954-4415-84a8-fcf943c05630

Corèdon, C., \& Williams, A. (2004). A Dictionary of Medieval Terms and Phrases (NED-New edition). Boydell and Brewer; JSTOR. www.jstor.org/stable/10.7722/j. ctt14brrmq

Coworking Resources. (2019). Global Coworking Growth Study / Forecast and Statistics 2019. https://www.coworkingresources.org/blog/key-figures-coworkinggrowth

De Stefano, V. (2015). The Rise of the Just-in-Time Workforce: On-Demand Work, Crowdwork, and Labor Protection in the Gig-Economy. Comparative Labor Law \& Policy Journal, 37(3), 471-504.

Deloitte. (2019). 2019 Global Human Capital Trends. Deloitte Insights. https:// www2.deloitte.com/insights/us/en/focus/human-capital-trends.html 
Deskmag. (2019). 2019 Global Coworking Forecast. Deskmag. https://www. dropbox.com/s/jjor71mecwqbxdy/2019\%20Complete\%20Coworking\%20Forecast. pdf?dl=0

Donald, W. J. A., \& Powell, L. M. (1931). Handbook of Business administration.

Duffy, F. (1997). The New Office. Conran Octopus Limited.

Duffy, F. (2008). Work and The City. Black Dog Publishing.

Fliart. (2019). Larkin Building Frank Lloyd Wright. https://www.shvpl.info/imagelgkl-larkin-building-frank-Iloyd-wright.htm

Flickr. (2012). Empire State-New York City. https://www.flickr.com/photos/132084522@N05/17178926219

Ford, M. (2015). Rise of the robots: Technology and the threat of a jobless future. Basic Books, a member of the Perseus Books Group.

George, D. (2019, September 4). Transport benefits "secondary" for Wellington's proposed $\$ 2.2$ billion mass transit system. Stuff. https://www.stuff.co.nz/national/115518612/transport-benefits-secondary-for-wellingtons-proposed-22-billionmass-transit-system

Gillen, N. (2019). Future Office: Next-generation Workplace Design. RIBA Publishing. https://books.google.co.nz/books?id=6b_DuQEACAAJ

Grid, A. (2019). Wynyard Quarter / GridAKL. https://www.wynyard-quarter.co.nz/ gridakl

Grinde, B., \& Patil, G. G. (2009). Biophilia: Does Visual Contact with Nature Impact on Health and Well-Being? International Journal of Environmental Research and Public Health, 6(9), 2332-2343. https://doi.org/10.3390/ijerph6092332

Haarhoff, E. (2016). NZIA Awards List. University of Auckland Architecture Archive. Docplayer. https://docplayer.net/34202350-Nzia-awards-list-university-of-auckland-architecture-archive.html

Haines-Eitzen, K. (2012). Scribes, Greece and Rome. In The Encyclopedia of Ancient History. American Cancer Society. https://doi.org/10.1002/9781444338386. wbeah22245

Harris, R. (2015). The changing nature of the workplace and the future of office space. Journal of Property Investment \& Finance, 33(5), 424-435. https://doi. org/10.1108/JPIF-05-2015-0029

Harrison, A., Wheeler, P., \& Whitehead, C. (2003). The Distributed Workplace: Sustainable Work Environments. Routledge.

Hoffmann, H., Stefani, O., \& Patel, H. (2006). Extending the desktop workplace by a portable virtual reality system. International Journal of Human-Computer Studies, 64(3), 170-181. https://doi.org/10.1016/j.ijhcs.2005.08.003 
Huet, E. (2019, March 15). Every Move You Make, WeWork Will Be Watching You. Bloomberg. https://www.bloomberg.com/news/articles/2019-03-15/every-moveyou-make-wework-will-be-watching-you

Ikei, H., Song, C., \& Miyazaki, Y. (2017). Physiological Effects of Touching Wood. International Journal of Environmental Research and Public Health, 14(7), 801. https://doi.org/10.3390/ijerph14070801

Iles, J. (2018, September 1). Sir Bob Jones' wooden office tower is "absurdly delayed" by construction industry woes. Stuff.Co.Nz. https://www.stuff.co.nz/ business/property/106649085/sir-bob-jones-wooden-office-tower-is-absurdlydelayed-by-construction-industry-woes

Jasmax. (2019). B:Hive Smales Farm. Jasmax.Com. /projects/featured-projects/ bhive-smales-farm/

Joedicke, J. (1962). Office buildings. Praeger.

Johnson, A. (2019, July 17). Elon Musk wants to hook your brain up directly to computers. NBC News. https://www.nbcnews.com/mach/tech/elon-musk-wantshook-your-brain-directly-computers-starting-next-ncna1030631

Kaplan, R. (1993). The role of nature in the context of the workplace. Landscape and Urban Planning, 26(1), 193-201. https://doi.org/10.1016/01692046(93)90016-7

Khan Academy. (2019). Matthew in the Coronation Gospels and Ebbo Gospels. Khan Academy. https://www.khanacademy.org/humanities/medieval-world/ carolingian1/a/matthew-coronation-and-ebbo-gospels

Kubátová, J. (2014). The Cause and Impact of the Development of Coworking in the Current Knowledge Economy. European Conference on Knowledge Management; Kidmore End, 2, 571-577. https://search.proquest.com/docview/1672881587/ abstract/820369F287084F1BPQ/1

Laing, A. (2013). Work and workplaces in the digital city. Center for Urban Real Estate. Columbia University, USA.

LeCun, Y., Bengio, Y., \& Hinton, G. (2015). Deep learning. Nature, 521(7553), 436-444.

Maclean, E. S. (2002). Architect of the Angels: The Churches of Frederick de Jersey Clere. Steele Roberts.

Manyika, J. (2017). Mckinsey June 2017 Al Data. https://www.mckinsey.com/

Marriage, G. (2019). Tall: The design and construction of high-rise architecture. Routledge.

McGregor, D. (1960). The human side of enterprise (Vol. 21). New York McGrawHill. 
Mckinsey. (2017a). A Future that Works: Automation, Employment and Productivity. https://www.mckinsey.com/ /media/mckinsey/featured\%20insights/Digital\%20Disruption/Harnessing\%20automation\%20for\%20a\%20future\%20that\%20 works/MGl-A-future-that-works-Executive-summary.ashx

Mckinsey. (2017b, November). What the future of work will mean for jobs, skills, and wages. https://www.mckinsey.com/featured-insights/future-of-work/jobslost-jobs-gained-what-the-future-of-work-will-mean-for-jobs-skills-and-wages

Meyers-Levy, J., \& Zhu, R. (2007). The Influence of Ceiling Height: The Effect of Priming on the Type of Processing That People Use. Journal of Consumer Research, 34(2), 174-186. https://doi.org/10.1086/519146

Microsoft Research. (2016). Holoportation: Virtual 3D Teleportation in Real-Time. Microsoft Research. https://www.microsoft.com/en-us/research/video/holoportation-virtual-3d-teleportation-real-time/

Musk, E., \& Neuralink. (2019). An integrated brain-machine interface platform with thousands of channels. BioRxiv, 703801. https://doi.org/10.1101/703801

NBBJ. (2019). Amazon in the Regrade. NBBJ.Com. http://www.nbbj.com/work/ amazon/\#next

Nedelkoska, L., \& Quintini, G. (2018). Automation, skills use and training.

Nelson Pine. (2019). Nelson Pine Industries Ltd. http://www.nelsonpine.co.nz/ nelsonpine-|v|/gallery/

North, H. (2019, July 24). B:Hive Finalist Inside World of Interiors. Jasmax.Com. https://www.jasmax.com/news/bhive-finalist-inside-world-of-interiors/

NZ Future of Work Commission. (2016). Future of Work Commission Report 2016. Labour Government. https://d3n8a8pro7vhmx.cloudfront.net/nzlabour/pages/2371/attachments/original/1478147232/43229_LoO_Future_of_Work_Full_ Document_FINAL_2_LR.pdf?1478147232

NZOS, N. O. S. (2007). Antonello \& the Architect. https://www.nzonscreen.com/ title/antonello-the-architect-2007

NZTE. (2016). Regions for Opportunity (p. 123). New Zealand Trade and Enterprise. https://www.betterbydesign.org.nz/-/media/NZTE/Downloads/Investment-andfunding/Regional-investment-profiles/NZ-regional-investment-profile-FULL.pdf

Orts, S., Rhemann, C., Fanello, S., Kim, D., Kowdle, A., Chang, W., Degtyarev, Y., Davidson, P., Khamis, S., Dou, M., Tankovich, V., Loop, C., Cai, Q., Chou, P., Mennicken, S., Valentin, J., Kohli, P., Pradeep, V., Wang, S., \& Izadi, S. (2016, October 16). Holoportation: Virtual 3D Teleportation in Real-time. https://doi. org/10.1145/2984511.2984517

Petrulaitiene, V., Rytkönen, E., Nenonen, S., \& Jylhä, T. (2017). Towards responsive workplaces - identifying service paths for time- and place-independent work. Journal of Corporate Real Estate; Bingley, 19(3), 144-156. http://dx.doi.org/10.1108/ JCRE-10-2016-0034 
Pictify. (2019). Lever House, NY, 1952. http://pictify.saatchigallery.com/399330/ lever-house-ny-1952-som-architectstoller-photo

Pinterest. (2017). Bank of New Zealand drive-through entrance Vivian St. Pinterest. https://www.pinterest.com/pin/399342691953916920/

PLP Architecture. (2019). The Edge. PLP Architecture. http://www.plparchitecture. com/the-edge.html

Poole, D., Mackworth, A., \& Goebel, R. (1998). Computational intelligence: A logical approach.

Precinct Properties. (2019). Bowen Campus. Bowen Campus. https://www.precinct.co.nz/bowen-campus

Propst, R. L. (1966). The Action Office. Human Factors, 8(4), 299-306. https://doi. org/10.1177/001872086600800405

Ramada. (2019). Ramada Hotel and Suites Wellington. http://ramadawgtnresidences.propertyinvest.net.nz/

Randall, T. (2015, September 23). The World's Smartest Office Building Knows How You Like Your Coffee. Bloomberg.Com. http://www.bloomberg.com/features/2015the-edge-the-worlds-greenest-building/

Reddit. (2019). Lloyd's Building, London - Lloyd's Of London/Richard Rogers \& Partners (1986). https://www.reddit.com/r/1980s/comments/asech4/reddit_lloyds_ building_london_lloyds_of/

Ricoh. (2019). Ricoh Contact. Ricoh.Co.Nz. https://www.ricoh.co.nz/contact/

Saval, N. (2014). Cubed: A Secret History of the Workplace. Doubleday.

Slade, M. (2019, April 4). The ad agency making business more about people than profit. The Spinoff. https://thespinoff.co.nz/business/04-04-2019/the-ad-agencymaking-business-more-about-people-than-profit/

Smales Farm. (2019). Smales Farm Goodside. https://smalesfarm.co.nz/gallery/

Staal, G. (1988). Between dictate \& design: The architecture of office buildings. Uitgeverij 010 Pubs.

Susskind, R., \& Susskind, D. (2016, October 11). Technology Will Replace Many Doctors, Lawyers, and Other Professionals. Harvard Business Review. https://hbr. org/2016/10/robots-will-replace-doctors-lawyers-and-other-professionals

Taylor, F. W. (1911). The principles of scientific management. New York, 202.

Thames Pacific. (2019). The Paddington: Terraced houses in the heart of Wellington. Stuff. https://www.stuff.co.nz/sponsored-content/111999081/the-paddington-terraced-houses-in-the-heart-of-wellington 
Tumblr. (2013). Herman Hertzberger, Central Beheer, Apeldorn, 1974. Archive of Affinities. https://archiveofaffinities.tumblr.com/post/43096936413/herman-

hertzberger-central-beheer-apeldorn-1974

Turner, A. (2004). Depthmap 4: A researcher's handbook [Report]. Bartlett School of Graduate Studies, University College London. https://discovery.ucl.ac.uk/id/ eprint/2651/

van Meel, J. (2000). The European Office: Office Design and National Context. 010 Publishers.

Van Meel, J., Martens, Y., \& van Ree, H. J. (2010). Planning office spaces: A practical guide for managers and designers. Laurence King London.

WCC. (2015). Chinese Mission Hall. Wellington City Heritage. http://wellingtoncityheritage.org.nz/buildings/1-150/124-chinese-mission-hall

What's it Worth. (2019). 129-133 Taranaki Street, Corner Frederick Street, Wellington, Wellington, New Zealand, 6001. http://www.whatsitworth.com.au/search/real-estate/commercial/129-133-taranaki-street-corner-frederick-street-wellingtonwellington-new-zealand-6001-19277.htm\#.XMZ2NWgzZaQ

Wikipedia. (2006). Office Illustration by Julius Bernhard von Rohr. In Wikipedia. https://en.wikipedia.org/w/index.php?title=Office\&oldid=937154690

Wikipedia. (2019). St. Jerome in His Study (Antonello da Messina). In Wikipedia. https://en.wikipedia.org/w/index.php?title=St._Jerome_in_His_Study_(Antonello_ da_Messina)\&oldid=915882803

World Economic Forum. (2018). The Future of Jobs Report 2018. World Economic Forum. https://www.weforum.org/reports/the-future-of-jobs-report-2018/ 

ADDENDUM 


\section{0}

ON SITE EXAMINATION

The following addendum documents the material created for the on-site examination. Aesthetic changes were made to some images for presentation purposes. Cosmetic alterations such as furniture were also added, showing how the spaces could be used much more clearly.

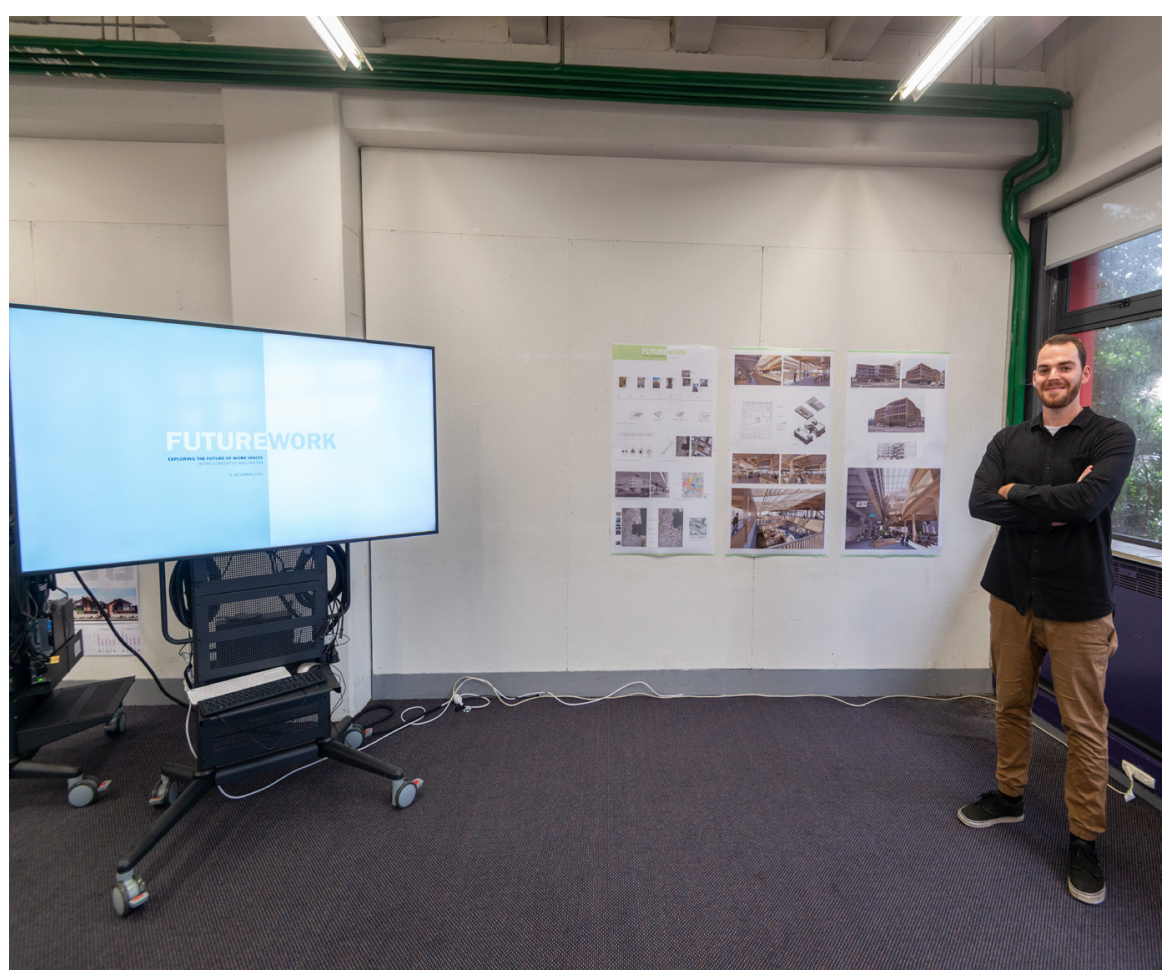




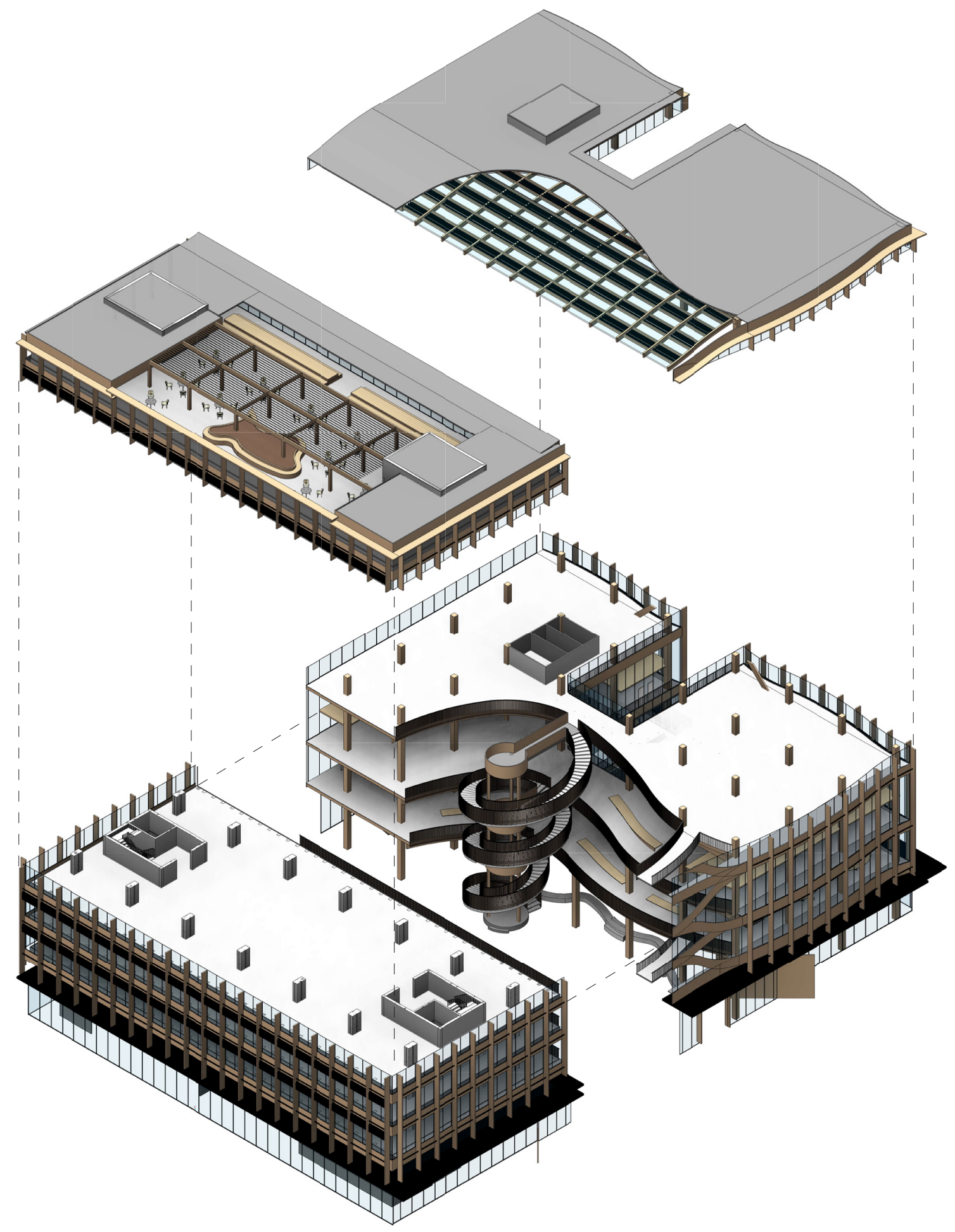



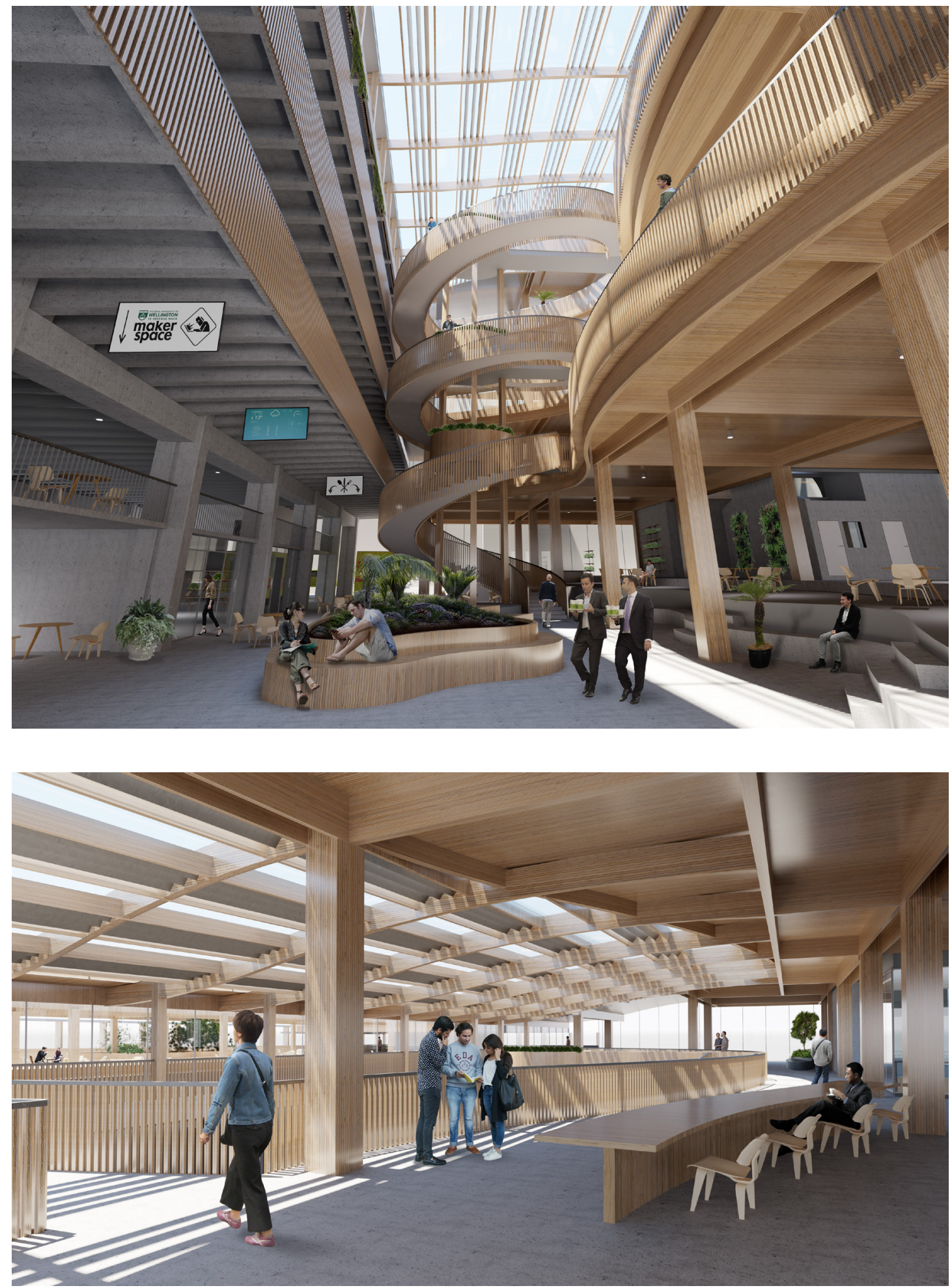

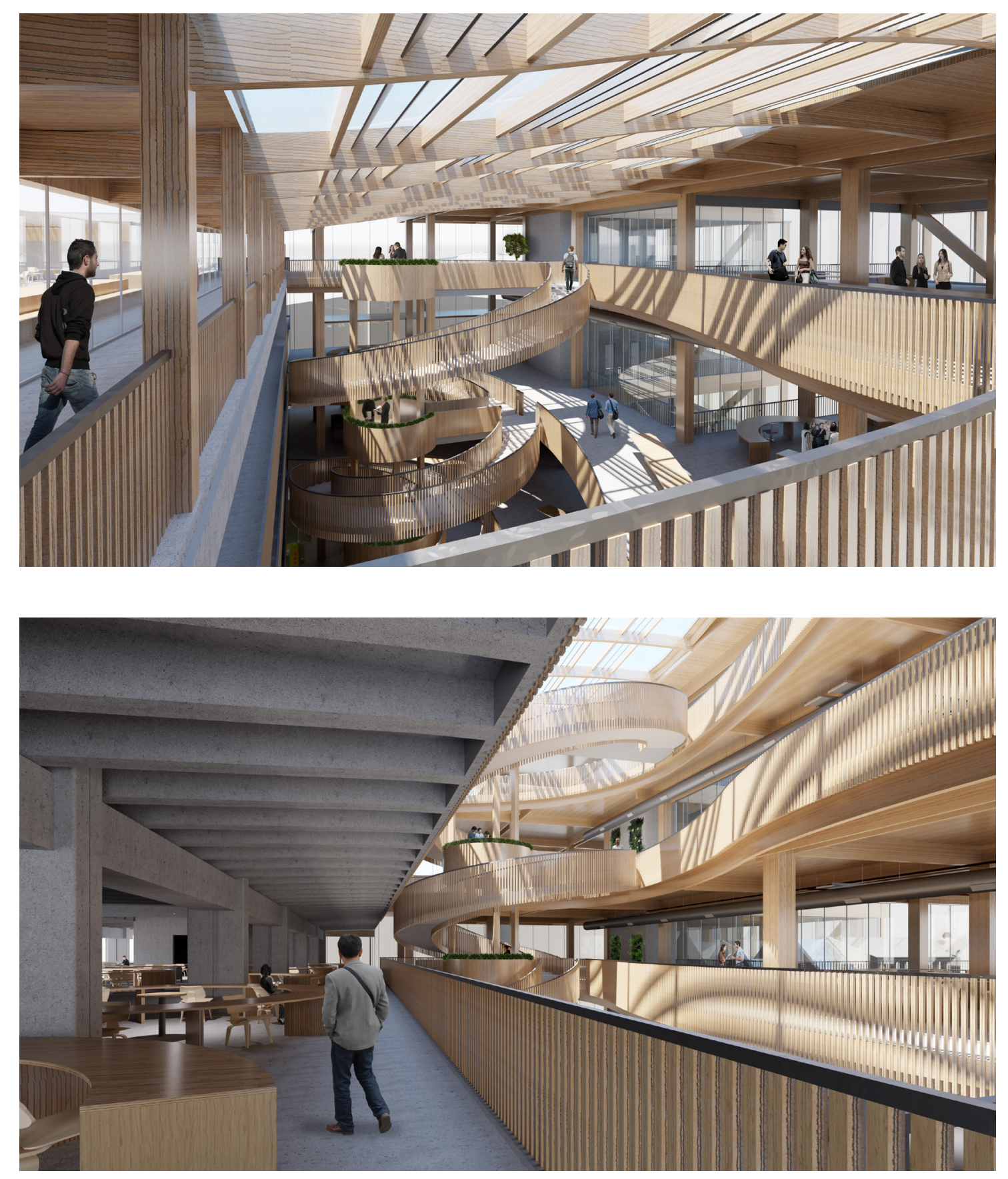

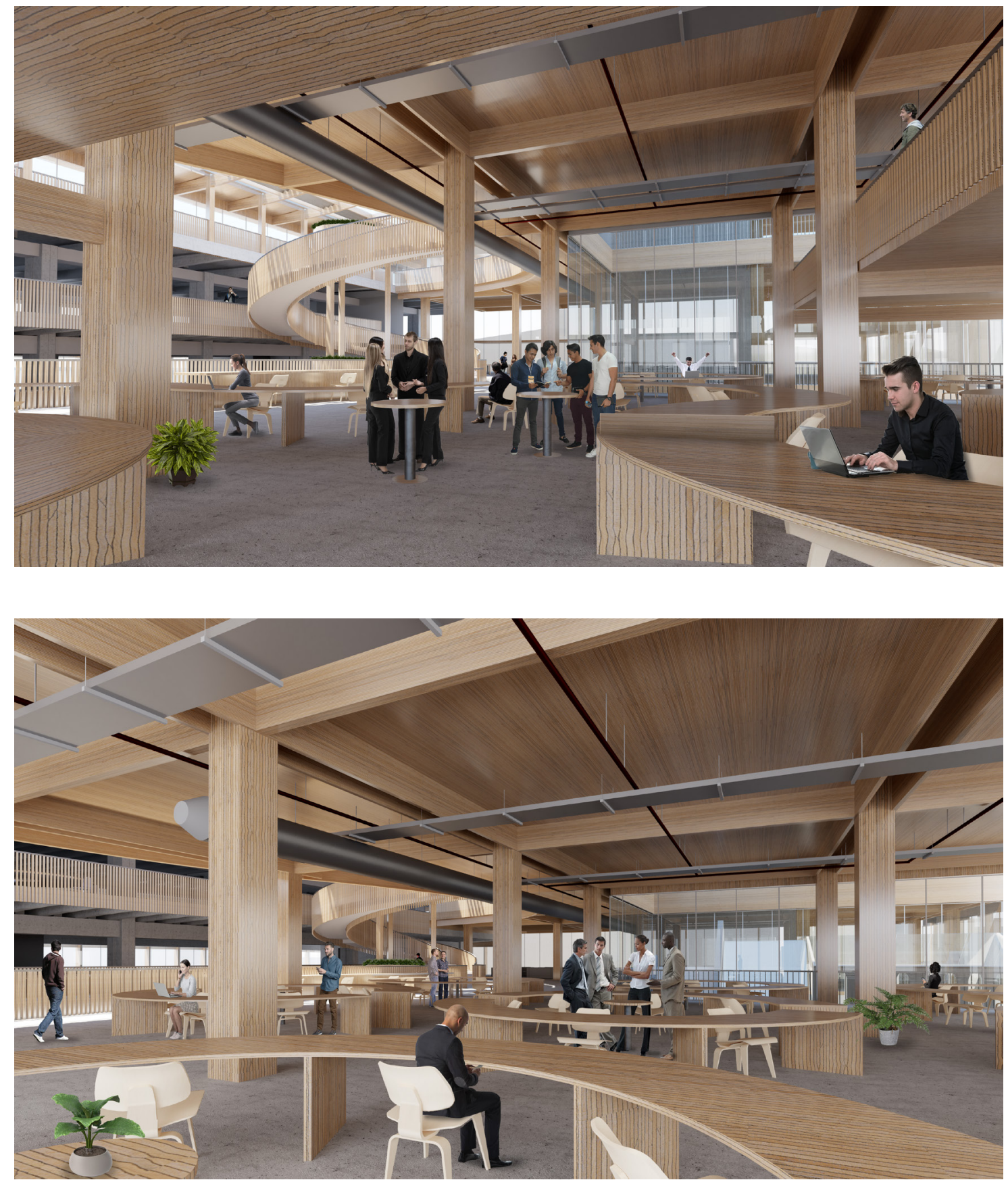


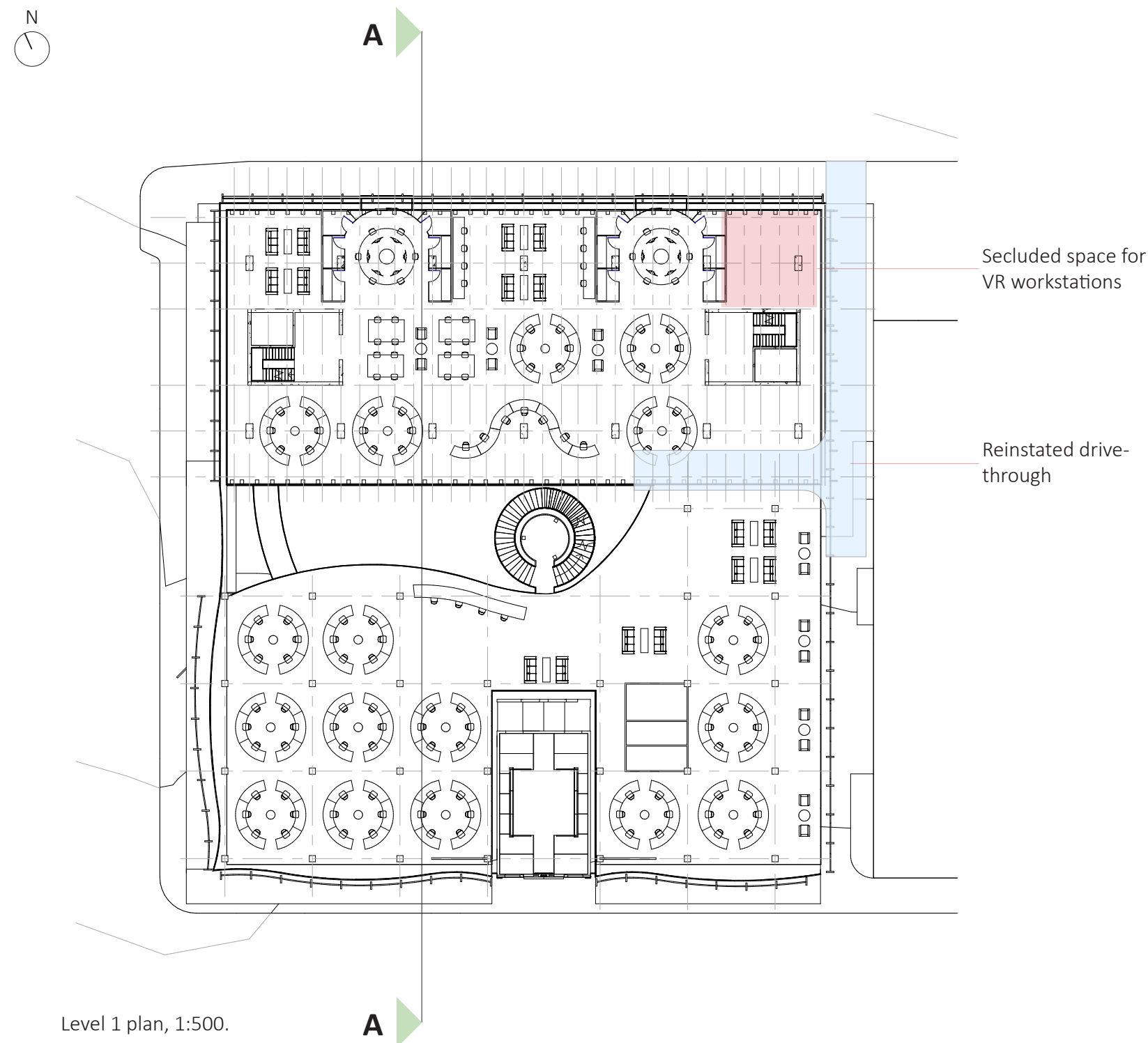




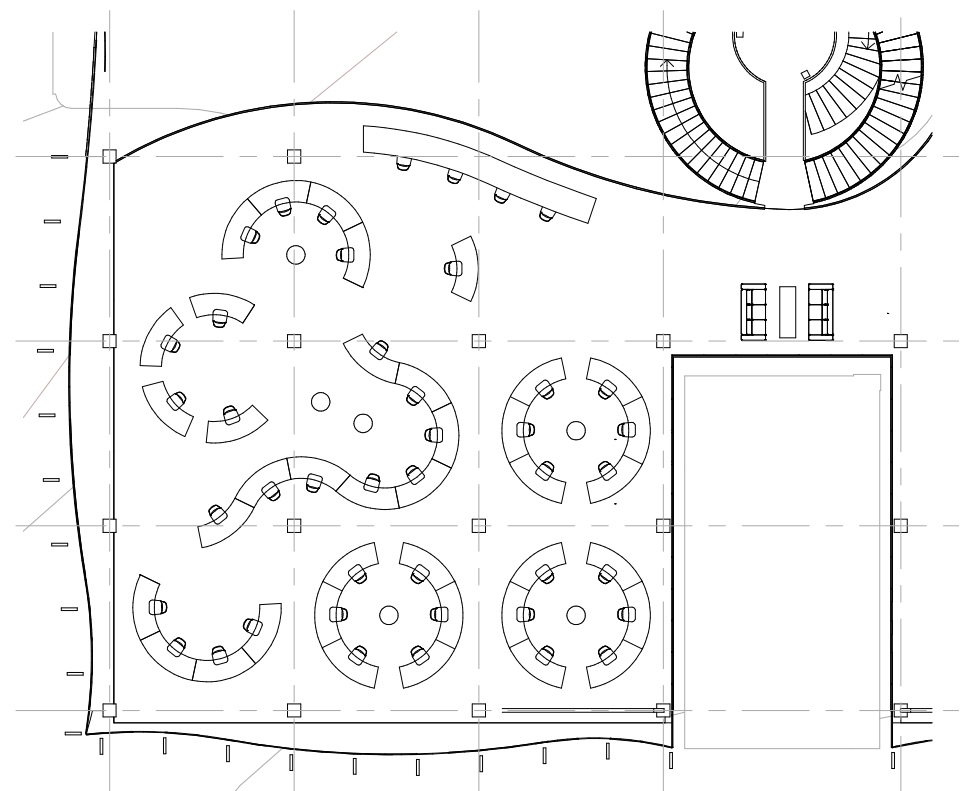

Level 2 plan

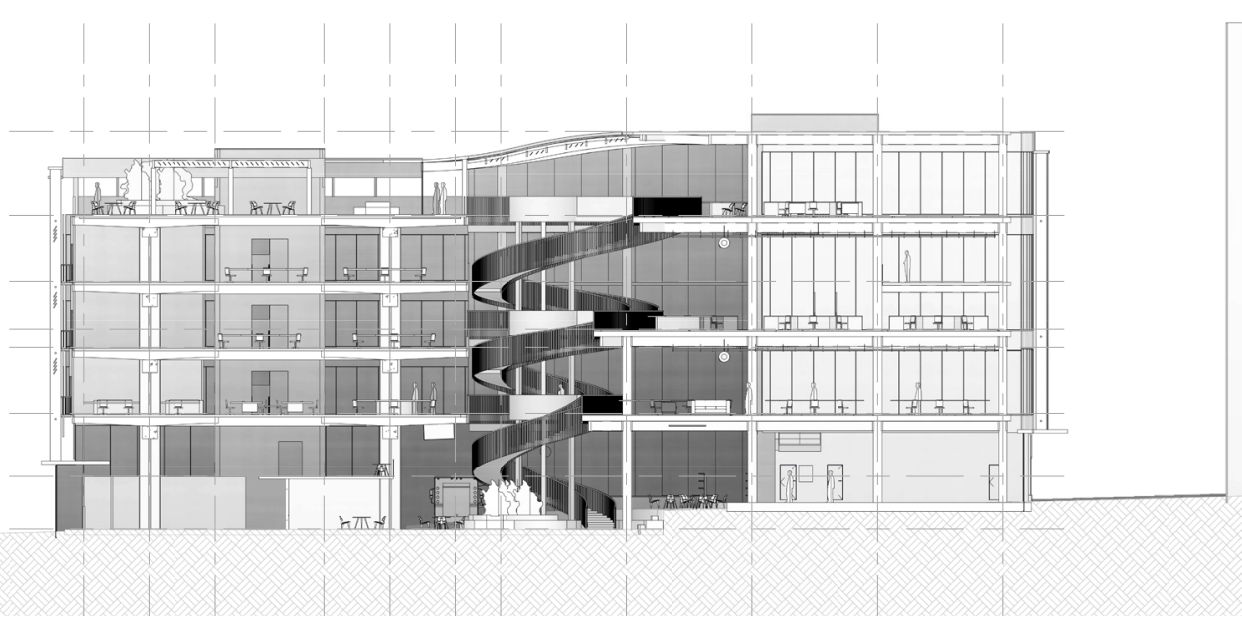

Section A-A, 1:500. 

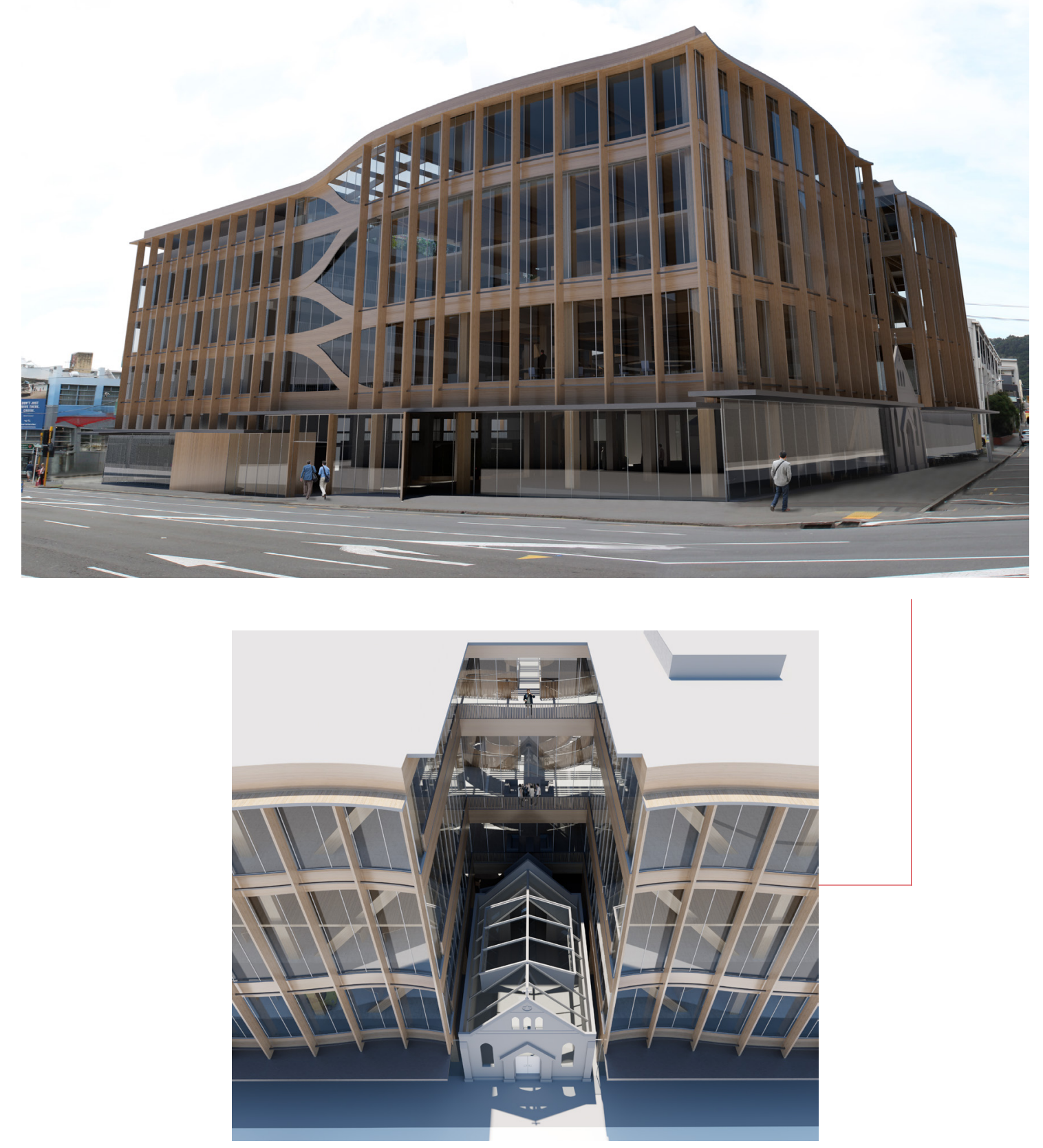

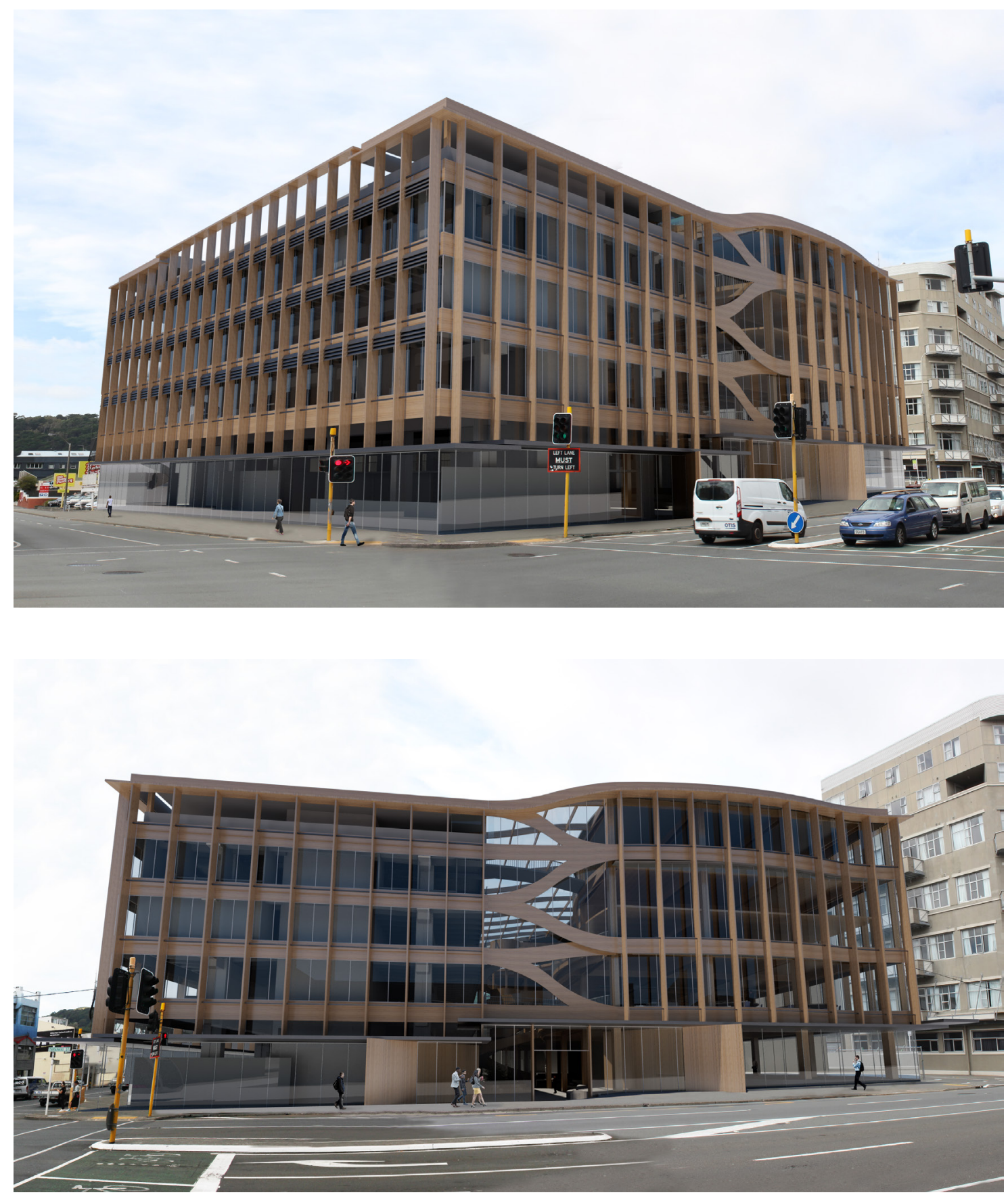